\title{
Will the benefit equal the effort? An investigation into the personal significance of the changes signalled in a mandated curriculum to New Zealand secondary school teachers.
}

\author{
Brenda Mary Service
}

February, 2014

\author{
A thesis \\ submitted to the Victoria University of Wellington \\ in fulfilment of the requirements for the degree of \\ Doctor of Philosophy
}




\begin{abstract}
A new school curriculum ${ }^{1}$ was implemented in all New Zealand schools during 2008 and 2009 and was mandated at the beginning of 2010. The changes signalled in the new curriculum required teachers to incorporate key competencies into their teaching and to move to student-centred practice which involves students in the decisions about their learning. It was possible that this social constructivist approach represented a change in teachers' beliefs about teaching and learning and to their practice.
\end{abstract}

Much of the literature on educational change appears to overlook the transformational nature of the learning needed to bring about changes in beliefs and practice and teachers' personal motivation to engage with it. Unless change is of personal significance to individuals they are unlikely to be motivated to engage with it. Using Eisner's (1998) method of educational criticism, this case study is an investigation into the personal significance of the new curriculum to the teachers' reality. In the spirit of educational criticism, the lens of an educational connoisseur was used to first develop an understanding of the teachers' reality followed by that of an educational critic to evaluate what occurred.

Over a two-year period the study involved semi-structured interviews with twelve secondary school teachers in three schools, observations of the classroom practice, and analysis of school documentation and societal messages. While all the participating teachers' espoused beliefs that were congruent with the philosophy of the new curriculum, constructivist practices were observed in the practice of only two teachers. What prevented the other teachers' wholehearted engagement in the implementation of the new curriculum was not their beliefs about teaching and learning but rather, the extent to which external pressures determined their priorities. These pressures included the misalignment of the school goals and cultural norms, the impact of NCEA assessment regime, time constraints, leadership issues, lack of conceptual understanding and the absence of professional learning to support transformative learning.

1 The New Zealand Curriculum is a statement of official policy relating to teaching and learning in English-medium New Zealand schools. Its principal function is to set the direction for student learning and to provide guidance for schools as they design and review their curriculum (Ministry of Education, 2007). 


\section{Acknowledgements}

I am grateful for the generous support I have received throughout this research from: My supervisors Dr Anne Hynds and Dr Liz Jones who gently guided me through the process and encouraged me to "keep the faith."

Dr Kate Thornton for her unwavering critical friendship and for her astute coaching skills.

Susan Kaiser for painstakingly editing the work.

My husband David and our family, Naomi, Rachel, Christopher, Edward and Madeleine, for their love and encouragement.

It is thanks to each of these wonderful people and many friends continually expressing their belief in me I was able to complete this study.

I also wish to thank the teachers who despite their busy lives, took part in this study, generously let me into their classrooms and so openly shared their thoughts and feelings. 


\section{Table of Contents}

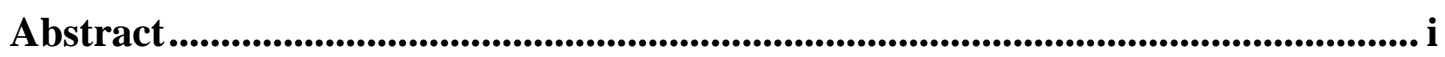

Acknowledgements.......................................................................................... ii

1. Setting the Scene ................................................................................................ 1

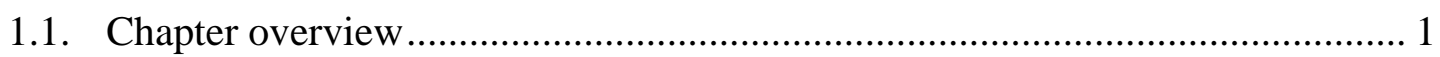

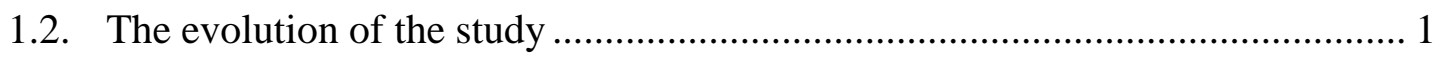

1.2.1. The situation in the school............................................................... 2

1.2.2. The response of the teachers............................................................. 3

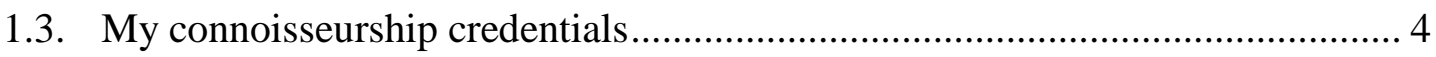

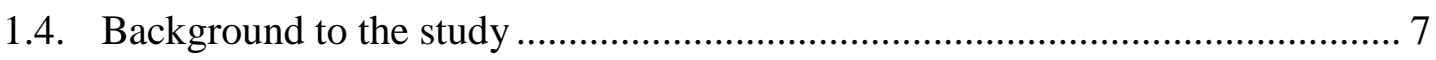

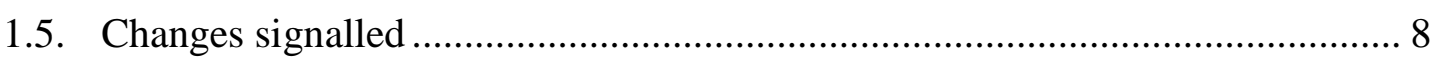

1.5.1. The integration of key competencies............................................. 8

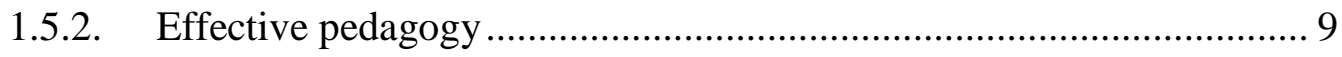

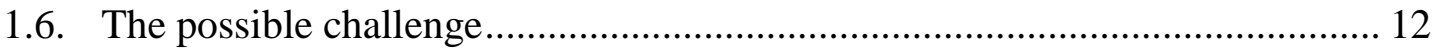

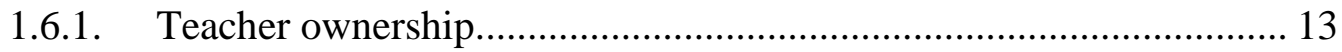

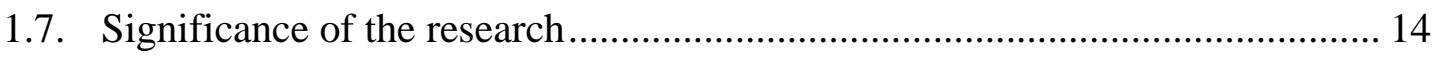

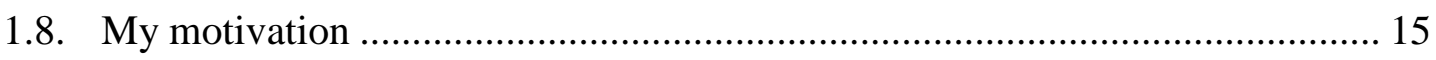

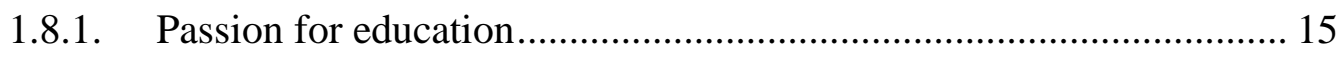

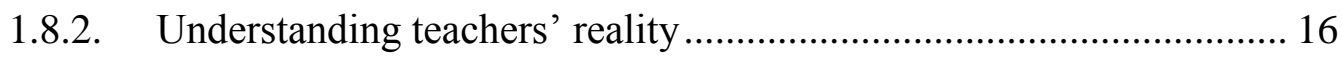

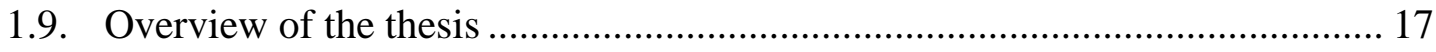

2. Literature review ................................................................................ 19

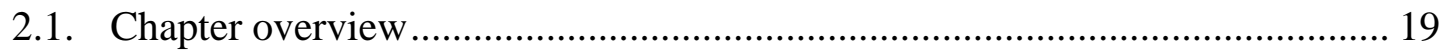

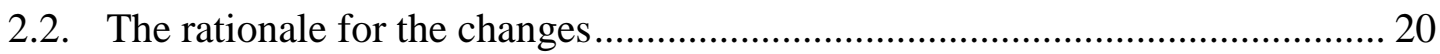

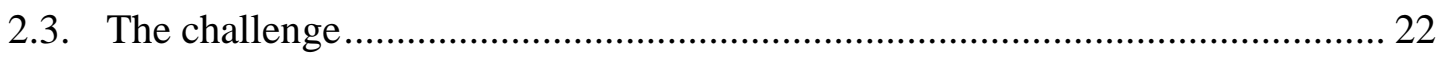

2.4. Looking more closely at beliefs................................................................. 23

2.5. Beliefs relevant to the changes in the new curriculum................................... 26

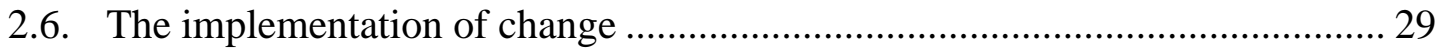

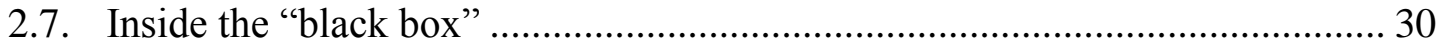

2.7.1. Lewin's Stage 1. Unfreeze: Creating the motivation to change ......... 31

2.7.2. Lewin's Stage 2. Change: Learning new concepts and new meanings 43

2.7.3. Lewin's Stage 3: Freeze .............................................................. 54 


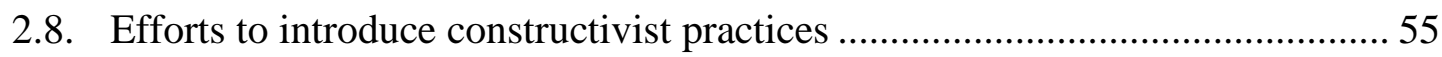

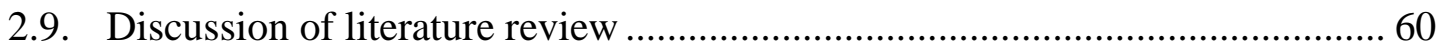

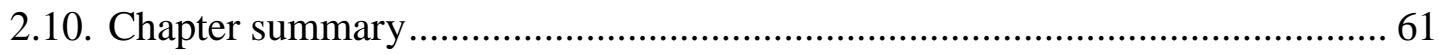

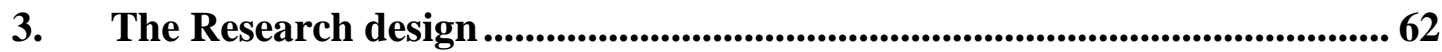

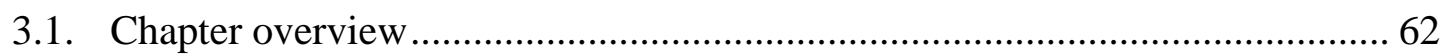

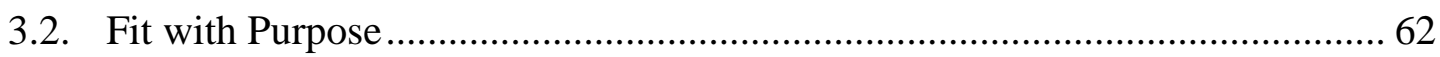

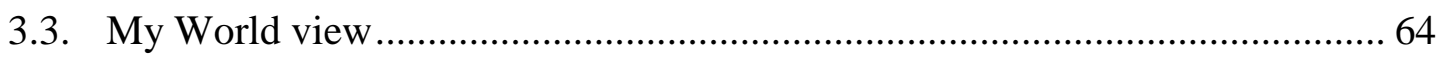

3.4. Characteristics of a case study qualitative methodology ................................ 64

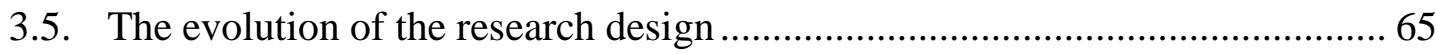

3.5.1. The proposed timeline for the study ................................................ 65

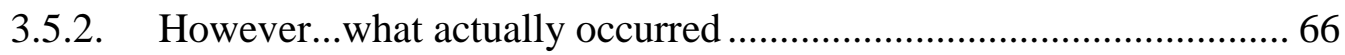

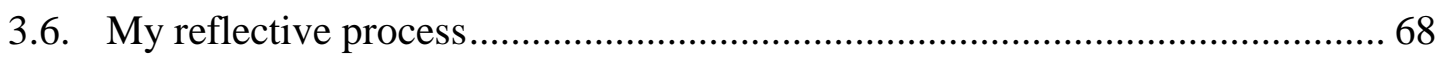

3.6.1. Reflection on entering the field and the implications.......................6 69

3.6.2. Reflection on initial interviews at Totara College........................... 69

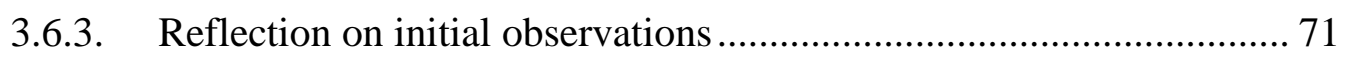

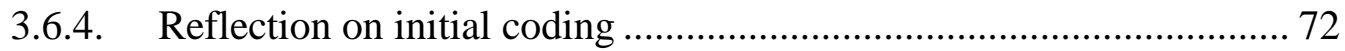

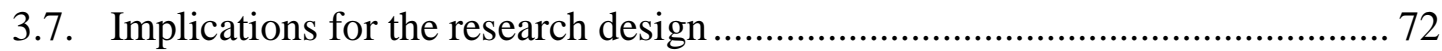

3.8. Reconsideration of research questions after reflection ................................. 73

3.8.1. Rationale for the changed questions ........................................... 73

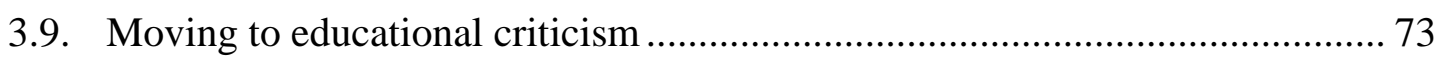

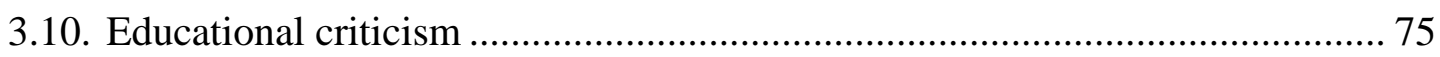

3.10.1. The educational connoisseurship component .................................... 76

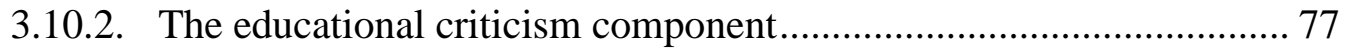

3.10.3. The structure of education connoisseurship and criticism ................ 77

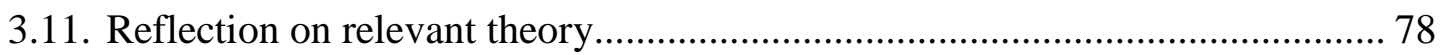

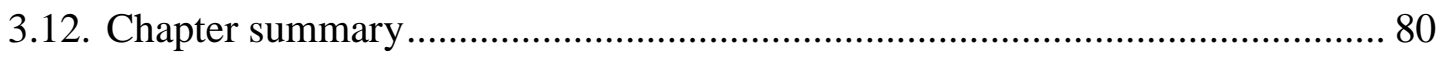

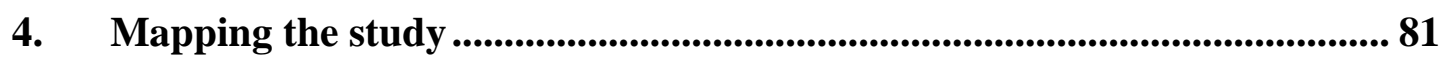

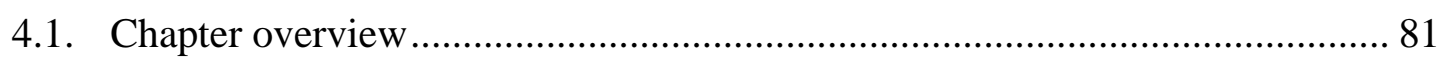

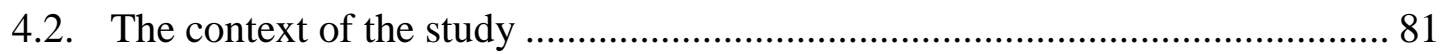

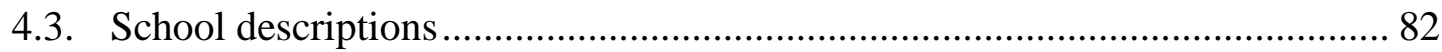

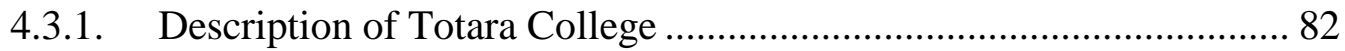

4.3.2. Description of Kauri High School ................................................... 83

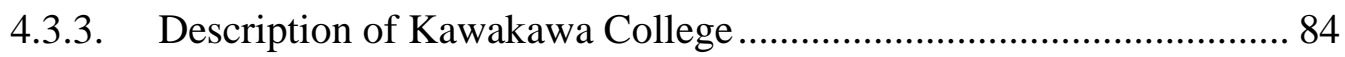




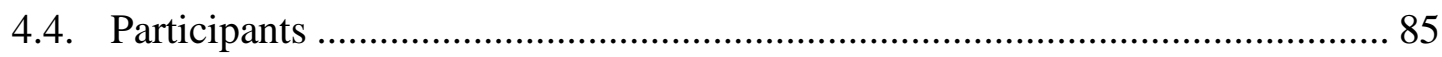

4.5. Data collection after reflection and reconsideration of questions .................... 86

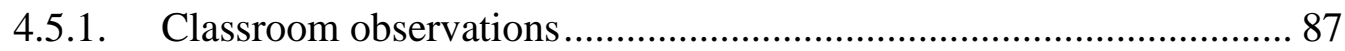

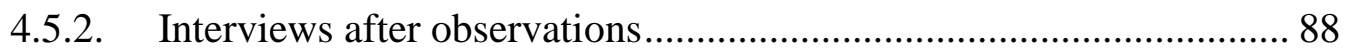

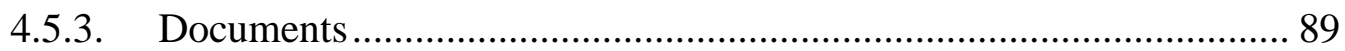

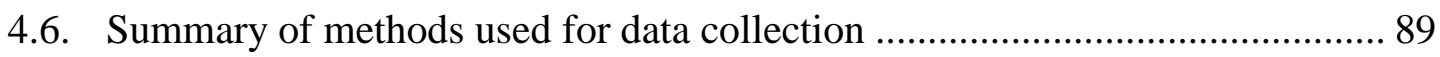

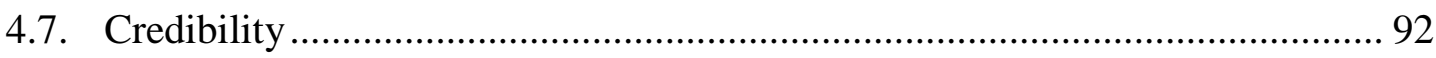

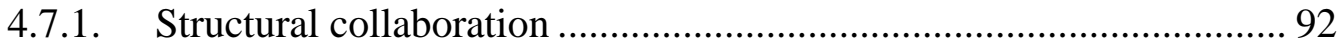

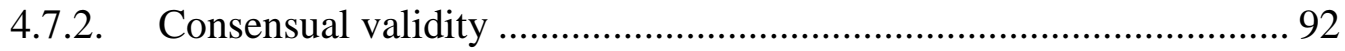

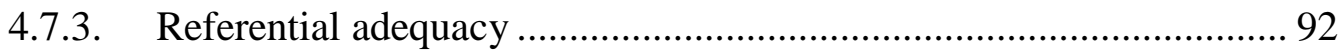

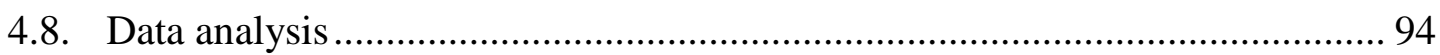

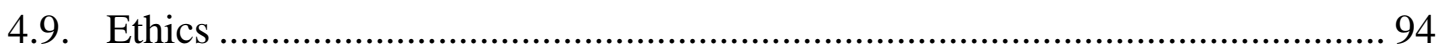

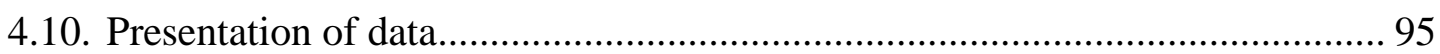

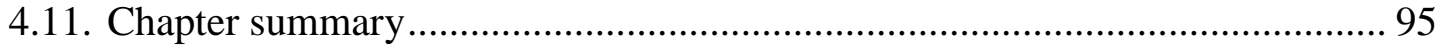

5. Meet the teachers ......................................................................................................... 97

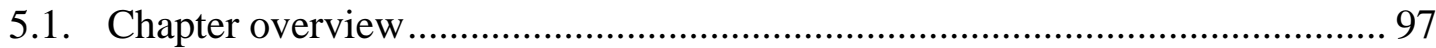

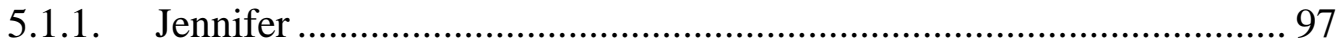

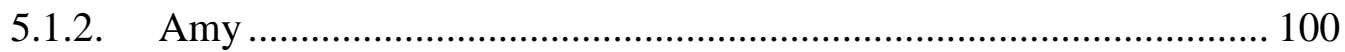

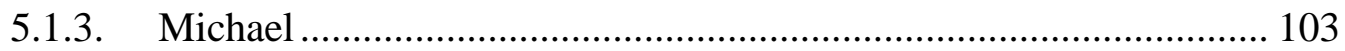

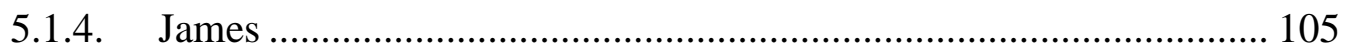

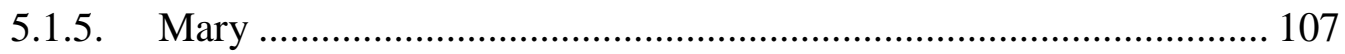

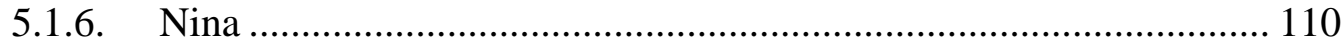

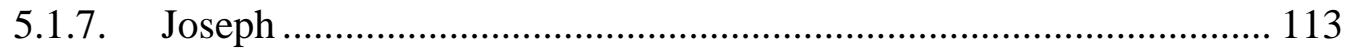

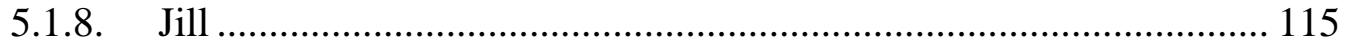

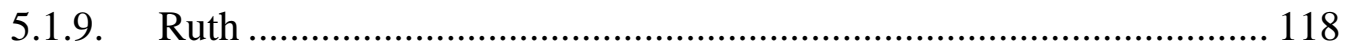

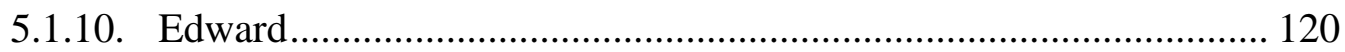

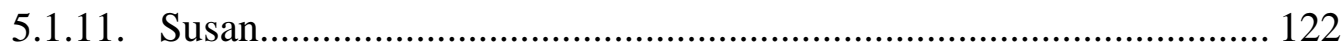

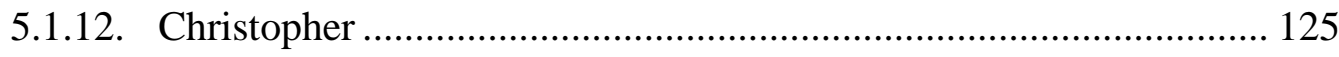

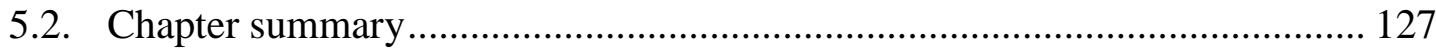

6. My connoisseur interpretation ............................................................... 128

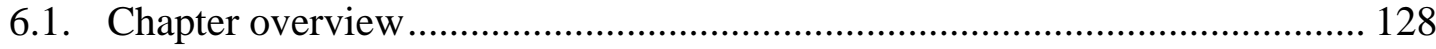

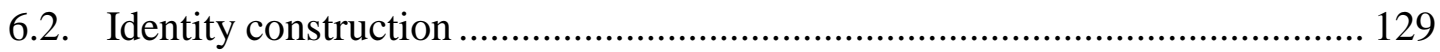

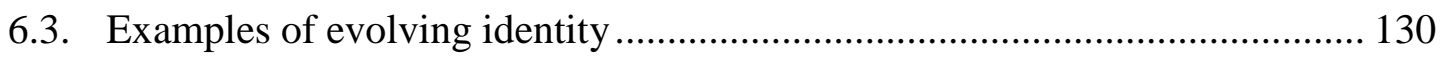

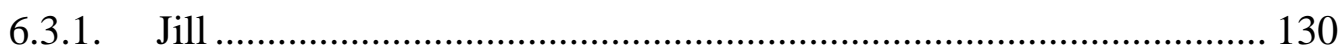




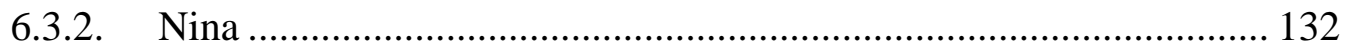

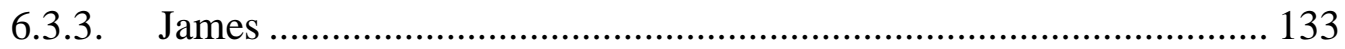

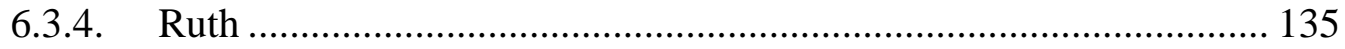

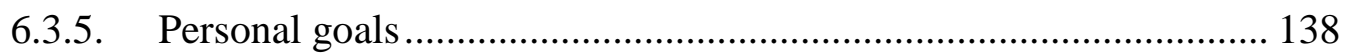

6.4. Emotional response to the signalled changes of the NZC ........................... 141

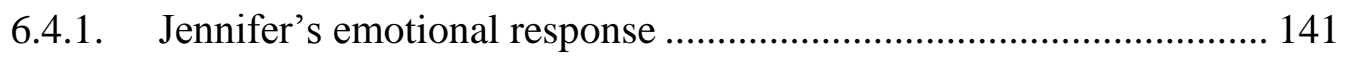

6.4.2. Michael's emotional response .................................................... 143

6.4.3. Other participants' emotional response ......................................... 143

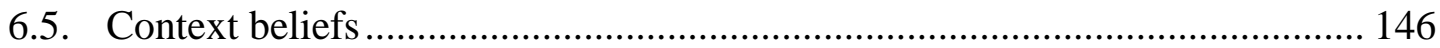

6.5.1. The perceived school goals ........................................................ 150

6.5.2. Realistic time allowance for the teachers ..................................... 151

6.5.3. Appropriate professional learning ............................................... 153

6.5.4. The integration of key competencies.......................................... 157

6.5.5. Competing initiatives.................................................................. 160

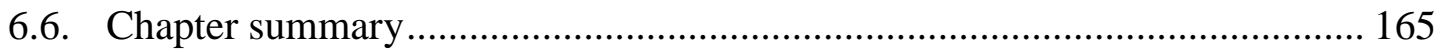

7. The Teachers in Action ......................................................................... 166

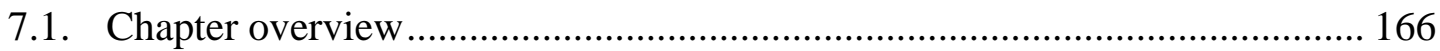

7.2. Interpretation though the lens of an educational connoisseur ....................... 166

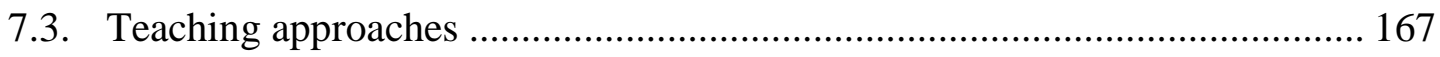

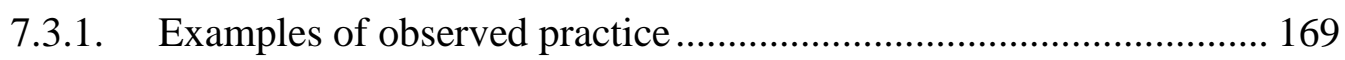

7.4. Links to the effective pedagogy of the NZC ............................................. 182

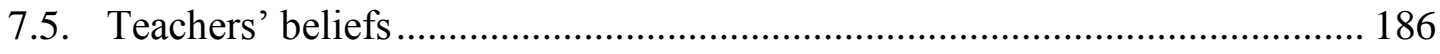

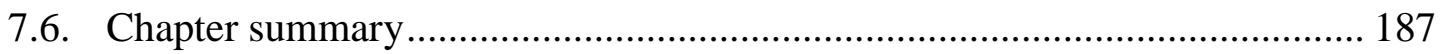

8. It's a good idea but... .................................................................................... 188

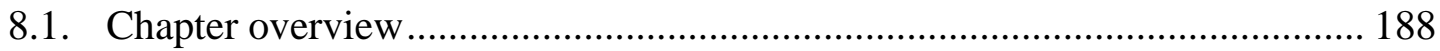

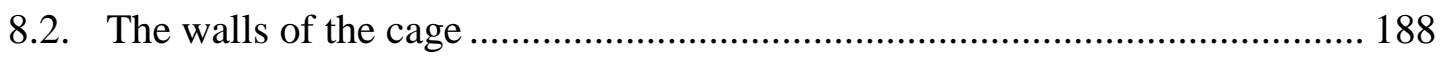

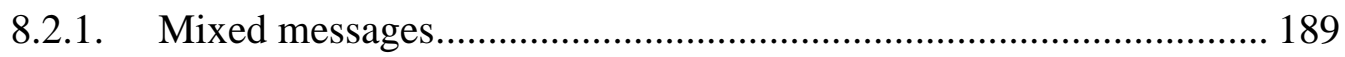

8.2.2. Messages from the political environment..................................... 189

8.2.3. Messages from their context........................................................... 192

8.2.4. Impact of the competitive environment......................................... 193

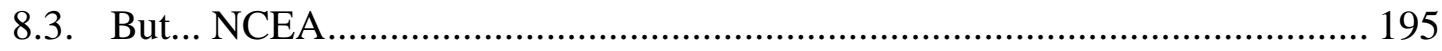

8.3.1. NCEA impact on curriculum....................................................... 196

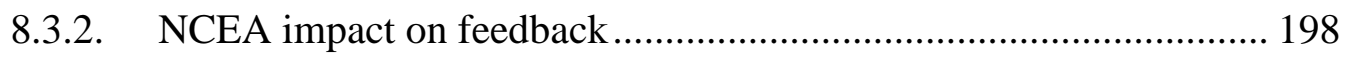

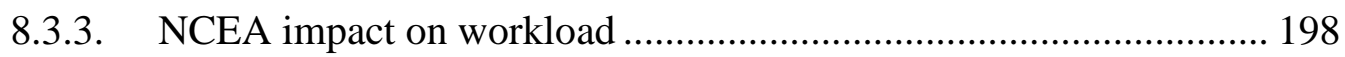




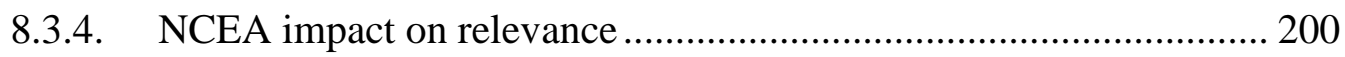

8.4. But... not motivated to make the change ...................................................... 202

8.4.1. Motivational significance of the implementation of the NZC.......... 202

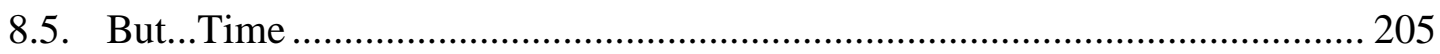

8.5.1. Time to cover the curriculum ...................................................... 206

8.5.2. Time to focus on teaching and learning ...................................... 207

8.5.3. Time allocated for professional learning ..................................... 207

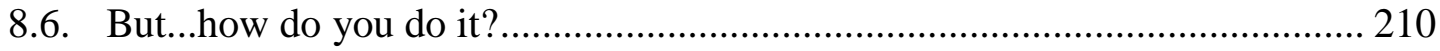

8.6.1. Key competency understanding …............................................. 214

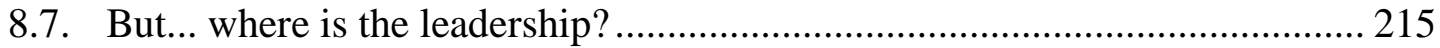

8.8. But...there is so much else going on ......................................................... 217

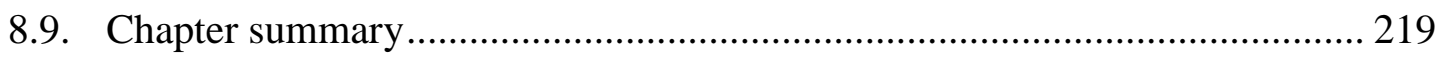

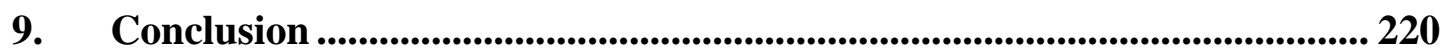

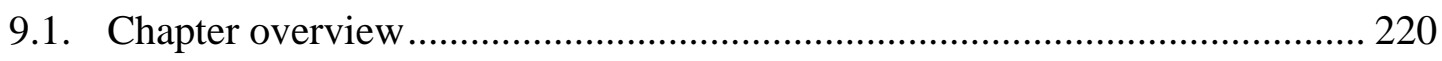

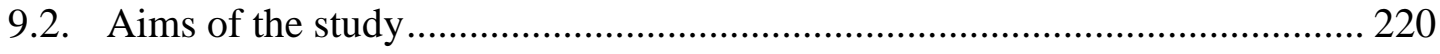

9.3. Implications for the implementation of change …....................................... 221

9.3.1. Aligned messages about education goals .................................... 222

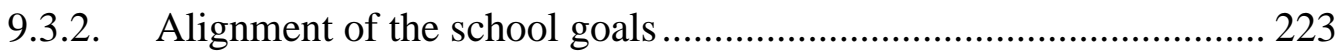

9.3.3. Conceptual understanding of professional learning to support

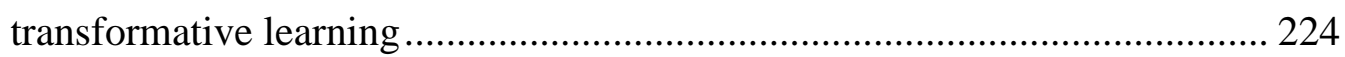

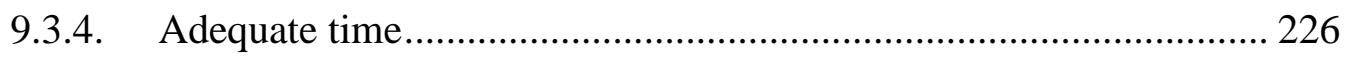

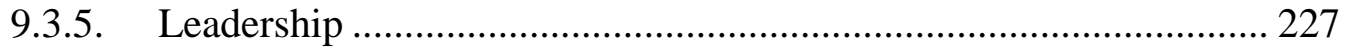

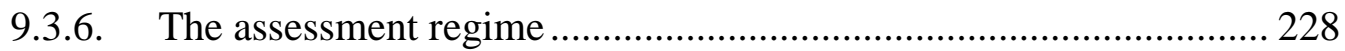

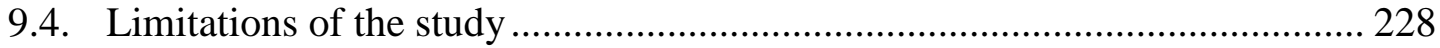

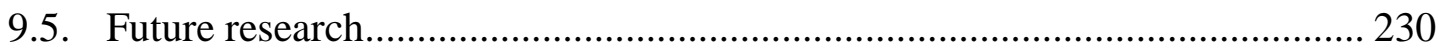

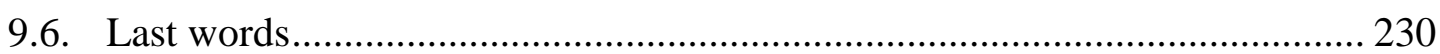

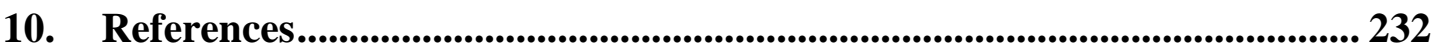

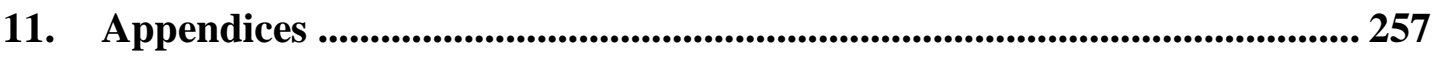




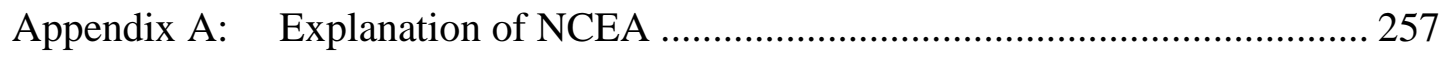

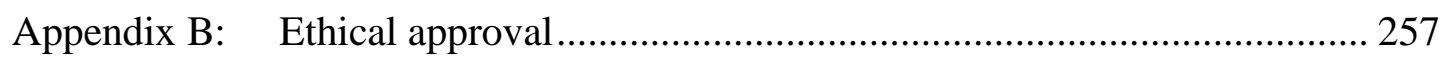

Appendix C: Information sheet for principal.................................................. 257

Appendix D: Information sheet for teacher....................................................... 257

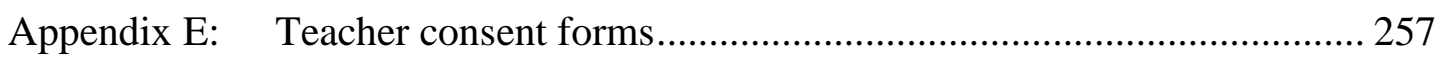

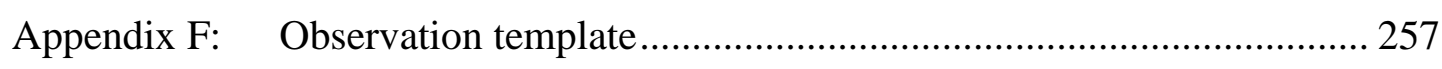

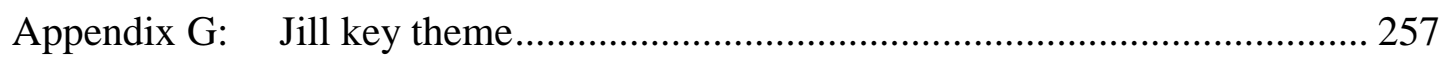




\section{List of Tables}

Table 1. A Comparison of a Traditional or Transmission Classroom to a Social Constructivist Classroom .................................................................. 11

Table 2. Questions that Guided the Literature Review ........................................... 19

Table 3. Comparison between Industrial Age and Knowledge Age ideas................. 20

Table 4. Schommer (1998) independent dimensions ............................................. 28

Table 5. Studies of the implementation of constructivist practice ............................ 58

Table 6. Comparison between this study and the characteristics of a qualitative case

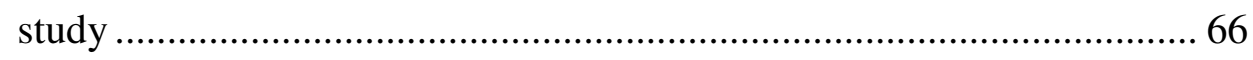

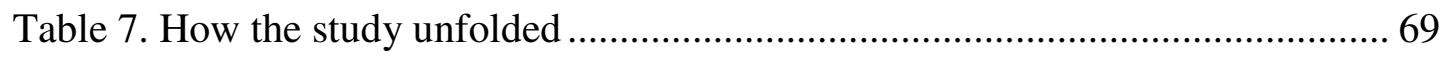

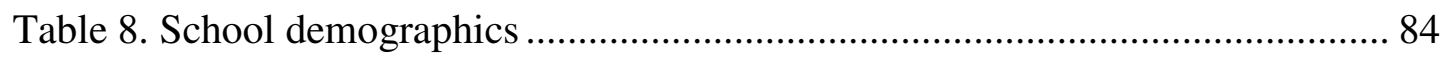

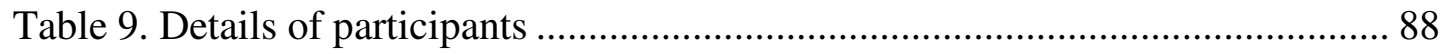

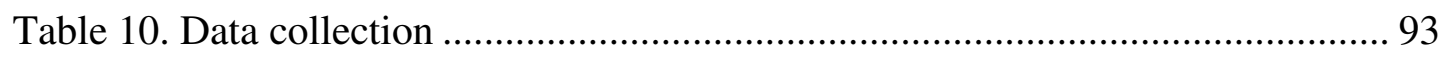

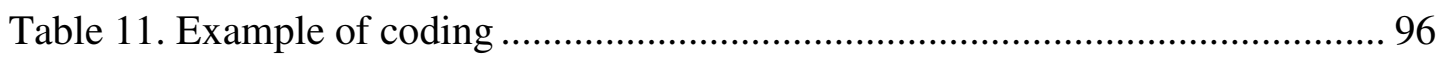

Table 12. Summary of Jill's construction of teacher identity ................................ 136

Table 13. Summary of Nina's construction of teacher identity ............................. 137

Table 14. Summary of James's construction of teacher identity ............................ 138

Table 15. Summary of James's construction of teacher identity (teaching) ............. 139

Table 16. Summary of Ruth's construction of teacher identity ............................. 140

Table 17. Summary of the construction of identity .............................................. 141

Table 18. Link between personal goals the NZC ................................................. 143

Table 19. Emotional response to the effective pedagogy and key competencies of

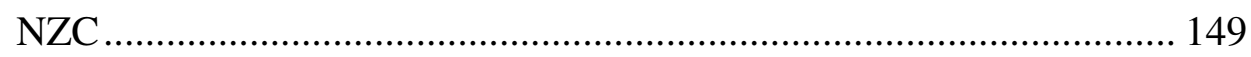

Table 20. Totara College strategic plan .............................................................. 150

Table 21. Kauri High School strategic plan ........................................................... 152

Table 22. Kawakawa College strategic plan ........................................................... 153

Table 23. Professional development in each context ............................................... 158

Table 24. The teachers' appraisal of their context's support for the changes.......... 165

Table 25. Teachers appraisal of the signalled changes ......................................... 167

Table 26. Stated relevance for learning in observed classes ................................. 189

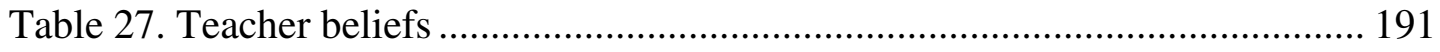

Table 28. Links between approaches, NZC and epistemological beliefs ............... 219

Table 29. A systems approach to the alignment of focus. .................................... 230 


\section{List of Figures}

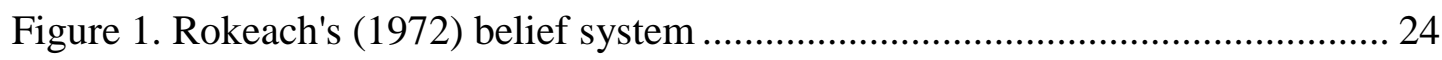

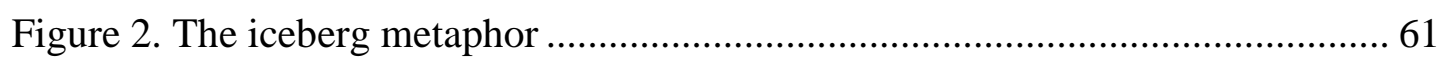

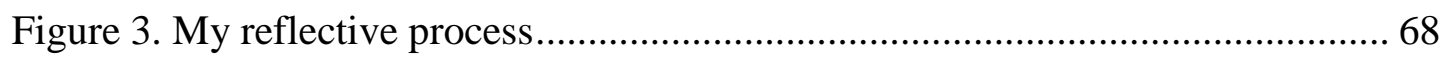

Figure 4. The appraisal of the new curriculum leading to perceived significance .... 80

Figure 5. The data collection process................................................................. 93

Figure 6. Teachers' motivation to accommodate change...................................... 130

Figure 7. Range of teaching approaches used ................................................. 167

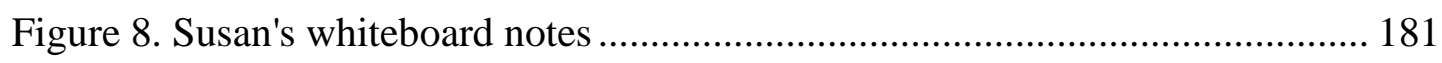

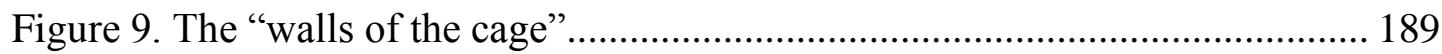

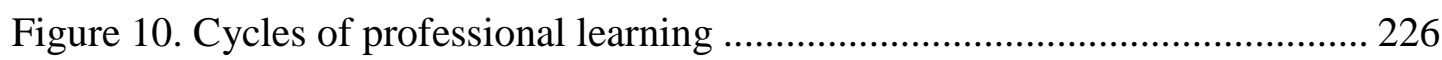




\section{Setting the Scene}

The matrix is definitely not two dimensional ... it's not even three dimensional, it's more like six dimensional ... I do my best but I know I don't do a lot of it well because I'm ... I can't do that many things all the time every time. (Mary).

\subsection{Chapter overview}

This thesis is a report of an investigation into the significance of the implementation of a mandated new curriculum for twelve New Zealand secondary school teachers presented though the lens of an educational connoisseur and critic. It is a story of the teachers' realities and also of my learning. The aim of this introductory chapter is to provide a reader with an overview of the study. It begins by describing what I set out to research and why; when confronted by the complexity of the teachers' lives, my approach and my research design changed. Next my credentials for educational connoisseurship are presented. This is followed by an explanation of the context of the study and a justification for the aspects I chose as my focus. The significance of the study and my motivation for embarking upon it are presented successively. The chapter concludes by outlining the organisation of the thesis.

\subsection{The evolution of the study}

Initially this study appeared to be straightforward. The New Zealand curriculum $^{2}$ (NZC) was revised and implemented in all schools during 2008 and 2009 and mandated at the beginning of 2010. My plan was to carry out a case study in one New Zealand school on the impact on the teachers' beliefs and practices as they experienced the implementation of a new curriculum. As will be elaborated on in section 1.5, this was based on my belief that two aspects of the NZC involved a constructivist approach to teaching and learning and as such possibly represented challenges to secondary school teachers' current beliefs and practice. My key research question was: In what way does the implementation of the new curriculum affect the teachers' educational beliefs and classroom practices within a New Zealand secondary school? However, my initial experiences in the field prompted comprehensive reflection and a reconsideration of my methods and my question. One aspect was the situation in the school and the other was the response of the teachers.

2 The New Zealand Curriculum is a statement of official policy relating to teaching and learning in Englishmedium New Zealand schools. Its principal function is to set the direction for student learning and to provide guidance for schools as they design and review their curriculum (Ministry of Education 2007). 
In the following sections I explain how these impacted on my thinking and led me to change my key question and to use educational criticism to present and analyse the data.

\subsubsection{The situation in the school}

The Ministry of Education's (MOE; 2007a) goals for the two year implementation of the new curriculum were:

- to create an environment that supports change at the school and system levels

- to support professional inquiry, exploration, and the development of professional practice

- to enable sustained curriculum development within schools and across the system. (MOE, 2007a)

I had assumed that, to meet these goals, there would be an ongoing process of implementation to support teachers' learning in the school. From my reading of literature on educational change I was aware of the ingredients suggested for an environment that supports systemic change (discussed in chapter 2) and had planned to observe the professional development (PD) that would be provided. However, difficulties delayed my entry into the field and when I was finally able to do so, I was informed that the implementation process had consisted solely of two government funded days, referred to as "teacher- only," when students did not attend classes allowing teachers to take part in professional learning. I was also told that the professional learning that took place did not include an examination of any implications for changes in teaching practice. In addition, as will be further explained in chapter 3, from my initial interviews it appeared that the teachers did not see a need for any change in their beliefs and practices. It was therefore not feasible to attempt to research the effect of the implementation on teachers' beliefs and practice when there was no planned process or PD that challenged their beliefs or practice. I recorded in my journal "where is the implementation?" (Research journal, 2010). It was beginning to appear that I was attempting to research something that did not exist and I began to reconsider my research question. 


\subsubsection{The response of the teachers}

As I spent time in the school I was also struck by the complexity of the teachers' lives as evidenced by the following extract from my research journal:

Students jostled in line, their arms full of books, at the cluttered library checkout desk where the teacher and I struggled to make a space to sit. This was Susan's lunchtime, eating her lunch, checking out students' books and using the only space in her day for an interview with me. Later in the day I listened to the recording, our discussion accompanied by the buzz of a busy library and with the flow constantly interrupted by questioning adolescent voices, Susan patiently answering them. This was her reality, a day in which she was teaching more than one hundred students, contributing to the smooth running of the school library supervising the library, relating to colleagues and dealing with administrative matters. And on top of all that, she was explaining her theories of teaching and learning to a researcher! (Research journal)

After encountering many such turbulent scenes, on entering the field I began to seek a way that, instead of simply looking for answers to my questions, I could do justice to the teachers' reality during a time of mandated change and ensure their voices were heard. The depth of the teachers' response to me as a researcher also contributed to my reflection. Their openness was unexpected and very much appreciated. Over the two years of the study I developed trusting relationships with the participating teachers to the extent that they felt comfortable expressing their feelings. Some described anxiety, some frustration or anger, and one teacher cried in exasperation. Others, while expressing approval for the changes in the new curriculum, detailed the various reasons they felt it was not appropriate to attempt to embed it in their context. This was a humbling experience which led me to reflect on how I was positioning myself as a researcher with my original question: In what ways does the implementation of the new curriculum affect the teachers' educational beliefs and classroom practices within a New Zealand secondary school? I realised that underpinning this question was my belief that for the implementation to be successful their beliefs and practices would need to change and that I was looking to evaluate the extent to which it occurred. Faced by their honest and often emotional depiction of their work and concerns, I saw that with my initial question I had taken a deficit stance that undervalued the teachers' working lives.

\section{Reconsidered research question}

My reflection on the school situation and the response of the teachers led me to change my research question to one that I felt acknowledged teachers' professionalism and which would provide a way to validate their experiences. The 
key question thus became "what is the personal significance of the changes signalled in the mandated curriculum to New Zealand secondary school teachers?"

Reconsidered methodology

My thinking and my reading broadened as I explored the literature for a research method that would enable me provide a picture of the teachers' reality to a reader. The result was a strong resonance with educational criticism (Eisner, 1998) which provided a way to include not only what was explicit in the classroom but also what I perceived to be occurring based on my knowledge and experience. As Uhrmacher (2011, p. 29) expresses it, in this method "one is able to exploit what one knows as well as what one sees." By doing this I could see that I could move beyond a simple identification of key themes to hopefully provide a reader with a nuanced picture of what was occurring and to discuss the implications of this. Eventually, after extensive discussions with my supervisors, rather than directly enquiring about beliefs and practice I employed educational criticism for the study. There are two components to educational criticism. The first involved my adoption of the role of an educational connoisseur throughout the study as I listened to the teachers' stories, observed them teaching, analysed school documentation and educational sector commentary, and described the complexity of the situation. The second was to follow this by educational criticism, interpreting and evaluating what had occurred. Through this process I have attempted to interpret what was important to the participating teachers in the context in which they worked, what motivated them to change their beliefs and practice, and to what extent the changes signalled in the new curriculum were of significance to them.

\subsection{My connoisseurship credentials}

A more detailed explanation of education criticism is provided in chapter 3 . However, at this stage I present support for my claim to educational connoisseurship. In any field, connoisseurship, "the art of appreciation," is a pre-requisite to criticism. Connoisseurs need to have the ability to "make fine grained discriminations among complex and subtle qualities" (Eisner, 1998, p. 63). It follows that for their interpretation to have credibility, a connoisseur in any arena needs to be acknowledged as having appropriate knowledge. In educational criticism that means an in-depth classroom specific knowledge and general knowledge about educational theory (Eisner, 1998).

While I make no claim to be an "expert" and gratefully acknowledge that I learned a great deal from the teachers in this study, I do believe that I have 
sufficiently broad and in-depth knowledge and understanding of the secondary education sector to be a connoisseur and a critic. I have had a long and varied experience in New Zealand secondary school education. For twenty-two years, I taught in a variety of secondary schools, some co-educational, some single sex, some Catholic integrated, others state schools, ranging from low to high decile. ${ }^{3}$ I have therefore had the experience of teaching a variety of subjects to junior and senior students in different contexts. I also worked as a head of department and as a deputy principal. Over this time, motivated by my dissatisfaction with my original way of teaching, I worked to develop my teaching practice, gradually moving from the transmission model I had experienced in my own education and in my initial teacher education to a more student-centred one. The change was difficult. Looking back over my process of change I could identify incidents that had caused a sense of discrepancy between my teaching goals and my practice which motivated me to make changes. However, even when I felt the discrepancy, I struggled to embed a student-centred approach as a more effective way of teaching, often reverting to a transmission approach when under pressure. Sometimes the pressure came from the behaviour of the students and other times from the context's emphasis on assessment results. At such times, my confidence in a constructivist approach faltered. I therefore understood the challenges for other teachers seeking to accommodate new understandings about teaching and learning that undermined deeply held but often not recognised beliefs and contextual constraints.

My final teaching position was as a deputy principal and teacher of a junior class at a new low decile school, the multicultural student body comprising New Zealand European/Pākehā 42\%, Māori 40\%, Samoan 9\%, Asian 4\%, other Pacific $3 \%$, and other ethnic groups $2 \%$. This school had been established as the result of a merger of two schools within the community. The merger caused considerable anxiety and uncertainty for everyone involved. Before the merger these schools had competed for students, creating a sense of rivalry and mistrust that was still evident amongst the staff and within the senior management team, which comprised staff

3 Deciles are a way in which the Ministry of Education allocates funding to schools. A school's decile rating reflects the average family or whānau backgrounds of students at the school. There are ten deciles and around 10\% of schools are in each decile. Decile 1 schools have the highest proportion of students from low socio-economic backgrounds whereas decile 10 schools have the highest proportion of students from high socio-economic backgrounds. The lower a school's decile rating, the more funding it gets. The increased funding given to lower decile schools is to provide additional resources to support their students' learning needs. The decile rating does not measure the standard of education delivered by a school (Ministry of Education, 2011). 
from each former school. These feelings affected relationships throughout the school. In addition, the community, unhappy about the prospect of a merger, had invested considerable time and emotion fighting the proposal. As a result, the staff felt the pressure of inspiring the confidence in the community that the new school would provide quality education for their children.

Leadership was therefore required to build a professional learning community in which the staff would be willing to support and challenge each other and to work together to achieve success for the students. In my role I had responsibility for pastoral care of both students and staff, and for PD. This was an extremely challenging, often painful, but ultimately stimulating experience through which I learned a great deal about forging relational trust with staff and the community and supporting teachers to develop their teaching practice. I developed an understanding of the personal and professional challenges teachers faced and had multiple opportunities to observe their practice. Feeling the need to learn more about leading change during this time I completed a Master of Education focusing on leadership of change and PD. This degree provided me with a deeper understanding of educational change theory and adult learning theory.

The school merger was the first of many to be carried out as part of a governmental plan. As a result it was well publicised and attracted interest from different sectors of the country. This proved to be of benefit for me: when I entered the field for my research I found that having been part of a senior management team involved in the merger, as well as having been a deputy principal and teacher in what had the reputation of being a challenging environment, provided me with a measure of credibility with school leaders and with teachers which led to trusting relationships. It appeared that I had "street cred".

After five years in the merged school I moved to the university as an advisor in leadership and management for secondary schools. In this role, for two years, I worked with senior management in 11 secondary schools to support their instructional and PD planning. This involved observing classroom teaching and providing feedback to staff. In many cases, the schools were taking part in several innovations funded by the MOE. I was, therefore, able to observe the degree to which the teachers did or did not engage with the projects and to what extent the initiatives brought about sustained change. My current position is as lecturer and Academic Director of the Graduate Diploma of Teaching (Secondary). In these roles I 
have witnessed the challenges the students face and have had contact with all the secondary schools in my region.

I understand from my years as a teacher, and from the observation of over 200 classes in a range of contexts, the complexity of a classroom and the challenges a teacher faces on a daily basis. I believe my experience and my studies provided me with school and classroom specific knowledge and the understanding of educational theory needed to be a connoisseur and ultimately a critic of the practices I observed in secondary schools. I also believe that my skills as a connoisseur and a critic have been enhanced through this research process, by being forced to confront and reflect on my assumptions and by having the privilege to develop a greater understanding of the teachers' realities.

\subsection{Background to the study}

When the new curriculum was introduced, the then Secretary for Education, Karen Sewell, maintained that it provided "a framework designed to ensure that all young New Zealanders are equipped with the knowledge, competencies, and values they will need to be successful citizens in the twenty-first century" (MOE, 2007b, p. 4).

The nationally mandated curriculum is outlined in one document with each school required to design a local curriculum for teaching and learning based on the framework it describes (Hipkins \& Boyd, 2011). The local curricula therefore need to provide teaching and learning programmes that are based on the NZC learning area statements underpinned by its principles and that address the stated values, key competencies, and achievement objectives (Sinnema, 2011). Unlike earlier curriculum documents, the NZC also includes a section on effective pedagogy with guidance for teaching and learning processes. The intention of the NZC signals a shift in thinking not only about what should be taught but also how it should be taught to meet the needs of today's learners (Abbiss, 2011; Body \& Watson, 2006). In a speech at the time the New Zealand curriculum was introduced, the then Minister of Education acknowledged the level of change involved, describing the new curriculum as changing the system:

It is about viewing education through a different prism, it's about a different framework, a different way of working with learners to open doors and find revised pathways. (Maharey, 2007, emphasis added). 


\subsection{Changes signalled}

From my observation of teaching and from my own experience as a classroom teacher I considered that in particular two aspects of the NZC represented a challenge to secondary school teachers' beliefs and practice: the integration of key competencies, and the embedding of the suggested effective pedagogy. In the following section I explain why beliefs and practices could be affected by these aspects.

\subsubsection{The integration of key competencies}

Looking at the requirement to link all teaching and learning to a vision and to underpin it with the principles, values and key competencies of the NZC, I considered the key competencies to present a significant challenge for secondary school teachers. I could understand how schools could work together to develop a vision, and explore how the values and principles of the NZC could be modelled in their context. However, I considered the integration of key competencies would require individual teachers to rethink their approach to teaching and learning.

The key competencies described in the NZC are aligned with the common core of key competencies identified by the OECD (2005) and which are reflected in international survey work such as the PISA assessments of mathematics, reading and scientific prolem solving. The New Zealand MOE considers the results of these surveys to be a valuable source of evaluation of their educational policies (Rutherford, 2005) with the data often used to support innovations. It was therefore considered appropriate that the key competencies of the NZC would be a fit with those assessed in the international surveys. The resulting five key competencies chosen and outlined in the NZC (subtitled capabilities for living and lifelong learning) are: thinking; using language, symbols, and texts; managing self; relating to others; and participating and contributing.

Key competencies are to be considered holistic and contextual, fitting with the socio-cultural perspective of the NZC (Brewerton, 2004) as expressed in the following excerpt from the NZC document:

Key competencies are not separate or stand alone. They are key to learning in every learning area. The development of the competencies is both an end in itself (a goal) and the means by which other ends are achieved. Successful learners make use of the combination with all the resources available to them. These include personal goals, other people, community knowledge and values, cultural tools (language, symbols and texts), and the knowledge and skills found in the different learning areas. (MOE, 2007b, p. 12) 
Hipkins and Boyd (2011) maintain that "schools are expected to give life to the NZC's $21^{\text {st }}$ century vision by designing learning programmes that weave the key competencies through the concepts specified in the learning areas" (p. 73, emphasis added). The expectation to weave the key competencies into all learning involves a significant change in how teaching is currently planned and delivered - a dimension of the different prism alluded to by the Minister of Education and one that could represent a challenge to teachers. Therefore, I considered that the weaving of key competencies would represent a significant change of beliefs about New Zealand secondary school teachers' approach to teaching.

\subsubsection{Effective pedagogy}

The other signalled change is the inclusion of a section on effective pedagogy which describes how teaching should occur. This section states that students learn most effectively when they understand what they are learning, why they are learning it, and how they will be able to use their new learning. It also states that teachers should look for opportunities to involve students directly in decisions relating to their own learning and to take greater ownership of their learning (MOE, 2007b). The changes requiring teachers to involve students in the decisions about their learning in "a learning community where everyone including the teacher is learner" (NZC, p. 34) appear to be based on the belief that meaningful learning is a social process of the learner constructing new knowledge individually and with others on the basis of current knowledge (Brooks \& Brooks, 1993). While not explicitly stated in the curriculum documents, this is a move to a model based on a social constructivist view of learning in which individuals create meaning through their interactions with each other and with the environment in which they live and in which teachers support students to construct their learning (Bell, 2005; B. Kim, 2001; Selby \& Probert, 2004). In a social constructivist classroom the teacher's role changes from someone who dispenses knowledge to students, to someone who can develop their understanding through authentic activities (Brooks \& Brooks, 1993). This is in contrast with a more commonly employed teacher-centred or content-centred (Hall \& Kidman, 2004) model often referred to as a "transmission" model (Bereiter, 2002; Cuban, 1990), where "the teacher controls what is taught, when and under what conditions in the classroom" (Cuban, 1993a, p. 6).

Table 1 compares a traditional or transmission classroom with a social constructivist one. Links to the Effective Pedagogy section of the revised curriculum 
have been added. However it should be noted that teachers do not neatly fit in one of these categories. For example, a teacher with a constructivist view of teaching and learning may at times employ direct instruction having ascertained that the students had sufficient prior understanding to accommodate the new learning (Hyslop-Margison \& Strobel, 2008). This table therefore overlooks the complexity of teachers' beliefs and practices which will be discussed in section 2.5, p.28. 
Table 1. A Comparison of a Traditional or Transmission Classroom to a Social Constructivist Classroom

\begin{tabular}{|c|c|c|}
\hline $\begin{array}{l}\text { Classrooms based on a transmission theory of } \\
\text { teaching and learning (Brooks \& Brooks, 1993, p. 17) }\end{array}$ & $\begin{array}{l}\text { Classrooms based on a social constructivist theory of } \\
\text { teaching and learning (Brooks \& Brooks, 1993, p. 17) }\end{array}$ & $\begin{array}{l}\text { Links to the effective pedagogy described in revised } \\
\text { curriculum (MOE, 2007, p. 34) }\end{array}$ \\
\hline $\begin{array}{l}\text { Strict adherence to fixed curriculum is highly valued. } \\
\text { Curricular activities rely heavily on textbooks and } \\
\text { workbooks. }\end{array}$ & $\begin{array}{l}\text { Curricular activities rely heavily on primary sources of } \\
\text { data and manipulative materials. }\end{array}$ & $\begin{array}{l}\text { Students learn most effectively when they understand } \\
\text { what they are learning, why they are learning it and } \\
\text { how they will be able to use new learning. Effective } \\
\text { teachers stimulate the curiosity of their students, and } \\
\text { require them to use or apply what they discover in new } \\
\text { contexts or new ways. }\end{array}$ \\
\hline $\begin{array}{l}\text { Students are viewed as "blank slates" onto which } \\
\text { information is sketched by the teacher. }\end{array}$ & $\begin{array}{l}\text { Students are viewed as thinkers with emerging theories } \\
\text { about the world. }\end{array}$ & $\begin{array}{l}\text { Effective teachers look for opportunities to involve } \\
\text { students directly in decisions relating to their own } \\
\text { learning and take ownership of their own learning. } \\
\text { Students learn best when they are able to integrate new } \\
\text { learning with what they already know. Effective } \\
\text { teachers deliberately build on what their students } \\
\text { already know and have experienced. }\end{array}$ \\
\hline $\begin{array}{l}\text { Teachers generally behave in a didactic manner, } \\
\text { disseminating information to students. }\end{array}$ & $\begin{array}{l}\text { Teachers generally behave in an interactive manner, } \\
\text { mediating the environment for students. } \\
\text { Students primarily work in groups. }\end{array}$ & $\begin{array}{l}\text { Students learn as they engage in shared activities and } \\
\text { conversations with other people. Teachers cultivate the } \\
\text { class as a learning community where everyone } \\
\text { including the teacher is a learner. }\end{array}$ \\
\hline $\begin{array}{l}\text { Teachers seek the correct answer to validate student } \\
\text { learning. }\end{array}$ & $\begin{array}{l}\text { Teachers seek students' point of view in order to } \\
\text { understand students' present conceptions for use in } \\
\text { subsequent lessons. }\end{array}$ & $\begin{array}{l}\text { Teachers encourage students to stand back from the } \\
\text { information or ideas that they have engaged with and } \\
\text { think about these objectively. Over time students } \\
\text { develop their creativity, their ability to think critically } \\
\text { about information and ideas, and their metacognitive } \\
\text { ability. Teachers encourage such thinking when they } \\
\text { require students to critically evaluate the material they } \\
\text { use and consider the purpose for which it was originally } \\
\text { created. }\end{array}$ \\
\hline $\begin{array}{l}\text { Assessment of student learning is viewed as aspirate } \\
\text { from teaching and occurs largely through testing. }\end{array}$ & $\begin{array}{l}\text { Assessment of student learning is interwoven with } \\
\text { teaching and occurs in a variety of ways. }\end{array}$ & Challenge, support and feedback are always available. \\
\hline
\end{tabular}




\subsection{The possible challenge}

Debate over constructivist practices has existed for a century (Cuban, 1990); however, implementation processes to introduce them into schools have failed because, in the opinion of many researchers, teachers have no personal experience of them (Hanley \& McArthur, 2002; Windschitl, 2002), and therefore the new practices do not fit their beliefs about teaching and learning (Cuban, 1990). Some researchers maintain that most teachers believe in a transmission approach: that learning happens when knowledge is transmitted to students who then absorb it (Bereiter, 2002; Cuban, 1990). Constructivist pedagogy is inconsistent with this belief. Belief in the transmission of teaching and learning is therefore considered a major obstacle to changing to a focus of putting students' own efforts to construct knowledge at the centre of teaching and learning (Bereiter, 2002; Brooks \& Brooks, 1993; Prawat, 1992; Windschitl, 2002). This may be true in New Zealand. Given that 62 percent of New Zealand secondary teachers are between the ages of 40 and 64 (MOE, 2008), it is possible that many were themselves taught in teacher-centred classrooms in a transmission model of teaching and learning. In addition, most teachers in New Zealand received their pre-service training over ten years ago in an era when teaching was seen as a transmission model (Education Review Office (ERO), 2000). Their own prior knowledge and experience would affect how they arrive at their personal interpretations of the changes (Schmidt \& Datnow, 2005). In my observations of over 200 secondary school teachers at different stages of their careers, I became aware that a teacher-centred model was the dominant approach. I therefore believed that this new curriculum presented a challenge to the beliefs about teaching and learning in the current practices of many secondary school teachers.

I had also noted that most Education Review Office ${ }^{4}$ (ERO) reports of secondary schools' cases recommend that schools provide professional learning for teachers in the use of constructivist teaching as outlined in the pedagogy section of the revised curriculum. These reports supported my contention that, while these practices are considered desirable, they are not practised by the majority of New Zealand secondary teachers (ERO, 2008).

Therefore, the changes signalled in the revised curriculum involved teachers planning to integrate key competencies, modifying teaching approaches and modifying beliefs about their role in the classroom. For many teachers this would represent a

The Education Review Office (ERO) is the New Zealand government department that evaluates and reports on the education and care of students in schools and early childhood services. ${ }^{4}$ 
reconsideration of their beliefs about what is effective teaching. Hipkins (2007) describes it as "cutting to the very core of a teacher's identity". It was difficult to understand how this would happen given the busyness of a teacher's work day which Hipkins describes as "a blur of interactions, tasks and general busy work" (p. 135).

The driver for this study was my assumption that many teachers hold theories which may not be compatible with the proposed change. To explore this possibility leaders implementing change should first study teachers' present realities (Eisner, 1998). However, my experience and my literature search led me to believe that implementers of change do not provide for teachers' current beliefs to surface and that this neglected aspect needs to be addressed. During my career I have been involved in educational change in different capacities: as a secondary school teacher taking part in many innovations; as a senior manager leading and managing change; and as an advisor attempting to facilitate change. All change I have experienced was introduced without consideration of teachers' current beliefs.

\subsubsection{Teacher ownership}

Teachers need to feel a sense of ownership for the change being implemented. If teachers do not feel ownership of the changes there may again be the potential for conflict and resistance (Bereiter, 2002; Datnow, 2000; Datnow \& Castellano, 2000; Hargreaves, 1997). The new curriculum is a Government imposed innovation and while teachers had been given the opportunity to be involved in the design and to give feedback on the draft, it may be possible that many did not feel it represented change that they would have chosen. The effective pedagogy section, for example, is clearly based on Alton Lee's (2003) government funded Quality Teaching for Diverse Students: Best Evidence Synthesis and not on input from teachers (Benade, 2009). Further, the fact that teachers had been invited to participate did not guarantee they would feel ownership. In a study of an organisational change project which sought employee participation in the structural design, Labianca, Gray, and Brass (2000) found that many employees felt sceptical that their input would have any impact, that seeking their opinion was "merely window dressing" (p. 245), and that key decisions had already been made. This could be the case with the NZC. A survey of 1,798 teachers carried out by Colmar Brunton (2006), to gauge the penetration and understanding of the revised curriculum in draft form, found that about $40 \%$ of stakeholders had made or planned to give feedback. However, it is not known if these intentions were carried out or how many secondary school teachers 
were represented in the $40 \%$. Another finding in the survey was that only 4 out of 10 secondary teachers surveyed agreed that the direction of the revised curriculum would have a greater impact on student learning, suggesting that the majority did not have a sense of ownership. I wished to enquire if the extent of their feeling of ownership and their belief in its potential effectiveness impacted on their "buy-in" to the implementation of the revised curriculum.

\subsection{Significance of the research}

An implementation project of this significance in New Zealand schools offered a unique opportunity to research over a sustained period what actually happens in secondary schools when teachers are required by government policy to reconsider their context, what they are teaching, and how they are teaching it. I believed that this research had significance for several reasons.

Firstly this study contributes to the knowledge about the implementation of mandated change in New Zealand secondary schools by alerting leaders to teachers' possible responses to change and by identifying support strategies and barriers for them as they experience an implementation process. The literature on educational change is extensive; however, most studies of change implementation in schools involve primary schools (Forrest, 2008; Fullan \& Earl, 2002) with little known about how New Zealand secondary classrooms function (Carr et al., 2000). Fullan and Earl (2002, p. 420) state that "we would encourage the study of secondary school characteristics, and management of change in high school." This study was an opportunity to do so.

An implementation of change ultimately depends on teachers' classroom practice (Bereiter, 2002; Cuban, 1993, 1996; Datnow \& Castellano, 2000). However, many researchers note the scarcity of empirical evidence related to the processes that support teachers to challenge their beliefs about teaching and learning, and enable teachers to make changes in the classroom (Bereiter, 2002; Hargreaves, 1997; Timperley, Wilson, Barrar, \& Fung, 2007). There was the risk that the key changes as suggested in the New Zealand new curriculum would not be transferred into teaching and learning if the implementation process in schools did not provide an environment that supported change. There was also a risk that the implementation of change could have a negative effect on the schools involved. Change can be emotionally debilitating when it undermines or undervalues teachers' current beliefs and practice (Schmidt \& Datnow, 2005). If an implementation process was to be 
successful, or at least not damage teacher morale, it must address teacher anxiety and support them (Du Four, 2004; Horn, 2000; Woods, 1994). This study of the implementation of the revised curriculum provided an opportunity to identify ways this support could be provided. It could help to anticipate secondary school teachers' response to changes and to identify the support strategies or the barriers for them as they work through change.

Secondly, through educational connoisseurship, the study reveals what was important to the participating teachers and in New Zealand schools. It exposes the conflicting messages for teachers within the secondary sector in New Zealand and the resulting dilemmas they represent for teachers. The findings could also apply to other secondary teachers in New Zealand schools and therefore could encourage leaders to explore the enacted goals of education in their context.

Thirdly, the teachers described how their beliefs and practice had developed by the learning they had independently sourced throughout their careers to meet their personal goals for their teaching. This provides insight into what motivates teachers to make changes. These findings will inform professional learning practices in schools and perhaps prompt school leadership to explore the valuable contribution of expertise and knowledge that teachers in their schools can make to an implementation process.

\subsection{My motivation}

I was highly motivated to undertake this study for two reasons. One was my passion for education and support for the more student-centred teaching approach that I believed the implementation of the NZC could drive. The other was a desire to understand what would support teachers to make changes. I felt that teachers were often unfairly portrayed in research and in the media as being obstacles to reform, a view which overlooked the complexity of their lives and their desire for their students to succeed. Each of these motivations is discussed in the following sections.

\subsubsection{Passion for education}

For 30 plus years I have been involved in education as an educator and also as a parent observing my five children progress through five different secondary schools. Over this time I had been, and remain, fascinated by the learning process. I feel that as educators we are challenged to engage students in an active learning process. A comment by Shirley Clarke (2004) sums up my thinking. She maintained 
that at the end of the school day, instead of teachers being exhausted and students eagerly rushing home, teachers should be able to skip out of the school gates while the students staggered out, worn out by a day of hard work learning. To achieve this, I believed teachers needed to see learning as a student-centred process that actively involved the student throughout. I was therefore excited by a new curriculum that explicitly described learning as a meaningful active process and I was hopeful that its implementation was an opportunity to develop student-centred pedagogy throughout the secondary school sector.

\subsubsection{Understanding teachers' reality}

I saw this research as a unique opportunity to describe the subjective experiences of secondary school teachers during the implementation of mandated systemic change to let their realities emerge. I was realistic. In my work with a range of schools I had became aware of how many innovations had come and gone in schools leaving little trace of sustained change. Sometimes I would be told by staff "We did some great PD on using literacy across the curriculum a couple of years ago" but I would not see any of the strategies used in the classrooms suggesting that the learning had not impacted on teachers' beliefs about teaching and learning. In the meantime, the school had moved on to another focus for staff PD.

Moreover, as explained in section 1.3, despite my personal motivation to embed new learning into my practice, I had clear memories of the struggle I had experienced as a busy classroom teacher. I had taken part in many PD workshops that had stimulated my interest and yet, despite my best intentions, the ideas were often lost in the rush between the staffroom, the bulging pigeonhole, the waylaying by students, and finally the arrival of 25 noisy adolescents in my classroom all needing to be immediately engaged. Knowing this, I perceived the plan to implement systemic change into all New Zealand schools to be an enormous challenge. I empathised with secondary school teachers knowing that this could represent yet another dimension in their complex environment.

I was aware that to be successful educational change needs to ultimately impact on what happens in the classroom (Fogarty \& Pete, 2007; Reio, 2005). Therefore, teachers are considered to be important agents of change and are expected to play a key role. Paradoxically they can also be seen as obstacles (Prawat, 1992). I felt this was an unfair perception of teachers; teachers want to become better so that their students will benefit (Hargreaves, 2005). However, they often do not see any 
positive effect that the reform, which they did not choose and which had been externally imposed, will have on them and their students (Schmidt \& Datnow, 2005). As a result, many teachers resist reforms when the rhetoric of change does not match with the reality of their everyday experiences (Vulliamy, Kimonen, Nevalainen, \& Webb, 1997). Understanding how people change is the key to change itself (Fullan, 1996) and there is a need to let knowledge of teachers' realities emerge (Goodson, 1992). However, while there has been extensive research on educational change theory, there appears to be a scarcity of literature from the teachers' point of view (Dzubay, 2001). I perceived this study as a vehicle for the teacher's voice which, using educational criticism, I was able to do.

\subsection{Overview of the thesis}

This thesis comprises nine chapters. Chapter 1 has set the scene for the study describing the issue under investigation, the significance of the research and what motivated me to undertake it. I have explained why, after entering the field I reconsidered my research design and eventually chose to employ educational criticism as a way to provide a picture of the complexity I encountered. In this chapter I have provided my credentials to support my use of the lens of an educational connoisseur and critic throughout the thesis. There will be further explanation of the two components of educational criticism, connoisseurship and criticism in chapter 3 .

Chapter 2 is the literature review that I undertook before embarking on the study and during the early stages. In it I describe the drivers that led to the development of the new curriculum and the implications for teachers. This is followed by a review of the literature on the implementation of change in general, on the role of teachers' beliefs, and on the learning that is required to bring about a change in beliefs and practices.

In chapter 3 I further justify my choice of educational criticism and describe the evolving nature of the study by explaining how I reflected on unanticipated events and reconsidered my original plan. The four stages of educational criticism, descriptive, interpretative, evaluative and thematic are described.

Chapter 4 provides the reader with an overview of the study. In it I describe the phases of the study, the choice and details of the sites, the participants and the method of data collection. It could be seen as a "nuts and bolts" chapter providing a guide for a reader. 
In chapter 5 I introduce the participants. This is a descriptive aspect of the study in which the reader is invited to develop their own interpretation of the teachers' stories without being affected by mine as the educational connoisseur and critic.

My interpretation as an educational connoisseur of the teachers' stories is presented in chapter 6 . In this chapter I discuss the critical incidents that impacted on the teachers' construction of their identity. The teachers' emotional response to the NZC and the degree to which I perceived the signalled changes were of significance to their personal goals and to their context are described.

Chapter 7 presents a combination of descriptive and interpretative stages of educational criticism. In this chapter I both describe and interpret the lessons that were observed by linking them to the spirit of the NZC and to possible epistemological beliefs.

In chapter 8 I explore the ways in which the participants in this study believed that elements of the New Zealand educational system affected their perception of the significance of the signalled changes to the NZC and therefore to their willingness to engage with it.

Chapter 9 is a discussion of how, taking the implications of the findings of the study into consideration, the implementation of change could be carried out in New Zealand secondary schools. 


\section{Literature review}

Perplexity is the beginning of knowledge (Kahlil Gibran, 1963).

\subsection{Chapter overview}

This study was based on the assumption that the implementation of effective pedagogy and the key competencies of the NZC would involve change of beliefs and practice for the teachers in secondary schools. The purpose of this literature review, embarked upon at the beginning of the study, was therefore to explore what is known about the role of beliefs in the implementation of change and the processes that would impact on individuals' beliefs and behaviour. Further literature that was explored as the study evolved will be discussed in the following chapters.

Table 2 explains the questions that guided the literature review and the resulting aspects that were explored. First, the rationale for the changes signalled in the New Zealand curriculum documents is discussed. This is followed by an exploration of the implications for teachers and for their beliefs. Next, the role of beliefs is discussed. Finally, the literature on the implementation of change in general and educational change is examined. This review will show that any change that challenges existing beliefs and practices is daunting and complex, and involves transformational learning which is seldom acknowledged in educational change literature. It also explores how the significance of the proposed change affects teachers' readiness which in turn affects the level of teachers' commitment - an essential element that is often overlooked.

Table 2. Questions that Guided the Literature Review

\begin{tabular}{ll}
\hline Questions & \multicolumn{1}{c}{ Literature explored } \\
\hline Why have these changes been signalled? & Rationale for the changes \\
\hline What does the change involve for teachers? & $\begin{array}{l}\text { The challenge. } \\
\text { The role of beliefs. }\end{array}$ \\
\hline How can change be implemented? & What implementation involves. \\
& Lewin's (1947) three stages of implementation. \\
\hline $\begin{array}{l}\text { What would motivate teachers to make } \\
\text { changes? }\end{array}$ & $\begin{array}{l}\text { Lewin's stage 1: Creating the motivation to change. } \\
\text { Understanding the process within teachers. } \\
\end{array}$ \\
& $\begin{array}{l}\text { An exploration of the appraisal of "readiness" that } \\
\text { affects the motivation to change. }\end{array}$ \\
& The role of emotions. \\
\hline
\end{tabular}




\begin{tabular}{ll}
\hline Questions & \multicolumn{1}{c}{ Literature explored } \\
\hline What is needed for change to happen? & Lewin's stage 2: Changing. \\
& The role of leaders \\
& Creating an environment to support change. \\
& Professional learning to support change. \\
& Transformative learning. \\
& Models of professional learning. \\
\hline What is needed to embed changes? & Lewin's stage 3: Freezing. \\
& Examples of research studies on the \\
& implementation of constructivist practices. \\
\hline What can this study contribute to the literature? & The gaps in the literature. \\
\hline
\end{tabular}

\subsection{The rationale for the changes}

New Zealand is not alone in facing the challenges of curriculum reform as governments come to realise that the old fact-based curriculum does not meet the needs of today's students (Avenstrup, 2005; Gilbert, 2003). Governments, perceiving education as a vehicle for creating citizens capable of competing in a global workforce, are pushing for skills such as those described in the key competencies of the NZC higher level thinking, interpersonal skills, creativity and problem solving skills - to be developed (Avenstrup, 2005; OECD, 2001; Sahlberg, 2004; Wallace, 2004). The vocabulary of the new curricula is often "competencies", "skills" or "standards' instead of a list of facts (Avenstrup, 2005). These are deemed appropriate for the age we now live in, and the world our students will work in, often referred to as the knowledge age (Bereiter, 2002; Capper, Fitzgerald, Welden, \& Wilson, 2000; Gilbert, 2003). It appears that while students have changed, schools have not with most still operating in a way that prepares students for an industrial age where teachers find and train the useful parts of children that can serve an industrial-based system (Bereiter, 2002; Capper et al., 2000; Elmore, 1995). Gilbert's (2003) summary of the difference is described in Table 3. However it should be noted that this table overlooks the complexity of ideas which will be discussed in section 2.5, p.28.

Table 3. Comparison between Industrial Age and Knowledge Age ideas

\begin{tabular}{lll}
\hline Dimension & Industrial Age Idea & Knowledge Age Idea \\
\hline Minds & $\begin{array}{l}\text { Are like containers or } \\
\text { filing cabinets - they } \\
\text { store knowledge. }\end{array}$ & $\begin{array}{l}\text { Are resources that, when connected, can generate } \\
\text { knowledge. }\end{array}$ \\
&
\end{tabular}




\begin{tabular}{lll}
\hline Dimension & Industrial Age Idea & Knowledge Age Idea \\
\hline Ability & Is measurable. & Is difficult to define, let alone accurately quantify. \\
& Primarily involves & Takes many forms and because we cannot know which \\
& verbal/linguistic and/or & kinds will be most useful in the future, we must try to \\
mathematical capacities. & develop them all. \\
Some individuals & All individuals have particular strengths and \\
& naturally have more & weaknesses. Education should develop their ability to \\
& ability than others. & work with others to maximise the strength of the team. \\
\hline
\end{tabular}

Knowledge age ideas, as described by Gilbert, are compatible with learnercentred teaching or constructivism, the predominant theory active in education today and incorporated into many curriculum models (M. Richardson, 2007; Sahlberg, 2004). If we accept the assertion that most teachers practise a transmission approach to teaching (Bereiter, 2002; Brooks \& Brooks, 1993; Prawat, 1992; Windschitl, 2002), the widespread focus on constructivism suggests that educational change is a fact of life for teachers in Western countries across the world (Hannay \& Ross, 1997).

While some argue that the purpose behind aspects of the new curriculums being mandated by governments is a political one designed to meet a country's economic needs (Benade, 2011; Broadfoot, 2003; Codd, 2005; Neyland, 2010), it is also accepted by researchers that the constructivism is a theory of how learning actually does happen. A constructivist view maintains that students come with a range of prior knowledge and experiences that influence how they respond to new information and that learning is an active, intellectual process of constructing knowledge that occurs gradually over a period of time, not the passive assimilation of knowledge (Piaget, 1954; Dewey, 1929; Vygotsky, 1978). A teacher with a constructivist view would therefore employ what is often referred to as a "studentcentred" approach, a term which appears to have a range of interpretations (Hall \& Kidman, 2004). However if interpreted as described in the effective pedagogy of the NZC (2007) it could be considered as a focus on the identified needs of the students, provision of strategies to facilitate knowledge building with consideration of the knowledge base of the subject, and is of relevance to the students. The NZC also refers to encouraging "student ownership of their learning" by involving them in decisions relating to their learning (NZC, 2007, p.35).

The focus on student-centred or constructivist teaching and learning is one that the research community supports as a move towards more effective teaching practices (Cuban, 1990; Hopkins, 2001; van Veen, Sleegers, Bergen, \& Klassen, 2001; Windschitl, 2002). However, a change to student-centred approaches involves 
a fundamental shift in what many teachers believe about teaching and learning. A fundamental shift in beliefs requires transformational learning which Mezirow (1997) describes as "the process of using a prior interpretation to construe a new or revised interpretation of the meaning of one's experience in order to guide future action" (p. 162). To facilitate transformative learning, leaders of change must help learners to be critically reflective, that is, to become aware and critical of their assumptions and to redefine problems from a different perspective (Mezirow, 1997; Taylor, 2007). I began to comprehend that the degree of challenge this represents should not be underestimated as I continued to review the literature (Bereiter, 2002; Cuban, 1993; Gregoire, 2003; Windschitl, 2002). In the following section I explored what is involved.

\subsection{The challenge}

The core of the matter is that changing the behaviour of people, which is at the heart of any reform, is difficult (Fullan, 2007; Hopkins, 2001; Kotter, 1990).

Conventional wisdom is that crisis is a powerful motivator. However, in a dramatic example of the challenge involved in changing behaviour, research which was carried out in America of people who had severe heart disease suggests that even a potentially life-threatening crisis may not be a powerful enough motivator. The participants in this research had undergone heart bypass surgery. While this procedure alone does not necessarily prolong life nor mean that chest pains will not recur, the patients could lessen their fear of death and avoid the return of the problems by changing to healthier lifestyles. However, the research found two years after their operation, $90 \%$ of the patients had not made the necessary changes to their lifestyle (Deutschman, 2007). Fullan (2007) commented on this study maintaining that it is an example of how even "fear, as in fear of dying turns out not to be a powerful motivator beyond an initial immediate effect" (p. 43). He related this to the United States One Child Left Behind legislation which, despite punitive consequences for those schools, did not show significant progress and had only limited short-term effects. This suggests that the legal requirement to implement the changes or the surveillance of an external agency such as ERO would not necessarily motivate New Zealand teachers to change their beliefs and practice.

Institutions are able to persistently resist charge (Levin, 2000); in the corporate world about $70 \%$ of all company attempts to bring about a change in employee behaviour by installing technology, downsizing, restructuring, or trying to 
change culture fail (Beer \& Nohria, 2000). Educational change also has a record of limited success. Hargreaves and Goodson's (2006) research into three decades of educational change found (as I had when visiting schools) that while some change had been evident over that period of time there was evidence that very little reached the stage of being embedded in teachers' everyday practice, suggesting that the behaviour of the majority of teachers had not changed. This is not commensurate with the investment made (Hoyle \& Wallace, 2007). Sarason (1998, p. 2) asks:

\begin{abstract}
Why is it that despite billions of dollars expended in the post world war 2 era the results have been so meagre? You can always find a classroom or a school - nearly always an elementary school - whose features and accomplishments are exemplary. Why do these instances remain isolated - why haven't they spread to other classrooms and other schools?
\end{abstract}

There appears to be a gap between the research on effective teaching and learning and what is happening in the classrooms despite countless efforts to make change (Hart \& Hargreaves, 1998). It seems that because the change to a constructivist approach is not simply introducing new strategies but is a process whereby individuals need to experience transformational learning and change the beliefs about teaching and learning underpinning their practice, most efforts to embed it systemically fail to progress beyond early implementation (Hopkins, 2001; Windschitl, 2002).

\title{
2.4. Looking more closely at beliefs
}

Given their apparently entrenched nature I sought a deeper understanding of beliefs. Nespor (1987) described beliefs as relying on episodic memory organised by personal experience. Of particular relevance to me as a researcher is the fact that while beliefs may be simple propositions, they are difficult to directly observe (Kagan, 1990; Rokeach, 1972). While a person may state that "I believe..." this may not always be accurate, being influenced by a number of factors. Some teachers, for example, may not have the language to describe their beliefs, or may be reluctant to express what they perceive to be an unpopular belief (Kagan, 1990). Beliefs, therefore, must be inferred by what individuals say and do (Kagan, 1990; Rokeach, 1972; van den Berg, 2002). A belief may be applied in an arbitrary way to a range of situations, or transferred to other aspects of an individual's life that may be unrelated to its origin (Nespor, 1987; Rokeach, 1972). This suggests that teacher beliefs about teaching and learning may have their origins in other aspects of their lives. For example, they may transfer beliefs about how to discipline their own children to include beliefs about how to control their students' behaviour (Ertmer, 2005). 
Rokeach (1972) describes five types of beliefs that make up an individual's beliefs system. These beliefs vary in strength from those that are of minor importance (inconsequential beliefs) and are easily changed, through the peripheral beliefs to beliefs about authority, and finally to core or primitive beliefs which are those most resistant to change (See Figure 1).

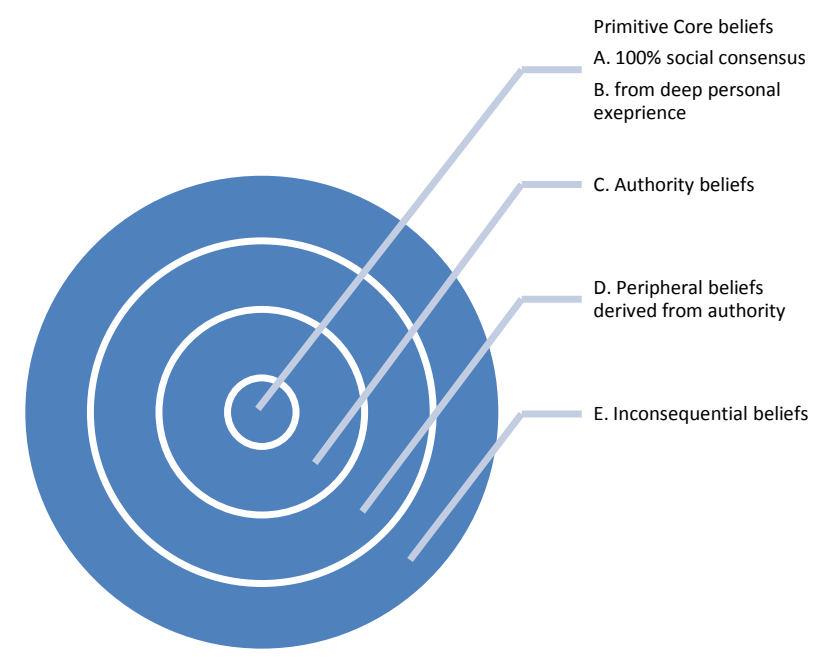

Figure 1. Rokeach's (1972) belief system

According to Rokeach (1972), there are two types of primitive or core beliefs. Type A are those fundamental beliefs we share with everyone else about, for example, the nature of physical reality. Type B beliefs, relevant to this study, are those primitive beliefs that are constructed through deep personal experience and which are private and which we believe regardless of the opinion of others. They may, for example, include positive and negative beliefs about personal ability, beliefs about teachers and teaching and an image of a teacher. Both these primitive beliefs are hard wired and extremely resistant to change. Nisbett and Ross (1980) describe them as the "raw material which bias the interpretation of later-encountered information" (p. 172) and maintain that disconfirming data alone is unlikely to affect any significant change. In addition, any change to the primitive beliefs would affect the rest of the belief system. Second, Type $\mathrm{C}$ beliefs are those that Rokeach maintains represent the authorities we trust or do not trust to help us decide what to believe or what not to believe. Examples of the authority for the purpose of this study may be educational leaders or researchers. Type D beliefs are those accepted from authoritative sources that are trusted rather than from direct experience. While these are important beliefs, they can be changed if the change is mooted by the authority or if there is a change in authority belief. An example of this may be when an individual is confronted with suggestions from an authority perceived to be more credible. 
Rokeach calls the final type of belief, E, inconsequential beliefs such as taste which can change without having any effect on the individual's belief system.

However, simply categorising belief, as Rokeach has, becomes complicated when teachers' beliefs are considered. Each teacher develops a personal interpretative framework, or professional identity (Butt, Raymond, McCue, \& Yamagishi, 1992; Spillane, Reiser, \& Reimer, 2002; van den Berg, 2002) or self-understanding (Kelchtermans, 2009) through his or her career. Teachers' beliefs are part of the construction of their teacher identity (Beijaard \& De Vreis, 1997; Kelchtermans, 2009). They are complex, overlapping and intertwined with what is referred to in the literature in different ways as, for example, practical knowledge (Feldman, 2000), an “encyclopaedia of personal knowledge” (Duffee \& Aikenhead, 1992, p. 495) or selfunderstanding and educational theory (Kelchtermans, 2009). This fund of knowledge is a personal system of knowledge and beliefs about education that teachers use on the job, practical theories based on what teachers have found to be successful through a process of trial and error in their classroom ( Kelchtermans, 2009), "rules of thumb to help them with decision-making" (Feldman, 1999, p. 607). Other terms used in the literature are schemata (Hyslop-Margison \& Strobel, 2008; Timperley \& Robinson, 2001), personal interpretative framework, or professional identity (Butt et al., 1992; Spillane et al., 2002; van den Berg, 2002). They are developed from the interpretation of their childhood experiences, from early educational experiences, from their teacher education, from role models and authority, from their personal lives, from their context and crucially, from their experiences as a teacher (Butt el al; 1992; Goodson, 1992; Kelchtermans, 2009).

Of particular relevance for this study it appears that those beliefs developed in early life from experiences as students in their own education become part of their "pedagogical platform" (Barone, 1987, p. 12) and are the most entrenched and impervious to change (Barone, 1987; Rokeach, 1972). As Lortie (1975) pointed out, every teacher has spent an extended time (in New Zealand up to 13 years) as "an apprentice of teaching" (p. 24) by observing their teachers in the classroom during their own education. It is reasonable to believe that during this time as apprentices in their own education, most would have experienced a transmission method of teaching. This experience creates beliefs about teachers and teaching and an image of a teacher. The image of a teacher formed early in life is brought by student teachers to their teacher education and to their own teaching practice. Despite being exposed to a range of theories of teaching and learning in their teacher education which may differ from their internalised image, this image, developed over time by the interpretation of experiences 
both inside and outside the classroom is resistant to change (Beijaard \& De Vries, 1997; Briscoe, 1991; Mezirow, 1997; Pajares, 1992; Richards, Gallo, \& Renandya, 2001). This suggests that the beliefs about teaching and learning may meet the descriptions of Rokeach's (1972) primitive B beliefs. Teachers may subsequently deal with issues in ways that their primitive beliefs suggest are effective. While a teacher's knowledge may be developed further by insights from teacher education, PD, readings and collaboration, their core beliefs are more personal, idiosyncratic convictions built up through experiences (Kelchtermans, 2009). Therefore new knowledge is only integrated into the subjective educational theory if teachers find it works for them in the classroom (Kelchtermans, 2009) which does possibly explain why many innovations are not embedded into practice. Teachers' beliefs about teaching and learning which guide their actions are therefore a blend of personal beliefs, dispositions, practical knowledge and educational theories mediated by interpretation of their experiences and the culture or the context in which he or she works (Assaf, 2008; Schmidt \& Datnow, 2005).

Considering the complex, overlapping and intertwined nature of a teacher's personal interpretative framework it is not surprising that Pajares (1992) describes teacher educational beliefs as an elusive construct which is "broad and encompassing" (p. 316). Teachers as adult learners have substantial knowledge that means accepting that when they encounter new knowledge, they bring to the learning an elaborated knowledge that cannot be simply categorised into beliefs, attitudes and practices. They are intertwined and as such should be considered together for research purposes (Kelchtermans, 2009; Pajares, 1992; Spillane et al., 2002). What is relevant to this study is that, whatever label is put on it, it is through this complex personal interpretative framework that teachers make sense of their work and of change propositions, which therefore, as frequently noted in the literature, needs to be explicitly examined in any change implementation (see for example, Albion \& Ertmer, 2002; Kelchtermans, 2009; van den Berg, 2002).

\subsection{Beliefs relevant to the changes in the new curriculum}

Acknowledging the complexity of a teacher's personal interpretative framework, the beliefs that I considered relevant to my study were those that teachers held about the nature of teaching and learning: How students learn, the teacher's role in the classroom, the abilities of the students, and the relative importance of content (Craig, 2006; Schommer, 1998). These beliefs are core to the decisions people make about their teaching and therefore to educational change (Bandura, 1989; Craig, 
2011; Nespor, 1984; van den Berg, 2002). As with all learners, teachers' new learning is filtered through knowledge and beliefs that they already have: their interpretation or sense-making of new learning is therefore based on their prior knowledge and beliefs about teaching and learning (Keys, 2007; Luttenberg, Veen, \& Imants, 2011; Spillane, 2000; van den Berg, 2002). To embed student-centred or constructivist practice teachers therefore need to have a philosophical, psychological and epistemological understanding of constructivism, or there is a risk it may be rejected or become reduced to a procedure (Bereiter, 2002; Brooks \& Brooks, 1993; Windschitl, 2002). Crucially, constructivism involves a reculturing of the classroom affecting the important teacher/student relationship (Windschitl, 2002), which may be confusing for both parties with power becoming an issue (V. Richardson, 1997). It could be a challenge, even threatening, for a teacher whose self-image is that of one with the authoritative knowledge (V. Richardson, 1997; Savasci \& Berlin, 2012; Windschitl, 2002).

In her discussion on the difference between a constructivist model of teaching and learning and a transmission one, Schommer (1998) maintains that the model used is dependent on a teacher's epistemological beliefs. To further explain her argument, she identified five independent dimensions of epistemological beliefs that teachers may hold about teaching: structure, certainty, source of knowledge, control, and speed. She maintained that proponents of a transmission model of teaching hold an objective view of knowledge, believing that it resides in authority and that it is unchanging. They may also believe that concepts are learned quickly or not at all, that learning ability is innate and that knowledge is simple, clear, and specific. In a transmission/objectivist model the teacher is seen as the source of knowledge and the students as passive receptacles of that knowledge.

In contrast, constructivists believe that knowledge is complex and uncertain, that it can be learned gradually though reasoning processes, and that it can be constructed by the learner. A constructivist learning model emphasises the creation of active leaning environments that permit critical thinking, discovery, and collaboration (Hopkins, 2001). In a constructivist model the teacher is a facilitator who supports the students in actively constructing their own understanding. For a teacher with an objectivist epistemological view to change to a constructivist one would therefore require a paradigm shift involving the relinquishing of former beliefs described by Brooks and Brooks (1993) as "the willing abandonment of familiar perspectives and practices and the adoption of new ones" (p. 25). 
Schommer's points are adapted and summarised in Table 4.

Table 4. Schommer (1998) independent dimensions

\begin{tabular}{lll}
\hline Dimension & An Objectivist epistemology & A Constructivist epistemology \\
\hline $\begin{array}{l}\text { Structure - the organisation of } \\
\text { knowledge: from simple and } \\
\text { compartmentalised to complex } \\
\text { and highly integrated. }\end{array}$ & $\begin{array}{l}\text { Teachers define concepts. } \\
\text { Students memorise facts. } \\
\text { Teacher lectures. }\end{array}$ & $\begin{array}{l}\text { Students examine complex } \\
\text { knowledge and draw their own } \\
\text { conclusion. }\end{array}$ \\
\hline $\begin{array}{l}\text { Certainty - the certainty of } \\
\text { knowledge: from certain and } \\
\text { absolute to tentative and } \\
\text { constantly evolving. }\end{array}$ & $\begin{array}{l}\text { Students learn as presented and } \\
\text { are penalised for } \\
\text { misconceptions. }\end{array}$ & $\begin{array}{l}\text { Students allowed to develop } \\
\text { alternative conceptions. }\end{array}$ \\
\hline $\begin{array}{l}\text { Source - the source of } \\
\text { knowledge: from handed down } \\
\text { by omniscient authority to } \\
\text { derived by reason. }\end{array}$ & $\begin{array}{l}\text { Teachers answer all questions } \\
\text { or ask students to refer to the } \\
\text { textbook. }\end{array}$ & $\begin{array}{l}\text { Students apply a critical eye to } \\
\text { what they read and hear - ask } \\
\text { questions of each other. }\end{array}$ \\
\hline $\begin{array}{l}\text { Control - the control of } \\
\text { knowledge acquisition: from the } \\
\text { ability to learn is innate and } \\
\text { fixed at birth to ability to } \\
\text { learn is acquired through } \\
\text { experience. }\end{array}$ & $\begin{array}{l}\text { Teachers believe that students } \\
\text { understand according to their } \\
\text { ability. }\end{array}$ & $\begin{array}{l}\text { Students can learn to learn. } \\
\text { Learning is process orientated } \\
\text { e.g. students use strategies for } \\
\text { reading comprehension. }\end{array}$ \\
\hline $\begin{array}{l}\text { Speed - the speed of knowledge } \\
\text { acquisition: from learning is } \\
\text { quick or not-at-all to learning is } \\
\text { acquired gradually. }\end{array}$ & $\begin{array}{l}\text { Quick - students learn from } \\
\text { well designed curricular } \\
\text { materials and presentations e.g., } \\
\text { they watch multimedia } \\
\text { presentations. }\end{array}$ & $\begin{array}{l}\text { Gradual - students learn from } \\
\text { discovering or doing. }\end{array}$ \\
\hline
\end{tabular}

It needs to be emphasised that Schommer maintained that rather than a coherent structure these were independent dimensions of beliefs suggesting that teachers may hold beliefs from each approach with regard to the various dimensions. The possibility that the dimensions are not mutually exclusive was evident in Hashweh's (1996) study of 35 Palestinian teachers who were asked to complete a questionnaire on beliefs about knowledge and learning. When he categorised the data into two constructivist groups and two objectivist groups he found that some teachers belonged to both sets of groups. In addition, Hofer and Pintrich (1997) discussed developmental stages or positions through which individuals may progress through a process of assimilation or accommodation. For example, there may be a move from a black and white view of knowledge to one that accepts a diversity of opinions which they refer to as "multiplism" (p. 357). Importantly, in their review of the literature on personal epistemology, Hofer and Pintrich (1997) found that there was a range of thought on the relevant dimensions and also whether epistemological beliefs were related to specific subject domains. van Veen et al. (2001), for example, in their study of 452 Netherlands secondary school teachers' professional orientations found that Mathematics and Science teachers supported the transmission of knowledge 
while Social Studies teachers were more inclined towards constructivist practices. While I would hesitate to suggest that this applied to all teachers of these subjects, these findings do demonstrate that identifying a teacher's personal epistemology may not be a simple matter.

This section has identified the complexity of teachers' personal frames of reference and explored the possible conflict between their epistemological beliefs and those that underpin constructivist approaches to teaching and learning. In the following sections literature on the implementation of change is discussed with attention paid to ways of engaging teachers.

\subsection{The implementation of change}

Fullan (2007) describes three stages to a change process. Stage 1 is the initiation of a new policy in the case being studied, the decision to adopt a new curriculum. Stage 2 is the implementation, the introduction of the new curriculum over, in New Zealand, a two-year period in an attempt to put the ideas into practice. Stage 3 refers to the ensuing years when the changes are embedded into practice or in many cases, despite extensive professional learning for teachers, are cut back or only operating at a rudimentary level (Fullan \& Miles, 1992).

It is stage 2, the implementation, which is the focus of this study. Fullan (2000) believes that the introduction of large scale reform in the 1960s failed to take because issues of implementation were ignored, and because it was assumed that the move from stage 1, introduction of change, to its use in the classroom would be unproblematic. It is now acknowledged that the adoption of a policy or innovation does not guarantee its use and the important and complex issue of implementation cannot be taken for granted (Geijsel, Sleegers, van den Berg, \& Kelchtermans, 2001; Hall \& Irving, 2010; Reio, 2005). It is not a simple linear process of adopting the policy, implementing it, and enjoying positive outcomes (Hall \& Irving, 2010). However, it appears that policy makers in some instances still consider that the hard work is done when political or ideological analysis leads to a reform programme (Levin, 2000) and that the implementation process is complete when a new curriculum has been gazetted and the relevant documents have been written and delivered to a school (Fullan \& Levin, 2009; Wheatley, 2002). This attitude ignores the fact that implementation is not simply an extension of planning and adoption process, it is "a phenomenon in its own right" (Fullan \& Pomfret, 1977, p. 336) which is a messy process of "influence, pressure, dogma, expediency, compromise, resistance, error 
opposition and pragmatism" (Levin, 2000). While the policy can provide a framework for implementation, it stops at the classroom door (Hopkins, 2001; Reio, 2005; Spillane, 2000). As discussed earlier, it is the interpretation of the policy by the teachers who are the agents of change that will determine its impact and it is this aspect which has proved to be problematic. Reform can be imposed from the outside, transformation, changing the way teaching and learning is perceived and embedding it into practice must happen within the school. As an indication of the challenge involved, Bereiter (2002) maintains that up till now "education has experienced reform but not transformation" (p. 311). The history of educational change demonstrates this (Bereiter, 2002; Cuban, 1990; Hargreaves \& Goodson, 2006).

\subsection{Inside the "black box"}

Darling-Hammond (1990) described the implementation of change as an unexplored "black box" between policy enactment and measuring outcomes: what it takes to make a policy or innovation which has been designed and adopted fully operational in schools. It includes how the policies are introduced to schools, how any signalled change is supported, and the impact the suggestion to change has on the teachers (Hopkins, 2001). In this section the literature on the black box of implementation of change is reviewed.

Lewin's change theory, underpinned by motivation theory, is frequently cited in change literature including educational change (Keys, 2007; Reio, 2005; Wirth, 2004). Kurt Lewin theorised a three-stage model of change, known as the unfreezechange-refreeze model that requires prior learning to be rejected and replaced (Wirth, 2004).

Schein (2002, p. 36) describes what is involved in each stage:

Stage 1. Unfreeze:

Creating the motivation to change

Disconfirmation of current behaviour

Creation of survival anxiety or learning anxiety

Creation of psychological safety to overcome learning anxiety.

To support teachers through this stage leaders of an implementation need to have an understanding of the change process within teachers (Fullan, Cutress, \& Kilcher, 2005; Patterson \& Rolheiser, 2004; V. Richardson, 1990). 
Stage 2. Change:

Learning new concepts and new meanings

Trial-and-error learning.

During this stage teachers will need: leadership that works with staff to clarify goals and expectations (Fullan et al., 2005; Coburn, 2003; Bishop, 2008; van Veen \& Sleegers, 2005); an environment that supports a learning community (Fullan et al., 2005; van Veen \& Sleegers, 2005); adequate and appropriate PD experiences, monitoring and support; and the provision of resources including time (Fullan et al., 2005; Coburn, 2003; Bishop, 2008).

Stage 3. Refreeze:

Internalising new concepts and meanings

Incorporating into self-concept and identity

Incorporating into ongoing relationships and groups.

At this stage ongoing monitoring and support is needed to ensure the new learning is sustained (Brown \& Sprangler, 2006; Timperley et al., 2007).

Each of these elements is discussed in the following sections.

\subsubsection{Lewin's Stage 1. Unfreeze: Creating the motivation to change}

Fullan (2007) states succinctly: "Educational change depends on what teachers do and think" (p. 129). Therefore leaders need firstly, an understanding of the change process within teachers, and secondly, to "unfreeze" current ways of thinking and to create in teachers a motivation to make the changes (Fullan et al., 2005; Patterson \& Rolheiser, 2004; Weiner, 2009). In the following sections the understanding of the change process within teachers and motivation factors are explored.

An understanding of the change process within teachers

A crucial part of understanding the change process within teachers is an acceptance that they react in a range of ways when confronted by mandated change. Oreg (2006) suggests that the subjective experiences of teachers during change should be explored to reach an understanding of what any perceived resistance may be really about. The possible reasons identified in the literature are many and include: lack of intrinsic motivation to implement changes initiated by someone else and which do not match their own goals for their teaching (Oreg, 2006; van Veen, 2001), lack of a clearly articulated and coherent vision (Fullan, 2007; Harris, 2000), lack of understanding of the instructional change involved (Alesandrini \& Larson, 
2002; Lai \& Pratt, 2008; Ryan, 2006; Windschitl, 2002), see no personal value in the change (Armenakis, Bernerth, Pitts, \& Walker, 2007; Thoonen, Sleegers, Oort, Peetsma, \& Geijsel, 2011), concern about job security (Kelchtermans, 2009; Oreg, 2006), a threat to autonomy and professionalism (Eisner, 1998; Evans, 2010; Neyland, 2010), lack of trust in the leadership (Armenakis et al., 2007; Oreg, 2006) or the organisation and culture of the school (Hargreaves, 1994; Coburn, 2003; Horn, 2000); lack of confidence that contextual support will be provided (Assaf, 2008; Ballet \& Kelchtermans, 2008) or simply their own disposition which is explained by Oreg (2006) as “they just do!" In addition, teachers may have a negative emotional response to any of the above factors (Datnow \& Castellano, 2000). Leaders of change need to understand people are complex and that any, or all, of these reactions may be experienced by their staff. In this section I describe the findings from the literature on what teachers do and think when change is introduced into their school and explore the reasons why they may react in the above ways.

\section{Teacher motivation to change}

In her synthesis of motivation literature, Dzubay (2001) found that there were few studies that directly addressed teachers' motivation. Instead they tended to focus on how to get teachers to make changes and provided findings of only short-term visible changes - or lack of change, leaving the issue of motivation "untapped" (p. 8). As Grundy (2002) who led curriculum reform in Western Australia observed, the challenge is often considered to be "how to get those pesky teachers who have their own ideas and are resistant to change to implement the reform” (p. 55). Indeed, when reviewing the literature advising leaders on the process of implementing educational change I found little that addressed teachers' subjective meaning of proposed change. With the pressure to implement mandated change it appears that the importance of teachers' personal motivation is often overlooked. What is clear is that individuals own their motivation, it is complex and cannot be "done" to someone (Day, 2002; Debowski, 2007; Gregoire, 2003) and that therefore the advice to try to understand it and work to inspire it is obviously applicable in the educational environment (Dzubay, 2001).

\section{Understanding teachers' motivation}

Ford (1992), in his explanation of a "motivational systems theory," describes motivation as "the organised patterning of three psychological functions that serve to direct, energise and regulate goal directed activity: personal goals, emotional arousal 
process and personal agency beliefs" (p. 3). He uses the example of a middle aged overweight man who has been told by his doctor that he needs, for the sake of his health, to undertake a strenuous exercise programme. If the man is unconcerned about his health and his appearance, the programme may be irrelevant to his goals and he will not act on the programme regardless of his emotional reaction or his expectancy of the programme. Even if the programme is a fit with his goals, he may still not undertake it if he lacks faith in his doctor, his ability to carry out the programme or doubts that the programme will produce positive results for him. If we accept Ford's (1992) formula, to be motivated to make changes a teacher must therefore believe that the change will help them reach their personal goals, the emotions aroused need to prompt them to action, and they must believe that they are capable of making the changes and that their context and leaders will support them to do so (Armenakis et al., 2007; Ford, 1992; Leithwood, Steinback, \& Jantzi, 2000). Individuals seek autonomy, to be themselves and to pursue their personal goals, to feel good at what they do and to have meaningful connections with others.

Motivation will be higher when these needs are met (Ryan \& Deci, 2000). This suggests that, in the implementation of educational change leaders need to pay attention to these components of motivation. A teacher's attitude towards mandated change will be based on their subjective affective, cognitive and evaluative response to what is suggested, seeking to achieve a balance between their personal goals for their teaching and those of the policy (Ajzen, 1991; Armenakis et al., 2007; Luttenberg et al., 2011; Spillane et al., 2002). In addition, individuals, having different inner resources and a range of goals for their teaching, will interpret the implied challenges in the variety of ways already described with their resulting evaluation determining their openness to change (Dzubay, 2001; Ford, 1992). Exploring teachers' subjective evaluations could therefore help leaders to appreciate the reasons for the range of responses within their staff. This would not be a simple undertaking and further discussion of it needs to be included in the advice to "understand the change process within teachers."

\section{Teachers ' perception of the personal significance of change}

Teachers' evaluative responses will be the precursor to their subsequent behaviour in the change process (Black, 1995) and offer an explanation for the range of responses described earlier. After reviewing organisational change literature, Armenakis et al. (2007) identified five evaluative responses to change which constitute the readiness for change. Each of these responses links to Ford's (1992) 
motivation systems theory and could provide a useful framework for leaders of change. I have interpreted the precursors from the perspective of a teacher: 1) Discrepancy: Teachers must believe that change is needed. For teachers this would involve recognition that current practice is not meeting their personal goals;

2) Appropriateness: Teachers believe that the suggested changes will work towards eliminating the discrepancy; 3) Efficacy: Teachers believe they are capable of including the changes in their classroom practice; 4) Principal support: Teachers are confident that the change is supported by key personnel in the school; 5) Valence: Teachers believe that they will personally feel the benefits of the change. Their evaluation of each of these components will impact on teachers' perceptions of the personal significance of the changes and ultimately affect their motivation to engage with them. Each component is discussed in the following sections.

\section{Discrepancy: Teachers must believe that change is needed}

The "unfreeze" stage, requiring current behaviour to be rejected and for individuals to believe that change is needed, is the most difficult and also the most important stage (Schein, 2002). Some teachers may already feel that their current practice is not meeting their personal goals and therefore that change is needed. In Earl and Lee's (2000) evaluation of a Canadian school improvement project they found that one third of the 22 schools showed substantial movement and appeared likely to sustain the changes. The schools that were succeeding had experienced a "call to action. Something had happened in these schools that had jarred them and forced them to believe that change must happen and quickly" (p. 33). However, as may be the case in some New Zealand schools, if teachers do not personally feel dissatisfied with their current practice, leaders of the implementation are faced with providing a compelling reason to make changes (Fullan, 2004).

This requires leaders of change to provide an environment that supports individuals to accept a need for change with a degree of "survival anxiety" that motivates individuals to make change without being overwhelmed by a potentially immobilising "learning anxiety" (Schein, 2002).

Schein (2002, p. 38) maintains that a leader of change must try to convey simultaneously to staff that:

1) Your present behaviour or attitude is unacceptable (disconfirmation);

2) It is causing us to fail in getting the job done (induction of guilt and/or anxiety); but 
3) I understand that learning something new is itself anxiety producing, so I will help you to change and make you feel safe while you learn a new behaviour (creation of psychological safety).

Achieving the balance suggested by Schein is a delicate operation. To achieve an impetus towards change leaders often choose to present staff with data on student achievement, which suggests a need for change to improve results. However, this strategy may not be enough to cause disconfirmation and, instead of an acceptance that their present instructional practices do not lead to desirable student outcomes, can result in defensive behaviour (Nisbett \& Ross, 1980; Schein, 2002). This type of reaction could be explained by attribution theory which explains how an individual uses information to form a causal judgment (Weiner, 2000). In Weiner's attribution approach to motivation he discusses three underlying causal properties: locus, stability, and controllability. Each of these links to the main two determinants of motivation: expectancy which is the perceived likelihood of success and the personal value of taking action.

Locus refers to the individual's subjective location of the situation which is either within them or outside. Weiner (2000) provides ability and effort as examples of internal causes for the situation. Help from others is an example an external cause. While some causes can be altered, others cannot. For example, Bishop, Berryman, Tiakiwai, and Richardson (2003) interviewed Year 9 and 10 Māori students, their parents, their principals and their teachers, asking them what they saw as the most important influence on the students' educational achievement. The students, parents, principals and some teachers identified the quality of the interactions with teachers as the strongest influence. In contrast, the majority of the teachers stated that it was the children themselves, their family circumstances, or the school structures. The researchers saw the teachers' perceptions of educational achievement as being caused by students' ability or attitude, and external circumstances (thus stable and not able to be controlled by them) as the major impediment to Māori students' success in education. This research led to the Te Kotahitanga project mentioned earlier, a professional development project "designed to challenge teacher beliefs and expectations for Maori students and to shift classroom instruction from a transmission approach to a more discursive, interactive model” (Meyer el al 2010, p.13). When presented with the students' narratives the teachers accepted that, by changing their teaching approach, they could more effectively support learning (Bishop, Berryman, Cavanagh \& Lani, 2009). 
In their discussion of challenging teachers' beliefs, Timperley and Robinson (2001) provided another example of attribution theory. They described how teachers, when confronted by a review which identified their schools as providing inadequate education for their students, perceived the causes as being student and family deprivation. These were externally located, stable, and uncontrollable causes and therefore did not motivate the teachers to make changes to their practice. However, when further data that focussed on exploring their assumptions provided evidence that they were unfounded, the teachers were willing to consider the more unstable and controllable causes, namely their own practice. This suggests that leaders need to provide an environment in which teachers are able to safely articulate their reservations about data without being considered simply "resistors". These discussions could lead to a further collaborative exploration of alternative data to test their assumptions.

\section{The role of emotions}

Keltner and Gross (1999) defined emotions as "episodic, relatively short term, biologically based patterns of perception, experience, physiology, action and communication that occur in response to specific physical and social challenges and opportunities" (p. 468). As Hargreaves (2005) points out, "teachers are not just well oiled machines, good teaching is charged with positive emotion" (p. 279). Therefore, teachers' emotional bond to their work affects their responses to change and should be carefully considered by leaders of change. The appraisal process in which they evaluate their interpretation of what the change may mean for their professional identity, their personal goals, or their workload can create an emotional response (Oatley, 2000; Schmidt \& Datnow, 2005; van Veen \& Sleegers, 2005).

An exploration of the role of emotions sheds light on the survival anxiety or learning anxiety states. If their emotional response causes teachers to feel at conflict with the change, intense and possibly negative reactions can result (Olsen, 2002). If the response to an event is too intense, as it may be to data that are threatening to their self-esteem, an individual can experience the learning anxiety referred to by Schein (2002) which results in them becoming immobilised, choosing denial, attributing it to external causes as described above, or resisting the concepts (Jansz \& Timmers, 2002; Wirth, 2004). This was evident in Earl and Lee's (2000) study of 22 Canadian secondary schools involved in the implementation of schools' improvement. They found that none of the schools were standing still. Instead they were either energised and motivated or "moving downward on a slide of blame, 
frustration and helplessness" (p. 32). In another example, in their study of Canadian teachers implementing external accountability initiatives, Leithwood et al. (2000) found that some teachers felt insulted while others experienced frustration, stress, annoyance, and or anxiety. Their emotional reaction negatively affected the implementation process.

Discussions of learning often focus on the intellectual and cognitive aspects, overlooking the affective (Dirkx, 2006). They tend to overlook the fact that after experiencing intense feelings individuals can, after a period of uncertainty, experience survival anxiety, choosing "fight" instead of "flight" (Jansz \& Timmers, 2002). Survival anxiety can create a sense of urgency and can therefore be a key driver for change and galvanise individuals to act to make changes (Kotter, 1990) leading to reasoning, creativity and for transformative learning to occur (Dirkx, 2006; Pablomo Weiss, 2000; van Woerkom, 2010). Survival anxiety can therefore motivate teachers to consider the suggested alternative approaches, to elect to take risks and eventually gain insight (Ross \& Hannay, 2001; Schein, 2002). In this way, emotions can be seen as a part of the learning process (Värlander, 2008). In the earlier alluded to Earl and Lee (2000) study of the Canadian secondary schools, those who successfully implemented change in teaching all had, after experiencing discrepancy, experienced a sense of urgency which energised the teachers to make change.

With such potential to cause harm to teacher self-esteem and perhaps jeopardise the change process, creating discrepancy would require careful handling. As advised by Schein (2002), the challenge for leaders is to inspire in teachers a desire to make changes without arousing such guilt and anxiety that, instead of encouraging new learning, results in learning anxiety and defensive behaviour. It could be a perilous undertaking for school leaders to find a process by which teachers accept dissatisfaction with their current practice without jeopardising the relational trust associated with leaders demonstrating that they value teachers and take into account workplace concerns (Robinson, Lloyd, \& Hohepa, 2009). Relational trust is important: studies show that leadership is more effective in improving student outcomes if school leaders incorporate relationship building into every aspect of their work (Duignan, 2009; Robinson et al., 2009)

Ignoring the emotions aroused by proposed educational change may therefore damage relational trust, cause pedagogical change to fail and result in passive aggressive behaviour from teachers (Fraser-Thomas \& Beaudoin, 2002; Hargreaves, 
1994). Unfortunately, a consideration of teachers' emotions appears to be an aspect of the change process that is often overlooked (Hargreaves, 2005; Muro, 2007; Spillane et al., 2002).

Appropriateness: Teachers believe that the proposed changes will work towards eliminating the discrepancy

Another dimension of the teachers' response to any proposed change which can also affect their motivation to engage is their cognitive appraisal of the new learning (Armenakis et al., 2007; Timperley \& Parr, 2005; Spillane et al., 2002). Even if teachers accept the need to make changes, to accept those proposed they must believe that this particular mandated change will address the discrepancy between the current state and the desired one. Importantly, the changes will need to fit with their beliefs about effective teaching and learning or they will need to be willing to consider a change in their beliefs.

It is not realistic to expect teachers to change their beliefs and practice based on statements or descriptions in a document (Fernandez, Ritchie, \& Barker, 2008; Nisbett \& Ross, 1980). Fernandez et al. (2008) investigated how the vision for a change to constructivist teaching practice as described in the curriculum document impacted on ten physics teachers in a New Zealand secondary school. They found that the document contained ideas that did not correspond to the shared meanings of many of the teachers. This left them with the challenge to not only make sense of it but also to understand the implications for their practice. This particular implementation did not lead to significant change - five years later a study by McGee et al. (2002) found that over two thirds of physics teachers had not changed their practice.

Nisbett and Ross (1980), in their discussion on theory maintenance and theory change, maintain that, based on empirical evidence, it is clear that "opinions, once formed are slow to change in response to new evidence" (p.167). Their stance highlights the level of difficulty leaders face in their efforts to encourage teachers to change their beliefs and practices and to accept the validity of a new way of working. However, there are suggested strategies in the literature. One is that a clear understanding of the new state must be expressed by the leaders of the implementation (Debowski, 2008; Bishop, 2008). This is a challenging issue in the case of the implementation of constructivist practice. Leaders need to have a sound understanding of the pedagogical changes (Robinson et al., 2009) to be able to articulate what the change would "look like," and to inspire confidence it can be 
achieved. It would be difficult for teachers and perhaps the leaders to gauge if constructivism is an appropriate teaching model if they do not have sufficient understanding of it. Teachers may be told what to do but not how to do it (Tyack \& Cuban, 1995). This can be confusing for teachers and create uncertainty. Several studies have found constructivism to be a new and little understood way of working for many teachers ( Elkind, 2004; Silins et al., 2002). As discussed earlier, many teachers were educated, trained and have practised within transmission mode schools and may have had little personal experience or even observed constructivism (Alexandrini \& Larson, 2002; Hargreaves, 2005). It is possible that many educational leaders may also have limited understanding for the same reason. Buchanan and Engebretson (2009), studying the perspectives of leaders of a religious education curriculum change in Australia, found that the leaders themselves did not understand the theoretical underpinnings of the changes. Their lack of understanding interfered with the implementation. A similar finding is described in Polyzoi and Cerna's (2001) exploration of the understanding of educational change in the Czech Republic. Because the proposed change was systemic the researchers interviewed key stakeholders, including ministry officials, teacher educators, school leaders and teachers. They found that change was hindered by the absence of a clear vision at each level throughout the system. Three years after the implementation, fewer than $10 \%$ of teachers made changes to their practice (Polyzoi \& Cerna, 2001).

Another constraint can be that, although teachers may in principle be in favour, they do not know how to begin (Beck et al., 2000; Kennedy \& Kennedy, 1996). Studies of teachers in the United States attempting to implement a new mathematics curriculum revealed that they struggled with their own lack of knowledge about learner-centred practice (Cohen \& Ball, 1990; Darling-Hammond, 1990). In each case the new policy required changes in teachers' beliefs about their subject, about how the students learned, and about their own role in the learning process. The teachers' struggle to make the changes led Cohen and Ball (1990) to comment "how can teachers teach mathematics that they never learned, in ways they never experienced?" (p. 238). Darling-Hammond (1990) uses a Will Rogers quote to colourfully illustrate the same point: “you can't teach what you don't know any more than you can come back from where you ain't been" (p. 345). Therefore, the cognitive appraisal of the appropriateness of the new learning may be problematic in the implementation of constructivist practices. 
Efficacy: Teachers believe they are capable of including the changes in their classroom practice

The precursor of efficacy cuts to the heart of the issue for teachers. Do teachers believe they are capable of including the new practice in their classroom practice? How do they appraise their ability to action change in pedagogy if they have no clear understanding of what is involved? How can they commit to a new way of working when they are already busy? As previously identified, teachers can respond in a variety of ways (Abrahamson, 2004). Crucially, it is possible that the constructivist way of working does not fit with the teachers' beliefs about teaching and learning. This is delicate territory; as Keys (2007) explains: "changing curriculum and pedagogy is to change a teacher's beliefs on educating a child" ( $p$. 43).

If teachers feel confident that they have the ability to achieve the goal of the new learning they are more likely to engage in it (Abrami, Poulsen, \& Chambers, 2004; Thoonen et al., 2011). In their survey of 933 Canadian primary and secondary school teachers involved in a project to embed co-operative learning in their classes, Abrami et al. (2004) found that the perceived value of the innovation, the expectancy of success, and the personal cost accounted for $42.3 \%$ of the variance of self-reported use. Of these three, expectancy of success was the most important difference between users and non-users. This could be particularly challenging with the implementation of student-centred practice and the integration of key competencies which, as discussed, may be little understood, and therefore require a leap of faith on the part of the teachers. In addition, while the emphasis in constructivism is the discovery of learning through the construction of knowledge, in today's environment it may be difficult for teachers to believe in the authenticity of this approach when they are facing defined learning outcomes as is the case in the New Zealand outcomes-based qualification system.

One aspect in their efficacy appraisal will be that of the task demands (Weiner, 2009). Darling-Hammond (1990) maintains that learner-centred models make greater demands on the teachers, they are sophisticated, and they require indepth understanding. Constructivist practices require flexibility from the teachers and many are more complex than a content-centred model of teaching. This could be seen as daunting to teachers, leading them to wonder how they can manage in their already busy day to invest the time not only to acquire the new learning but also to resource and plan different lessons. 
Valence: Teachers believe that they will personally feel the benefits of the change

Armenakis et al. (2007) refer to the teachers' appraisal of the personal value of the change as valance. Individuals will weigh up if the change is important and if it will be of benefit to them. The more they value the change, the greater their commitment (Weiner, 2009). In this appraisal, teachers consider if the proposed change will support their personal goals for their teaching.

Ford (1992) defines goals as "psychological processes that are anticipatory and evaluative in character. They represent future states and outcomes and prepare the person to try to produce those desired states" (p. 73). To be motivated to engage with the implementation process a teacher needs to believe that the proposed change will support the achievement of his or her personal goals for the students and subsequently, it will be of personal benefit to them (Abrami et al., 2004; Armenakis et al., 2007). When an individual can voluntarily pursue the fulfilment of their personal goals they feel intrinsically motivated (Deci, Koestner, \& Ryan, 2001). It cannot be assumed that the teacher would have the same goals as those of the new learning. It is difficult to imagine this would be the case considering that a school is staffed by diverse individuals with a variety of goals yet required by mandated change to be working towards an imposed consensus of a goal (Rhodes, 1996; Stoll, 1999). Teachers' personal goals for their teaching appear to be another unexplored territory in the literature on educational change.

\section{Principal support: Teachers are confident that the change is supported by key} personnel in the school

As part of their appraisal of change teachers make a cognitive situational appraisal (Armenakis et al., 2007; Luttenberg et al., 2011) to ascertain if the environment in which they work will provide the support needed for change. Situational cognition refers to their perception of the school context or culture, leadership, habits, expectations, beliefs and norms of the school and the school community. Teachers will evaluate the culture of the school to ascertain if this proposed change is a fit with not only the espoused but also the enacted culture and goals of the school. In this appraisal they will look to the leaders or significant personnel within the school and appraise through non-verbal and verbal cues if the leadership genuinely supports the change, commonly referred to as "walking the talk" (Armenakis et al., 2007, p. 488). Leaders, in particular principals, influence the likelihood of change (Fullan, 2001). If teachers do not sense from their leaders' actions that they sincerely support the change, their buy-in will be affected. 
Stoll (2000) states that "School culture is one of the most complex and important concepts in education" (p. 9). Teachers will be able to appraise their schools culture's support for the change in a way that may not be evident to a casual observer. This is because the shared beliefs that "run like a red ribbon the school tying together adults and children" (Cuban, 1995, p. 9), often operate unconsciously making them difficult to surface and to change. Hargreaves (1994) describes two aspects of culture: content and form. Content includes the attitudes, habits and the norms of the school. Form relates to the relationships among the staff and, in the opinion of some researchers, has the most significant impact on educational change (Bryk \& Schneider, 2002; Clarke \& Wildy, 2010). Others have put greater emphasis on the content, the habit and norms of the school environment (Geijsel et al., 2001; Gordon \& Patterson, 2008). What is clear is that the situation or context is more than just a background environment; the common beliefs, social norms and organisational structures of the school affect the sense making of individuals (Du Four, 2004; Spillane et al., 2002).

Other personalities within the school environment could also enter into a teacher's appraisal of the context. Secondary schools have a large number of teachers on the staff and as already discussed there could potentially be a wide range of responses to mandated change. Datnow (2000), in her analysis of the case study data of 22 Canadian schools undergoing change, found that through considering the levels of power and ideological diversity it was possible to begin to understand how certain individuals and groups shape what happens in a school and affect the commitment to an implementation. Staff who were openly resistant to the change were also found to potentially undermine the process discussed in Beals, Hipkins, Cameron, and Watson's (2003) evaluation of the PD programme to support the implementation of a new arts curriculum in New Zealand, again a mandated change. Datnow and Castellano (2000) found that those who either just accepted or who opposed could lower the level of involvement by other staff or even derail the implementation process. Hynds (2010), in her New Zealand study of a Government instigated action research project that aimed to improve classroom practice and outcomes for marginalised students, found that not only some teachers but also parents resisted the reform for different reasons. Their responses impacted on the effectiveness of the initiative. These researchers were able to identify the sources of resistance or the potential "saboteurs" through their mandate to investigate and their ability to interview teachers and parents who could remain anonymous. It would be difficult for leaders in their roles within schools to discover the extent to which such factors 
impacted on the change process. However, they do need to be aware that such tensions could exist amongst the stakeholders in any mandated change process.

To sum up the context appraisal, teachers seek coherence (Luttenberg et al., 2011; Spillane, 2002) to make sense of the change in the interface between their own frames of reference, the messages of the implementers of the innovation, support from peers, and the norms and expectations of their workplace (Luttenberg et al., 2011; Timperley et al., 2007). They will look for a collaborative understanding and commitment to goals and aims of the change and structures that support the change (Drath et al., 2008). In this way they evaluate whether their context will provide an aligned approach to the change (Ford, 1992; Luttenberg et al., 2011; Spillane et al., 2002).

Having discussed change within teachers, the following section examines the literature that links educational change to Lewin's stage 2: change.

\subsubsection{Lewin's Stage 2. Change: Learning new concepts and new meanings}

\section{The role of leaders}

To set the scene where new concepts and new meaning can be learned requires leadership that works with staff to clarify goals and expectations of the change and that facilitates the process (Fullan et al., 2005; Coburn, 2003; Bishop, 2008). Leaders need to decide how they will approach this. Fullan (1994) maintains that to bring about educational change both external pressure to change and strong internal support are needed. This can be achieved through a combination of "top down" and "bottom up" strategies, neither one alone being effective. Beer and Nohria's (2000) classification of change theories as Theory E and Theory O explain the difference between the two strategies. Top down, Theory E, is rationalistic change focused on achieving a successful outcome in results, requires strong leadership, and involves careful integration of systems and processes. While each of these aspects is important, on its own this theory has limited success. An example of Theory E or "top down" is Mintrop's (1999) study of the effects of state policy changes in eight former East Germany secondary schools. In these schools there was little obvious resistance. In fact there was a strong attitude of compliance by teaching staff even when they did not necessarily agree with the changes. They did, for example, change their systems, textbooks and even the history curriculum. However, instructional practice remained unchanged despite directives from an uncontested government authority. Mintrop maintains that his findings confirm the "tremendous 
stability of the classroom as an ecological microcosm within the educational system" (p. 293). As earlier discussed, it appears that coercion or accountability alone does not change beliefs or create the behaviours necessary for success (Fullan, 2005). As Cuban (1995) explains, "teachers, in their rooms choose what to teach and how to teach it" (p. 5).

"Bottom up", Theory O, on the other hand, is based on building organisational capability, is inclusive, and involves everyone learning together (Beer $\&$ Nohria, 2000). Ideally, both theories should be combined by setting the direction from the top while also building the capacity of all stakeholders. In this combination there should be a focus on both the structures and systems and on the culture and on the learning of the teachers (Beer \& Nohria, 2000; Fullan, 2004; Patterson \& Rolheiser, 2004).

Elmore's (2000) description of the role of an educational leader is a combination of Beer and Nohria's (2000) two theories. He maintains that educational leadership is an alignment of all aspects of the school:

(Educational leadership) is primarily about enhancing the skills and knowledge of people in the organization, creating a common culture of expectations around the use of those skills and knowledge, holding the various pieces of the organization together in a productive relationship with each other, and holding individuals accountable for their contributions to the collective result. (p. 15)

The key message that educational leadership is "primarily about enhancing skills and knowledge" of all stakeholders is supported by much of the leadership literature (see, for example, Bryk \& Schneider, 2003; Dinham, 2007; Leithwood, Louis, Anderson, \& Walstrom, 2004). The question is, in changes such as those required by the NZC, how will the capacity be built and by whom?

A strategy frequently suggested for educational leadership is that of creating a professional or learning community (Du Four, 2004; Robinson el al, 2009; Stoll, Bollam, McMahon et al., 2006) in which teachers work collaboratively towards a deep understanding of teaching and learning. This strategy requires leadership that develops an environment in which an effective learning community can thrive. The potential challenges inherent in achieving this are discussed in the following section.

\section{Creating an environment that supports a learning community}

The emphasis in definitions of a learning community is on staff purposely working together, with shared goals, and collective responsibility (Hipp \& Huffman, 2010; Robinson et al., 2009). However, teachers may not be working in an 
environment they perceive to support shared learning. An example could be a culture often referred to as an "egg carton" which Hargreaves (1994) categorises as being one of individualism in which work is done in isolation. Another culture that does not encourage collective responsibility is that of "balkanisation" (Hargreaves, 1994 p.18) which describes teachers forming small protective groups. In secondary schools this can mean staff remaining in their departments and choosing to isolate themselves from the wider culture of the school. I have observed balkanisation developing simply because of the layout of the school buildings. Some teachers, not wanting to sacrifice their brief break time in a long walk to the communal staffroom, stayed in their departments gradually cutting themselves off from the rest of the staff. Eventually the physical separation led to an almost defensive shared mindset within the department.

Even when school structures do provide opportunities for teachers to be part of a learning community and learning new practices, the structures, by themselves, do not cause the learning to occur (Peterson et al., 1996; van Veen \& Sleegers, 2005). In many New Zealand secondary schools, for example, the students arrive one hour late one day a week during which teachers undertake professional learning. In this designated time provided by the Board of Trustees teachers could be required to work towards implementing the change. Hargreaves (1994, p.17) calls this “contrived collaboration." Because it is compulsory it does not necessarily provide an environment that encourages change (Horn, 2000; Senge, 2006). Or there could be “voluntary collaboration" (Hargreaves, 1994, p.192) in which teachers spontaneously and voluntarily choose to work together to develop their practice over a period of time. This does have the potential to bring about change if those working together are actively and interactively engaged, feel comfortable socially and emotionally, and are intellectually challenged (M. Richardson, 2007).

Being intellectually challenged is key: Peterson et al. (1996) do not believe that simply being exposed to new ideas and working in a collegial community is enough to bring about change. Learning new skills involves a new way of thinking about knowledge and relationships. It is a complex process and collaboration is not enough. De Lima (2001) provides an argument that the quality of the teachers' relationships can impact on the effectiveness of the collaboration. If teachers, for example, choose to work with "favourite buddies" (p. 110), their desire to protect the relationship can inhibit the degree of cognitive conflict necessary to promote change. 
What matters is the type of discourse which occurs when teachers are working together. If teachers simply discuss and share ideas about various instructional methods without critically analysing why they choose to teach in a certain way, limited learning will result (Mezirow, 1991). Mezirow refers to the "why" as "premise" reflection which Kreber (2004) describes as "critical scrutiny of the presupposition underlying what we believed was true" (p. 33). In her two qualitative studies of Canadian academics, Kreber found that premise reflection seldom occurred. It seems that teachers are more inclined to reflect on how they teach rather than on why. However, unless the why is addressed in professional learning groups, transformational learning will not occur (Mezirow, 1991). This suggests a level of expertise would be needed within a professional learning group, someone who recognised the need to explore the underpinning beliefs and who had the skills to facilitate such a discussion.

Tillema and Orland-Barak's (2006) research offers another interesting consideration. In their study of two groups of teachers working collaboratively they found that the participants' different views on knowledge influenced their participation in activities to build knowledge. Seeking an understanding of the relationship between beliefs and perceived outcomes of collaborative work, the criteria for the authors' inquiry would be appropriate for evaluating a NZC focussed professional learning group. It was:

1) Problem understanding: increased fine-tuning of knowledge and achieving new insights about their practice.

2) Perspective shift: to become more open to and acknowledging ideas advanced by other people in the team, which could lead to conceptual change and to knowledge transformation.

3) Commitment: developing a readiness to engage in collaborative exchange and a willingness to share (sometimes) private knowledge for the benefit of improved practice. (p. 602)

They found that those with a constructivist view encouraged "transformative, change orientated learning" (p. 603) while those with a more traditional, transmission orientation were less inclined to share understanding or challenge others' insights. van Veen et al.'s (2001) study of Netherland's secondary school teachers supports this; they found that teachers who had a constructivist orientation valued consultation with colleagues while those with a transmission approach expressed reluctance to do so. It would appear that those who would gain the most from their involvement in a 
group seeking an understanding of constructivism could be those who need it less. These findings are something of a "catch 22" for professional groups engaging with the constructivist approach of the NZC!

The key concern is that while teachers may feel appreciated and supported working with colleagues, they may tend to avoid the disagreement and conflict which they do not recognise as being needed for development but which may be necessary to ensure that change happens (Kreber, 2004; Senge, 2006). If teachers share beliefs and values they could promote the status quo in teacher thinking and impede intellectual challenge or the advancement of new ways of working (Hargreaves, 1994). It could also be a case of the blind leading the blind: who can lead the new learning if no one in the group has a clear understanding of it or a commitment to it? Tschannen-Moran, Hoy and Hoy (1998, p. 221) warn that this can result in "collective inefficacy." What can be overlooked is establishing within the community a shared understanding and acceptance of the types of actions that will support teachers to make changes and, importantly, who is responsible for facilitating it (Hopkins, 2005; Senge, 2000).

\section{Professional learning to support transformative learning}

In this section the literature on the type of professional learning that would be appropriate to support the changes signalled in the NZC is reviewed. First, it needs to be acknowledged that the literature reviewed in the preceding sections clearly indicates that professional learning alone cannot bring about a change in behaviour. Implementing change cannot be achieved by workshops or even by establishing a learning community. It requires a systems-wide commitment to the articulated goals and expectations (Bishop, 2008; Drath et al., 2008; Luttenberg et al., 2011; Spillane et al., 2002). Coburn (2003) proposes four interrelated dimensions that impact on change: depth, sustainability, spread, and shift from an externally driven reform to internal ownership. Bishop (2008) encapsulates these elements in his model GPILSEO which provided a framework for the New Zealand Te Kotahitanga project which led to change in teacher beliefs and understandings (Meyer et al, 2010). This model involves the establishment of a Goal to improve student achievement by embedding and maintaining a focus on a new Pedagogy within Institutional structures that support the change. It requires instructional and distributed Leadership and the development of capacity to gather and analyse Evidence to track progress of both students and teachers. Finally if the change is to be sustained Bishop includes developing shared Ownership within the institution. This model requires not only 
careful planning by leaders of the design and evaluation of the programme but also careful consideration of the structures, budgetting, and resourcing to provide release time from teaching and support including the possibility of external facilitation (Guskey, 2000; Piggot-Irvine, 2006).

Secondly, when considering the model of professional learning, leaders should take into consideration that learning for everyone - adults and students - takes place through discovery (M. Richardson, 2007; Webster-Wright, 2009). The professional learning that would support teachers in the process of understanding the new learning therefore needs to follow the tenets of a constructivist model. This requires learning that is interactive, learner centred, and fosters critically reflective premise thought, imaginative group deliberation, and problem solving. Like students, teachers should not be considered "blank slates". Instead, their prior knowledge and skills should be incorporated into the design of the programme. However, it appears that this is another area where there is a gap between research and practice. In her review of 230 studies across a range of professions, Webster-Wright (2009) found that there was an emphasis on programmes with a focus on the transmission of knowledge rather than on knowledge building in which individuals are supported to construct their own understanding.

Thirdly, adult learning theory should also underpin the design of professional learning (Piggot-Irvine, 2006; Thoonen et al., 2011; Webster-Wright, 2009). This would entail teachers having control of their learning, that what they learn would be personally relevant, of value and of immediate use for them, time would be allocated so they could experiment with it, and that it would take place in a collaborative, respectful and informal environment (Fullan, 2007; Piggot-Irvine, 2006; Timperley et al., 2007). It would also be appropriately and developmentally paced with the acknowledgement that they are diverse learners who are problem orientated and have respect for their strong sense of self (Westrup \& Jack, 1973).

Finally, in Timperley et al.'s (2007) Best evidence synthesis iteration (BES), those studies which made a difference to student learning and therefore, it is assumed, had impacted positively on teacher learning had the additional component: they challenged teachers' beliefs and knowledge. Timperley et al. (2007) suggest that "the challenge of change should be considered to be one of mediating between competing theories at the interface between PD providers' change messages and the teachers coping with the myriad agendas in their practice situation" (p. 199). This is a confrontation between two cultures: the culture of the policy makers and the culture 
of actual practice (Luttenberg et al., 2011; van den Berg, 2002). There are two elements involved in this process. One is that in order to consider a possibly "competing" theory teachers need to reflect on and uncover their existing theory of practice by critical reflection (Mezirow, 1997). Secondly, ideally the approach should be to explore the proposed theories and the allied practice. In this way the new theory should not be presented as a superior one (Timperley et al., 2007). I use the word ideally because in a new mandated curriculum with effective practice prescribed, the underpinning theory would appear to be a given, therefore considered superior and not open to transparent negotiation. Leaders would need to provide an environment where teachers felt safe to be honest. In reality teachers would be reluctant to offer what could be seen as outdated theory beliefs without considering that doing so could have negative consequences for them (Piderit, 2000). There remains a scarcity of empirical evidence related to the processes that support teachers to eventually experience transformative learning (Bereiter, 2002; Hargreaves, 1997; Timperley et al., 2007). However, there is literature on transformative learning in general which is discussed in the following section.

\section{Transformative learning}

Mezirow (1997) suggests that new learning for adult learners is only a resource; it is their response to it that determines the learning that takes place. Literature reviewed earlier in this chapter strongly suggests that transformative learning is a challenging enterprise. Mezirow (1997) offers further explanation for this when describing four processes that can occur when adults are confronted by new learning which in the following have been applied to the teachers' situation. Teachers may react in a one or a combination of four ways. One can be to elaborate their existing interpretative framework by seeking evidence to support it. A reaction of a teacher may be, for example, "I already do that." This may lead them to reject or ignore the new learning or perhaps continue with their prior way of doing things believing that it is the new learning (Nisbett \& Ross, 1980; Timperley et al., 2007).

A second reaction can be can be to support the existing framework by finding what is wrong with the new information (Nisbett \& Ross, 1980). In learning about constructivist teaching a teacher may insist "that would never work, they would never pass the assessment". It is not surprising that this reaction could also lead to rejection of the new learning.

A third can be to alter an aspect of the framework by critically reflecting on it when confronted with an experience that disturbs prior beliefs. "I was surprised - the 
students came up with their own insightful ideas without my input." They may then begin a process of what Schein (2002) refers to as "cognitive redefinition" (p. 39) which may involve 1) semantic redefinition, a realisation that words can have different meanings from those they have attributed to them; 2) cognitive broadening, that a concept may have broader meaning from what was formerly assumed; or 3) new judgement or evaluation, a redefinition of the understanding of key ideas. Depending on the extent to which they redefine their prior beliefs, teachers may subsequently select parts of the new learning and adapt it to their current practice or reconsider their conceptual understanding. As Tyack and Cuban (1995) point out, "innovations never enter educational institutions with the previous slate wiped clean" (p. 83). Instead of replacing former practice, introduced change is more commonly assimilated into it (Spillane et al., 2002; Tyack \& Cuban, 1995) and does not involve any substantial change on their frame of reference. It is this course of action which results in the adaptation referred to as reductionism (Bereiter, 2002) or "lethal mutations" (Spillane et al., 2002, p. 416). Bereiter describes reductionism as an adapted version of the innovation and cautions that "reductive practices can go unrecognized and sometimes achieve the status of pedagogical activities" (p. 442). In their studies of implementation of the whole school reform, Success for All programme in two Californian elementary schools, Datnow and Castellano (2000) found that almost all teachers made adaptations to the programme. This was in spite of the developers' demands to closely follow the model and the provision of resources and guidelines for lessons. They maintained that even if teachers strongly supported the change this does not guarantee fidelity to the original intent. It is possible this could be interpreted as teachers' frustration with prescribed materials which limited their creativity and professional freedom rather than a rejection of the changes. Cho (1998) does not see adaptations in the same light as Bereiter (2002) and Spillane et al. (2002), believing teacher autonomy should be acknowledged. He argues against the success of an implementation being measured by fidelity, the extent to which it is faithfully followed. He advocates the empowerment of teachers stating that "policy makers need to provide practitioners with more autonomy in interpreting and using a curriculum guideline rather than dictating a teacher proof curriculum" (p. 13).

A redefinition of their conceptual understanding may, however, lead teachers to Mezirow's (1997) fourth reaction. Teachers may transform the basis of their interpretative framework and become critically reflective of, for example, their epistemological view. This is not an easy task; as discussed it is difficult for anyone 
to make transformative changes when what is learned does not sit comfortably with their existing interpretative framework and attempts to do so will be vigorously resisted (Prawat, 1992).

Transformative learning therefore requires deep and thoughtful critical reflection on current beliefs and assumptions and access to the justification for the new knowledge (Mezirow, 1997; Thoonen et al., 2011). Given that beliefs are generally tacit (Briscoe, 1991; Kagan, 1990; Nespor, 1987) and cannot be addressed directly, how does one critically reflect on them? (Tillema \& Orland-Barak, 2006). Kelchtermans (2009, p. 261) uses the analogy of someone wearing glasses to explain the tacit nature of belief and that an individual may not be aware of the "lens" through which they view teaching and learning: "People who wear glasses are most of the time not consciously aware that they are doing so. If the glasses provide a clear view or fit properly one tends to forget about them." Even if they have some awareness of their beliefs, teachers may either not be able to articulate them or be reluctant to do so if they suspect they will be poorly received (Kagan, 1990). In addition, articulated beliefs may not necessarily be associated with a congruent style of teaching. One of the questions in Keys' (2003) doctoral investigation of Australian primary and secondary science teachers' implementation of constructivist practices in a new curriculum was "How has the science curriculum taken form or shape through the primary and secondary teachers' knowledge?" (p. 10). He found that the teachers' practice was influenced only rarely by their expressed beliefs which were congruent with the changes but more frequently by their personal interpretative framework of entrenched beliefs reinforced by their experience in the classroom. It was these beliefs that shaped the enactment of the curriculum (Keys, 2003). Ertmer (2005), in a review of studies of American teachers using technology, also found that, despite the fact that most teachers described themselves as having constructivist philosophies, their teaching practices did not reflect this. In another example, Hynd's (2007) New Zealand study of a project that "aimed to improve teaching practice and outcomes for Māori students through the development of collaborative partnerships between Māori and nonMāori” (p. 7) also found "considerable gaps and contradictions between how they believed they should behave, and the way they actually modelled behaviour." (p. 228). These examples describe a conflict between what Argyris and Schon, (1987) describe as a teacher's espoused theory of action to which they give allegiance, and their actual theory in use. Pajares (1992) points out that these types of inconsistencies illustrate the difficulties inherent in trying to measure beliefs accurately. Again, in these studies the inconsistencies surfaced through independent research. As discussed earlier, it would be 
a challenge for leaders of change to provide a means by which individuals could safely critically reflect on their espoused and manifested beliefs within their contexts.

\section{Professional learning opportunities}

In considering the design of their professional learning leaders could consider a model that, instead of beginning with exploration of new conceptual understanding, supports the premise that change in beliefs occurs after an individual using suggested strategies finds that the change in behaviour is effective (Carlisle \& Baden-Fuller, 2004; Guskey, 2002; Fenstermacher, 1987). Guskey (2002) maintained that teachers are motivated to make changes to their practice if they have evidence that the new practices are beneficial to student learning. This model requires teachers to experiment with the changes in their practice followed by an evaluation of the impact on student learning. If teachers perceive the changed practice to benefit their students, this will bring about change in their beliefs which will eventually support embedded change in instructional practice. In this model it is not the specific PD process that changes teachers' attitudes and beliefs. The change occurs because the positive experience of using the strategies motivates teachers to reflect on their interpretative framework (Guskey, 2002). This is a cyclical approach in which teachers have their current beliefs challenged by being exposed to other possibilities, learn new skills, experiment with small changes and evaluate the results (Timperley, 2007). Carlisle and Baden-Fuller's (2004) findings appear to support this model.

Their study of change in the oil industry found that when employees realised that the required changes benefitted the aspects of their work that they valued, they subsequently re-evaluated their response to change. If Rokeach's (1972) explanation that primitive type B beliefs (such as the belief about effective teaching) are based on personal experience is accepted, Guskey's (2002) approach does appear to offer a way to possibly bring about change in a hardwired belief. However, this model assumes there is expertise available to support the teachers as they experiment and evaluate.

This model, using external facilitators, was employed in the PD for the Arts curriculum in NZ in 2001 and 2002 (Beals et al., 2003). Described as an "experience first" model (p. 1), teachers were introduced to new strategies that they could experiment with before undertaking more formal lesson planning. The facilitators found that teachers embraced the action/reflection model. However, while teachers may embrace the strategies, a change in beliefs will not take place unless they are exposed to the theory that underpins the skills. Skills on their own do not develop 
deep understanding or teachers may develop superficial understanding leading again to reductionist practice. To bring about deep and lasting change to occur, beliefs and assumptions have to be explored. Theory and practice need to be integrated (Guerra \& Nelson, 2009; Timperley et al., 2007).

Fenstermacher (1987) maintains that leaders of change employ four methods to bring about change. He claims that the first is "Make them eat cake." In this approach changes are mandated without consultation and teachers are told what changes to make. He describes this as "shoving it down their throats" (p. 3), surely the ultimate "top down" approach! It also could be the way in which the changes of the NZC are perceived by teachers. The second is "Where is the cake?" If student achievement is not as expected, for example, in assessment results, the teacher is directed to specific professional learning in order to be "fixed" by making a change. Fenstermacher describes the third "Let them eat cake" as a "gentler but none the less authoritarian approach" (p. 4) which entails teachers being encouraged to take part in professional learning to upskill. While they may have input into the design, they usually have no voice in the outcome. The fourth, which he promotes, is a "Have your cake and eat it too" system which aligns with Guskey's model. This involves a researcher or leader or peer working with a teacher to together reflect on the teacher's practice and to experiment with change.

While the latter method may be daunting for school leaders because of the time, money and staff resources involved, it does acknowledge that teachers want to become better so that their students can learn (Hargreaves, 1997); it also examines the teachers' work in their own context, and focuses on the person at the centre of the change (Goodson, 1991). Importantly, it is way to support a teacher's PD and their personal goals as opposed to "fixing" a teacher. Personal experiences supported by support in the classroom to prompt an exploration of beliefs appear to be an important way to influence the change of beliefs about teaching and learning (Beijaard \& De Vries, 1997; Guskey, 2002; van Driel et al., 2008). However, in the case of mandated change it is difficult to see how this approach could be considered to be genuinely open to the teachers' input as opposed to "steering" them towards the required change.

The experience before belief models (Fenstermacher, 1987; Guskey, 2002; van Driel et al., 2008) contrast with many of the examples of successful innovations described in Timperley et al. (2007. p. xxxvii). In the majority of these cases the implementers sought to motivate teachers by providing documented evidence that the 
present practice did not benefit students following the sequence of: providing a catalyst to engage such as documented evidence that the present practice did not benefit students; frontloading of new learning; suggesting activities to translate new knowledge into practice and repeated opportunities to revisit and refine new knowledge.

It is clear that regardless of the model offered, it is essential that there is a focus on practices and beliefs (Borko, Davinroy, Bleim, \& Cumbo, 2000). Ideally, PD to support change should offer multiple pathways to meet the needs of the teachers. Borko et al., (2000) when carrying out a case study of two elementary teachers undergoing change, found that experience first can suit some teachers while frontloading the learning is preferred by others stating that "teacher change can be understood as a dialectical relationship between beliefs and practices sometimes beginning with beliefs and sometimes with practice” (p. 303). Meeting teachers' range of learning styles may therefore mean that both methods must be considered by leaders of change.

Whether they decide to provide theory or experience first, leaders may additionally be influenced by the research on the transfer of learning into practice. Without feedback and ongoing and sustained learning, there is the danger that only a small proportion (estimated to be $10 \%$ by Joyce and Showers, 2002) of what is learned through presentations and demonstration is transferred into classroom practice.

Therefore, for new learning to be embedded into teachers' practice, opportunities to practise and receive feedback must be provided (Deemer, 2004; M. Richardson, 2007; Timperley et al., 2007). A way of providing this support needs to be incorporated into the design of an implementation process.

\subsubsection{Lewin's Stage 3: Refreeze}

Stage 3 of Lewin's model, refreeze (making the change permanent), is the final stage where the new behaviour becomes embedded in everyday practice. For this to happen the new behaviour needs to fit with the beliefs of the individual and, importantly, have ongoing support within the context or it will be short lived (Schein, 2002). Implementers of change must realise this takes considerable time, possibly five to six years in a secondary school (Brown \& Spangler, 2006; Earl \& Lee, 2000). Discouragingly, in their study of educational change over three decades, Hargreaves and Goodson (2006) found that secondary schools have been unable to change to 
meet the needs of their increasingly diverse students. While some schools had been able to implement change, initiatives tended to plateau after two years and not reach a stage where they were institutionalised.

\subsection{Efforts to introduce constructivist practices}

There were three studies that reported successful implementations of constructivist approaches each of which reveals the degree of intense ongoing support needed for teachers to experience transformative learning: Bell and Gilbert's (1994) government funded project which exemplifies adult learning, the key components described by Timperley et al. (2007), and the suggestion by Robertson and Murrihy (2005) that any implementation of change has to consider the whole person. Bell and Gilbert facilitated a three-year project with 48 volunteer New Zealand secondary and primary science teachers to support them in developing constructivist teaching and student thinking. The researchers held weekly two-hour meetings with the teachers in groups of eight after school over one or two school terms. These were sharing sessions in which the researchers used anecdotes and introduced new teaching activities. Often the activities were developed to include, not exclude, the teachers' prior ideas, beliefs and experiences.

This project enabled teachers to try new ideas, evaluate their learning, and practise over an extended time in a collaborative environment where teachers could receive support and feedback and critically reflect. The project design addressed elements discussed in earlier sections of this chapter including: teachers were aware of a discrepancy; prior knowledge was affirmed; beliefs were surfaced; emotional responses were addressed; the learning was valued by the teachers; and an ongoing supportive context was provided.

Many of the teachers had privately identified a self-initiated discrepancy or problem in their practice before they embarked on the project. Others who joined for other reasons had not identified a discrepancy. The study showed that unless this was addressed within the programme the second group of teachers made no progress.

Data analysis showed that teachers had developed professionally, "moving from constructivist technicians to becoming constructivist teachers" (Bell \& Gilbert, 1994, p. 491). They also developed socially, learning to work collaboratively and personally feeling that their concerns about change, being a teacher, and their subject had been addressed. Bell and Gilbert maintained that professional, social and affective issues had to be addressed for learning to occur. Emotional concerns in particular influenced the 
pace of the learning and needed to be validated and allayed before PD could take place. Having been immersed in literature that described the complexity of changing beliefs and behaviour, it was exciting to read of a study that encompassed the key findings. However, it appears that despite its success, this approach has been sidelined.

There were two other effective projects located. However, both involved what could be considered extraordinary support and resourcing which is unlikely to be replicated in New Zealand schools. Yager (1999) reported on Scope, sequence and coordination: The Iowa Project, a national reform effort in the USA in which middle school teachers were supported to use constructivist strategies. In this project teachers had ownership of the overall design of the curriculum and leaders were involved in a three-week summer camp to design and prepare modules and material to support the teaching. This material was supplied to the teachers who had ongoing support and feedback on their efforts to implement it. Subsequent observations of lessons showed that teachers had increased confidence in using constructivist strategies. The researchers maintained that "The evaluation of Iowa-SS\&C over the 1990-1994 period reveals that it responds to the calls for reform and restructuring of middle school science. Massive data are available to verify change in curriculum, teaching and student learning" (p. 191). What accounted for its success was that the teacher could see that the students benefitted from the changes in their practice (Yager, 1999). It would be interesting to know if the change was sustained.

Similarly, in a USA study, Howard, McGee, Schwartz, and Purcell (2000), believing that many teachers were in favour of constructivist practice but did not know where to begin, selected 41 "master teachers" (p. 458) from a national pool of applicants to take part in a four-week intensive off-campus residential course. The teachers had classes six days a week and learned about constructivism by doing it. The course involved discussion, peer observation and feedback and daily reflection. Their beliefs were challenged by instructors and peers and their accommodation of new beliefs was supported. In addition, the teachers were provided with time to create and have critiqued lesson plans to take back to their schools. The pre and posttests showed that the participants had changed their epistemological beliefs by the end of the course. While the researchers maintained that this project showed that beliefs could be changed in a short time with an intensive focus, it is not known if this was sustained on the teachers' return to their school.

\section{Other studies}


In my search of the literature I looked for studies of secondary teachers' experiences of mandated curriculum change that involved constructivist practices. In addition to those cited throughout this chapter, the studies in Table 5 had a focus on elements of teachers' subjective understanding of the changes. These studies confirm the resilience of existing beliefs and the degree to which teachers' appraisal of their context affects their engagement with change. However, none addressed the multi-dimensions of teachers' responses to the mandated curriculum which this study has done. In addition, there was very little research carried out in New Zealand secondary schools. 
Table 5. Studies of the implementation of constructivist practice

\begin{tabular}{|c|c|c|c|}
\hline Author/s & Country & Focus & Findings \\
\hline $\begin{array}{l}\text { Fraser-Thomas \& } \\
\text { Beaudoin, } 2002\end{array}$ & Canada & $\begin{array}{l}\text { Implementing a physical education curriculum: a case study } \\
\text { of two teachers' experiences. }\end{array}$ & $\begin{array}{l}\text { Teachers had a positive attitude. Constraints were time, poor } \\
\text { resources, lack of development. Constraints outweighed the } \\
\text { coping strategies. }\end{array}$ \\
\hline $\begin{array}{l}\text { Brodie, Lelliott, \& } \\
\text { Davis, } 2002\end{array}$ & South Africa. & $\begin{array}{l}\text { Forms and substance in learner-centred teaching: teachers } \\
\text { take up from an in-service programme. } \\
18 \text { teachers over } 3 \text { years. } \\
\text { Interviews, observations. }\end{array}$ & $\begin{array}{l}\text { Majority took up the form rather than the substance. } \\
\text { Embraced the idea but unable to put it into action. No take-up } \\
\text { in senior secondary. }\end{array}$ \\
\hline Cronin-Jones, 1991 & USA & $\begin{array}{l}\text { Science teachers' beliefs and their influence on curriculum } \\
\text { implementation: two case studies. }\end{array}$ & $\begin{array}{l}\text { The teachers' beliefs impacted on how they implemented the } \\
\text { lessons - their beliefs about the role of the teacher, how } \\
\text { students learn, and assessment. } \\
\text { Both teachers focussed on facts rather than learning problem } \\
\text { solving. }\end{array}$ \\
\hline Bondy, 2007 & New Zealand & $\begin{array}{l}\text { How a mandated technology curriculum had been } \\
\text { implemented in four secondary schools and what affected its } \\
\text { interpretation. Interviews with teachers and students. }\end{array}$ & $\begin{array}{l}\text { Teachers' experience, the context and students' learning } \\
\text { needs shaped the interpretation. Existing practices were } \\
\text { sustained in at least two schools. }\end{array}$ \\
\hline Swann \& Brown, 1997 & Scotland & $\begin{array}{l}\text { Twenty-one teachers, interviews and observation. } \\
\text { In the context of Scotland's objectives-based national } \\
\text { curriculum. In what ways are teachers' conceptions of their } \\
\text { classroom goals influenced by the introduction of standards? } \\
\text { Years 5-14. }\end{array}$ & $\begin{array}{l}\text { Mismatch between the conceptual and theoretical substance } \\
\text { of the change and teachers' existing mental processes. } \\
\text { Changes were not internalised into practice - established } \\
\text { ways of thinking took precedence. }\end{array}$ \\
\hline $\begin{array}{l}\text { Czerniak \& Lumpe, } \\
1996\end{array}$ & USA & $\begin{array}{l}\text { Science education reform. Questionnaire } 400 \mathrm{~K}-12 \text { Teachers } \\
\text { on beliefs and practice. } \\
\text { What are science teachers' beliefs regarding the necessity of } \\
\text { the strands? } \\
\text { What was their perception of their implementation? } \\
\text { How do their beliefs relate to their perceived } \\
\text { implementation? }\end{array}$ & $\begin{array}{l}\text { The teachers supported aspects of the reform but over } 80 \% \\
\text { did not believe in the constructivist strategies; } 74 \% \text { reported } \\
\text { using them less than once per week. Beliefs were the } \\
\text { strongest predictor of implementation. }\end{array}$ \\
\hline
\end{tabular}




\begin{tabular}{|c|c|c|c|}
\hline Author/s & Country & Focus & Findings \\
\hline $\begin{array}{l}\text { Roehrig, Kruse, \& } \\
\text { Kern, } 2007\end{array}$ & USA & $\begin{array}{l}\text { New inquiry-based Chemistry curriculum. } \\
27 \text { Chemistry teachers. } \\
\text { What are the differences between teachers and schools in the } \\
\text { implementation? } \\
\text { What teacher and school factors affect the implementation? } \\
\text { Semi-standardised interviews and observations. }\end{array}$ & $\begin{array}{l}\text { Teacher beliefs and school support played a large role in the } \\
\text { implementation. }\end{array}$ \\
\hline $\begin{array}{l}\text { van Veen, Sleegers \& } \\
\text { van de Ven, } 2005\end{array}$ & Netherlands & $\begin{array}{l}\text { A case study into the cognitive-affective processes of a } \\
\text { secondary school teacher in the context of constructivist- } \\
\text { based reforms. }\end{array}$ & $\begin{array}{l}\text { Initial enthusiasm for the new way of working disappeared as } \\
\text { lack of time and workload impacted. The teacher } \\
\text { subsequently reported decreased work satisfaction, increasing } \\
\text { isolation, and feelings of anger, frustration, shame, and guilt. }\end{array}$ \\
\hline
\end{tabular}




\subsection{Discussion of literature review}

Since there is extensive literature on change it remains puzzling that so many efforts fail. Herold, Fedor, and Caldwell (2007) suggest three possible reasons: 1) The advice from literature is not applied; 2) The range of implications for the agents of change, the teachers, is not taken into consideration; or 3) The role of the context is overlooked. After reviewing the literature and taking into consideration my experience in schools, I suggest that all three reasons are interlinked, the latter two requiring the closer examination that has been undertaken in the study described in this thesis.

What should occur is described but very little on the how. For example, it is acknowledged that change cannot be "managed" (Fullan, 2004; Wallace, 2003) and that leaders should have understanding of the change process within teachers (Fullan et al., 2005; Patterson \& Rolheiser, 2004; V. Richardson, 1990). However, with the exception of Bell and Gilbert's (1994) study there was little exploration within the educational change literature of what that really means. The suggestions in various studies were that change would begin by seeking an understanding of teachers' frames of reference and their perception of the reforms. However, an exploration of what that involves is not described in educational change processes. The potential impact on teachers is thoroughly discussed, but, there is a scarcity of literature that provides the teachers' point of view. As Duzbay (2001) found, most educational change literature appears to be on how to get those teachers to change and appears to override teachers' motivation. Any link to their priorities or ways to engage with their efforts to pursue their personal goals for their teaching, their readiness for change, is not acknowledged in processes for educational change. It is ironical that in a discussion of constructivist practices, teachers are often considered in the literature to be "blank slates" with the richness of what they bring to the learning overlooked. This study addresses that gap. In addition while school culture is discussed in the literature very little examines how teachers' perception of their context affects change. This study explores in depth the teachers' appraisal of their context and shows that it has a profound effect on the degree to which teachers perceived that the proposed changes had significance for them.

These issues all suggest that, while teachers are the acknowledged agents of change, their perception of its significance for them and therefore of their readiness to engage with it has not been explored. I liken it to an iceberg: the degree to which teacher change is discussed is just the tip of the iceberg with the important aspects 
remaining hidden and underexplored. These elements are the hidden part of the iceberg that is addressed in this study.

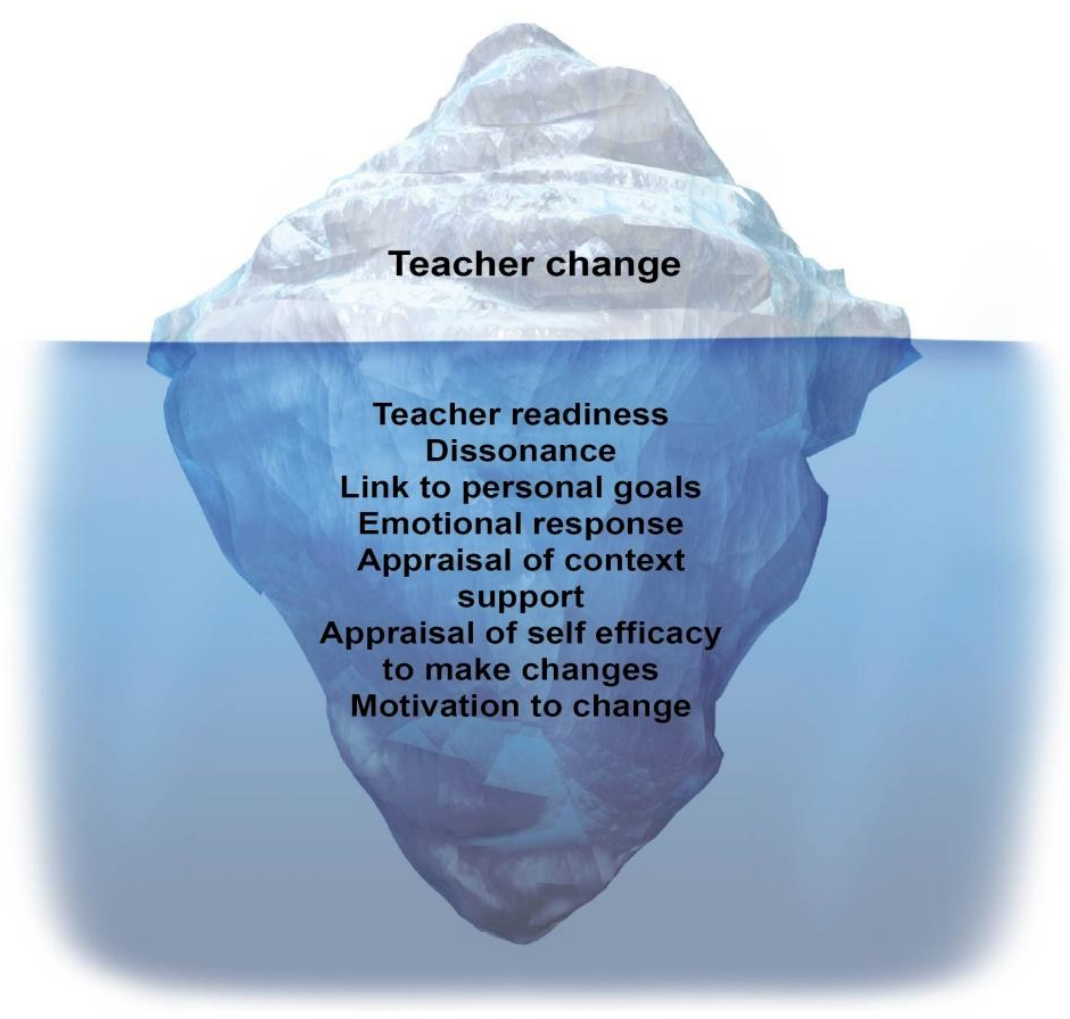

Figure 2. The iceberg metaphor

\subsection{Chapter summary}

This chapter has established gaps in the literature on educational change.

Through this review I have explored what is known about the role of beliefs in the implementation of change and the processes that would impact on individuals' beliefs and behaviour. There is an impressively wide range of literature on educational change; however, as discussed in section 2.9, the teachers' point of view is unrepresented. This study provided an opportunity to describe teachers' reality at a time of the implementation of mandated change and to explore the elements that affect their perception of its personal significance. 


\section{The Research design}

There is no "cookbook" for qualitative research. (Maxwell, 2005, p.79)

\subsection{Chapter overview}

This and the following chapter provide details of the research design. The purpose of this chapter is to explain in detail my decision to choose educational criticism as an appropriate qualitative methodology for this case study. Chapter 4 provides a more detailed explanation of the data collection procedure, methods and analysis.

Because of the emergent nature of qualitative research, researchers are advised, through reflection on their experiences, to check the effectiveness of the design (Stake, 1995) and make any changes necessary to ensure that the research can accomplish its aims, by a process of "tacking back and forth between the components of the design, assessing the implications of goals, theories, research questions, methods and validity threats" (Maxwell, 2005, p. 3). This was my experience. As explained in chapter 1, after reflection, I found it necessary to both change the research questions and reconsider my method of data collection and analysis to understand the issue being studied and to be able to provide a clearer picture of what was happening. It was this reflective process, described in the following sections, which led me to decide that educational criticism (Eisner, 1998) would be an appropriate method of data collection and analysis, and presentation.

In the following sections I explain how the study sits within a social constructivist world view and how the research questions and the method of inquiry evolved to educational criticism to fit the phenomenon being studied. The research design at the beginning of the study is explained. This is followed by a description of my reflection process and how after entering the field this impacted on my research design. Finally, I describe and justify my choice of educational criticism.

\subsection{Fit with Purpose}

Key question:

What is the personal significance of the implementation of signalled changes in the NZC to New Zealand secondary teachers?

Sub questions:

- What are the crucial life episodes of the teachers' past personal and 
professional life that have impacted on their beliefs and practices?

- How do elements of the current context interact with and shape their beliefs and practice?

- What is the significance of the NZC to their beliefs and practices?

- What is the significance of the NZC to their personal goals?

- What is the significance of the NZC to their personal agency?

- What is the significance of the NZC to their context?

- How does the implementation of the NZC impact on them emotionally?

To choose a method that best suited this research I originally considered which method represented the purpose of the study, which reflected my ontological and epistemological views and then, gradually, as the fieldwork progressed, which fitted the changing circumstances (Cohen, Manion, \& Morrison, 2000; Eisner, 1998; Maxwell, 2005; Richards \& Morse, 2005; Stake, 2005).

Although the key questions changed during this study, the purpose remained essentially the same: It was to discover how the participants perceived the new curriculum (Cohen et al., 2000) by describing their context, by interviewing them, and by observing their practice in the classroom as they experienced an implementation process. A qualitative approach was therefore appropriate for studies such as mine which sought a deep understanding of a phenomenon by learning how the participants experienced it, and how they interpreted their experience (Denzin \& Lincoln, 2005; Richards \& Morse, 2005).

A qualitative case study also appeared to be particularly suited to a study such as this which sought to understand, in a real life context, how the contemporary phenomenon of implementation of a new curriculum impacted on teachers' beliefs, why impact change had or had not occurred and was one in which I, as the investigator, had little control over events (Yin, 2009).

Merriam (1988, p. 19) states that "case studies are differentiated from other types of qualitative research in that they are intensive descriptions and analyses of a single unit or bounded system." In this study the unit analysis, the bounded system, is the experience of the teachers during an implementation of a new curriculum. A qualitative case study was therefore appropriate for this research because it offered the opportunity to "understand contextual conditions" (Yin, 2009, p. 18), and allowed me, as the researcher, to develop an intensive, holistic description and analysis of the 
phenomenon (Stake, 2005). A case study of teachers experiencing the implementation of a new curriculum provided an opportunity to "unravel the complexities" (Denscombe, 1998, p. 31) of the interconnected relationships within the context and the political and social environment which impacted on it (Stake, 2005).

\subsection{My World view}

A world view, or paradigm, is "a basic set of beliefs that guide action" (Guba, 1990, p. 17). This research was based on a social constructivist world view which Creswell (2007) describes as:

One in which individuals seek understandings of the world in which they live and work. They develop subjective meanings of their experiences - meanings directed towards certain objects or things. These meanings are varied and multiple leading the researcher to look for the complexity of views rather than narrow the meanings to a few categories or ideas. (p. 20)

This definition fits with the goals of my research which was to learn about the multiple realities constructed by the participants and the implication of their perceptions for the implementation of the NZC. It therefore revealed a constructivist philosophy based on the premise of ontological relativity which holds that reality is constructed by individuals as opposed to an objective positivist approach which views the world as external to the individual (Creswell, 2007; Patton, 2002). Social constructivism extends this concept maintaining that individuals' subjective meanings are formed not only by their own interpretations of their experiences but also developed in social settings and through the historical and cultural norms of their context (Creswell, 2007).

A social constructivist world view reflects my personal philosophy. My focus in each aspect of my work is from a social constructivist view of teaching and learning which considers that individuals' meanings are unique to them and are formed through their own drive to make sense of their world through their own background and experiences, through their interaction with others and with their context (Creswell, 2007). My epistemological assumption was that understanding the impact of this curriculum implementation will be co-constructed through collaboration with the research participants in this study.

\subsection{Characteristics of a case study qualitative methodology}

It was clear that the purpose of my study and my world view positioned it within a qualitative case study research methodology. As a further check of 
appropriateness I followed Hoepfl's (1997) recommendation that the researcher compares the characteristics of a qualitative case with the methods employed in the research, and compared my study with the characteristics of qualitative case study research provided by Creswell (2007) and Yin (2009).

Table 6. Comparison between this study and the characteristics of a qualitative case study

\begin{tabular}{ll}
\hline $\begin{array}{l}\text { Characteristic of a qualitative } \\
\text { case study }\end{array}$ & This study \\
\hline Researcher as key instrument & Data were collected and interpreted by myself \\
\hline Multiple sources of data & $\begin{array}{l}\text { The sources of data were: interviews, observations, post- } \\
\text { observation analysis of observations with the teachers, analysis } \\
\text { of school documents, public commentary in the educational } \\
\text { sector, personal research journal. }\end{array}$ \\
\hline Inductive data analysis & $\begin{array}{l}\text { Categories and themes were developed from the data, not from a } \\
\text { deductive method of testing themes from a theory }\end{array}$ \\
\hline Participants' meaning & $\begin{array}{l}\text { The focus in this study was on learning the teachers' realities, } \\
\text { understanding their beliefs and their practices and their } \\
\text { perception of the implementation process. It followed a } \\
\text { qualitative researcher's process of description and interpretation } \\
\text { as opposed to one that seeks to measure and predict }\end{array}$ \\
\hline Emergent design & $\begin{array}{l}\text { Throughout this study changes were made to accommodate the } \\
\text { direction indicated by the collection of the data. }\end{array}$ \\
\hline Interpretive inquiry & $\begin{array}{l}\text { This study aimed to discover and interpret the meaning of } \\
\text { change for the participants. }\end{array}$ \\
\hline Holistic account & $\begin{array}{l}\text { The complexity of educational change from a teacher's point of } \\
\text { view has been developed through this study. }\end{array}$ \\
\hline A bounded system & The teachers' perception of the implementation \\
\hline
\end{tabular}

\subsection{The evolution of the research design}

To explain the evolving nature of the study, in the next section I have outlined the proposed timeline for the study followed by one that shows how it actually unfolded.

\subsubsection{The proposed timeline for the study}

The original plan was a study over two years. It involved observation of the implementation process, interviews and observations of ten teachers in one school. The original key question was "how does the implementation of the NZC impact on the beliefs and practices of New Zealand secondary teachers?" My expectation was that the cycles of observing the professional learning involved, interviewing and observing the teachers over the time of the implementation would develop an 
understanding of how the participating teachers' beliefs and practices were affected by the process. It was expected that this would be completed by the end of 2010 .

\subsubsection{However...what actually occurred}

Several incidents impacted on the timeline and resulted in changes to the research design, to the questions, and to the method employed to collect and analyse the data. These included the six-month delay in entering the field, the small number of participants in the first school, and the lack of structured implementation processes. One outcome was to seek participants in two other schools and another was that the key question became "what is the personal significance of the changes signalled in the mandated curriculum to New Zealand secondary school teachers?"

Each of the unanticipated events which impacted on the study are included in bold in the following table and further examined in the reflection section. 
Table 7. How the study unfolded

\begin{tabular}{ll}
\hline Date & Action \\
\hline June 2008 & $\begin{array}{l}\text { Totara College approached - met with principal to discuss proposed } \\
\text { study. Permission granted by the principal to seek participants at this } \\
\text { school in } 2009\end{array}$ \\
\hline November 2008 & Proposal accepted. \\
\hline January 2009. & Ethics approval granted. \\
\hline February 2009. & $\begin{array}{l}\text { Entry attempted. Principal was on leave and the acting principal was } \\
\text { unaware of the research or of the permission granted. Entry had to be } \\
\text { renegotiated. I repeatedly emailed and phoned her seeking a meeting. }\end{array}$ \\
\hline May 2009 & Eventually a meeting with acting principal. Entry granted. \\
\hline
\end{tabular}

This represented a six-month delay to the start of the study. In addition, it meant I had not been able to observe the introduction of NZC to the staff.

\begin{tabular}{ll}
\hline May 2009 & $\begin{array}{l}\text { Presentation of the research to all staff. Four staff volunteered. The } \\
\text { acting principal was adamant that no other staff could be approached. }\end{array}$ \\
\hline June 2009 & $\begin{array}{l}\text { Meeting held with the four volunteers to explain the research and } \\
\text { gain consent. }\end{array}$ \\
\hline July 2009 & Initial interviews with the four participating teachers. \\
\hline September 2009 & Observations and follow-up interviews with three teachers. \\
\hline
\end{tabular}

It was disappointing to have only four participants. In addition, one withdrew after the initial interview ignoring requests to schedule an observation. Another was enthusiastic and fully participated but was granted a year's study leave for 2010. This meant that by the end of 2009 there were only two participants. Therefore participants were sought at two other schools.

February 2010

Kauri High School approached - meeting with deputy principal. She granted entry to her school and explained the research to staff she believed could be interested. Four teachers volunteered to take part in the study.

February 2010

Kawakawa College approached - meeting with principal. He granted entry to his school and explained the research to four staff he believed would be interested. All four consented to take part in the study.

\begin{tabular}{ll}
\hline February 2010 & Interview with leader of professional learning Totara College. \\
\hline March 2010 & Interviews of four teachers Kauri High School. \\
\hline
\end{tabular}

There were ten participants through 2010. During this time I began to reconsider the focus of the study. As there was little evidence of a planned implementation process in any of the schools the study evolved to a study of the teachers and their reality. The questions, the research design and the data analysis method were subsequently changed as will be further explained in the following sections.

\begin{tabular}{ll}
\hline April 2010 & $\begin{array}{l}\text { Totara College - Second observation and follow-up interviews with } \\
\text { the two remaining teachers. } \\
\text { Interview with leader of the professional learning Totara College. }\end{array}$ \\
\hline May 2010 & $\begin{array}{l}\text { Observation of lessons and post-observation interviews with four } \\
\text { teachers Kauri High School. }\end{array}$ \\
\hline October/November 2010 & Interviews with four teachers from Kawakawa College. \\
\hline March - August 2011 & $\begin{array}{l}\text { Face-to-face check of key themes with two teachers from Totara } \\
\text { College, one from Kauri High School and one from Kawakawa } \\
\text { College (other checks were via email). } \\
\text { Observations and follow-up interviews with four teachers from } \\
\text { Kawakawa College. } \\
\text { Interview with leader of the professional learning Kawakawa } \\
\text { College. }\end{array}$ \\
\hline
\end{tabular}




\begin{tabular}{ll}
\hline Date & Action \\
\hline Remainder 2011/2012 & Withdraw and complete analysis. \\
\hline The research design evolved as I reflected on my experiences on entering the
\end{tabular}

field. In the following section I describe my reflective process and the reflections on the initial interviews and the observations carried out in Totara College in 2009.

These early experiences began a process of reflection that continued throughout 2010. The reflections are followed by a justification of the subsequent decision change, the research questions, and to use an educational criticism approach.

\subsection{My reflective process}

Patton (2002) warns qualitative researchers to: "Prepare to be changed. Looking deeply into other people's lives will force you to look deeply into yourself" (p. 35). The truth of his statement became apparent to me during the course of this study and encouraged me to follow his advice to question the biases that might screen my perceptions asking "what has shaped my perspective?" (p. 66). I was also influenced by what Ely, Anzul, Friedman, Garner, and Steinmetz (1991) refer to as the learning which "occurs in the interplay between not only the cognitive but also the affective in qualitative research" (p. 1). As I proceeded in this study I undertook a reflection process to explore how my assumptions, my biases, my thinking and my emotions impacted on the research process and on the participants.

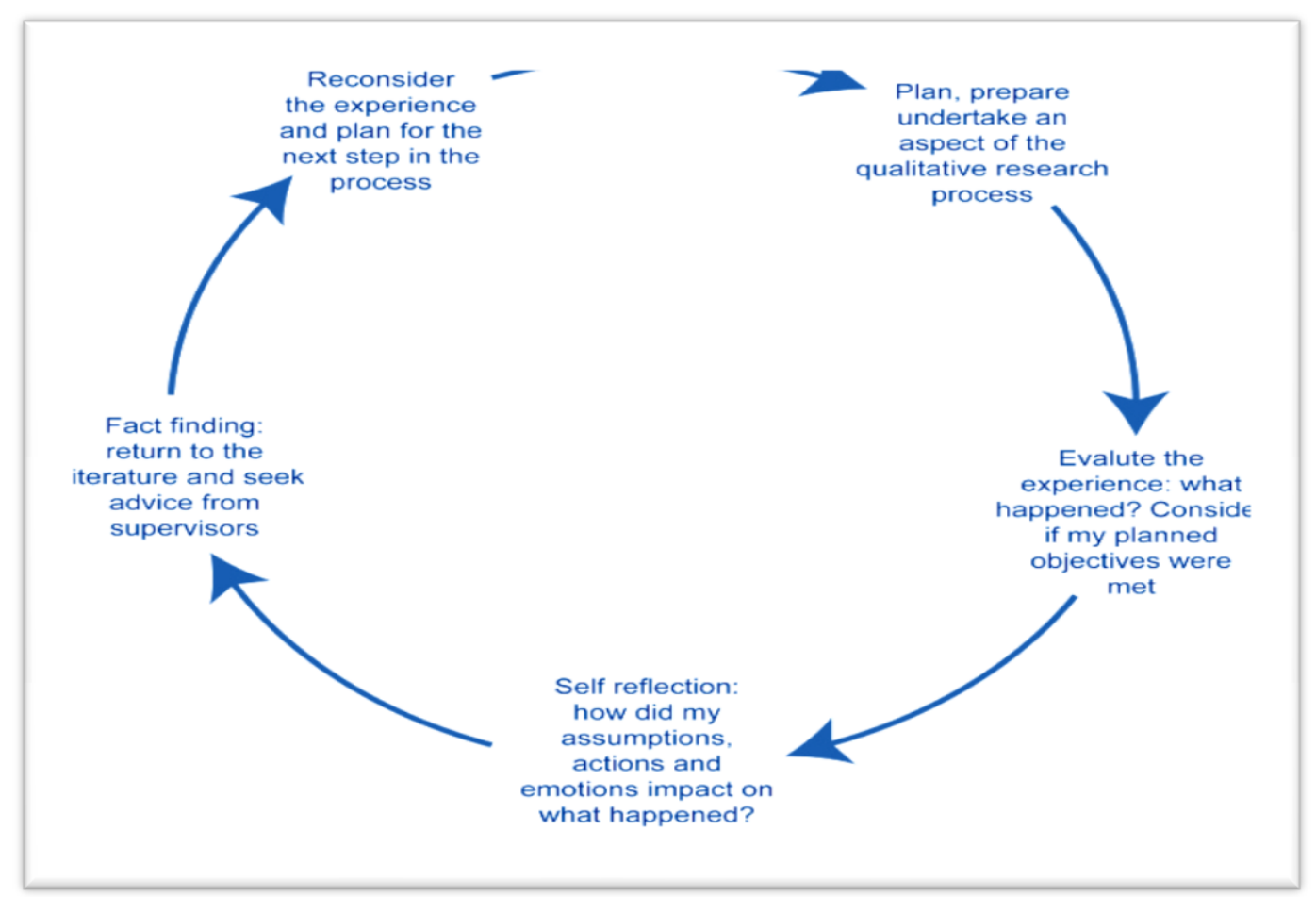

Figure 3. My reflective process 


\subsubsection{Reflection on entering the field and the implications}

Evaluating and reflecting on my experiences of seeking entry into the field and the impact of the delays, I realised that I had assumed I could keep to a timeline to suit my schedule without considering the reality of the busy lives of the principal and the teachers. While I had stated in my research proposal that my research would provide access to multiple realities (Cohen et al., 2000), in fact I had begun my research by ignoring the reality of the school world. This was a dynamic and turbulent environment in which people had busy and complicated lives. Although I was disappointed that only four teachers had volunteered to take part in the study, the principal's insistence that I did not seek more made me realise that what I had perceived as a setback to my plans was actually a glimpse into the reality of the school. Returning to the literature, I read Creswell's (2007, p. 138) warning "that convincing individuals to participate in the study, building trust and credibility and getting people to respond" is challenging. My experience was simply part of a qualitative research process. In addition, while I had written that as a research instrument I had no control over events, in fact I had expected the research to unfold in the way I wanted. I began to understand what Brook et al. (2010) meant when they stated that doctoral qualitative research is not a "linear scholarly journey" but a process of "path making that is emotional, creative and passionate" (p. 657).

\subsubsection{Reflection on initial interviews at Totara College}

The purpose of the initial interviews was to begin to develop an understanding of the teachers' current beliefs about teaching and to develop a framework that connects that knowledge to underlying theories of the revised curriculum. I had intended that this would provide a "benchmark" by which I could evaluate any changes in their beliefs and practices as they experienced the implementation process. These were semi-structured interviews of approximately one hour involving the use of open-ended questions in which there were some questions related to areas I wished to explore but which varied in response to the direction the interview was taking (Merriam, 2009).

Before embarking on fieldwork I had felt confident about interviewing. I had experience of interviewing in other careers and believed I had honed my listening skills in my different roles. However, none of my previous experiences prepared me for the dynamics of interviewing for my research project. I was aware that an 
interviewer needs to have a strong advance plan (Stake, 2003), to have prepared questions for semi-structured interviews and to have piloted them with teachers and colleagues (Merriam, 2009). I had done this and felt well prepared. However, I struggled with the initial interviews. In preparation for the interviews I had sent the four teachers the page on pedagogy from the NZC (MOE, 2007b) and asked them to read it before the interview. The purpose of this was to provide them with a framework with which they could connect their current beliefs and practice to discussion of the new curriculum. My plan was to ask them to describe how the pedagogical focus of the revised curriculum aligned with their beliefs about teaching and learning. However, this strategy had limited use. I found that the teachers had not undertaken an in-depth study of the new curriculum and had little interest in engaging with the section I had sent them. In addition, this approach appeared to create defensiveness in the teachers suggesting that they felt they were being tested or judged. My initial enquiries about the effective pedagogy section of the new curriculum in interviews were met with puzzlement, sometimes a guilty expression followed by, "We have looked at it" or, "Oh yes, I think we had some whole staff days on that" or "we are going to look at it in our department meetings sometime." I felt dismay at this. I had expected that the implementation of the new curriculum would be at the forefront of their minds, would be a focus of staff development meetings, and therefore would generate much discussion in our interviews. What I discovered was that it appeared to be just another thing in their busy lives that they would take on board when they got around to it. The teachers had not had the time to examine the new curriculum document in depth. Not all considered it necessary: "I didn't see the roof leaking" or that it had credibility: "Who the heck wrote this? Where is the reference list?" Another comment was: "Well, it doesn't look too different from what we have been doing."

These comments presented a setback - the carefully considered questions to guide the interviews no longer seemed appropriate. In addition, it became obvious that my focus on the pedagogy section of the new curriculum was of no significance to the teachers because they had not had the opportunity to consider its implications. My initial feeling was that I was trying to research something that did not exist, that I was trying to create a problem when teachers did not see one. Rossman and Rallis (2003) suggested that researchers do not let their opinion "prevent them from seeing clearly and widely in the settings. Remain open to the opinion of others" (p. 52). This advice now made sense: I had to learn to do this, to put aside my own point of view 
and to listen to their stories. While I wanted to discuss the new curriculum, the teachers were enthusiastic about their teaching and wanted to talk about their experiences during their careers and their subject. Stake (1995) also warned that participants may be willing to be interviewed but that does not necessarily mean the interview will be good. I was worried that what I was listening to would not address my research question, yet felt reluctant to be dismissive of what was clearly important to the teachers. I was aware of thinking "that's very interesting but..." and trying to steer the discussion to suit my purposes.

Patton (2002) states "Qualitative interviewing begins with the assumption that the perspective of the others is meaningful, knowable and able to be made explicit. We interview to find out what is in and on someone else's mind, to gather their stories" (p. 341). What I was hearing were the meaningful perspectives of the participants providing me with an opportunity to understand what was really happening (Tellis, 1997). I began to consider how I could do justice to their stories.

\subsubsection{Reflection on initial observations}

I had prepared a template for observation (see appendices). On this I expected to note examples of traditional transmission teaching or the constructivist/childcentred teaching advocated in the new curriculum. What I had overlooked (how could I have forgotten!) was the chaos and busyness of a classroom. Ely et al. (1991, p. 48) warned that observation can be "overwhelming in the very richness and complexity of what is being played out". I was overwhelmed and felt that a checklist was not enabling me to capture the richness or the complexity of what was happening. Students moved around, they changed groups, they went to the computer lab, the teacher roved. I wondered who to watch - the students or the teacher. If I followed a group to the computer lab, what would I miss in the classroom?

What took place in the classroom could not be easily followed or neatly labelled as a type of pedagogy. There were overlaps and many layers: the students were given choice, but was it from their agenda or the teacher's? They were in groups but were they constructing knowledge or just enjoying working together? They appeared to know what they were learning but did they know why? The whiteboard listed activities but where was the learning? What was I seeing, what should I be seeing, was it relevant, what was important, was I wasting my time and the teachers'? Once again, returning to the literature with greater appreciation, I was 
able to finally follow the advice of Ely et al. (1999) and tried to write down everything I saw without worrying if it was trivial or important (Eisner, 1998).

\subsubsection{Reflection on initial coding}

As I began coding the data from the interviews and from the observations I realised that, without being aware of it, "anticipatory data reduction" (Miles \& Huberman, 1994, p. 10) was dominating my analysis. While reading the data I had provisional codes (Saldana, 2009, p. 121) in the back of the mind. I realised that I was searching for data that fit within my conceptual frameworks of change theory. Merriam (2009) maintains that while qualitative research is designed to inductively build rather than to test concepts, hypotheses, and theories, the research questions reflect a theoretical orientation. While I accepted the inevitability of her comment and realised that having a start list of codes can be helpful to help focus work in the field (Miles \& Huberman, 1994; Yin, 2009), there was a risk that I would be looking for data to fit with my provisional codes and that, in the process, I could overlook new ideas. In addition, provisional codes could distort my interpretation of what was really happening (Saldana, 2009). I reminded myself that this was a study of the teachers' realities, understanding their beliefs and their practices and their perception of the implementation process. Therefore, I ensured that I read the data several times trying to approach it each time with fresh eyes and to consider a method that allowed me to present its richness.

\subsection{Implications for the research design}

As described above the signalled changes were not a dominant focus in the schools and that while teachers were aware of the new curriculum, it was just another thing in their busy lives. This became increasingly evident as I transcribed the data. In addition, professional learning work on the implementation of the NZC was episodic. For example, as I discovered as the study progressed, in one Totara College whole school PD programme had taken place in one school term and in another it had consisted of three teacher only days. In both of these schools these days were followed by reliance on departments to further develop understanding and on volunteers to experiment with aspects of it. As a result, in some instances, work on the new curriculum was individualistic and fragmented. In addition, the implementation was competing with other innovations such as numeracy, literacy, 
differentiation and NCEA standards alignment. All of this was on top of business as usual. This realisation impacted on my plan.

\subsection{Reconsideration of research questions after reflection}

After reflecting on my experiences I began to reconsider the relevance of my questions. If there was no ongoing focus on the new curriculum I would be unlikely to track the progress of developing beliefs and practices. I eventually decided the questions listed in section 3.2 were more relevant to the study.

\subsubsection{Rationale for the changed questions}

From the initial data it was apparent that the teachers I had interviewed and observed were not, as often claimed, "resisters" of change (Zembylas \& Baker, 2007). Each expressed an agreement with effective pedagogy and the key competency integrations of the new curriculum. They did not criticise it or refuse to take part in the PD involved. All had attended implementation whole staff workshops, 6 of the 12 were working on the integration of subjects and 5 had been involved in departmental discussions. They were teachers committed to their students who actively sought ways to improve their practice. However, the extent to which they engaged appeared to be determined by the significance of the changes to their personal goals for their practice and to their context.

As I progressed in the study I began to see that the teachers who participated had all developed their beliefs and their teaching practice during their careers and that the triggers were not brought about by mandated change but from critical moments in their personal or professional lives. It was possible that by exploring these I could begin to understand what motivated them to develop their professional identity during their careers which might, in turn, provide insights into how change could be implemented (Butt et al, 1992). However, whatever change took place for them sat within the school culture and the political environment. I began to see their development as constrained within the ecology of teaching.

\subsection{Moving to educational criticism}

After reflecting on these initial experiences and beginning the coding of the data I began to investigate an alternative method to record the complexity of what I had been told in interviews and observed in classes. Educational criticism appeared 
to offer a method that could capture the complexity of the study. I noted, for example, that in a three-year study of classroom observation methods Jones and Sherman (1980, p. 556) concluded that educational criticism provided a method to "shed light on concerns that are often difficult to observe and explicate" such as the context, what is important, how it relates to other behaviours, and the social and/or historical context for an incident. In this study Jones and Sherman compared the use of Flanders' interaction analysis with educational criticism. Flanders' interaction analysis was similar to the method I had been using. Their study involved recording verbal behaviour and classifying teacher and student talk into categories similar to the way I had been using an observation sheet to categorise the types of events taking place in the classroom. Eisner (1979, p. 14) likened the practice of using defined categories to evaluate an observation of teaching to that of using a net "which unintentionally designed to let most of the fish get away and then to conclude from those that are caught of what the variety of fish in the sea consists.” Jones and Sherman (1980) found educational criticism provided what could be considered a finer woven net: thick description, subjectivity and quality of data - while the Flanders' method, resulted in thin description, objectivity and quantity of data. This led me to further investigate Eisner's (1998) educational criticism. I sought incidences of this method in studies which had a similar focus to mine. One example was Keys' (2003) thesis which was a case study of how primary and secondary teachers' beliefs influenced the implementation of a science curriculum introduced into Queensland, Australia in 1999. The research addressed four questions: 1) What teacher knowledge has the primary and secondary teachers found useful to make the science curriculum more meaningful to them? 2) In what ways does the knowledge of the primary and secondary teacher differ in relation to the enactment of the science curriculum? 3) How has the science curriculum taken form or shape through the primary and secondary teachers' knowledge? 4) What type of support is necessary to assist the primary and secondary teachers to manage curriculum change? Keys used Eisner's method of educational criticism by presenting the data as a dialogue between participating teachers, interpreting, and evaluating teachers' enactment of the curriculum in a case study.

In another thesis, Murrihy (2009) carried out a narrative inquiry into the growth and development of three participants taking part in a coaching and mentoring course. She asked the questions: Does coaching assist the growth and development of educators? In what ways? Murrihy used educational criticism as a 
tool for the analysis and the presentation of the teachers' stories. In a further example, Uhrmacher and Bunns (2011) book of essays used Eisner's method providing rich description of classrooms followed by interpretation and exploration the themes of risk taking, creativity, care and community and connectness. In another relevant study, Moroye (2005) used educational connoisseurship and criticism through an ecological lens in observations of teachers' classroom practice to investigate "What happens when we look at classroom practice through an ecological lens? How can we organize the implicit and explicit themes that emerge from that lens? What do these themes help us to understand about educational practice?" (p. 124). I believed that her description of "ecological lens" as a perspective that attends to the relationships and interconnectedness, both literal and figurative, present between humans and their environments" (p. 125) described what I was seeking to achieve in this study. Finally, Flinders (1989) used educational criticism in his case study of the professional lives of high school English teachers focussing on their work demands and teaching strategies. My interest was intensified reading McLaughlin's comment in the foreword of Flinders' book because of its relevance to the unfolding data from my study. She described the case studies in the book as “elaborating the many ways in which classroom practice and teachers' conception of their task are constructed almost on a daily basis as teachers respond to diverse features of their workplace environment" (Flinders, 1989, p.ix).

While the presentation varied in each of these studies, all provided a comprehensive description of the events that occurred through which a reader could picture the teachers or the classroom or whatever the researchers were "attempting to help them understand" (Eisner, 1998). This appealed to my desire to do justice to the teachers in my study, and reflecting on my experiences, I ultimately chose to use educational criticism as a way to describe and interpret the ecology of the schools, as a method of analysing my data and to report my study.

\subsection{Educational criticism}

Eisner's (1998) description of education criticism aligns it with a qualitative case study: multiple sources of data, holistic account, interpretive inquiry, participants meaning, researcher as key instrument, field focused, coherence of the case (Creswell, 2007; Yin, 2009). Moreover, as in case study, educational criticism fits with Yin's (2009, p. 18) reason for choosing case study: "You would choose case study because you wanted to understand a real life phenomenon in depth, but such 
understanding encompasses important contextual conditions - because they are highly pertinent to your phenomenon of study." Educational criticism has two components - connoisseurship and criticism - both of which have their roots from what the work critics have done in visual arts, literature, film and music (Bresler, 1994). Eisner (1976) considers that educational criticism is an appropriate educational inquiry because "Teaching is an activity that requires artistry, schooling itself is a cultural artefact, and education is a process whose features may differ from individual to individual, context to context" (p. 140). This view of teaching as artistry is supported by Kagan (1989) who maintains that "in a very real sense, teachers as artists create precisely crafted experiences through which students can enact various forms of intellectual inquiry" (p. 12).

In carrying out educational criticism the critic "calls upon his/her knowledge to describe, interpret, and evaluate providing multiple aspects that serve to expand the dialogue of educators to alternative possibilities and to help educators understand the complexities of the educational process" (Koetting, 1988, p. 1). In this way, Flinders and Eisner (1994) maintain that educational criticism can provide insights and understanding that may serve to enlighten in order to improve the quality of teaching and learning.

\subsubsection{The educational connoisseurship component}

Eisner (1998) uses the example of a connoisseur of wine to explain the dimensions of connoisseurship. He explains that a wine connoisseur needs not only to have the access to wine and the ability to taste it, they must also be able to perceive the different qualities of wines to appreciate what its appearance and smell indicate, the varied elements within the taste. A wine connoisseur notices the effects of the wine on the inside of his or her mouth and compares it with other wines within the category of wine it represents. Eisner maintains that in that way a wine connoisseur's knowledge of how a wine is made and of its history contribute to the perception of its quality; an educational connoisseur uses his or her knowledge of education to perceive and to interpret teaching and learning. Therefore, unlike some other research methods, educational criticism requires the researcher not only to have knowledge of research methods but also to have specialised educational knowledge.

Classrooms are complex subjects for connoisseurship (Eisner, 1998). It therefore follows, as explained in chapter 1, that to be an educational connoisseur it is necessary to have a wide range of knowledge about education. Perception and 
interpretation of what occurs in a classroom can be helped by knowledge of the teachers, of the context, and of the background to the lesson and the school culture. This is not enough, however; an educational connoisseur also needs to have an understanding of educational theory, of meaningful pedagogy, and of appropriate teacher-student relationships (Eisner, 1998). This knowledge will influence what is perceived and how it is interpreted (Eisner, 1998; Koetting, 1988; McCutcheon, 1981). I have justified my belief that I had the credentials to be an educational connoisseur in chapter 1.

\subsubsection{The educational criticism component}

Criticism is often considered to have pejorative connotations, conjuring up expectations of judgments or negative comments (Barrett, 1989). This view is reinforced by media presentations of film or restaurant critics. However, in the context of educational criticism the role of the critic is to write about what has been researched in "illuminating ways" (Barone \& Eisner, 1997, p. 100). Educational criticism is the process through which the "qualities, meanings and significance of some situation or object are made visible through the activities of the educational critic" (Barone \& Eisner, 1997, p. 100). Eisner (1985) maintains that critics' task is that of "acting as a midwife to perception" (p. 217). While educational connoisseurship can be a private activity, educational criticism is the act of disclosure. It is possible to be a connoisseur, to simply appreciate without being a critic, but it is not possible to be a critic without being a connoisseur (Eisner, 1998).

\subsubsection{The structure of education connoisseurship and criticism}

There are four dimensions to educational criticism: description, interpretation, evaluation, and thematic (Eisner, 1998). Description seeks to make the researched topic vivid for the reader enabling them to see what has been researched to help them understand and to evaluate the interpretation provided by the critic (Bresler, 1994). In chapter 5, I have described the teachers' stories as they related them in interviews. Description and interpretation of the classroom observations are provided in chapter 6 . From the descriptions a reader will form their own interpretations. However, description alone does not necessarily allow a full understanding of what has occurred (McCutcheon, 1981). In chapter 7 in the role of a connoisseur I offer my interpretation and evaluation (with which a reader may or may not agree), of what has been described, address the questions of the research and relate the interpretation to educational theories. Finally, after description, 
interpretation and evaluation, the educational critic identifies the major ideas that have emerged from the study. The thematic dimensions are the focus of chapter 8 where I discuss the recurring messages that occurred throughout my research and their implications for the implementation of the NZC.

\subsection{Reflection on relevant theory}

As already discussed, my expectation that, because the implementation of the NZC would represent change for teachers' beliefs, there would be strategies provided to support their learning were not met. There appeared to be no evidence that there had been deep discussions in the schools of the effective pedagogy and the integration of key competencies or about implications for teachers' practice. From my initial interviews and from my field notes I had no sense that the teachers anticipated change. In the interviews each participant stated they supported the effective pedagogy and the incorporation of the key competencies. However, none of their comments indicated that this signalled a change to their current practice but instead they saw it as a reminder for staff to continue to develop their current practice. While the word change was used, this was not supported by the comments. Jennifer, for example, expressed it as confirmation that the teachers were on the right track "Nothing here that is radically different. It's not new but it's a clear signal to continue the good things that are happening."

As the interviews and observations progressed, the themes emerging from the data appeared to suggest that the significance of the new curriculum for the teachers depended not only on the extent that it fitted with their existing terms of reference, but also the extent to which it could appropriately work towards attaining their personal goals or the goals of their context. Their appraisal may or may not lead them to incorporate aspects of the effective pedagogy or to integrate the key competencies. The extent to which teachers incorporated the philosophy of the new curriculum into their practice was influenced by their beliefs about their capacity to do so but this appraisal went further than a consideration of their personal skills and understanding. The efficacy dimension was also complex including a significant affective dimension: the implementation aroused a range of emotional response both positive and negative. Teachers considered whether they could carry out the changes given the norms, values, and expectations of their school and community. In considering the valence of any change, teachers considered "what is at stake for me in this context?" 
The teachers' stories told of how they had been motivated to develop their professional knowledge through their careers and what sources of personal and professional learning had supported that. Each had their own personal goals. They led busy lives and had identified what was important to them. Now this new curriculum had been presented to them. What did it mean for them and how did it fit with their beliefs and practices and their goals for teaching in their context?

As I started to interpret the data I began to see themes that linked to aspects of individual motivation and teacher readiness (Armenakis et al., 2007; Bandura, 1989; Dzubay, 2001; Ford, 1992; Leithwood et al., 2000; Locke \& Latham, 1990). As discussed in chapter 2, Ford (1992) maintains that an individual's motivation to change depends on their evaluation of the need for change to meet their goals by appraising the change to ascertain if it will help them reach their goals, and if it is personally achievable, if their context will support their efforts, and on their emotional response to it. Similarly, Armenakis et al. (2007) describe readiness to make changes as experiencing a sense of discrepancy, believing the change is appropriate for resolving the discrepancy, self-efficacy beliefs, appraising key personnel support for the change, and finally an appraisal of the personal value in the changes. Taking both these approaches into consideration the guiding theoretical framework thus became based on the possibility that the significance of the signalled changes of the new curriculum would depend on the teachers' appraisal of:

- Any sense of discrepancy between meeting their personal goals and their current practice. (Do I need to make changes?)

- Cognitive appraisal of the signaled changes. (What do these changes involve? Are they appropriate for my practice or to meet my goals for my teaching?)

- Beliefs about personal capacity. (Do I know how to do this? Do I have the time, resources etc?)

- Perception of the fit with the goals, culture and norms of the context. (Do the leaders, the opinion leaders, parents, my peers, other stakeholders, authorities I have faith in believe in and support these changes? Does the structure of the school support the changes?)

- Emotional response to the signaled changes. (What's in it for me? How do I feel about each element above?) 
In addition to gauging teachers' readiness and therefore the significance of the signalled changes for the teachers I have sought an understanding of what had motivated them to make changes in their practice. Leithwood et al. (2000) used a similar framework to investigate USA teacher motivation to implement accountability policies.

Figure 4 shows my proposition that the significance of the signalled changes may depend on the teachers' appraisal of these elements.

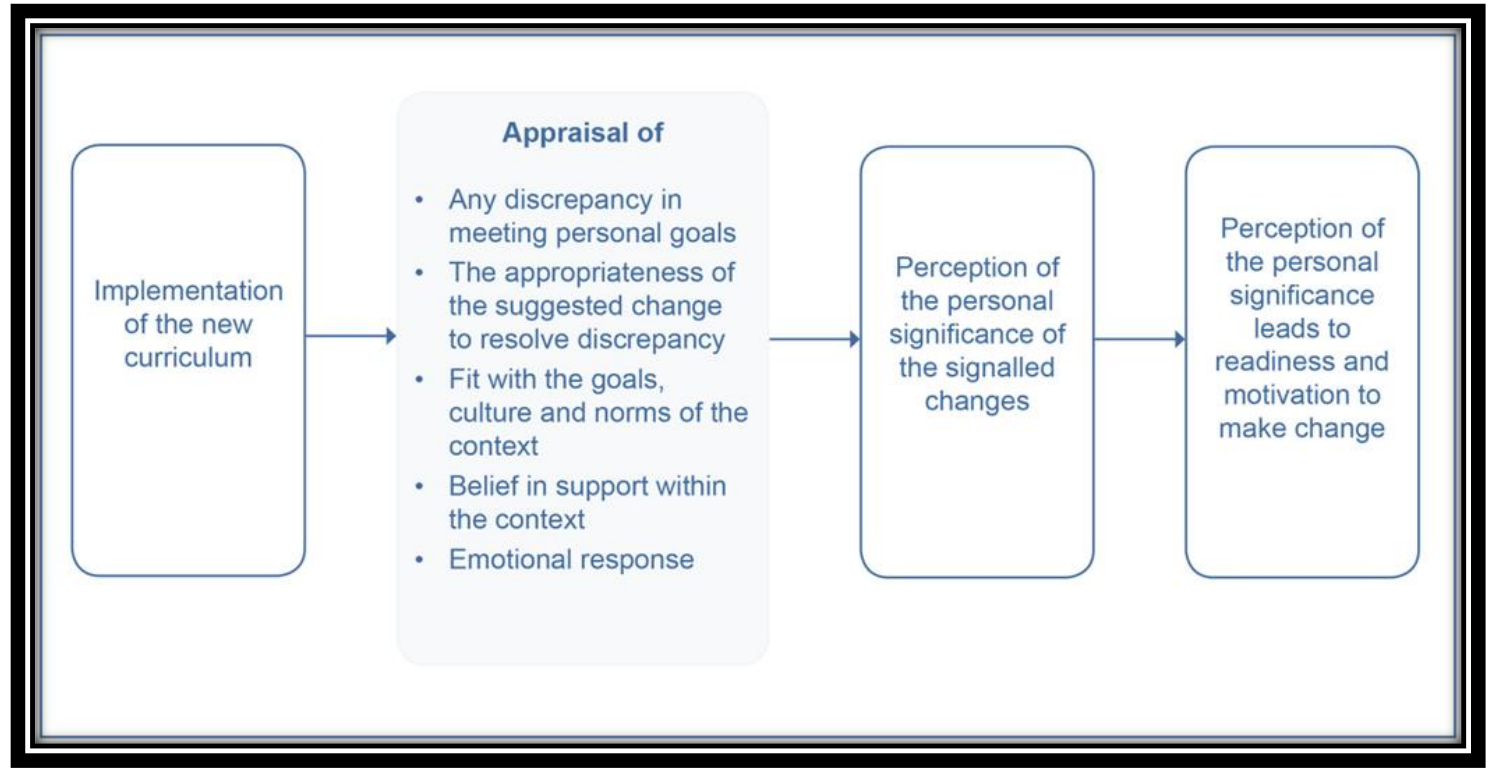

Figure 4. The appraisal of the new curriculum leading to perceived significance

\subsection{Chapter summary}

The purpose of this chapter was to provide a justification for the eventual research design. In it I have explained how the research design evolved over the course of the study, how I reflected on unanticipated events and how this led me to reconsider my questions, to incorporate educational criticism within a qualitative case study and how it impacted on the theoretical framework. In chapter 2 I used the metaphor of an iceberg to represent what I believed were the unexplored aspects of change within teachers. The theoretical framework of the study described above has developed from these aspects and from my early findings on entering the field. In the following chapter the procedures followed are explained. 


\section{Mapping the study}

It's huge to break down what the students come in with. (Amy)

\subsection{Chapter overview}

The purpose of this chapter is to provide a reader with the details of the participants, the data collection procedure, methods and analysis. I first provide the context of the study. This includes a description of the schools that were involved, the criteria for choosing them, and an indication of their engagement with the NZC. Next is a description of the participants in the study followed by the data collection process and analysis using Eisner's (1998) three methods of verification: structural corroboration, consensual validation, and referential adequacy.

\subsection{The context of the study}

As per my original plan I sought one site for the study. The criterion for a site was one which represented some typicality of secondary schools in New Zealand where entry would be possible and where I could build strong relationships (Eisenhardt, 1989; Merriam, 2002; Rossman \& Rallis, 2003; Stake, 1995). With this criterion in mind, I first sought a school that was used to innovations and likely to be positive towards change and to participation (Patton, 2002).

Being aware of the potential for bias as in my various roles I had worked with most Wellington secondary schools in some capacity, I sought a school in another city in which I had not previously worked which would meet the criteria. After consultation with advisors in Leadership and Management at Victoria and Massey universities I first approached a school outside the Wellington area that met the criteria because the advisory group believed that staff were used to innovations and they would have a positive attitude towards change and towards participation. This school is referred to as Totara College.

As noted in the phases of the study in chapter 3, I was unable to enlist enough teachers in the first school. In 2010 I therefore approached two other schools which also fitted these criteria because they were considered by the advisory group and by the ERO reports to be innovative and committed to ongoing teacher professional learning (ERO, 2006). These schools are referred to as Kauri High School and Kawakawa College. The study finally involved 12 teachers from three different 
schools with different decile ratings and input from three senior managers with responsibility for professional learning (see Table 9).

Table 8. School demographics

\begin{tabular}{lccc}
\hline & Totara College & Kauri High School & Kawakawa College \\
\hline Type & State co-educational & State co-educational & State co-educational \\
\hline Decile & 5 & 9 & 10 \\
\hline Location & $\begin{array}{c}\text { Semi rural suburb of } \\
\text { small city }\end{array}$ & Inner city & Urban suburb of a city \\
\hline Roll & 752 & 1041 & 1175 \\
\hline Teachers & 50 & 65 & 73 \\
\hline Ethnicity \%: & & & 69 \\
Pākehā & 55 & 68 & 7 \\
Māori & 26 & 17 & 2 \\
Pasifika & 5 & 2 & 12 \\
Asian & 5 & 5 & 10 \\
Other & 9 & 8 & 58 \\
\hline Gender \%: & 54 & & 42 \\
Male & 54 & 46 & \\
Female & 46 & & 7 \\
\hline
\end{tabular}

\subsection{School descriptions}

\subsubsection{Description of Totara College}

This school is a decile 5 co-educational state school for students from years 9-13 located in a semi-rural setting in an outer suburb of a small city with a population of approximately 80,000 (Statistics NZ, 2006) where seven secondary schools compete for students.

The school was officially opened on 1 December 1976 when the suburb largely comprised families with children. However, the demographics have changed over time. There are currently 4,383 residents; many of the children have grown and left, with only parents remaining in the family home. The result has been a falling roll at the college from 975 students in 2003 to 725 currently. This drop in numbers has impacted on the funding provided by the MOE and on the staffing at the school. Over the past three years the school has undergone a Curriculum and Pastoral Needs Analysis (CAPNA) process. The CAPNA is a document which requires a school to analyse its staff usage in relation to its curriculum and pastoral needs and is most commonly used when a school has a falling roll (Post Primary Teachers' Association, 2009).

The school is an attractive collection of buildings sitting in expansive playing fields. It is the most common school bloc type (Connell Wagner, 2001), a single 
storied 'Nelson' plan which involves a series of H-shaped single-storey classroom blocks with low pitched roofs and internal open courtyards typical of many schools built in New Zealand in the 1970s. Although the classrooms are dated, and show no evidence of any significant change since they were built, they are well maintained. The students appeared relaxed to have a stranger in their class and were friendly when approached. The entrance lobby was attractively decorated with prominent photos of former head students, duxes and other students achieving success lining the walls signalling a school focus on student achievement. The staffroom had a collegial welcoming atmosphere, the staff evidently enjoying each other's company as they had their morning tea and lunch. The walls here also displayed a celebration of student achievement. A student uniform policy was strictly adhered to and staff dress could be described as "smart casual.'

John, the deputy principal with responsibility for PD, explained that the first day of whole staff PD on the NZC had consisted of everyone looking at the document in its entirety and on a second day, on staff working in departments. Effective pedagogy of the NZC had been discussed but "it was a one-off discussion so whether it stayed - people got on with it - we have moved on." Since then, staff have worked in their own departments. John believed that no-one had a deep understanding of the implications of the NZC and he wondered "where do you find the expert?"

\subsubsection{Description of Kauri High School}

Kauri High School was the first co-educational secondary school in New Zealand. It is a decile 9 inner city state co-educational school for students in years $9-13$, the only co-educational, non-uniform secondary school in the city. Located close to the city centre it has a student population of 1050 students. Over the last three years the school roll has stabilised after a period of growth resulting in the implementation of an enrolment scheme in 2004 (ERO, 2010). The school attracts a significant number of new students at senior levels.

Many of the current buildings date from the 1980s and are in the "brutalist' style which primarily used concrete. Examples of this style are typically very linear, fortress like and blockish. It has an edgy city feel, tumbling down a sloping site on a constantly busy road, with little outdoor space, and is next to a tertiary institution. The main entrance to the school signals its modern student-centred approach. It has a colourful stylish cafe, a far cry from traditional school cafeterias. The library is also a visually stimulating and student friendly area with a range of alcoves, comfortable seating, and 
interactive materials. However, a visitor can find other parts of the school layout confusing: the stairway in the centre of the main block is a concrete twin spiral with notices instructing students to "go up the left stairway and down the right." The students, however, were very helpful and understanding when this visitor threatened to cause a traffic jam by choosing the wrong spiral! The busy and cluttered reception area is internal making it gloomy. It does not obviously advertise students' achievement and has a mixture of decorative styles with decor appearing to be unimportant. On the other hand, the staffroom is sunny with a view of the city. On the walls are posters that summarise PD sessions and school events. The atmosphere of these areas is that of a busy school focused on the teaching and learning and not concerned with appearance. The staff dress casually and have an easy interaction with the students.

While the students do not wear a traditional uniform, from a visitor's point of view there appears to be certain deliberate "look" which could be seen in alternative music magazines. One participant teacher at the school maintained that "it's very competitive who can be the biggest individual, who can be most different." The students were open but generally took no notice of a stranger visiting their classes.

Staff reported that the year before there had been teacher only days to explore the NZC document and that time had been spent on the key competencies. As a result, staff had constructed a booklet outlining what the key competencies meant for each department. Subsequently there had been little whole staff PD. Instead, staff elected to be in a learning group with others who had a common interest. Each group was required to report back to the rest of the staff twice during the year and to post their findings on the staff intranet. The staff were not told explicitly to incorporate key competencies but the participants believed it was assumed this would be done.

\subsubsection{Description of Kawakawa College}

Kawakawa College is a decile 10 state secondary co-educational non-uniform school with a roll of approximately 1220 . Established in 1956, it is situated in the northern suburbs of a city. At the time it opened, the fact that it was co-educational when other high decile schools were single sex and that it offered a broad curriculum attracted students from further away than the immediate suburbs.

The school is on a spacious site with buildings that have a "topsy" sense of being added on to over the years with several prefabricated buildings on a slight rise to the right of the rest of the school. A visitor parks on the netball court outside the staffroom and accesses the school via the school office to the side. This is a small 
open area with newsletters available on a side table but no conspicuous display of student achievement. The students were unselfconscious wearing a variety of casual styles. Unlike Kauri High School, there did not appear to be a certain "look" although there may have been a code not obvious to an adult. They were relaxed, open and friendly and appeared accustomed to visitors to their classes.

The PD for the NZC consisted of two days when the whole staff explored the document. This was followed by the staff working in self-selected learning groups each Tuesday morning during the first school period focussing on what the NZC meant for the students. In addition to the implementation of the NZC, learning groups have also been working on Information and Communication Technology (ICT) and Māori culture, focusing across specific areas and team teaching. Patricia, the deputy principal with responsibility for PD, maintained that each group had contributed to the learning culture of the school: “there's a lot going on here... that's the reality." Since the teacher only days there has been no more whole staff PD on the key competencies but there has been a focus group working on it which was expected to report back to the staff in 2012. When discussing the implementation of the NZC, Patricia, believed that "individual teachers could say it's happening in classrooms but not school wide, we haven't got the language, that's what we are working on, developing a common understanding." The focus for whole school professional learning has now moved to constructing a shared learning philosophy and developing an understanding of the principles of assessment to lay the basis for differentiated practice, integrating ICT and supporting literacy in the junior school. In addition to the school-based PD teachers could apply to go to courses or conferences offered by external consultants.

\subsection{Participants}

The teachers from Totara College volunteered to participate after I had presented the aims of the study to the staff. In schools B and C the deputy principals with responsibility for professional learning at their schools invited teachers who were innovative and who they believed would be interested in taking part. When four teachers from each of those schools professed an interest in the study, I met each to give them the information sheet and explain the project further. All consented to be participants in the study. As can be seen from Table 10, the participants varied in teaching experience from two years to twenty-five years, taught a range of subjects, and in some cases held positions of responsibility. 
Table 9. Details of participants

\begin{tabular}{|c|c|c|c|}
\hline Name (pseudonyms) & $\begin{array}{c}\text { Teaching } \\
\text { experience }\end{array}$ & Gender & Role \\
\hline Amy & 11 years & $\mathrm{F}$ & $\begin{array}{l}\text { Teacher of Mathematics } \\
2009 \text { acting Head of Department } \\
2010 \text { Assistant Head of Department }\end{array}$ \\
\hline Christopher & 9 years & M & Science teacher \\
\hline Edward & 8 years & M & $\begin{array}{l}\text { Social Sciences teacher } \\
\text { Head of Department }\end{array}$ \\
\hline $\begin{array}{l}\text { James } \\
\text { (on study leave 2010) }\end{array}$ & 26 years & M & $\begin{array}{l}\text { Teacher of accounting } \\
\text { Head of Department } \\
\text { Dean of Year } 13\end{array}$ \\
\hline Jennifer & 24 year & $\mathrm{F}$ & $\begin{array}{l}\text { Teacher of English } \\
\text { Deputy Principal } \\
\text { Term } 12009 \text { Acting Principal }\end{array}$ \\
\hline $\begin{array}{l}\text { Jill } \\
\text { (moved from Kauri High School to a } \\
\text { Head of Faculty position at } \\
\text { Kawakawa College in 2012) }\end{array}$ & 7 years & $\mathrm{F}$ & Teacher of Geography/Social studies \\
\hline $\begin{array}{l}\text { Joseph } \\
\text { (Appeared to avoid a post } \\
\text { observation interview). }\end{array}$ & 7 years & M & Teacher of Physical Education \\
\hline Mary & 2 years & M & Teacher of Mathematics \\
\hline $\begin{array}{l}\text { Michael } \\
\text { (withdrew after the first interview) }\end{array}$ & 26 years & M & $\begin{array}{l}\text { Teacher of Mathematics } \\
2009 \text { Acting Deputy Principal } \\
2010 \text { Head of Department }\end{array}$ \\
\hline Nina & 6 years & $\mathrm{F}$ & Teacher of Physical Education \\
\hline Ruth & 15 years & $\mathrm{F}$ & $\begin{array}{l}\text { Science teacher. } \\
\text { Specialist Classroom Teacher }\end{array}$ \\
\hline Susan & 4 years & $\mathrm{F}$ & English teacher \\
\hline
\end{tabular}

\subsection{Data collection after reflection and reconsideration of questions}

After my reflections as described in section $3.3 \mathrm{I}$ began to wonder what was the purpose of interviewing and observing to identify change over time if there was no trigger to stimulate change. I therefore decided to focus on striving to develop snapshots of each teacher's reality by listening to their stories. I use "stories", not as defined in narrative methodology, but in the spirit of Locke and Riley's (2009) argument that "all research reports are telling stories in one way or another" (p. 502). Stories as data provide access to individuals' interpretations, and moreover, a variety of stories provides a variety of views (Rhodes, 1996). With this in mind, I began the interviews by asking the teachers to tell me about themselves, about their teaching careers, and about their beliefs about effective teaching. To gain an understanding of the teachers' perception of their role as a teacher and their personal goals for their 
teaching I included an exploration of the formative experiences that had led to their construction of their teacher identity. As discussed in chapter 2, a teacher's identity develops over time influenced by various experiences from both their personal and professional lives (van Veen \& Sleegers, 2006; Zembylas \& Barker, 2007). Sikes, Misor, and Woods (1985) maintain that teachers develop their professional knowledge and beliefs by reflection on critical incidents that can represent turning points in their careers which pivotal decisions revolve. These critical incidents may be when an experience causes, for example, disconfirmation, surprise or selfquestioning (Strauss, 2008). I approached this by asking the participants if they could recall critical incidents, which I referred to as "aha" moments, in their personal or professional lives which had impacted on their beliefs about teaching and learning and which had motivated them to seek further understanding.

All the participants were interviewed for approximately one hour. As described in my interview reflection I discovered that teachers are eager to talk and that the challenge for the researcher is to keep the process focused on relevant aspects. However, I learned to accept that I had limited control and that I needed to feel confident that subsequent analysis of the raw data would, as Kagan (1990) suggested, allow me to infer beliefs. The interviews were audiotaped and transcribed. Teachers were subsequently sent a copy of the transcription and asked to check it for accuracy.

\subsubsection{Classroom observations}

Eleven of the participants were observed teaching, four of them twice. The purpose of these observations was to further develop an understanding of their beliefs by observing their "theory in action" (Argyris \& Schon, 1987) which they may have been reluctant or unable to explain in the interview (Maxwell, 2005; Patton, 2002). Observation further added to an understanding of the complexity of teaching and of the context in which the teacher was operating (Eisner, 1998; Patton, 2002). Merriam (2009) provides a range of stances a researcher can take as an observer from full participation to complete observer. My role fitted the description of "observer participant" (p. 124). That is, the teachers and the students were aware of my presence; I was part of the class but I was introduced to the students as a researcher from the university who was there simply to observe. I was mindful that while this was an important research activity for me, it was an intrusion in the life of 
the teacher and I therefore sat at the back of the class and tried to be as unobtrusive as possible.

In these observations I was more open to what was taking place and tried to write down everything that occurred. The scripts and the data from the templates formed the raw data and both were considered in interpretation. In the spirit of educational criticism aspects of the observations are included in the interpretation in chapter 6 to allow a reader to "see" the classroom (Eisner, 1998).

\subsubsection{Interviews after observations}

The data collected from the observations provided guidance for the follow-up interview and contributed to the building of a complete picture of the lesson. In the follow-up interview with the teacher we discussed the script together giving the teacher the opportunity to explain his/her actions and provide the context. Locke and Riley (2009), referring to educational criticism, ask "if the observed teacher is an artist, what they might want to say to the connoisseur observer and how this talking back might affect the criticism itself?" (p. 489). Discussing the script of my observation addressed this concern by allowing the teachers' opinion to inform the subsequent interpretation. In some cases, this was how this lesson fitted with earlier lessons or how the actions were to meet the particular needs of a child. Follow-up interviews took place on the same day or as soon as could be arranged after the observations of ten of the participants. In one case it became impossible to schedule a follow-up interview and the remaining participant withdrew from the research.

During the post-observation interviews teachers were asked to describe their thinking during the interactions and explain why they chose specific instructional strategies. Their narration helped to develop an understanding of their cognitive processes and their tacit beliefs. Brickhouse (1990) cautions that observations are not theory neutral and that theoretical commitments influence the interpretation of the observations. It was therefore important to develop rapport to reduce participants' anxiety that they may hold unpopular views (Kagan, 1990) and to be aware that it may be difficult for them to verbalise their tacit knowledge (Calderhead, 1981). As a proponent of social constructivism, this was something I had to keep in mind in the interviews; it was important that I did not appear to approve or disapprove of the teachers' practice and/or the beliefs which prompted it.

It was possible that the teachers' lessons were influenced by the initial interview and that the lesson may not have been representative of their typical 
practice (Kagan, 1990). It was therefore important to discuss with the participants the relationship between explanations and the evidence from observations. In these interviews I read sections from my observations and asked the teachers to explain, for example: "tell me why you did this" or "can you tell me what was happening here?"

\subsubsection{Documents}

The strategic plans and the annual plans from each school were examined to further develop the picture of the context in which the teachers worked. In addition, newspaper clippings that helped to expand the understanding of issues in the external environment were collected over the course of the study. Findings from the document examination are included in chapters 7 and 8 .

\subsection{Summary of methods used for data collection}

The challenge and the obligation of case study research is to "understand the case" (Stake, 1995, p. 4). The data that build towards an understanding of this case consist of all the information that was gathered about the case: "interview data, observations, documentary impressions, contextual information" (Patton, 2002, p. 449). Yin (2009) provides three principles of data collection for case study research. They are: 1) using multiple not just single sources of evidence; 2) creating a case study database; and 3) maintaining a chain of evidence. In this study there were multiple sources of data collection: interviews, observations and documents. Field notes of impressions were also used to further develop understanding of what was happening. Databases have been maintained separately as Yin (2009) recommends. All raw data, coded data, and analysis could be accessed from designated files. Yin's principle of a chain of evidence has provided a prompt to link the inter-related parts of the research checking the evidential trail.

As explained earlier, at the start of the study I had intended to observe new curriculum PD, to interview each teacher, observe them teaching and conduct a follow-up interview with the teachers over the course of an implementation process, but because there was no defined implementation process in any context my plan changed. As a result, while two teachers in Totara College took part in two cycles of interviews, observation and post-observation interviews, after reconsideration of the research design I believed that it seemed pointless to attempt to track development of beliefs and practices and subsequently one cycle was undertaken with the remaining 
eight participants and a second observation with the teachers who were team teaching. 
Table 10. Data collection

\begin{tabular}{|c|c|c|c|c|c|c|}
\hline Name & $\begin{array}{l}\text { Interview } 1 \\
\text { (One hour) }\end{array}$ & Observation & $\begin{array}{l}\text { Post-observation Interview } \\
\text { (Ranged from } 30 \text { minutes to } \\
\text { one hour) }\end{array}$ & Observation & $\begin{array}{l}\text { Post- } \\
\text { observation } \\
\text { Interview } \\
\text { (One hour) }\end{array}$ & $\begin{array}{l}\text { Meeting to discuss key themes } \\
\text { (45 minutes) }\end{array}$ \\
\hline Amy & $\sqrt{ }$ & $\sqrt{ }$ & $\sqrt{ }$ & $\sqrt{ }$ & $\sqrt{ }$ & $\sqrt{ }$ \\
\hline Christopher & $\begin{array}{l}\qquad \sqrt{ } \\
\text { (Incomplete due to audio } \\
\text { malfunction) }\end{array}$ & $\sqrt{ }$ & $\sqrt{ }$ & & & $\begin{array}{l}\text { Key themes emailed for } \\
\text { verification }\end{array}$ \\
\hline Edward & $\sqrt{ }$ & $\sqrt{ }$ & $\sqrt{ }$ & & & $\sqrt{ }$ \\
\hline James & $\begin{array}{c}\sqrt{ } \\
\text { ( on study leave 2010) }\end{array}$ & $\sqrt{ }$ & $\sqrt{ }$ & & & $\begin{array}{l}\text { Key themes emailed for } \\
\text { verification }\end{array}$ \\
\hline Jennifer & $\sqrt{ }$ & $\sqrt{ }$ & $\sqrt{ }$ & $\sqrt{ }$ & $\sqrt{ }$ & $\sqrt{ }$ \\
\hline Jill & $\sqrt{ }$ & $\sqrt{ }$ & $\sqrt{ }$ & $\begin{array}{c}\sqrt{ } \\
\text { (team teaching with Susan) }\end{array}$ & & $\sqrt{ }$ \\
\hline Joseph & $\sqrt{ }$ & $\sqrt{ }$ & $\begin{array}{l}\text { Unable to schedule post- } \\
\text { observation interview }\end{array}$ & & & $\begin{array}{l}\text { Key themes emailed for } \\
\text { verification }\end{array}$ \\
\hline Mary & $\sqrt{ }$ & $\sqrt{ }$ & $\sqrt{ }$ & & & $\begin{array}{l}\text { Key themes emailed for } \\
\text { verification }\end{array}$ \\
\hline Michael & $\begin{array}{l}\quad \sqrt{ } \\
\text { (withdrew after this } \\
\text { interview) }\end{array}$ & & & & & $\begin{array}{l}\text { Key themes emailed for } \\
\text { verification }\end{array}$ \\
\hline Nina & $\sqrt{ }$ & $\sqrt{ }$ & $\sqrt{ }$ & & & $\begin{array}{l}\text { Key themes emailed for } \\
\text { verification }\end{array}$ \\
\hline Ruth & $\sqrt{ }$ & $\sqrt{ }$ & $\sqrt{ }$ & & & $\begin{array}{l}\text { Key themes emailed for } \\
\text { verification }\end{array}$ \\
\hline Susan & $\sqrt{ }$ & $\sqrt{ }$ & $\begin{array}{l}\sqrt{ } \\
\text { (took place after } 2 \\
\text { observations) }\end{array}$ & $\begin{array}{c}\sqrt{ } \\
\text { (team teaching with Jill) }\end{array}$ & & $\begin{array}{l}\text { Key themes emailed for } \\
\text { verification }\end{array}$ \\
\hline & & & lior managers with responsibilit & or Professional Learning & & \\
\hline Patricia & \multirow{3}{*}{\multicolumn{3}{|c|}{$\begin{array}{l}\text { Twenty minute interview on the school's PD plans } \\
\text { Informal discussion of the integrated studies programme } \\
\text { One hour discussion of the school's PD programme }\end{array}$}} & & & \\
\hline Christine & & & & & & \\
\hline John & & & & & & \\
\hline
\end{tabular}




\subsection{Credibility}

In this study, my challenge was to paraphrase Flinders and Eisner (1994): How would my account of the teachers' perspectives be believable? Merriam (2009) states that "the question should be what are the findings given the data presented?" (p. 215). In the following section I describe my sources of evidence for credibility using Eisner's (1998) suggested categories: structural collaboration, consensual validation, and referential adequacy.

\subsubsection{Structural collaboration}

Structural collaboration is a term used in educational criticism for what is referred to in other qualitative methods as triangulation (Creswell, 2003; Merriam, 2009). It refers to the use of different data sources to build a coherent justification (or lack of justification) for interpretation and evaluation of the study. In this study, data were collected by interviews with teachers before and after observations, from observations of classroom school leaders and from documentation. This is what Eisner (1998) refers to as "the mustering of evidence" (p. 111) which provided sufficient data to support my interpretation and evaluation and the identified themes.

\subsubsection{Consensual validity}

Consensual validity "is agreement among competent others that the description interpretation, evaluation and thematics of the educational situation are right" (Eisner, 1998, p. 112). In this study, the participants were sent transcripts of the interviews, discussed with me the scripts from their observations, and either met with me to discuss the key themes or accessed them via email (see Appendix G: Jill key theme). They were invited to give me feedback. In one case a correction was made to the key themes but the only other responses I received were 'I'm embarrassed I talked so much!"

\subsubsection{Referential adequacy}

This aspect of validity or credibility gauges the degree to which the study does actually illuminate "aspects of classroom meaning that would otherwise remain hidden" (Flinders \& Eisner, 1994, p. 354). In this study, the reader is provided with descriptions of the teachers, the context, the interviews, and the observations to provide a picture of the significance of the implementation of the NZC to the secondary teachers in relation to their context, experience, beliefs, values, and motivation. 
In Educational criticism one of the methods for establishing credibility is by consensual validity which is "agreement among competent others that the description interpretation, evaluation, and thematic of the educational situation are right" (Eisner, 1998, p. 112).

Figure 5 describes how I did this.

1) The transcripts from the interviews were sent to the participants for verification.

2) The scripts from observations were discussed with the teachers.

3) The key themes from the interviews and from the observations were either emailed to the teachers for verification or discussed with them in a meeting.

4) Through providing a description of the data used for interpretation a reader is able to apply their own critical eye and judge its validity.

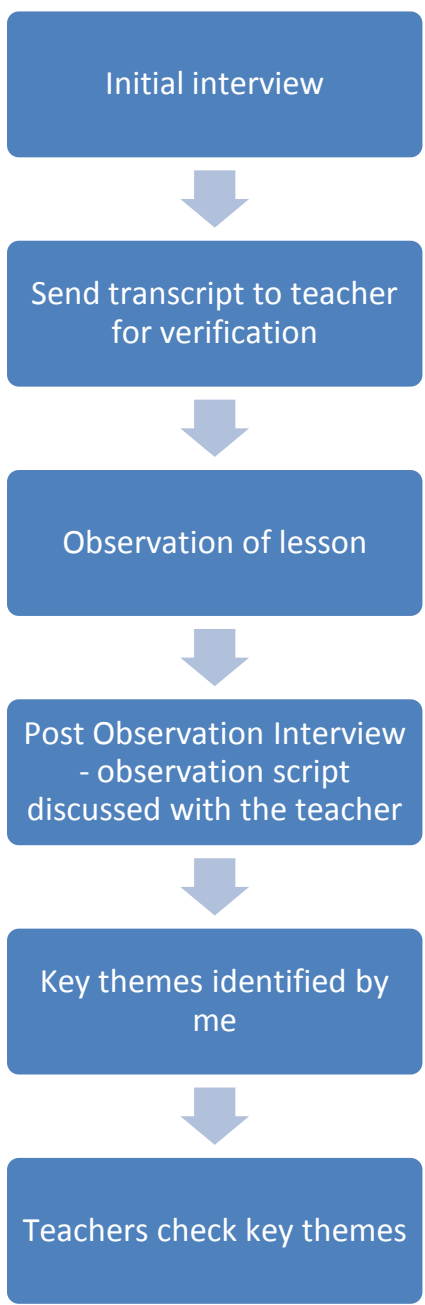

Figure 5. The data collection process 


\subsection{Data analysis}

Miles and Huberman (1994) define analysis as consisting of three concurrent and continuous flows of activity: data reduction, data display, and conclusion drawing/verification. This was the process I carried out throughout the research. I found it to be, as described by Rossman and Rallis (2003, p, 279) a "creative process entailing immersion, incubation, insight and interpretation". The interviews and the observation notes were transcribed and entered into the database of raw data. I began this process by immersing myself in the data (Rossman \& Rallis, 2003), carefully reading and rereading the transcripts and my field notes and following a process of data reduction at a basic level by allocating categories to segments, highlighting chunks of text, and applying descriptive codes in the margin (Miles \& Huberman, 1994; Saldana, 2009).

I next moved from merely labelling to linking the data to an idea and from there to other data pertaining to that idea (Richards \& Morse, 2007). This was a toing and fro-ing exercise that was ongoing through the study from the beginning of the data collection. For example:

Table 11. Example of coding

\begin{tabular}{lll}
\hline Code & Raw data & Potential theme \\
\hline J1/2 & $\begin{array}{ll}\text { they let them do integrated studies how they want that way and then } \\
\text { teachers do it so doing it without understanding differently it's } \\
\text { meaningless from each other so there is no full understanding }\end{array}$ & $\begin{array}{l}\text { Teachers work } \\
\text { independently. } \\
\text { No shared } \\
\text { understanding }\end{array}$ \\
\hline
\end{tabular}

As I explain in my reflection on initial coding, chapter 3 (section 3.6.4), I learned to resist allowing anticipatory codes to dominate my thinking (Saldana, 2009) and developed the ability to remain open to what was emerging from the data, reminding myself that this was a study of the teachers' realities, understanding their beliefs and their practices, and their perception of the implementation process. Therefore, I ensured that I read the data several times trying to approach them each time with fresh eyes. I gradually built up a range of codes which were a combination of provisional codes and new ones that emerged from the data.

\subsection{Ethics}

DeWalt and DeWalt (2002) maintain that researchers must be aware of ethical issues at every stage of the study - considering the questions, selecting the site, deciding on the methods through to publication. This involves an ethical imperative to seek transparency and consultation throughout. In participant observation the basic concept is 
that people have the right to be involved or not and that to make the decision they need to be fully informed about the project. They also have the right to privacy. Stake (1995, p. 447) cautions that "qualitative researchers are guests in the private spaces of the world. Their manners should be good and their ethics strict". It was therefore important not to assume participants had a full understanding of the aims of the project. I needed to ensure they understood both the aims of the study and that they had a choice whether they wished to be involved or not. When seeking entry to each school I met with the principals of two of the schools and the deputy principal of the third. I had emailed them the information sheet which described the purpose and the design of the research and a consent form (see appendices) before the meeting. At the meeting I talked to the information sheet and answered any questions the school leader had. I also talked through the consent form so that it was clear what the teachers would be undertaking. When meeting with each participant I also talked to the information sheet and asked them to carefully check the consent form before signing it. Throughout the study I shared the emerging findings with the teachers and informed them of the change in questions.

Approval for the study was granted by the Victoria University of Wellington Faculty of Education Ethics Committee. I was also guided by the Code of Ethics for Registered teachers (www.teacherscouncil.govt.nz/ethics/).

\subsection{Presentation of data}

Eisner (1998) does not provide a formula for the structure of educational criticism leaving it to the personal preference of the critic. His stated the reasons for this stance are because he believes that the research is dependent on the personal style and qualities of the researcher and because it is impossible to accurately predict how the study will unfold. The studies using educational criticism which I refer to in chapter 3 (section 3.9) are examples of personal preference in presentation. In this study I have chosen to separately introduce the reader to the participating teachers in chapter 5 through a description of their interviews. Chapter 6 is both a description of the lessons observed and my interpretation of what occurred using the data from the observations and from the post-observation interviews.

\subsection{Chapter summary}

The purpose of this chapter was to provide an overview of the study enabling a reader to understand the steps taken and to gain a sense of the context in which it 
was carried out. Having in chapters 3 and 4 described the research design and the procedures followed, the following chapter introduces the teachers. 


\section{Meet the teachers}

Listening to teachers should be a priority in teacher development work. It is not enough just to witness behaviour, skills and actions but listen too. Failure to understand the teacher's voice is failure to understand the teacher's teaching (Hargreaves, 1997, p. 343).

\subsection{Chapter overview}

Goodson (1991) maintains that in understanding something as personal as teaching it is critical we know about the person the teacher is. In this chapter I have described the interviews with the teachers to provide a way for a reader to gain an understanding of the teachers who participated in the study. As discussed in chapter 3, there are four stages in educational criticism: the descriptive, interpretative, evaluative and thematic stages (Eisner, 1998). This chapter is a descriptive stage of educational criticism. As Eisner (1998, p.90) points out, any descriptive writing involves inherent selectivity. My hope is that what I have included will enable the reader will gain an understanding of each teacher's background, what motivated them to make changes, and begin to gauge what significance the NZC had for them. There is no analysis in this chapter. In keeping with the spirit of the research design its purpose is to provide a way in which the reader can make an interpretation without having mine imposed on them. I liken it to the way an individual may view a work of art and form his or her own impression. Subsequently, when reading a critic's opinion they are able to judge its accuracy. To aid the process, a reader may wish to refer to the questions listed in section 3.2.

The details of the teachers are provided in chapter 4 (section 4.4). As explained in chapter 4 (section 4.5.2) instead of the questions on pedagogy that I had initially attempted, I found it more productive to ask teachers to tell me about their backgrounds, the experiences that had impacted on their beliefs about teaching and learning, and their responses to the NZC. The following section describes the teachers' stories.

\subsubsection{Jennifer}

\section{Background}

Jennifer, a senior manager in Totara College had been teaching for 24 years having initially undertaken a four-year conjoint degree which prepared her for primary school teaching. A dynamic articulate woman eager to share her strong views on the NZC, Jennifer had an outgoing personality and strong presence. The 
interviews with her took place in her deputy principal's office with Jennifer sitting behind her highly organised desk.

\section{Influences on beliefs of teaching and learning}

Jennifer identified three main influences on her beliefs about teaching and learning. The first was her training as a primary school teacher. Looking back she believed that the focus of her preparation for teaching fits with the effective pedagogy of the NZC. It was on carefully planning what was to be achieved, pitching it at the right level for the students and ensuring that the learning was meaningful: "the work that went into that was phenomenal really."

Another significant event was in her first teaching appointment at a secondary school when she was instrumental in developing an integrated subjects project. This project involved connecting and integrating key concepts across disciplines, a concept referred to as integrated subjects which is also a focus in the NZC. In Jennifer's experience it included education outside the classroom and making learning meaningful in authentic contexts. She described this as:

...innovative then in 1986, IBM sponsored computers, had lab of computers, then people, newspapers, were still working on typewriters. It was an amazing time. I was seconded. They needed someone, and being primary trained they said I could do it.

Finally, she described how her experiences after moving to the secondary school sector had also stimulated her interest in theories of change. Over the years she has taken part in several change projects and, as she moved into middle and senior management, leading them. Her growing interest in administration and in leading change motivated her to complete a Master's degree in Educational Administration.

Response to the NZC

Jennifer was dismissive of the new curriculum document stating derisively as she tossed it across her desk: "look at this document - who had input? Who do I know? How did they consult - they did but how was this arrived at? Then they flick this out. I don't feel personally connected to this document." She particularly resented the fact that the NZC document did not acknowledge the work done in schools over the past years, in many cases, work of which she had direct experience: With her wide range of experience and her studies over the years she believed she was qualified to critically evaluate the curriculum document: 
Finally I think, nah sod it, I'm going to have an opinion now, I'm actually going to call myself experienced with some knowledge to actually comment on what's happening, first of all, challenge it, for what it is. That's when I feel I'm at a stage to say well, hang on, hang on there, who said that we needed this again?

Jennifer did not express any concern about her own ability to incorporate the effective pedagogy. She did not think there was anything new in the NZC document, seeing it as summing up a wide range of things that are happening in schools across New Zealand: It's not new but it's a clear signal to continue the good things that are happening." The teacher inquiry aspect, for example, was familiar to her being part of her training 25 years before. She maintained that the document was an example of "ideas that go around and come back."

Jennifer believed that schools know what their students need and that they develop initiatives to meet these needs. The school had identified the areas they felt important for their students and the mandated curriculum could jeopardise their own projects: "Change from a national point of view runs across change already going on. They should butt out and let us get on with it." She was concerned that the range of professional learning involved would put excessive pressure on the staff and strain their resilience: "People only have so much energy - you can build a resistance to change - resistance versus resilience." On the other hand she appreciated that the NZC included a focus on effective teaching, something she felt has been neglected with the pressure of the work involved in introducing and becoming familiar with the national assessment system, National Certificate of Educational Achievement (NCEA). She believed that the ideas expressed in the NZC of students taking an active part in the learning had been accepted by teachers for some time. However, she is unsure whether the thinking had actually been translated into classroom practice. Therefore, it was appropriate that it had been made explicit in the NZC document. Despite this, she was concerned that the overall change involved with the NZC may eclipse the teaching and learning aspects, especially the need to align the assessment requirements of NCEA with the NZC. She also accepted the concept of key competencies in theory but again, had considerable concerns about the possibility of accountability being expected by ERO: "What scares me, you think oh no another thing I have to assess. I always suspect that someone will be lurking." Jennifer was deeply concerned that the lack of time allocated for PD relating to the new curriculum would put too much pressure on heads of departments who she believed have perhaps the most crucial role in the school and had the responsibility 
to lead any change in their departments. This was in addition to their other pressures and could cause emotional distress.

\subsubsection{Amy}

This was Amy's eleventh year of teaching. She was an intense, energetic woman, highly articulate and brimming with ideas. She spoke with evident passion about teaching and of her love for her subject Mathematics. We found space to sit in the small, crowded departmental office surrounded by teaching resources and with a teacher's voice audible from the class next door.

\section{Background}

Amy has a Science degree in biochemistry and cell biology and had also done some Mathematics and engineering papers. After graduating she worked in the Science department at a university until she had children. During this time she worked in early childhood centres, on contracts for a university in early childhood and did some adult teaching. Ten years later, when her children were at intermediate school, she trained as a secondary school teacher and when she had finished accepted a position at her present school. After the first three years she felt the stress of working full time and having teenage children was too great and opted to work part time. This continued until 2008. However, at the time of the first interview (2009), having worked full time for that year, she was again considering applying to work part time by job-sharing: "I like the job I would rather enjoy the job, there is no point in being paid a hell of a lot more if you are tired and can't do the job properly." (In 2010, Amy was again working part time).

\section{Influences on beliefs about teaching and learning}

When asked how her beliefs about teaching and learning had developed, she said that they had been informed by her experience working in Early Childhood and by the experience of bringing up children.

Another influence has been the professional learning Amy had undertaken in her own time driven by her personal interest in deepening her knowledge of her subject. In 2009 she studied a calculus paper and in 2010 she was undertaking a Master's paper in the history of mathematics. She explained that now she felt ready to pursue further study because with more teaching experience she "had enough to hang this on."

One significant impact on her teaching had occurred when carrying out interviews with senior students as part of a research assignment for one of her papers. Amy had never personally felt the need for relevance in her own maths education: " $I$ 
never had to have a context ... I don't ever believe whinging about not having a context, I loved manipulating the numbers." She believed this was true of many Mathematics teachers. "The people that are passionate about maths teach maths and they have learnt to love it, the generalisation and for me it was about the numbers it wasn't about what I was going to use it for." Therefore, she had not considered relevance important when teaching. However, she began to reconsider her attitude when she analysed the data from her interviews. She discovered that Year 13 calculus students stated that studying this subject developed their logic and, in one case, considered it "brain gym" while the Year 12 students could not see any relevance for statistics. These results were surprising and had impacted on her thinking and on how she approached her lessons. She now planned to take the findings to a department meeting: "and go, ok, are we making this relevant and visible?"

Amy identified the greatest impact on her teaching beliefs and practice since she began teaching had been her current involvement in a numeracy project. The numeracy project had the goal of developing students' capacity to work efficiently with numbers by developing their computational strategies. In this project teachers conducted a diagnostic interview to assess students' performance against a framework, and used this information as a starting point for teaching.

What made this project particularly effective for Amy was the Japanese lesson study model of PD that was employed. In this model teachers planned lessons together, observed each other teaching and together analysed the lesson providing feedback to the teacher and planning the next lesson. As coordinator of the project she had a time allowance allocated to meet with others in her position from other schools to share experiences and work together to plan lessons. In Amy's opinion, unlike traditional PD occasions, this was a highly effective method of learning for teachers. For Amy the key aspects of the study that helped teachers to develop their skills was the support from teachers planning together, observing each other teaching and then collaboratively modifying the plans. She found that this was highly stimulating and the experience had led her to critically reflect on her teaching practice:

I don't think necessarily that before my teaching was procedural by design, it's more procedural by habit and how I was taught ... and this project changed that with the idea of, you know, giving students a wider problem and getting them to work on it.

The numeracy project had deepened her interest in how students learn, making her more aware of the importance of teaching for understanding. She now 
made more effort to investigate the current student knowledge and differentiated the learning, and believed that she now has more faith in her professional judgment in assessing the needs of her students. However, she acknowledged that not everyone in the department worked that way and was unsure if the basic philosophy of the numeracy project would become the way everyone in the department would teach: "Year 10 teachers went to all the workshops. Everyone has students where they could benefit but we haven't moved everyone on yet. Some haven't listened to what was taught last year, just taught their old way."

She believed the numeracy project was dependent on her driving it because the other teachers did not have time. Some of those involved had time and priority issues in their roles as deans and her head of department had extra responsibility being seconded to senior management.

Response to the NZC

Amy believed that her participation in the numeracy project had prepared her for what she saw as the significant change signalled in the NZC. She likened the focus of the NZC to that of the numeracy project: "having a global goal, thinking about how we are going to teach, why we are teaching it and then refining it to lesson level."

Amy believed it was helpful for students to talk to each other about their learning and did use some cooperative learning strategies especially working in twos and threes. However, in her opinion, the use of cooperative learning often was a matter of time to do it. For example some teachers had five classes to prepare for and others were deans who often found that student issues dominated their time.

Over the year there had been little process on key competencies which Amy also felt frustrating: "Key competencies well that is not something we have discussed in any detail, school or department. I have no clear plan of how we are going to do this except being involved with the numeracy project."

However, in her opinion, without all teachers having a time allowance she was not confident that the pedagogy of the numeracy project and the NZC would pervade the department. Her understanding of NZC was developing through her personal studies. However, time was again a major consideration: "People haven't got time, I'm making time."

There had been two whole school days on the curriculum and since then one departmental meeting where ideas were shared. From her observation any development in the NZC was expected to happen at departmental level and therefore 
depended largely on leadership from middle management. She did not know what senior management was doing to check if this was actually happening. The lack of professional discussion in her own subject department about teaching and learning in general, about the numeracy project and about key competencies and the pedagogy of the NZC was a source of frustration for Amy. Her frequent request to have weekly departmental meetings on these topics was causing tension between her and the Head of Department: “It's exhausting, I know, it is almost wrong, it's embarrassing to feel this enthusiastic. I feel that it is ... he rolls his eyes... it's awful, it's really awful"

Although Amy maintained the goals from the strategic plan had not been circulated, she was aware that one of them was to develop learning communities. This interested her: she would like to see a learning community, such as she had experienced in the Japanese lesson study, developed within her subject department. However, there had been no department goals developed which also disappointed her and which had affected her ability to develop her own goals based on a departmental goal.

\subsubsection{Michael}

\section{Background}

Michael was an acting deputy principal at the college. Earlier I had observed him at a staff meeting describing a project to promote students' access to dental care and encouraging the staff to support what was a project to address equity. Michael was enthusiastic about the project and had obviously invested considerable time into it.

The interview with him took place in his office where Michael sat behind his file-covered desk. Michael's teaching career started in 1984 teaching mathematics and Outdoor Education in another town. He was there for 13 years eventually becoming head of department and coming to his present position as head of mathematics six years ago. For three years he had also been seconded to acting deputy principal as part of a rotation of senior management roles scheme at the school.

\section{Influences on beliefs of teaching and learning}

The most significant changes to his teaching came with curriculum changes a mathematics curriculum in 1994, then the introduction of unit and achievement standards (NCEA) between 2002 and 2004. He considered these were the biggest things that had occurred in the senior school and that were good for students but not 
for teachers because the original administration behind the introduction of NCEA was flawed. An example of this was the refusal to allow internally moderated tasks. In his opinion teachers were anxiously trying to second guess what the moderators wanted: "The nitpicking nature of it made teachers feel anxious." That worried him because it created resistance and meant that the system did not get full teacher support. He felt it was only recently that the culture of teachers feeling personally vulnerable about their professional judgement was beginning to change.

Michael believed that these days there were societal expectations that schools would attend to not only teaching and learning but also to areas which were formerly a family's responsibility such as attendance, bullying, and obesity. He considered teaching invoked a greater emotional investment than most other jobs and that this could be draining for an individual. Unlike other jobs, the boundaries were not always clear; in order to have a relationship with students you had to engage with them - he questioned what was a professional level of engaging with them compared to not engaging with them and how did you deal with it? Teachers: "have a blast of interactions with kids and adults, then another period ... On the whole teachers are carers; there is this strong idea that the person who has the most effective teaching is the person who cares about them but this takes a toll. If you have other issues going on in your life - It's hard to step back to the non-engaged role." He saw a tension between teachers becoming on one hand more technical, and on the other expected to develop warm relationships with the students.

Response to NZC

Michael did not believe the new curriculum was needed, stating: "I didn't see the roof leaking. I hadn't seen that we need something to pull it all together." He did like the fact that it specified what it meant to be an effective teacher. However, he does have reservations. While he agreed with the descriptions of effective pedagogy he expressed concern that some elements may be left out: "It's good; you have to agree with what is in there - but what isn't there? It's the intangible things - when we try to specify the intangibles they disappear."

Michael had responsibility for leading the implementation of NZC in the school. He explained that at the moment they were doing a stocktake of what people are doing and looking at the relevant websites. He believed that you cannot tell people what to think but you can expose them to what others think. There was a committee with responsibility for leading the implementation but no-one felt confident. 
After this interview Michael did not answer several emails seeking a time to observe a lesson, and appeared to avoid me when I visited the school. I inferred from this that he wished to withdraw from the study. He did not continue in the research and no lesson was observed. However, he did acknowledge the transcript of the interviews and the key themes when they were sent to him for verification.

\subsubsection{James}

James and I met in a busy office he shared with other deans. Throughout the interview other teachers came and went and students interrupted asking him for advice. James was gracious to everyone, apologised to me, but pointed out that this was the nature of his job.

\section{Background}

James grew up and was educated in Fiji. He described his own formal education as being a very traditional transmission model with very little student involvement. However, he had fond memories of more informal learning in the village: "I love to just sit in a circle and chat it was my experience of learning cultural things back home ... how trade skills were learned."

After completing school, he planned to study medicine. However, his father and the village chiefs decided he should study economics and agriculture after which he would return to Fiji and work in the government. He obediently came to New Zealand in 1980. By the time he had finished his degree he felt able to stand up to his father and elected to stay in New Zealand and work in foreign exchange for a bank. This was not satisfying work and he was attracted to an advertisement for teaching. Eventually, in 1987, he won a scholarship for initial teacher education.

\section{Influences on beliefs about teaching and learning}

James maintained that he did not remember teacher training involving much theory about teaching and learning but was focussed on curriculum content followed by being put in a classroom and being expected to get on with the job. His first teaching position was at what he describes as a "traditional" school and similar to what he had experienced in his own education in Fiji: "Mostly chalk and talk. It reminded me of home ... turn to page ... Smith stand up."

Although he did attempt to do some group work and use different techniques, he believed that the environment worked for him as a beginning teacher finding his way and, because at the time he was quite deaf, he felt safe in a traditional model in which he was in control. A subsequent operation resulted in an astonishing $700 \%$ increase in 
hearing. This outcome gave him the confidence to explore other ways of teaching: "it revolutionised my teaching." After two years he was approached by the principal of his present school to be head of a department. His initial reaction was that he was too inexperienced but he also knew he did not want to stay in his present school feeling dissatisfied. Looking at the teachers who had been there for a long time, he thought that they had reached a stage where they did not have the courage to move on: "they were scared to leave and I realised that I didn't want to become a frightened teacher."

In 1992, with his wife and four young children, he returned to Fiji for three years feeling that, after the coup he wanted to give something back to his country in its time of turmoil: "So I wrote to the Minister of Education and said I want to come back home so put me in a job anything you like, I'll take anything." The Minister obviously took him at his word; he was appointed to a position in a boys' military feeder boarding school in the bush. This was a dramatic change: moving from a coeducational school with a class of six Year 12 students to a single sex school with a class of 69 boys. Soon after his arrival, when a teacher left and was not replaced, he took on an additional workload unimaginable in New Zealand, teaching one class of 56 and another of 69 simultaneously. His response to this challenge was to develop creativity with his pedagogical approach. He split the class into groups of 10 and selected the 11 brightest students:

I would say right guys this is what we are doing today. I would teach them and then they would teach the others and then I would go to the other class and for 3 months there was no other teacher.

This experience taught him that, if they are provided with a supportive environment, students are able to drive their own learning.

Response to the NZC

James believed that there were a lot of things in the new curriculum which he was doing anyway. For example, he wrote a key competency in his plan book but did not give it deep thought or share it with the students. He was hopeful the changes in the new curriculum would benefit the students and had discussed the key messages within the document with the other deans. However, referring to his other responsibilities he wondered if he needed to reconsider them in order to plan and teach as suggested in the effective pedagogy of the NZC: "it comes down to time pressure-especially the last couple of years. I need to give up some things to do that effectively."

James believed that students brought valuable ideas to the class and that in some ways his intervention was an interruption. He also believed groups made 
learning happen and did use groups but admitted because of time constraints he probably did not teach that often enough. He had experimented with co-construction and was encouraged by the results. However, he believed there would need to be time made available for a change in pedagogy to occur across the school. There was also the issue of external pressure and outcomes-based assessment which he believed created tension between results which are published in league tables, and effective pedagogy.

For this to be the dominant pedagogy I think it will be finding the time to prepare - and it's still outcomes based - you have got that tension and the way, worry a bit, the Minister starts talking about league tables, and I think gee if you are going to go down that track - I think it's about how to marry the two um, use this form of pedagogy with getting the results I worry about that. Do I think the benefit will equal the effort? That question says a lot about me.

He appreciated the need for accountability and the feedback that an external eye such as ERO can provide. However, he believed that teachers do not get the acknowledgement for the good work that they do and can be judged as inadequate by the public when league tables are published.

For James, teaching was essentially an emotional investment. He maintained that learning should be fun for students and that the definition of learning should be wider to include more working together. He struggled with the education system believing that with the pressure to meet the assessment requirements of NCEA, coverage was too dominant. His preference would be to teach less and to give the students more responsibility for their learning. He did attempt to work in that way with juniors while managing to comply with the college common test regime by setting aside a teaching spell to prepare the students. However, with the pressure of NCEA he did not feel that he could work this way with the senior students.

\subsubsection{Mary}

\section{Background}

Mary and I met in a corner of the busy staffroom during her non-teaching period. She was enthusiastic about teaching but spoke of her determination to ensure that it did not take over her life. Mary brought a broad range of qualifications and experience to teaching. Her undergraduate degree was in product technology. She believed this background made her more flexible and she could find the links between mathematics and other subjects especially science and technology: "I'm not here because I love maths, yeah I like maths, but I'm here because I like teaching and I want to teach, not because I want to teach maths but that's my way of doing it." 


\section{Influences on beliefs of teaching and learning}

After university Mary had varied working experiences that exposed her to teaching and learning. One example was working as part of a team teaching part of the Health and PE curriculum in different secondary schools. In retrospect she believes her teaching had been influenced by the programme's holistic approach involving building values and morals and supporting the students in the decision making. Another was working as a training manager for a computer company. These experiences stimulated an interest in a teaching career. Mary explained her motivation: is "because at the end of the day when a light goes on or a kid walks out and says I really enjoyed that today or says I just feel like I've learned lots, there is a sense of that's what I am here for."

Response to the NZC

During the interview Mary expressed excitement for the holistic approach of $\mathrm{NZC}$, was pleased that the vision and principles were made explicit in the document, and supported the concept of embedding learning in key competencies. These elements were a fit with her espoused approach.

However, Mary admitted that she herself was struggling to understand how to teach in the way that makes the key competencies explicit for the students. Her way of coping was trying to model key competencies in the classroom. She believed that the rest of the staff were also confused to varying degrees by how to integrate key competencies, by the rationale and their potential effectiveness.

Mary was involved in an integrated programme which involved teachers of Mathematics, Science, English and Social Studies planning together and working on a common theme. This is a model supported by the NZC concept of de-siloing subjects and making the skills transferable to all disciplines. It was an initiative introduced and strongly promoted by senior management: "It's a philosophy that trying to come in from the top.... It's a huge structural and time table issue to try and push for us to have time to collaborate those lessons a bit more together." In 2010, the staff were learning how to make it work with some topics being more successful than others. While she found it difficult, she did feel it was a move in the right direction and that the concept would be clearer as a common understanding of what they were trying to achieve was developed by staff.

However, despite her support for integrated studies Mary did have a reservation: it was possible that with a focus on linking skills to other disciplines, which she often felt were superficial, there would be gaps in her students' 
mathematical understanding. This could possibly make them unprepared for NCEA assessment when they reached the senior classes:

And I have found this already with some of my year 12s, they haven't done geometric properties and they are missing out on the understanding for merit and excellence questions because they haven't got some of that understanding from earlier on and that's a difficult problem.

Mary was able to link some aspects of the NZC effective pedagogy with her learning in the Diploma of Teaching course. She described the concept of zone of proximal development and maintained that she tried to provide feedback for students and advice for their next steps. While she regarded this as good practice, it was a challenge for her because of the number of students in her classes. She also felt frustrated by the expectations of the school leadership for other initiatives: "I think there is I guess a sense sometimes that those that are not fulltime in the classroom are at times coming up with these great ideas but not actually replacing what they are adding."

One of these initiatives was a school-wide requirement for teachers to support students in setting learning goals for each subject and to have the opportunity to reflect on them, a strategy which links to the effective pedagogy of the NZC. Mary supported the idea but believed that while setting goals around a simple task, students needed a great deal of support to create meaningful ones: "I think we've lost, or not given this the scaffold really to get there for some of the kids. We expect them to just be able to write a goal and it is not easy."

In addition to the goal setting initiative there was also a directive for teachers in the integrated studies teams to teach essay writing skills and they had been provided with a three lesson structure to do this. Mary was worried that on the one hand this was outside her area of expertise, "we are expected to be competent in far more areas than what we have been trained for," and on the other that these lessons would take away time from her mathematics teaching leaving her unable to cover the curriculum.

When she thought of the need to differentiate her class's work, to cater for different learning styles, incorporate key competencies, encourage students to set goals and to reflect, to provide feedback and feed forward, plan for the integrated studies project and teach essay writing, Mary felt overwhelmed stating:

The matrix is definitely not two dimensional ... it's not even three dimensional, it's more like six dimensional ... I do my best but I know I don't do a lot of it well because I'm ... I can't do that many things all the time every time. 
This affected her confidence in her ability and battered her self-esteem, something she believed other teachers shared.

\subsubsection{Nina}

\section{Background}

Nina spoke rapidly, exuded high energy, and expressed confidence about her teaching. We met in the staffroom in her non-contact period between classes. On completion of her Diploma in Teaching, Nina taught for two years at a low decile school where she had been a student teacher. This was a very challenging environment but she described it as: "the best two years of my life. It was amazing, it made me become a better teacher, because you had to."

She had found the first year of teaching "hard, really hard, particularly one class of 34 Year 11 boys." In particular, she struggled with effective classroom behaviour management. In her second year, seeking a way to improve her skills, Nina eagerly took part in a course on controlling noise levels in the classroom. She was highly motivated because she had recognised significant gaps in her skills and was looking for a way to address them. Using the strategies she had learned made a significant difference to her teaching and as a result, her second year was more manageable. Gradually Nina's classroom management techniques developed to the extent that she became a designated mentor for other teachers. This involved observing other teachers in the school, giving them feedback and helping them with their classroom management skills. The experience of mentoring other teachers led her to believe that this is the way people learn new strategies:
I think they need to believe in it first, maybe they need to see it work to start with and then I think it needs to be done in a practice sense. You can't just say this is what you can do, try it. You need someone there to follow up and say, well, you are trying it but maybe tweak it a little bit and now try it again because otherwise it's just another piece of paper with the other six I have just got in a pigeonhole.

\section{Influences on beliefs of teaching and learning}

Looking back at her own education Nina felt she had not been acknowledged: "You know, I sat in there, I did all my work, got no appreciation for it - because you are the invisible good girl, exactly, and it wasn't until, oh, I'm really bored and you play up - BAM, attention!" She had some good teachers but hated going to some other classes because "I knew I would sit down, either get bollocked for doing nothing or just be bored." She also felt frustrated that she had very little say in some classes and she queried why student voice and opinions could not be heard. She was 
determined to recognise the students' role in her own classroom and was delighted when students were eager to come to class and try their best: "after a lesson they will come up and one Year 9 goes Miss, I think I'm going to be sick, I haven't run and played so hard in my whole life. I was like, great! He said, I have had so much fun and I used to hate this subject."

When she started teaching she made a deliberate effort to be positive: "I would stand out and greet all the kids and stuff and they would say like, I'm so happy to come here, you're positive, you never growl." If an issue arises she will discuss it with the students and make sure the expectations are clear and tell them: "If I do get grumpy it's because my expectations haven't been met and you are the ones that need to meet that so obviously you didn't manage yourself properly today, that is why I'm not as happy as I would be." She believed that learning should be positive and exciting and that the students should have ownership of what they do in their lessons. She had also noticed that some teachers "are grumpy all the time and always saying, you are not doing this, you are not doing that." She maintained that she does the opposite, praising everyone and not giving any attention to negative behaviour. She puts on a "smiley face' and instead of recording the names of misbehaving students as many teachers do, she invites those who are working well to write their names on the board: "They love it, love the ownership of putting their name off, they can come off so they have to be consistent but ... you know ... positive people deserve the attention, not the other people."

Nina maintained that she was very organised and wrote all the steps on the board:

You know, this is our aims, this is our focus, this is how we are going to do it, boom, boom, boom so if I need to deal with something like that just look at the board, Oh number 4 - done.

Response to the NZC

Nina believed that her work over the past years in her subject curriculum had prepared her for the NZC. This curriculum introduced in 1999 emphasised the integration of what was referred to as essential skills similar to the key competencies of the NZC. From her point of view this had been the case in her subject for a long time but that it had not been made explicit to the students. Now she connected the learning to the key competencies, told the students what the key competency was and constructed with them what it would look like and how they would do it. At the end of the lesson they reflected: "ok so this is what I did, yeah I probably could have 
done that a little bit better but then they are still linking it in with maybe basketball at the same time." In Nina's lessons the learning is the key competency and the topic is the vehicle in which it is learned. She considered her curriculum a fit with NZC pedagogy and that the teachers of her subject would find incorporating key competencies easier than other subject teachers because "we are accustomed to it."

Her focus has changed now from a focus on, for example, basketball, to a focus on a key competency. Students will train each other and reflect on how they used their interpersonal skills, how to train, how to instruct. They record their aims for the lesson in their learning journals at the beginning of the lesson and reflect on their progress at the end. This is the pattern in all her lessons and the students appear to appreciate it: "one kid said, Miss we have done more work in our one hour a week than we have had in subjects that we have for four hours. I have learned so much ... we know how to answer NCEA questions you know, what specifically they look for."

She was aware that the concept of student ownership was a key aspect of NZC. Nina had made a conscious effort since halfway through the year to involve the students more in the lessons:

I had, I think, 62 students down on that concrete part playing four square. They were coaching themselves, they were reffing, they were scoring, they set it up, they did the draws. I basically sat and I took photos and filmed them.

She said that the students loved it and came away knowing not just how to play the game but many other things as well. They were able to describe what they had learned in the reflection time at the end of the lesson. This demonstrated to Nina how much students can do and reinforced her conviction that it is important to have high expectations of students: "we can't just spoon feed them."

Nina believed that it was important that students learn how to learn and they will do this if they have ownership of their learning and learn the process as well as the end product. For this pedagogy to be embedded in the school each teacher has to make it a focus, not just a token gesture:

You need to be able to identify are you teaching it? Have you taught it? How do the kids know? So if you go into a lesson and you say, you know, what are you learning? They should be able to go, well we are learning basketball but at the same time we are learning to manage ourselves and we just ran a tournament and we had to set up all of the things for ourselves so they are learning two things at once and that's the hard thing but it needs to be so specific that they can see and that's why at the end of lessons the reflection part is so important. They need to be able to go, yeah I did manage myself today, this is how I did it. 
The ability to describe what learning has happened and use evidence to support your answer is a merit level in NCEA. Nina points this out to the students even at Year 9 level.

However, she acknowledged that teaching is individual and for a teacher to teach this way they would have to see the benefit of it and realise they cannot just be a subject teacher but teach key competencies as well. There has been some whole school PD on the NZC which some people were positive about; some who had been at the school longer wanted to continue teaching as they always had, and others were struggling but still wanted to try it. Nina felt that this was understandable; teachers are the same time trying to plan, mark work, and manage their classes. In her opinion teachers needed to master one thing at a time. A positive learning environment should be their top priority. She believed the staff needed more PD on the key competencies, watch someone do it, have the opportunity to practise and to get feedback. Some people: "put a wall up" because teachers were asked to do so many things. However, Nina maintained that, despite the busyness of the job, she continued to be motivated by her love of it and by her desire to make every lesson a great one.

\subsubsection{Joseph}

\section{Background}

Joseph and I met in his small sports equipment-cluttered office attached to the gym. He was relaxed and open about his views of teaching, admitting that when he undertook his Bachelor of Education he was not really concentrating on his studies: "I was unfocussed, not that interested in teaching - I was there to play sport, enjoy the booze culture. While he believes he learned "good stuff "about learning, it was not until he stared teaching himself that he began to consider how students actually learn.

\section{Influences on beliefs of teaching and learning}

Early in his career Joseph worked overseas for four years in a wide variety of subjects: "secondary drama, woodwork, physical education, food, relief teaching, take your pick". In these roles he often had challenging classes ("never taught academic kids") with wide ranges of ability and in many cases, with English as an additional language. These experiences impressed on him the importance of building relationships and of finding ways to engage students. Developing rapport with the students is now his priority: 
First thing is getting to know them, them feeling safe and secure is a big thing.

I have to get that rapport working, get to know everybody's name and then

from there, if they are comfortable, it's got to be clear, simple and obvious.

He has been in his present role for the last three years and looking back realises that over this time he has begun to think more deeply about how students learn. He has found that students cope best with "smaller simpler chunks of stuff that they can get more success out of."

Response to the NZC

Joseph was positive about the NZC focus on students being more involved with their learning. In the subject he is currently teaching, physical education, there had been a focus for some time on the key competencies although it had not been made explicit to the students. It was therefore not difficult for him to consider incorporating them into all his teaching. He showed me how he had written the key competency in his planning. His plan was to write the key competency involved in each lesson on the whiteboard so he would remember to include it in his day to day teaching:

This is a directive from the top. I will follow orders. I agree on the focus on key competencies. There was a strong push at the end of last year and this year and all our unit plans have to include covering a key competency.

He believed that even if it did not continue to be a requirement from management he would still have a learning intention because it was helpful. He could also see the relevance of key competencies as necessary for the students' futures and believed that incorporating a key competency would become a natural part of his teaching practice. In his opinion, which he had shared with the students, these adaptable skills would be more useful than having knowledge which will change. His challenge was to teach them more deliberately.

Joseph believed co-construction fitted with his beliefs about teaching and planned to continue working towards achieving it. So far his efforts had been time consuming: "Constructing with the students yesterday took half an hour trying to sort it out" but he intended to persevere.

His current challenge was finding a way to address the needs of some senior classes that found written language difficult. He has just assessed their first topic and realised he would need to concentrate by meeting the vocabulary needs of immigrant students so that every student would be able to attempt NCEA assessments. While in Joseph's classes there are several students with learning difficulties and some who often truant, he enjoys teaching them "all sorts of different aspects ... but they are fun." 


\subsubsection{Jill}

\section{Background}

This was Jill's seventh year of teaching and her second school. It was her lunchtime so we decamped to a nearby cafe to eat and talk. On reflection, Jill believed that she went teaching because she saw that teachers could influence people's lives and because she felt some students were missing out. "I didn't realise it at the start, you realise when you look back in it". In her third year of teaching she volunteered to take part in an assessment to learn project (ATOL) which focussed on formative assessment. When asked why, she said that trying to make learning better for students was harder than she had thought: "I guess it's a feeling things aren't right so you see something may be a possibility here and having the motivation to seek it out" Jill described this project as: "raising the red flag - an initial glimpse of what it could be."

\section{Influences on beliefs of teaching and learning}

The ATOL project, in which she was observed and given feedback from an external facilitator, helped her begin to understand formative assessment and she now believes that was when she started to see teaching as being more than coverage of a subject. However, when the project finished Jill still felt dissatisfied with her classroom practice: "I was still confused about the idea of formative assessment ... how do you do it?" An opportunity to become part of another project focussing on the needs of special education students presented itself. This time the project included time out of class to interview students and parents and to plan. Looking back, Jill considered this second project to have had the biggest impact on her beliefs and her practice:

I thought oh my gosh, when you have to listen to students and look at samples of students' work, and understand what you are looking for, I had to sort of learn what am I looking for in their work and you think, oh they haven't done learning, which is a reflection on me and you have to find your baseline and the students' baseline and you don't know.

While whole school professional learning provided in the school had given her examples of strategies she might be able to use, there had been no time provided to think about them. The fact that this project gave her time to do it, to go slowly, to do it properly, reflect on it and included an outsider coming in and "pointing you in different directions" allowed her to think deeply. Jill maintained that "professional development without the opportunity for deep thinking doesn't make a difference to your teaching. We need to be looking for a way to make a difference." 
The following year Jill enrolled in an action research Master of Education paper investigating effective pedagogy for Māori students. In this paper, in which she researched her own class, she was mentored by a lecturer from the university: "she had a huge influence ... it was a two way thing. It really helps to have someone like that alongside, someone from outside the school."

She followed this experience by applying for, and being granted, a year's study leave to complete her Master of Education: "that gave me the theoretical understanding of what was influencing what I am doing now ... I became aware of the why. It was nice to have the pressure off, real nice." While she was studying, Jill worked part time as a facilitator in the ATOL project. This involved visiting a range of schools, observing teachers and providing support and feedback for their learning. Visiting classrooms she noted that while there was more emphasis on meaningful discussion to deepen student understanding, the teacher still dominated the talking in the class. It is her belief that teachers continue to teach in a teacher-centred way because they feel more in control when they are "in charge" of the classroom.

Response to NZC

Jill subsequently moved to the school where these interviews took place. While always seeking to refine her skills, she was confident about her understanding of the NZC having been involved in exploration of the draft iterations in her previous school. The incorporation of key competencies and the effective pedagogy resonated with her because it described how her own teaching over the years had developed. She therefore perceived the document as validating her practice. In her subject department she had been leading the PD. This was because the Head of Department was still developing his understanding of the incorporation of key competencies, the effective pedagogy, and the focus on process rather than product. The feeling of the department was that the rest of the staff, all of whom were taking postgraduate papers, had a greater understanding than their head of department. Jill could understand why heads of departments found it difficult to keep up with pedagogical developments given that they had significant and time-consuming administrative responsibilities.

At this school there was minimal whole school development with departments developing their own understanding of the NZC. Jill believed that there was a need for a common vision of what the NZC would look like but was unsure that the leadership had a deep understanding of it: "what we need is an expert." It seemed to her that the culture of the school presented a possible barrier to a coherent 
approach. The school was proud that individuality was a point of difference with other schools. She questioned:

How can you form a school identity project wise, when the culture is one of individuality? There is no commonality of how you approach things or do things, everyone was doing their own thing, no bringing it back and sharing it, all doing great things but it was individual.

In her opinion, the best professional understanding was achieved when staff worked in small groups and shared their experiences of trying the new concepts, what worked and what did not and observing each other. However, it appeared that staff were often resistant to observations, because for many their only experience to date of being observed had been for appraisal purposes. She maintained that they needed to understand this is a way for the observer to learn, not a critique session.

An exception to this was her integrated studies group. She was finding the planning and discussions with a group of teachers working on the integrated studies for Years 9 and 10 encouraging. Teachers were open minded and willing to share ideas and experiences. However, there was still the challenge for teachers to make a shift in their perception of their role: "to be truly integrated that pressure for coverage would have to come off and I don't think that teachers want to ... they don't see themselves as teachers of skills. They see themselves as teachers of a subject." In some cases teachers were feeling pressure from their heads of department to cover the curriculum to ensure the students would be prepared for NCEA assessments when they reached the senior school.

Although ideally everyone wanted the NZC to be quickly embedded, Jill was sure that it would take a long time and require trial and refinement. For teachers to understand the implications of incorporating the key competencies and embedding the effective pedagogy, she believed that they first needed to carefully read the document and think about what changes were needed. For change to happen in a meaningful way Jill maintained that a teacher needed to next feel some discomfort with present practice and to look for a way to make it better. However, she appreciated how busy teachers are and acknowledged that her understanding is the result of her private study: "Writing, literacy, there is a lot on at this school ... I didn't really realise how much I am always doing things on the side but for others who just do what they have to, it's hard." In addition, she was aware that achieving good results in NCEA was very important to the school and to the community: "even Year 9 s are getting ready for NCEA, it can be a pressure." 


\subsubsection{Ruth}

Background

Ruth and I met in the small meeting room off the school foyer. She was a thoughtful woman who had a lively interest in all educational developments, describing herself as a "nosy cow." She had been teaching Science for 16 years with a year's break for each of her two children. Initially she started her career as a chemistry teacher but an accident in her first year of teaching resulted in a spinal injury that has permanently affected her coordination and made her question her safety working with chemicals. As a result, she worked part time and specialised in general science for juniors and seniors. A positive outcome of working part time is that she felt she had more "head space", time to think more deeply about her teaching and to pursue her educational interests through further study.

\section{Influences on beliefs of teaching and learning}

When Ruth considered the events that had impacted on her beliefs and practices she believed it was the interest her secondary school teachers took, not just her academic ability, but in her as a person that gave her the confidence to go to university. This made her realise the importance of building positive relationships with her students:

I felt it was really important for the whole student to be considered not just academic progress. Even if they couldn't academically succeed at the subject they could come in and feel accepted as people and a right to be there and that they were going to have fun and they were going to be respected - so that's always been a key focus for me.

Ruth has always been interested in ongoing learning, describing herself: "I'm somebody who really likes to be learning more and I hate the thought that somebody knows more than I do about something." In her own time, in her sixth year of teaching she completed her Higher Diploma of teaching:

I did some health, and I did one on relationships and a big one on science teaching and a big one on cooperative learning so it was really quite a broad spectrum of things and what I found useful was actually training alongside primary teachers.

Doing these papers made her realise there was a much broader role for teachers to play and also made her consider how she learned and how other people learned. In retrospect she realised that she had entered teaching seeing learning as: “cramming knowledge into their little heads. Pedagogy? I don't think that existed when I went to Teachers' College, we certainly didn't hear about it'. 
The most significant impact on Ruth's thinking about learning occurred when she had a daughter who exhibited learning difficulties. At about the same time she was asked to teach an alternative science class: "that's for our really low proficiency learners and the first year it damn near killed me."

Both these events motivated Ruth to find out more about learning difficulties and she subsequently studied a Diploma in Special Needs online in her own time. These papers involved working with a range of learning needs and disabilities such as Autism and Aspergers syndrome followed by another study of gifted and talented students. The latter encouraged her to learn more about differentiation. She acknowledged her broad background of study is unusual in a secondary school: "Really uncommon for science teachers, I think, to look at such broad things but for me that fitted right in."

As a result of her range of knowledge and experience, Ruth was at the time of the interview, a specialist classroom teacher, supporting other teachers in their classroom practice.

Response to the NZC

Ruth felt that her beliefs about teaching fitted with the effective pedagogy of the NZC. She believed that it was very important for the students to become independent learners which cannot happen if the teacher always controls the learning: "We always have learning outcome sheets at the start of the topic and so, you know, today's lesson is learning outcome number three. We have the learning outcome and then what does this look like?" She asks the students to reflect on their learning, self-assessing it against the success criteria and following up those who are confused.

At the start of the year, with her junior class (Year 10) she asks them to decide what their learning goals should be:

Some of them have I want to get excellences and for some of them it's I want to pass a test. We have a system in the department where after the assessment we feed back, the kids get a feedback sheet that says whether it was an achieved, merit or excellence and then the space for the student to fill in what they need to do to move up to the next level.

Ruth had been involved as part of the team writing the new science curriculum which also took into consideration the vision, principles, key competencies and effective pedagogy. She was positive about incorporating the key competencies seeing them as a way to look at the whole child and particularly useful when writing reports for parents: 
For so many kids it is so good to be able to comment that their selfmanagement skills still need development or that there is this aspect of their communication. I find the key competencies incredibly useful for juniors in terms of the overall view for report comments and progress.

While she felt the philosophy of the NZC would:"percolate through" the staff in time, there were, in her opinion, still many teachers who saw teaching as a transmission of fact.

Ruth welcomed the NZC; however, she did not see how it could be fully implemented in New Zealand with the present structure:

Look, I just can't see how we can do it properly in NZ. I get really quite upset ... I don't care about a pay increase but if we could only have smaller classes, I can't see how we can truly implement the new curriculum where we look at outcomes for all learners with the class sizes we have.

She would love to have the time to sit down with her Year 10 students individually and help their learning but it just was not possible. She believed the job had got busier and busier. Attending to the leaning needs, emotional needs, and social needs of the students was like "uber-parenting" and as a result teachers were exhausted.

\subsubsection{0. $\quad$ Edward}

\section{Background}

Edward and I met in the same meeting room where I had met Ruth. His eight years had all been at this school which he attended for his secondary education. He was head of a department, involved in training other teachers in Information Technology and teaching in three subjects. Thinking back, Edward believed that the idealism he entered teaching with had been: "not lost ... but balanced by pragmatism and I think that process sort of started halfway through Teachers' College really." He realised that he was not necessarily learning how to be the best teacher but learning how to be a teacher within the New Zealand system: "I think we do an ok job but it's always a compromise job". He remembered that he had observed a model of teaching that represented his original ideal when he visited a small alternative school. In that school, where the approach was student centred, the young people could develop their own learning pathways and engage with the community. Sadly he did not believe that was possible in a large state school.

Influences on beliefs of teaching and learning

Thinking back over his teaching Edward identified two "aha' moments. One was becoming a parent: 
I think it's made me a better teacher, it gives me a greater empathy for students, parents and all that sort of stuff and teaching your own child and the patience you need for all that to kind of apply that to toddlers and teenagers, not that far removed.

The second significant moment was when he handed back marked work and asked the students to raise their hands if they were surprised by their grades. Only three hands went up. This response led him to question the value of the comments he had made on their work:

Why do I write a 2 or 3 line comment that says you did this, you didn't do this, your work has neatened, good punctuation and stuff - they know if their grammar is good, they know if it's neat, they know if its messy so all those sorts of things.

This made him realise how aware students were of their own achievement, and that, provided they had a clear marking schedule, they could self and peer assess. This gave the students a greater investment in their own learning and also allowed Edward to focus on those students who needed guidance to move from a merit to an excellence standard of performance. He liked to encourage a learning community within the classroom with students taking more responsibility for their learning: "You don't teach someone to drive by sitting in the back seat - have to hand it over to them."

However, Edward's beliefs were tempered by timetables, the size of schools, teacher engagement, what he considered a disappointing lack of parent engagement, indifferent student engagement, challenges of resourcing, and the fact that he had the students for only four hours a week: "You do as much differentiation as you can, take this to a bigger idea but still you've got a syllabus to cover, you have got certain content that you need to get through."

Response to the NZC

After reading the NZC Edward maintained that it sat comfortably with him and that he was "a fan." The theory underpinning the effective pedagogy of the NZC appealed to him, reminding him of what he had seen in the alternative school. On reflection, he believed he would have personally benefitted from a student-centred model in his own education. However, he felt there will always be a compromise in mainstream schools because of the teacher/student ratio. Another limitation was the pressure of the national assessment system. For example, in Year 13 students sit a content exam: "and still I think in some ways the quickest way of getting through stuff is the transmission theory." There were changes in the external assessment mooted by NZQA that may provide more flexibility but at the moment, in his opinion, coverage was a dominant issue for senior students. 
He was concerned that student-centred learning, for example, giving students a choice of topics, may result in the loss of cohesion and that sometimes: "an adult knows best." He considered that social constructiveness was an effective model for some things but it meant that students did not necessarily get in-depth knowledge about the topic. To counter this, in his practice, he bridged the "guide on the side" and the "sage on the stage" models believing they both had their roles and purposes. He saw the teacher's role was to build positive relationships with the students, engage their interest, set the scene, and say why this was important to learn: "sort of fire them up". If there was a positive relationship between teacher and student he found the students wanted to do well because they liked the teacher and they wanted to make the teacher proud of them.

Edward was fully supportive of key competencies; his only concern, from his perspective as head of a department, was whether teachers were incorporating them effectively or just in a token way to comply with directives. While some of the key competencies may appear to be obvious in usual classroom practice he believed they needed deeper consideration:

You look at thinking for example, and think "well, of course we do that' and actually there's probably heaps of classes where that doesn't happen as thinking as defined by the curriculum, that cognition of reflecting on your learning and applying it to new situations and making that explicit in your classes. So I think that's a really important one.

Edward believed that the structure of schools militated against fostering the love of learning in students:

Fundamentally I think that humans really love learning and kids really love learning and that love of learning seems to slow down for many kids about age 6 or 7 - the further they go into school ... just the fact that you are stuck in a timetable, that you are learning at the same pace with 25 other kids or whatever in your classroom and there's not a huge amount of flexibility.

In his opinion, educationalists may be passionate about learning theories but appear to ignore or accept and fail to question the basic structure of schools. For Edward himself his goal was to work out ways that he could be more efficient, saving his time and making the learning better for the students.

\subsubsection{Susan}

\section{Background}

Susan and I met in her classroom in her non-contact period. She was very interested in this research and eager to share how her skills were developing. Susan was in her fourth year of teaching having completed a Graduate Diploma in Teaching after working for some years in the banking industry and having a family. 


\section{Influences on beliefs of teaching and learning}

In her first year of teaching Susan felt concerned that in her classes there would be one or two students who had low literacy scores and as a result struggled with the work. Having a wide range of ability in her class Susan felt she was unable to give them the support they needed. This concerned her: "that was what made me think there has to be a better way of helping these kids get established at school so that they can have some success at school." The next year she chose to be part of a team teaching initiative. This helped her move from task sheets and marking schedules to a greater understanding of learning and effective pedagogy. The two team-taught classes each had within the class a group of targeted students chosen because they had been diagnosed as having learning difficulties or had a low score on their entry literacy test. Their Science, Social Studies and English teachers worked together with learning support teachers to discuss strategies and to plan the units of work. This had made a significant difference to Susan's beliefs about teaching and learning: "a lot of how structures and strategies that we put in place for them are very much part of the ideal pedagogies that you would hope that all teachers will use."

She believed that teachers could learn a great deal from each other. Some people were more open to this than others who preferred the isolation of their own classroom but she had found when teachers got together to plan a programme they had more opportunities to make the relevant links for students that enabled them to transfer their learning across disciplines.

Teachers volunteered to be in team teaching and each year different teachers joined the initiative and at least half of the team teaching staff changed. Susan described this as: "spreading the love." There had been attempts to involve other members of staff in sharing ideas. An example occurred at the start of the year when all the core teachers of every Year 9 and 10 class met for an hour for the purpose of discussing strategies they could all use, but the size of the group and the limited time meant that they did not manage to move past sharing complaints about students. Susan believed that introducing more effective pedagogy was a big step for some staff who were satisfied with their teaching and preferred to keep teaching the way they had always done. Ideally she would have liked all English teachers and other departments to plan more together and develop a content map and subsequently be able to complement each other's teaching. 
Response to the NZC

There had been two teacher only days when the staff explored the NZC with specific time for unit planning and for discussion of the key competencies. In addition, at the start of the previous year all the staff, with the exception of the team teaching group, had PD once a week discussing how the NZC would impact on the school, working on the different sections, considering the meaning and how unit plans could be appropriately adapted. Because the team teaching group had their meeting at this time they could not be involved. She thought some people's reaction when they read the document was: "oh good, I'm already doing that or we are on the right path, we'll just keep going."

However, she believed that the staff found that the NZC did offer more flexibility. The teachers now felt they were free to decide on their learning outcomes and choose resources to support the learning. Many staff now felt they could teach less but explore the topics in more depth. For example, the English department, believing they assessed too much, had decided "to teach fewer achievement standards but do a richer job of teaching them."

Susan had been thinking how to explain the key competencies to the students. While they underpinned much of the work and were ticked off in the unit planning, it was not made sufficiently explicit to the students. Key competencies were evident in much of the work Susan described: team teaching staff co-constructed goals with students, most of which were derived from key competency skills, and students evaluated the social skills when working in co-operative learning groups. She saw the next step was to make all the students more aware of this.

One aspect of her teaching particularly concerned Susan. This was the distinction between the way she approached teaching in the junior school and the senior school. In the junior school, after working closely with learning support teachers, she thought more deeply about how the students were learning and employed the effective pedagogy as described in the NZC: "now I've got lots of steps in between and scaffolds and practice things and peer assessments and portfolio reflections and all this stuff so that the kids have a path to get from here to here." However, this was not the case with her senior classes:

As a senior teacher I feel that we are sometimes graded on our classes pass rates for NCEA and what I know I need to do to get kids to get 22 credits is teach them to jump through hoops and get them to write a formulaic essay. 
She did use group work in her senior classes but the outcome was very much focussed on how many credits the students would achieve. This frustrated her: "sometimes I want to throw away the essay structure and ask what they really think." In addition, although she was aware that the philosophy of NZC was that students should be able to follow lines of enquiry, the NCEA assessment schedule was tight and prevented the exploration of areas of interest unless they were included in the assessment task. This created tension for Susan: "on the one hand we want everyone to be really innovative and creative and visual and all the sort of things, but the restrictions for seniors are just so ... yeah black and white."

Susan described an experience of effective PD when the whole school was focussed on cooperative learning. In this programme, the staff would have a strategy demonstrated, be asked to use it during the following week and in the next session report back. In addition, teachers would take turns to model what they had done in their classes. She believed that this model created an environment where everyone could see what others were doing and she felt well supported in her learning. However, the work in the team teaching classes had been of greatest benefit to her. She had an interest in developing her skills but believed she would not have had an opportunity to see effective pedagogy being used without her involvement in these classes working with the learning support teachers.

\subsubsection{Christopher}

\section{Background}

Christopher moved to New Zealand in 1997 from North America and had been at this school for 11 years. We first met in a science laboratory. Unfortunately my digital recorder malfunctioned and therefore this report is a combination of what could be salvaged from the first interview and the second held in the busy science department office. Christopher was a highly reflective, earnest person. He supported the holistic philosophy of the NZC and believed that students need to be critically aware, know how to access information, evaluate it, and know how to use it.

\section{Influences on beliefs of teaching and learning}

When asked to consider what critical moments had impacted on his beliefs and practices, Christopher maintained that one had been when he took the juniors on their discovery learning field trip. He had found that way of teaching suited him and that the holistic nature of it made sense. 
The second moment had been when he had a child who had special needs. This was an unexpected event and forced Christopher to think deeply about the ethical issues of genetic screening: "Before I had him I thought differently. Now I can discuss this ethical issue in science, how it can change their lives. These important discussions have a role in education." He now looks for opportunities to discuss important issues with the students in his classes: "I like to squeeze it in. If something is important screw the assessment. It's what they take away that is important."

Response to the NZC

Christopher felt the NZC gave him the freedom to work in a student-centred and contextual way with his junior classes. As described above, he recently took a junior class on a "discovery' field trip. This involved taking them out of class to explore the local environment. He found that it enabled him to clearly link the learning to the key competencies in a way that the students could understand. Christopher enjoyed the teaching experience and began to realise that it was his preferred way. The students enjoyed it very much and Christopher noticed the change in those who were often bored when they were sitting in a class. He found the experience personally satisfying.

However, while Christopher felt he had the freedom to experiment with the pedagogy of the NZC with his junior classes, the senior classes were a different matter. His personal drive was for his students to succeed and for seniors this meant success in NCEA. When we met, Christopher felt there was a mismatch between the NCEA assessments for his subject and the philosophy of the NZC. There was an alignment being undertaken by NZQA which hopefully would address this. In the meantime, at the time of the interviews Christopher was feeling the pressure of internal assessments: "NCEA is becoming more intense. There are more internals: each takes four weeks and therefore more pressure." While he tried to contextualise his senior teaching by referring to documentaries in class, he believed most of his teaching in senior classes was assessment driven. He was frustrated by this but felt he needed to be accountable for his classes' NCEA results stating: "Assessment acts as a carrot and stick - it's bad pedagogy and we are being appraised on it."

Christopher identified several challenges in his teaching. One particular concern was the tail end of low achievers identified by the PISA reports. From analysis of the literacy entry test results and the standard-based science assessments he was aware of the students who needed greater support if they were to achieve academically and provided structures to help them: "I tag students who need help 
and follow them. Literacy is really important - I put them next to a student who can help them." However, he found differentiating his lessons difficult and believed he did not do it enough.

Positive relationships with staff were very important to Christopher who enjoyed the collaborative nature of his department: "We work as a dept not as individuals." Relationships with students were equally important. He believed a positive relationship with students was essential for them to succeed: "Success comes if my students enjoy a positive relationship with me. If they are not motivated I take it personally."

When asked to describe himself as a teacher, Christopher replied: "How I describe myself? Anxious, concerned. My job is important. I get stressed about how my students do. ... I have to be very resilient. I am personally happy at the end if, in retrospect, we have met the deadlines."

\subsection{Chapter summary}

This chapter provided an opportunity for a reader to "meet" the teachers. In this way an interpretation can be developed of the way they perceived that their identities had been constructed as they reflected on critical incidents. Also, it is possible to begin to understand how the teachers saw the significance of the signalled changes of the NZC to their beliefs and practices and the potential barriers that may have prevented them from engaging with it. In the following chapter I discuss my interpretation which may (or may not) complement that of a reader. 


\section{My connoisseur interpretation}

The holy grail of (system-wide) change is to know under what conditions hordes of people will be motivated to change. (Hargreaves, 2007, p. 41)

\subsection{Chapter overview}

Any change process should start by identifying what those involved believe to be of personal significance (van den Berg, 2002). Policy makers and academics (including this researcher) may have a clear view of how the change could evolve but unless it is of significance to the teachers and connects with their realities it has little chance of happening (Geijsel et al., 2001; Hall \& Irving, 2010; Keys, 2007).

Motivation was exemplified by Amy. When explaining why at this stage in her career she decided to enrol in postgraduate study, she said: "The time was right ... I had enough to hang this on," acknowledging that her existing knowledge would be an appropriate basis for her future learning. She was intrinsically motivated to learn about something that would support her to meet her personal goals for her teaching practice. She was enthusiastic because she could anticipate how she would be able to utilise her new learning in her work and, in choosing her own way of accessing it, she would have control over the process. The prospect of the new learning was a fit with her personal goals, her personal agency, and her context. In other words, this new learning was significant and she was motivated to pursue it because it connected with her reality as a teacher.

In this chapter, I have interpreted what motivated the teachers to make changes throughout their careers and the extent to which the implementation of the new curriculum connected with the realities they described. Data to support the discussion have been drawn from the interviews, from observations of classes and the context, and from analysis of documentation.

How motivated teachers will be and how much energy they will expend on the implementation will be determined, as Amy did, by how significant the changes are to their personal goals, their emotional response to them, how much they believe they have the personal capacity to action them, and by how much they believe their context will support their learning process. All four of these components are necessary for an individual to be motivated to instigate change (Ford, 1992; Goodson, 1991; Pintrich, 2003). Through this interpretation process I sought to understand: 1) The construction of their beliefs about teaching and learning, what motivated them to make changes, and the personal goals they held for their teaching; 
2) Their emotional response to the implementation of the NZC; 3) Their beliefs about the support their context would provide to support change. Each of these components is addressed in specific research questions:

\section{Identity construction}

This section addresses the sub questions:

What are the crucial life episodes of the teachers ' past personal and professional life that have contributed to their evolving professional identity?

What are their personal goals for their teaching?

What is the significance of the NZC to their personal goals?

\section{Emotional response}

This section addresses the sub question:

What is the teachers' emotional response to the implementation of the NZC?

\section{Context beliefs}

This section addresses the sub questions:

How do elements of the current context interact with and shape their knowledge and practice?

What is the significance of the NZC to their context?

\subsection{Identity construction}

As defined in chapter 2, goals represent a future state a person wishes to achieve and drive an individual's commitment and engagement motivating them towards a certain action (Bandura, 1989; Dzubay, 2001; Ford, 1992). Sugrue and Day (2001) maintain that there is little research on how teachers' sources of learning affect their ability to accommodate new learning. Through this process of interpretation I have explored how, over time, teachers had constructed their professional identity, accommodated new learning, and subsequently their personal goals for their teaching. Several teachers in this study had been prompted by critical incidents to recognise a discrepancy between their personal goals and their current practice. Negating the impression that teachers are reluctant to change their practice their stories show that they will engage with change if it meets their goals for their teaching and if they have the conditions for transformational learning. If these 
conditions were met they were motivated to take action to educate themselves and to work towards addressing the discrepancy. These teachers' commitment and their motivation to develop their practice appeared to be overlooked.

Four teachers are described in detail and the remainder are presented in a table 18. As explained in chapter 4, I asked the teachers if they could describe the critical moments (referred to in the interviews as "aha" moments) that had impacted on their beliefs about education and that had contributed to the construction of their professional identity. Some teachers believed that in retrospect, aspects of their own educational experience were significant in their beliefs about teaching. For others, it was events that had occurred within schools after entering the profession or in their personal lives. In each case, when a teacher reflected on a critical moment they could describe how the experience had alerted them to reconsider their beliefs and/or their practice. This led them to seek an appropriate way to address the gap between their current situation and how they wished to see themselves as a teacher. Teachers learn for a variety of sources (Butt et al., 1992; Dzubay, 2001) and these teachers' stories are examples of how teachers, through experiences in their private and personal lives, developed their personal professional knowledge themselves (DarlingHammond, 1990).
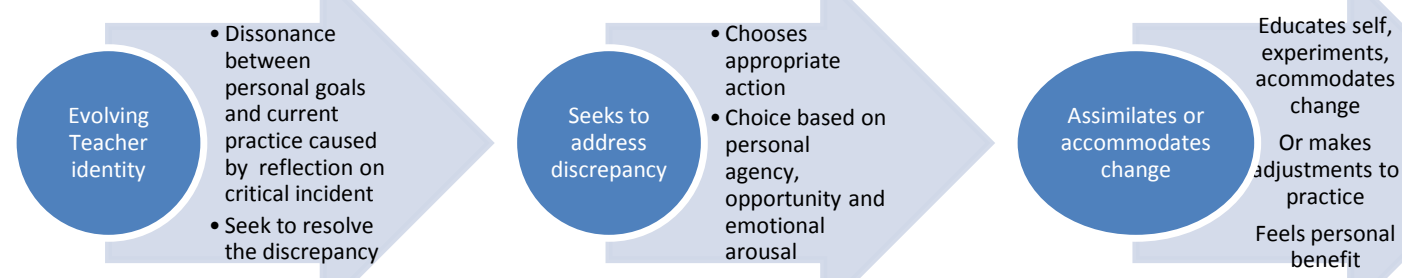

Figure 6. Teachers' motivation to accommodate change

\subsection{Examples of evolving identity}

\subsubsection{Jill}

As described in chapter 5, Jill believed, in retrospect, that the experience that influenced her beliefs about teaching was her observation that, in her own education, some of her peers were not getting the attention they needed. 
However, when she began teaching Jill found that ensuring "no-one was missing out" was more challenging than she had expected and she experienced dissonance. When an opportunity to take part in an assessment for learning project (a formative assessment focus) was offered in her school, she volunteered because she thought it may resolve her concerns. When, after the project finished, she still did not feel confident, she undertook another project to further develop her understanding. This project had the additional appeal of offering time out of class which she believed would give her the opportunity for deep thinking on the implications of what she was learning.

In the course of the second project Jill experienced another critical incident when she interviewed her target students and closely examined their work. To her disappointment she realised that they were not receiving enough attention in class, nor developing their learning in the way she felt was so important. In her interview Jill described how alarmed she felt: "I thought oh my gosh, when you have to look at samples of students' work ... you think oh they haven't done learning... a reflection on me."

Jill's story is an example of how, over the course of their careers, teachers can become self-seeking and develop their ideas by looking for their own answers (Beijaard \& De Vries, 1997; Berliner, 2004; Dzubuay, 2001). When critical incidents caused a sense of dissonance and to question her practice this stimulated a survival anxiety (Frijda et al., 2000; Strauss, 2008). The experience led Jill to take action to further educate herself so that she could meet her personal goals. Following the incident described above Jill undertook an action research paper which involved working with a university lecturer as a mentor who provided her with the crucial support and feedback (Schein, 2002) needed for change to become embedded. The year's study leave to complete a Master of Education provided the time and "head space" to think deeply about her learning, enabling her to gain a theoretical understanding of student-centred teaching. During this time her experiences as a facilitator of assessment for learning in several schools gave her a broad understanding of teaching across the sector. At the time of the interview, as a result of Jill's initiative to undertake professional learning, she felt that she had an understanding of the effective pedagogy described in the NZC. It was a fit with her prior knowledge and understanding, and was relevant to her personal goals. 
Table 12. Summary of Jill's construction of teacher identity

\begin{tabular}{llll}
\hline \multicolumn{2}{c}{ Incident in own educational experience } & \multicolumn{2}{c}{ Critical incident in practice } \\
\hline Critical incident & $\begin{array}{l}\text { Subjective } \\
\text { interpretation and } \\
\text { impact on identity as a } \\
\text { teacher }\end{array}$ & Dissonance caused & Action taken \\
& No one should miss out & $\begin{array}{l}\text { Students were } \\
\text { "missing out" }\end{array}$ & $\begin{array}{l}\text { Undertook professional } \\
\text { learning }\end{array}$ \\
\hline $\begin{array}{l}\text { Some people missing } \\
\text { out. }\end{array}$ & & & \\
\hline
\end{tabular}

\subsubsection{Nina}

As described in chapter 5, Nina remembered her frustration as a student when behaving well was ignored. The effect was demotivating: "I knew I would sit down, either get bollocked for doing nothing or just be bored." She therefore began her teaching career determined to follow the example of those teachers in her education who had acknowledged her efforts and who were positive role models. She saw herself as a teacher who would be positive and who would affirm student involvement in the lessons. However, as a beginning teacher she faced a barrier to this image: the reality of teaching a large number of adolescents challenged her classroom management skills. This was a critical incident which caused a dissonance (Armenakis et al., 2007; Thoonen et al., 2011). She realised she needed to develop classroom management skills if she wished to teach in her preferred way. This goal to develop her classroom management could be classed a sub-goal which would enable her to work toward her personally held goal of being the teacher she wished to be (D. Ford \& Lenrer, 1992). Subsequently when a PD course on classroom management was offered at her school, Nina was highly motivated and undertook it enthusiastically.

Once Nina had developed her classroom management skills she was able to practise in a way congruent with her beliefs, which was to focus on positive reinforcement. Her image of being a teacher with a positive approach to students was reinforced when she received feedback from her students, indicating that they appreciated her approach. Feedback from students on the effectiveness of teaching actions is a powerful support to a teacher's image and self-esteem (Hattie \& Timperley, 2007; Kelchtermans, 2009). In Nina's case, this feedback led to her further developing her strategies to acknowledge the students' efforts. As a result, she maintained a positive approach, looking for ways to acknowledge the students for appropriate behaviour in her current practice. 
Table 13. Summary of Nina's construction of teacher identity

\begin{tabular}{llll}
\hline \multicolumn{2}{c}{ Incident in own educational experience } & \multicolumn{1}{c}{ Critical incident in practice } \\
\hline Critical incident & $\begin{array}{l}\text { Subjective } \\
\text { interpretation and } \\
\text { impact on identity as } \\
\text { a teacher }\end{array}$ & Dissonance caused & Action taken \\
& $\begin{array}{l}\text { To be a positive and } \\
\text { affirming teacher. }\end{array}$ & $\begin{array}{l}\text { Struggle to control a } \\
\text { class. }\end{array}$ & $\begin{array}{l}\text { A course in classroom } \\
\text { management. }\end{array}$ \\
\hline $\begin{array}{l}\text { Positive and negative } \\
\text { role models. }\end{array}$ & & & \\
\hline
\end{tabular}

\subsubsection{James}

Teachers often teach the way they have been taught based on their years as a student in the classroom (V. Richardson, 1990) but in James's case, it was his memories of his traditional village upbringing that influenced his teacher identity, not his formal schooling which he described as being a very traditional transmission style of teaching. This experience appears to have remained in James's schemata as an effective way of learning: "I struggle with the system, with the lecturing way"

However, this was not how he began his teaching career. His teacher education was based on a transmission model: "We were put in classroom and told to go for it. It was still chalk and talk then." After James completed his teacher education he began teaching at a school he described as very traditional, reminiscent of his own formal teaching.

As explained in his interview, at that stage of his career James found that this model suited him because he struggled with a significant hearing loss which he believed limited his ability to be innovative. In a teacher-centred model he felt more in control of the class. However, the restoration of his hearing enabled him to change his approach. James gradually realised that in this current environment he would not develop the skills to be the teacher he wanted to be and he moved to another school that encouraged innovation.

In James's case, while he held personal goals for his teaching, this was not enough to empower him to pursue the development of skills that would fit his goals. His capacity, beliefs, and context beliefs constrained him. His deafness affected his beliefs about his personal capacity to teach in the way he valued (Dzubay, 2001; Ford, 1992). In addition, he did not believe his context, a very traditional school, would support a more student-centred model of teaching. At that stage of his career he was therefore not motivated to change his practice (Armenakis et al., 2007; Ford, 1992; Pintrich, Marx, \& Boyle, 1993). However, once the barrier to his personal capacity (his deafness) was resolved, he sought a context that would support his development. In a new school that 
encouraged innovation, James felt able to work in a more cooperative way with his students. The dissonance, the gap between how he saw himself as a teacher and how he was actually practising, motivated him to make a change. It appears that James responded to these critical incidents because, in his interpretation of them, he began to understand what was important to his sense of self (Kelchtermans, 2009).

Moving to Fiji at a time of political turmoil demonstrated James's willingness to take risks and his openness to change. It proved to be a startling change for him in many ways. As described in chapter 5, James was eventually faced with the daunting challenge of teaching one class of 56 and another of 69 at the same time. His way of dealing with this was to think creatively. This experience was another critical incident that further expanded James's understanding of how students could have more ownership of their learning: "I think kids are really creative and if we can provide them with the right atmosphere to do things they all just go with it. I have that belief and if I didn't I would probably give up teaching."

Back in New Zealand James had attempted to involve the junior students in their learning. However, he was frank about the contextual constraints admitting that: "I have to play the game - I put aside a period to do a summary for the test" and with the pressure of NCEA he did not feel that he could work this way with the senior students. The implications of this conflict are explored in chapter 7.

Table 14. Summary of James's construction of teacher identity

\begin{tabular}{|c|c|c|c|}
\hline \multicolumn{2}{|c|}{ Incident in own educational experience } & \multicolumn{2}{|c|}{ Critical incident in practice } \\
\hline Critical incident & $\begin{array}{l}\text { Subjective } \\
\text { interpretation and } \\
\text { impact on identity as } \\
\text { a teacher }\end{array}$ & Dissonance caused by & Action taken \\
\hline $\begin{array}{l}\text { Learning traditional } \\
\text { trade skills in the } \\
\text { village. }\end{array}$ & $\begin{array}{l}\text { The definition of } \\
\text { learning should be } \\
\text { wider to include more } \\
\text { working together. }\end{array}$ & $\begin{array}{l}\text { Operation removed } \\
\text { barrier to seeking more } \\
\text { innovative ways to } \\
\text { teach. } \\
\text { The observation of } \\
\text { 'frightened teachers.' }\end{array}$ & Left the school. \\
\hline
\end{tabular}


Table 15. Summary of James's construction of teacher identity (teaching)

\begin{tabular}{|c|c|c|c|}
\hline \multicolumn{2}{|c|}{ Incident in teaching } & \multicolumn{2}{|c|}{ Experience in practice } \\
\hline Critical incident & $\begin{array}{l}\text { Resulting impact on } \\
\text { identity as a teacher }\end{array}$ & $\begin{array}{l}\text { Dissonance } \\
\text { experienced }\end{array}$ & Action taken \\
\hline $\begin{array}{l}\text { Experience in overseas } \\
\text { school. }\end{array}$ & $\begin{array}{l}\text { "Kids are really } \\
\text { creative and if we can } \\
\text { provide them with the } \\
\text { right atmosphere to do } \\
\text { things they all just go } \\
\text { with it. I have that } \\
\text { belief and if I didn't I } \\
\text { would probably give } \\
\text { up teaching." }\end{array}$ & $\begin{array}{l}\text { The constraint of } \\
\text { NCEA, other } \\
\text { responsibilities. }\end{array}$ & $\begin{array}{l}\text { Applied for and won a } \\
\text { study award for a } \\
\text { year's leave to } \\
\text { complete his master's } \\
\text { degree and to consider } \\
\text { his priorities. }\end{array}$ \\
\hline
\end{tabular}

\subsubsection{Ruth}

Role models also impacted on Ruth's image of teachers. She had been impressed by those teachers who had taken an holistic interest in her as a student. On reflection, she believed it was the encouragement of these teachers which had resulted in her attending university and explained how this had affected her beliefs about teaching. As described in chapter 5, Ruth had throughout her career undertaken study to deepen her understanding of teaching and learning and as a result had broadened her skill base. However, her personal experience of having a child with learning difficulties strengthened her beliefs that she needed to explore further and to attend to the individual needs of her students: "It really got me thinking about that whole person - you know before I had children it was so easy to call a kid a little, you know, little toe rag." Her child's situation built on her interpretation of the helpful teachers in her own education and reinforced her belief in the importance of acknowledging the whole child.

Her challenge was to teach in the way she espoused. When she was presented with a challenging class, Ruth found she struggled to action her beliefs. Realising that she did not have the skills she needed to effectively teach this class, Ruth undertook further studies in special needs education.

The combination of the critical incidents - her child and the challenging class - led Ruth to seek to educate herself, significantly changing her teaching approach:

I changed dramatically my expectations. It taught me to get to know the learners. I used to transmit information. These experiences made me want to analyze the individual learner and see what's blocking them, what steps have been left out and how to scaffold their learning. Back then that way of teaching was not talked about. I had never heard of scaffolding the learning. 
Table 16. Summary of Ruth's construction of teacher identity

\begin{tabular}{|c|c|c|c|}
\hline \multicolumn{2}{|c|}{ Incident in own educational experience } & \multicolumn{2}{|c|}{ Critical incident in practice and private life } \\
\hline Critical incident & $\begin{array}{l}\text { Subjective } \\
\text { interpretation and } \\
\text { impact on identity as a } \\
\text { teacher }\end{array}$ & Dissonance caused & Action taken \\
\hline Positive role models & $\begin{array}{l}\text { Every student can } \\
\text { succeed in some way. } \\
\text { They must should have } \\
\text { fun, be respected and } \\
\text { accepted as people. }\end{array}$ & $\begin{array}{l}\text { Alternative class: } \\
\text { "I realised I had } \\
\text { entered teaching } \\
\text { thinking it was } \\
\text { cramming knowledge } \\
\text { into their little heads." } \\
\text { Having a daughter } \\
\text { with learning } \\
\text { difficulties. } \\
\text { How does a teacher } \\
\text { find a way for every } \\
\text { child to succeed? }\end{array}$ & $\begin{array}{l}\text { Studied a Diploma in } \\
\text { Special Needs online in } \\
\text { her own time. }\end{array}$ \\
\hline
\end{tabular}

The teachers' stories provide an insight into what triggered a reconsideration of their beliefs and practice. It appeared that when they encountered a critical incident that was a jolt to their previous beliefs or practices, their interpretation of the event led to some course of action. As can be seen in the following table, this could be to seek professional learning or to modify beliefs and/or practice. 
Table 17. Summary of the construction of identity

\begin{tabular}{|c|c|c|c|}
\hline Teacher & Critical moment/dissonance & Interpretation of critical incident/s & Resulting Action \\
\hline \multirow[t]{2}{*}{ Amy } & Interviewing statistics students. & $\begin{array}{l}\text { The relevance of the learning needs to be } \\
\text { made explicit. }\end{array}$ & Seek departmental discussion on relevance. \\
\hline & Japanese lesson study experience. & Critically reflect on teaching practice. & $\begin{array}{l}\text { Change practice to support the students to } \\
\text { construct meaning. }\end{array}$ \\
\hline Christopher & Having a child with special needs. & $\begin{array}{l}\text { Rethought ethical issues. Students need to } \\
\text { critically evaluate science. }\end{array}$ & $\begin{array}{l}\text { Look for opportunities to include critical } \\
\text { awareness in class. }\end{array}$ \\
\hline Edward & Students' self-assessment effectiveness. & Students are able to self-assess. & Integrated self-assessment practices. \\
\hline \multirow[t]{2}{*}{ James } & School environment. & Don't want to be a frightened teacher. & Change schools. \\
\hline & Teaching in Fiji. & Students can drive their own learning. & $\begin{array}{l}\text { Encourage student ownership in junior } \\
\text { classes. }\end{array}$ \\
\hline Jennifer & Facing the challenge of leading change. & To sustain change. & Take relevant Master papers. \\
\hline Jill & The disappointing results with target students. & $\begin{array}{l}\text { If "everyone should be heard' need to find out } \\
\text { how to do it. }\end{array}$ & Seek PD. \\
\hline \multirow[t]{2}{*}{ Joseph } & Challenged to engage reluctant students. & $\begin{array}{l}\text { Working on relationships with students } \\
\text { increases engagement. }\end{array}$ & Prioritise relationships. \\
\hline & Instructions from leadership. & Important to comply. & Add on strategies. \\
\hline Mary & School expectations. & Assessments a priority. & Focus on NCEA results. \\
\hline Nina & Challenge to manage class. & $\begin{array}{l}\text { To teach in preferred way need to learn } \\
\text { classroom management skills. }\end{array}$ & Seek PD. \\
\hline Ruth & $\begin{array}{l}\text { Challenging class. } \\
\text { Having child with learning difficulties. }\end{array}$ & $\begin{array}{l}\text { To be an holistic teacher need to know more } \\
\text { about learning difficulties. }\end{array}$ & Seek appropriate papers. \\
\hline Susan & Some students in class being overlooked. & Need to meet the needs of all students. & Join team teaching team. \\
\hline
\end{tabular}




\subsubsection{Personal goals}

From the teachers' stories the following are the personal goals the teachers appeared to have for their teaching. While not explicitly articulated, their personal goals could be inferred (Kagan, 1990). In Table 19 links between the teachers' personal goals and the signalled changes in the NZC have been identified. One teacher had developed her understanding of the changes through her personal study and was accustomed to working in this way. Another was developing the model in her junior classes and was committed to ongoing development. As can be noted, there were no teachers who felt a sense of dissonance that they believed would be addressed by the effective pedagogy of the NZC. There appeared to be several reasons for this. One was that, despite espousing support for the signalled pedagogy, with the exception of Jill, there was an apparent lack of confidence that the suggestions of the effective pedagogy would result in successful NCEA assessment results. Therefore, teachers did not believe that a constructivist approach would benefit them. This suggests either a lack of understanding of the implications or that their epistemology beliefs may not have been a fit with those underpinning the NZC. Other reasons were linked to the culture of their school. These issues will be discussed in chapter 8 .

In this and following tables I have used a method employed by Leithwood et al. (2000) using - and + symbols. In this table the symbol - indicates a lack of fit with personal goals and + indicates a fit with personal goals. 
Table 18. Link between personal goals the NZC

\begin{tabular}{|c|c|c|c|}
\hline Teacher & Personal goals & A sense of dissonance? & $\begin{array}{l}\text { Did they perceive an NZC link to personal goals, } \\
\text { beliefs and values? } \\
\text { Would it address any dissonance? }\end{array}$ \\
\hline Amy & $\begin{array}{l}\text { The aims of the Numeracy project } \\
\text { Filling the gaps in students learning }\end{array}$ & $\begin{array}{l}\text { No. Dissonance addressed through the } \\
\text { professional learning associated with the } \\
\text { numeracy project }\end{array}$ & $\begin{array}{l}+ \text { There is a link between the numeracy project and the } \\
\text { NZC effective pedagogy } \\
\text { - Detracts from focus on subject and other initiatives }\end{array}$ \\
\hline Christopher & $\begin{array}{l}\text { To be a well regarded teacher } \\
\text { Job security } \\
\text { To teach holistically } \\
\text { Positive relationship with students } \\
\text { NCEA success } \\
\text { To meet deadlines }\end{array}$ & $\begin{array}{l}\text { Conflicted. Current practice resulted in } \\
\text { successful NCEA results but felt more satisfied } \\
\text { by the student-centred teaching with juniors }\end{array}$ & $\begin{array}{l}\text { + Fits with espoused personal beliefs } \\
\text { - Tension with the pressure for NCEA success }\end{array}$ \\
\hline Edward & $\begin{array}{l}\text { Efficient teaching } \\
\text { NCEA success } \\
\text { Positive relationship with students }\end{array}$ & $\begin{array}{l}\text { No. Current practice achieved good NCEA } \\
\text { results }\end{array}$ & $\begin{array}{l}\text { + Fits with espoused personal beliefs } \\
\text { - Tension with the pressure for NCEA success } \\
\text { - School structures }\end{array}$ \\
\hline James & $\begin{array}{l}\text { Work in a student-centred model. } \\
\text { Success in NCEA } \\
\text { Positive relationships with students }\end{array}$ & $\begin{array}{l}\text { Yes. Felt unable to teach in his preferred way } \\
\text { but was unsure if changing was possible } \\
\text { because of busyness and assessment regime. }\end{array}$ & $\begin{array}{l}\text { + Aligned with espoused personal beliefs } \\
\text { - Tension with the pressure for NCEA success }\end{array}$ \\
\hline Jennifer & $\begin{array}{l}\text { Schools succeeds } \\
\text { Staff welfare } \\
\text { Students achieve in NCEA }\end{array}$ & $\begin{array}{l}\text { No. School working on their own initiatives to } \\
\text { meet student needs. }\end{array}$ & $\begin{array}{l}\text { + Focus on teaching and learning } \\
\text { - More assessment } \\
\text { - No need } \\
\text { - Pressure on teachers and heads of departments } \\
\text { - Detracts from embedding current initiatives }\end{array}$ \\
\hline Jill & $\begin{array}{l}\text { Student-centred teaching } \\
\text { Ensuring everyone has a voice }\end{array}$ & $\begin{array}{l}\text { Not a dissonance but wished to continue to } \\
\text { develop her skills }\end{array}$ & + Affirmed her espoused personal beliefs \\
\hline Joseph & $\begin{array}{l}\text { Positive relationship with students } \\
\text { Finding a way to engage his students } \\
\text { Academic success for his students }\end{array}$ & $\begin{array}{l}\text { No, but could see that directives from } \\
\text { management would improve his practice }\end{array}$ & + Fits with espoused personal beliefs \\
\hline Mary & $\begin{array}{l}\text { Holistic teaching } \\
\text { Positive relationships with students } \\
\text { Academic success for her students }\end{array}$ & $\begin{array}{l}\text { Yes but conflicted by mixed messages } \\
\text { Struggle to embed all suggested changes }\end{array}$ & + Fits with espoused personal beliefs \\
\hline
\end{tabular}




\begin{tabular}{|c|c|c|c|}
\hline Teacher & Personal goals & A sense of dissonance? & $\begin{array}{l}\text { Did they perceive an NZC link to personal goals, } \\
\text { beliefs and values? } \\
\text { Would it address any dissonance? }\end{array}$ \\
\hline Michael & Protect teachers & No. & $\begin{array}{l}\text { + Acknowledging teacher effectiveness } \\
\text { - Not needed } \\
\text { - Ignores intangibles }\end{array}$ \\
\hline Nina & $\begin{array}{l}\text { Students enjoy her classes } \\
\text { Success for students in NCEA } \\
\text { Be acknowledged as an effective teacher }\end{array}$ & $\begin{array}{l}\text { No. Current teaching met her personal goals. } \\
\text { Wished to continue to develop it }\end{array}$ & + Fits with espoused personal beliefs \\
\hline Ruth & $\begin{array}{l}\text { Holistic teaching } \\
\text { Positive relationships with students } \\
\text { Academic success for her students }\end{array}$ & $\begin{array}{l}\text { No. Had developed a practice that was } \\
\text { effective in the context and to meet the } \\
\text { challenge of her classes }\end{array}$ & $\begin{array}{l}\text { + Fits with espoused personal beliefs } \\
\text { - Tension with the pressure for NCEA success } \\
\text { - School structures }\end{array}$ \\
\hline Susan & $\begin{array}{l}\text { Continue to develop student-centred skills } \\
\text { NCEA success for seniors }\end{array}$ & $\begin{array}{l}\text { Satisfied that her practice with junior classes } \\
\text { was developing effectively } \\
\text { Frustrated by approach with seniors but it did } \\
\text { achieve good NCEA results }\end{array}$ & $\begin{array}{l}\text { + Fits with espoused personal beliefs } \\
\text { - Tension with the pressure for NCEA success }\end{array}$ \\
\hline
\end{tabular}




\subsection{Emotional response to the signalled changes of the NZC}

As discussed in chapter 2, teachers' emotional response to the signalled change can frustrate or enhance an implementation (Schmidt \& Datnow, 2005). The arousal of emotions depends on an individual's cognitive appraisal of an event (Firjda et al., 2000; Oatley, 2000) and as such is a motivational force which can indicate how ready teachers are to make a change (Ford, 1992). The appraisal could include how the teachers see the event impacts on their professional identify, on the role of a teacher, on their responsibilities, on their subject, or on their workload. Emotions can be aroused by what this event represents for the teachers personally, and also by the different contextual demands they are confronted with which can be the school itself, the organisational culture, the norms, collegial relationships, or their relative power and status (Schutz \& Zembylas, 2009; van Veen et al., 2001).

It was therefore important to consider the teachers' emotional response when interpreting the significance of an implementation. In the following section, I have discussed Jennifer's and Michael's emotional responses in detail. I have chosen these two teachers because they were leaders in their school and therefore their response had the potential to affect the implementation process in their context. This is followed by a summary of all the participants' emotional responses.

\subsubsection{Jennifer's emotional response}

As a reader will have noted in chapter 5, Jennifer had a strong emotional reaction to the implementation of the NZC. Jennifer was interviewed four times over the two years, and in her final interview to discuss key themes (2011) she remained upset about the NZC document, appearing to consider it an insult to her professionalism:

I was bitterly disappointed to see a document, ah, which had no bibliography. there was no acknowledgment of any work done by anybody in New Zealand, and the ideas are often not original ... they come from other people's research and work in schools.

Neyland (2010) maintained that teachers experience job satisfaction when they have a sense of personal achievement from enjoying aspects of their work and personal growth without a carrot and stick but with the freedom to do the job the way they want. The mandated NZC implementation had the potential to limit Jennifer's freedom to focus on what she believed was important. Consequently, her job satisfaction, her sense of autonomy and her motivation were threatened (Evans, 2008).

Jennifer had been involved in many innovations, had led change and now she felt that she was being dictated to by an authority which had not supported its 
assertions with cited research. The anonymous writers of the document were, she believed, taking credit for work that had been done in the sector by teachers in the field without acknowledging their source. An example was the 1986 secondary school integrated studies project Jennifer was involved in. It was a student-centred, integrated subject and used cooperative learning - all elements now implied in the NZC document. The project was ahead of its time, integrating computers into teaching before they were in general use in business and very rarely used in schools. As such, it drew a great deal of attention throughout the educational sector: "we had lots of visits from other schools, the university initiated it and researched it ... there was a huge spotlight on it." It is therefore possible to understand why Jennifer felt resentful to see the same concepts introduced in the NZC document: "when you think 20 years ago if someone picked this up you would you think it's a whole new beginning but it's not ... where the hell has this come from-you would think they have just invented this themselves." Key competencies aroused another emotional response: they "scared" her representing more pressure and arousing the suspicion that there would be external monitoring.

The potential impact of the change on teachers and the heads of departments in her school and prompted an emotional reaction.

I suppose for me and my role what I've talked about are the competing changes and challenges that teachers have to take on, because the new curriculum isn't just one thing in isolation, that's happening, there's multiple things coming at them.

Jennifer described herself as someone who does embrace change. However, she was also aware, from her experience and from her studies in her Master of Educational Administration, that sustained change is difficult to achieve. She believed that her school knew what was needed to benefit the students who attended and had been engaged in initiatives planned to improve their learning. Each initiative had involved considerable professional learning for the teachers and Jennifer was concerned that the focus on the NZC would be a distraction which could prevent the learning that had occurred from being embedded and sustained. In preference to implementing more change, which the school had not sought nor in her opinion was it needed, Jennifer believed a wiser use of staff time and energy would be to spend it on embedding what they had already learned: "I am sick of change for whose sake. You're just the person who has to implement somebody else's ideas." 


\subsubsection{Michael's emotional response}

Michael said that he supported the effective pedagogy and the key competencies but, like Jennifer, did not believe any mandated change was needed in his context: "I didn't see the roof leaking." His chief concern was for the possible emotional impact on the teachers. While he considered each element of the effective pedagogy to be valid, he believed that teaching was complex, involved considerable emotional investment, and could not be reduced to a checklist. It was what was not in the effective pedagogy section that worried him. Schon (1995, p. 28) describes teachers as "working in the swampy lowlands of everyday practice facing situations that are complex and messy." Their daily reality can mean responding to problems in a dynamic environment, on the run, and based on their knowledge of their students, practical considerations and on their experience (Neyland, 2010; Robinson \& Lai, 2006). The intangibles involved in their work may not be captured by a list of effective practices and Michael maintained that with the emotional bond with the student central to how teachers work, teaching cannot be reduced to technical competence or clinical standards (Hargreaves, 2005). Reading this aspect of the NZC, teachers could feel inadequate and Michael believed this could erode their confidence. He maintained that teachers had only recently felt less personally vulnerable about their professional judgement which had been shaken when many of their assessment activities were rejected by moderators in the introduction of NCEA. Michael believed that there was a risk that their confidence would be again undermined.

\subsubsection{Other participants' emotional response}

All participants maintained that they supported the elements of the effective pedagogy and the integration of the key competencies. However, there were reservations about it being successfully implemented. Most of the participants' concerns were related to the capacity of the context to support a change in pedagogical practice and to integrate the key competencies. These will be discussed further in the context capacity section of this chapter. The quotes below provide examples of the range of emotions expressed. Each indicates that even those who are enthusiastic about a change may be demotivated when their context causes such conflicting emotions (Schmidt \& Datnow, 2005):

Ruth: $\quad$ Look, I just can't see how we can do it properly in NZ. I get really quite upset ... I don't care about a $4 \%$ pay increase but if we could only have smaller classes, I can't see how we 
can truly implement the new curriculum and we look at outcomes for all learners with the class sizes we have.

Mary: $\quad$ You're constantly being told what you don't do and what you need to do and feeling inadequate because you can't do it because there are so many things you need to do.

Christopher: I I would describe myself as anxious, concerned.

James: $\quad$ I just have to watch I don't overinvest and get burnt out. What this new curriculum is causing me to do is thinking that in order to do this properly I need to slow down and give up other things like deaning. I don't know if that's good or not for the whole of teaching if people have to give up some of their other responsibilities.

Amy: $\quad$ It can be quite frustrating, we have no resources we are expected to rewrite all the externals every one!! We do it to make it good for the kids - in our own time - don't know if NZQA and MOE even talking. (Exclamation marks added in an attempt to indicate how passionate Amy was about this.)

Table 19 summarises the teachers' emotion about the implementation of the effective pedagogy and key competencies. As can be seen while there were some positive emotional responses, each teacher also had experienced a negative emotional response. Critics of Mezirow's (1997) theory of transformative learning maintain that it relies on a rational reflection ignoring the important part that emotion plays (Taylor, 2007). It is possible that the participants' negative emotional response could block their openness to the transformative learning needed to change beliefs. 
Table 19. Emotional response to the effective pedagogy and key competencies of NZC

Key: + indicates a positive emotional response, - indicates a negative emotional response

\begin{tabular}{|c|c|}
\hline Teacher & Emotional response \\
\hline Amy & $\begin{array}{l}+ \text { Pleased it fits with the numeracy principles } \\
\text { - Anger with leadership } \\
\text { - Frustration with other staff }\end{array}$ \\
\hline Christopher & $\begin{array}{l}+ \text { Happy with the freedom it represents with junior students } \\
\text { - Anxious about appraisal and succeeding in NCEA }\end{array}$ \\
\hline Edward & $\begin{array}{l}+ \text { Pragmatic } \\
\text { - Not realistic in the assessment environment }\end{array}$ \\
\hline James & $\begin{array}{l}\text { + Supports the concepts } \\
\text { - Frustration at other responsibilities. } \\
\text { - Concerned about lack of time } \\
\text { - Worried the changes would not be effective }\end{array}$ \\
\hline Jennifer & $\begin{array}{l}\text { + Supportive of the emphasis on teaching and learning } \\
\text { - Anger at lack of acknowledgement of teachers' work } \\
\text { - Frustration at increased workload } \\
\text { - Anger at more change } \\
\text { - Resentment that it would distract from local efforts } \\
\text { - Suspicious of external assessment of key competencies }\end{array}$ \\
\hline Jill & $\begin{array}{l}\text { + Practice affirmed by philosophy of NZC } \\
\text { - Concerned that workload and time allowance will prevent other teachers from developing } \\
\text { deep understanding. } \\
\text { - Frustrated by lack of shared vision }\end{array}$ \\
\hline Joseph & + Will follow orders \\
\hline Mary & $\begin{array}{l}\text { + Excited by philosophy of NZC } \\
\text { - Self-esteem battered by pressure of initiatives } \\
\text { - Stressed finding balance }\end{array}$ \\
\hline Michael & $\begin{array}{l}\text { - Resentment of more change } \\
\text { - Concerned for teachers' vulnerability }\end{array}$ \\
\hline Nina & $\begin{array}{l}+ \text { Excited by philosophy of NZC } \\
- \text { Concerned other teachers have not engaged }\end{array}$ \\
\hline Ruth & $\begin{array}{l}+ \text { Excited by philosophy of NZC } \\
\text { - Concerned about workload and time allowance } \\
\text { - Frustrated by class numbers }\end{array}$ \\
\hline Susan & $\begin{array}{l}+ \text { A fit with her developing practice } \\
- \text { Frustration that NCEA pressure precludes use with seniors }\end{array}$ \\
\hline
\end{tabular}




\subsection{Context beliefs}

Successful change requires an alignment of all parts of the system, in which "all the interacting parts form a complex and unified whole that has specific purpose" (D. Kim, 1999, p. 2). Fullan and Quinn (2012) refer to this as a "shared mindset" (slide 18). In a school with an aligned focus or shared mindset working towards a change there would be a clear vision of what the change involved, leadership at all levels would initiate and support it, the school structure would make the change possible, there would be collegial focus to support the change, appropriate and ongoing professional learning would be provided and there would be a realistic time allowance for the teachers (Hargreaves, 2007; Hopkins, 2001; van Veen \& Sleegers, 2001).

In this section I have interpreted the participants' perception of the degree to which, in their context, there was an alignment of systems and collegial support for the changes signalled in the NZC.

The teachers in the study were not aware of a clear vision for the implementation of the effective pedagogy and the integration of the key competencies. In addition, they had mixed feelings about their leadership's commitment and understanding of the signalled changes.

There had been a general discussion in Totara College about the effective pedagogy but there was no evidence that there had been any deeper analysis of its implications "it was a one-off discussion so whether it stayed-people got on with it - we have moved on." It was now up to departments to do further work. It was not clear how that would be accomplished and by whom. Michael believed that no-one in his school was an expert: "no-one felt confident."

The current strategic plan for the school did have goals for staff professional learning.

Table 20. Totara College strategic plan

\begin{tabular}{ll}
\hline Expected outcomes & Milestones \\
\hline $\begin{array}{l}\text { Robust support for the implementation of } \\
\text { government initiatives, e.g., the NZC and Ka }\end{array}$ & $\begin{array}{l}\text { Teacher-only days } \\
\text { Annual department reports } \\
\text { Hikitea. }\end{array}$ \\
\hline $\begin{array}{l}\text { Good practice and successful innovations are } \\
\text { shared within and beyond the staff of the } \\
\text { College. }\end{array}$ & Staff meetings once a month \\
\hline
\end{tabular}


However, while goals for other aspects of school, for example roll growth, had clearly specified outcomes, those for professional learning were vague. It was not clear what good practice and successful innovations meant in this document and the teachers who took part in my study did not appear to have a clear picture either. It appeared that in this context the effective pedagogy and the incorporation of key competencies was not a focus for staff development but was left to the discretion of departments under the leadership of their heads of department. According to Amy, there was no accountability for this: "I don't know what else management has in the idea of making sure it happens in departments."

Two of the participants in Totara College were senior managers who could be expected to be promoting a vision of the implementation of the NZC for the rest of the staff. However, as discussed in the section 6.4, they appeared to be wrestling with the requirement to implement the NZC and from their comments it seemed that there were no clear goals or expectations decided upon. Ironically, Jennifer believed the additional administrative work could take away the focus on the part of the NZC that she did support which was the section of suggestions for effective practice. This was a realistic concern given that heads of departments would have the responsibility for the alignment of the imminent new assessments with departmental schemes of work in addition to an expectation they would lead the understanding of the NZC changes. It is possible that the staff engagement with the NZC in Totara College would be affected by sensing their leaders' lack of commitment (Armenakis et al., 2007).

Two teachers in the school acknowledged that there had been development on the descriptions of key competencies by two departments and that their work had been reported back at a staff meeting. There were posters on Jennifer's classroom walls describing key competencies; it is possible that her department may have been one which had held discussions. In addition, James stated that he included key competencies in his planning. However, there did not appear to be any discussions on how key competencies were to be integrated into lessons and they were not observed being explicitly integrated into any lessons in this context. This suggests that the professional learning on key competencies had been surface only with no discussion of the underlying conceptual understanding (Simmena, 2011).

The goals in the strategic plans of the other contexts were also couched in general terms. For example, there appears to be a mismatch between Kauri High School's aim and the expected outcome: 


Action $\quad$ Expected outcome

Continued implementation of the NZC

Increased use and awareness of e-learning

There was no school documentation which detailed what the implementation of the effective pedagogy and the key competencies would look like in action in any context. Jill, in Kauri High School, discussed this in her interview. She believed that there was a need for a common vision of what the NZC would look like but was unsure that the leadership had enough deep understanding of the NZC to develop one with the staff. She also maintained that "what we need is an expert." In her appraisal of the school leadership she did not feel confident about their understanding of the changes: "I think the management half understand, even the person in charge just the way she is talking, I question what her understanding is just the way she talks." Her Head of Department was also finding the conceptual understanding challenging: "he is chalk and talk. - I ran a PD session on Wed for our faculty and I was aware he needed more explanation." Developing a common understanding was always going to be a challenge in a school that was proud of its respect for individuality. Jill believed that the culture which emphasised individuality militated against a common goal. At this school there was, in her opinion, minimal whole school development with departments developing their own understanding of the NZC.

Mary, in the same context as Jill, implied a need for leadership to support the development of the common understanding or vision in her integrated studies project. While the integrated studies initiative was strongly promoted by senior management and she does feel it was "a move in the right direction," there was a need for the teachers to develop a common understanding of what they were trying to achieve. Each team working on the integrated studies worked on their own plans making the work dependent on the expertise within the team. This need was acknowledged in 2012, when the school offered a management unit for a staff member to develop their expertise and lead the conceptual understanding of the integrated studies teams.

Kawakawa College's strategic plan also focussed on e-learning with no mention of the effective pedagogy or of the key competencies: 
Table 22. Kawakawa College strategic plan

\begin{tabular}{lll}
\hline Actions & \multicolumn{1}{c}{ Target Date } & \multicolumn{1}{c}{ Expected Outcomes } \\
\hline Curriculum Review & Phase 1 - end of Term 2 & \\
\hline $\begin{array}{lll}\text { Continued } \\
\text { implementation of the }\end{array}$ & End of Year & $\begin{array}{l}\text { Increased use and awareness of } \\
\text { e-learning }\end{array}$ \\
NZC & &
\end{tabular}

Expertise was also sought in Kawakawa College where Patricia, the senior manager with responsibility for professional learning, admitted that the school had yet to develop a common understanding of the effective pedagogy but that it was a work in progress: "that's what we are working on ... a common understanding. People have their own pedagogical knowledge." While constructing common understanding is an effective professional learning approach (Drath et al., 2008; Ford, 1992; Luttenberg et al., 2011; Spillane et al., 2002), it was perhaps indicative of the impact of many initiatives in this school that this strategy was being considered in 2012, four years after the initial implementation of the NZC and two years after it was mandated. There had been little professional learning focussed on the key competencies but there was a focus group exploring them who would at some stage report back to the rest of the staff. There was no visible evidence of the key competencies on the walls of the classrooms and they were not observed being integrated into lessons.

There had been whole staff professional learning on the NZC for one term in 2009 at which Susan explained that staff:

...looked at what all the different bits meant and how you could possibly adapt unit plans and all that sort of thing... Yeah, it's just that people look it up and say oh yeah, sort of make links between what it says and what we are doing and say oh good, ... if it's not broken then they don't think they need to fix it. It requires people to sit down and rethink what they are doing and sometimes it's just too busy.

Following the whole staff sessions there had been groups looking at the NZC for an hour each week but Patricia did not yet feel there was a shared or deep understanding of its implication for the students' learning.

While each context was to some extent developing strategies indicated by the NZC, there did not appear to be any exploration of the theoretical underpinning of the signalled changes. Nor was there evidence that there was leadership with the confidence to lead such a discussion. 


\subsubsection{The perceived school goals}

Apart from Angela who taught only junior classes, the pressure of NCEA was evident in the participant's interviews. Nine of the participants maintained that one of the major constraints for the implementation of the effective pedagogy and the integration of key competencies was the pressure for their students to achieve well in the external NCEA assessments. This suggests that while it might not be explicitly expressed in a mission statement, the goals and expectations in their environment was for their students to succeed in NCEA assessments. For the teachers this represented a disjuncture between the goals of the context and the proposed changes in the NZC. Lasky (2005) speaks of this as "adapting under conditions of ambiguity" (p. 910). Darling-Hammond (1990) encountered a similar conflict of goals in her study of mathematics reform in California. As in the effective pedagogy of the NZC, the mathematics reform was supposedly focussed on teaching for understanding. However, the teachers still felt accountable for a test. All the teachers in her study commented on time and coverage pressures leading Darling-Hammond to observe that the more immediate pressures will, of necessity, win out. These pressures were evident in this study.

Jill believed that achieving good results in NCEA was very important to Kauri High School and to the parents in her context, and this affected the teaching throughout the school. In some cases, for example, teachers were feeling pressure from their heads of department to cover the curriculum with the junior students to ensure that they would be prepared for NCEA assessments when they reached the senior school.

This perception of the schools' focus was supported by the comments of Mary and Nina who were in the same school as Jill. Mary maintained that her focus was on understanding the concepts so that the students could pass the assessment: "I have pushed for understanding to get at least achieved; maybe those with more understanding will get merit or excellence." The influence of NCEA was also evident in Mary's concern about the integrated subjects project. In this project the core subject teachers worked together to plan concepts that could be taught across subjects. Mary worried that the learning was superficial and would not provide junior students with sufficient grounding in her subject to cope with the assessments in their senior years. In her interviews Mary maintained that her degree enabled her to see the links between subjects. However, in her current environment, despite being in a project that emphasised conceptual links between subjects, she was concerned about coverage. 
In Nina's observed lesson the students were told that the purpose of the learning was to pass the assessment. Despite the fact that the topic of contraception could be considered highly relevant for year 11 students, this was not discussed in the class. Instead Nina made it clear that the purpose of the learning was to pass the assessment. She explained in her interview that she makes working towards success in NCEA clear to all her students at every year level. In other schools teachers felt that their school and their professional competence was judged by the NCEA results:

Susan: $\quad$ The school does see it as important, yeah, got to keep our percentages up there. As a teacher of seniors I feel that we are sometimes graded on our classes' pass rates for NCEA.

Christopher: $\quad$ Assessment acts as a carrot and stick. It's bad pedagogy and we are being appraised on it.

James spoke of the teachers being judged by the NCEA results of their school in the publication of league tables: "you have got that tension and the way, worry a bit, the minister starts talking about league tables again."

James, Susan and Christopher spoke of feeling more able to work in a student-centred way with juniors than they could with seniors and Edward believed that the need for coverage precluded widespread use of student-centred pedagogy in his senior classes. They maintained that the pressure of NCEA restricted their ability to teach seniors in this way. Their belief that a student-centred model of teaching would not result in successful NCEA results for seniors indicates that they were not confident that it did lead to effective learning and raised a question of their epistemological beliefs about teaching and learning.

The dominance of NCEA also appeared to affect the relevance of learning in some observed junior classes. For example, in Jennifer's year 10 class, students were being assessed using a Year 10 version of NCEA level 1 (more commonly an assessment for Year 11 students). Other examples will be discussed further in the next chapter, The Teachers in Action.

\subsubsection{Realistic time allowance for the teachers}

Eight of the participants believed that lack of time was an issue which would impact on the implementation of the NZC. They pointed out that teaching was already an extremely busy job and that it would be a huge challenge for teachers to take the time to understand, reflect on the meaning of the changes, and following that to prepare their lessons in a student-centred way. The mandated curriculum was an 
addition to their workload. Mary expressed her frustration that this did not seem to be appreciated by senior management who were no longer in the classroom.

As Jennifer pointed out, while there had been three teacher only days provided by the MOE, any additional time had to be funded by the school. There was no extra time given to them.

Nina acknowledged the need for teachers to have time to consider the implications of the changes. She pointed out teachers' everyday reality:

.... and you are still thinking I've still got to plan period 4 and then okay I've got year 11 now I think I might need to withdraw this kid because he's probably going to be playing up again because he's going to be sitting next to ... and we are supposed to be doing some managing self stuff but I really want to get this person under control ... but I still need to plan for the lesson. You can't win teaching, you can't win.

James's comment suggests that it is his perception that the effective pedagogy of the NZC would take more time to prepare for than alternative ways of teaching. He maintained that for a change in pedagogy to occur across the schools, there would need to be time made available: "For this to be the dominant pedagogy I think it will be finding the time to prepare."

Ruth believed that aspects of the effective pedagogy were unrealistic:

And it takes, you know I've got kids in my year 10 and if I could sit down with a couple of them and say, what I've been saying in real terms is this ... then they can learn that way, but I can't do that. People like ... have to work for hours, teachers worn down and hard to cope with change can't do all that and teach 5 classes a day - it's hard to get people to understand.

Edward and Mary had similar concerns.

You are really restricted sometimes with ... for a number of reasons ... you know timetable, the fact that you have got them for four hours, you just ... you do as much differentiation as you can. (Edward)

I think that has, there has been a big shift to the feed forward and the way we write reports but again some staff will say 28 kids, I've got an hour, do I take 10 minutes on each one and I've not taught a lesson. (Mary)

Jennifer believed that teachers would sacrifice personal time: "Yes, business as usual - here are all these changes, put them in place and teachers are very good at doing it but it's done with a huge amount of time outside of course as always." This was true of Jill who admitted that gaining a deep understanding of the suggested changes had required private study on her part, something that could not be expected of all teachers.

Both Ruth and Amy felt the benefit of working part time. Ruth believed this provided the "head space' to reflect on her teaching and the curriculum changes 
while Amy found that this allowed her to invest sufficient time in her planning and teaching: "there is no point in being paid a hell of a lot more if you are tired and can't do the job properly." Each of these teachers had invested considerable time further educating themselves, something they did not believe would have been possible if they had worked full time.

\subsubsection{Appropriate professional learning}

The ingredients for effective professional learning described in chapter 2 include: leadership that works with staff to clarify goals and expectations and actively supports teachers' efforts to change; norms that support collegiality and experimentation; effective PD pedagogies which provide teachers with opportunities to discuss and negotiate the meaning of the new learning and its implications for practice; followed-up assistance that continues long enough for new behaviours to be incorporated into ongoing practice and formal and informal methods for monitoring the process and used to help overcome obstacles; engaging their theories of practice (Fullan, 2007; Piggot-Irvine, 2006; Timperley et al., 2007; Webster-Wright, 2009). The degree of congruence between teachers' existing beliefs and those promoted by the PD needs to be understood. If this does not happen, engaging teachers' new practice is likely to be layered on top, not replace it (Timperley et al., 2007).

From the interviews, observations of the environment and examination of school documentation the interpretation of the PD offered in each context was as shown in Table 23. As can be seen, while there were elements of what the literature suggests as effective PD, some key aspects appeared to be missing in each context. 
Table 23. Professional development in each context

\begin{tabular}{|c|c|c|c|c|}
\hline Practice & Citation & Totara College & Kauri High School & Kawakawa College \\
\hline $\begin{array}{l}\text { Leadership that works with } \\
\text { staff to clarify goals and } \\
\text { expectations and actively } \\
\text { supports teachers' efforts to } \\
\text { change }\end{array}$ & $\begin{array}{l}\text { Bishop, 2008; Coburn, 2003; } \\
\text { Fullan et al., 2005; van Veen \& } \\
\text { Sleegers, 2001. }\end{array}$ & $\begin{array}{l}\text { Senior managers in the } \\
\text { study not committed to } \\
\text { the change } \\
\text { Head of departments } \\
\text { expected to lead. }\end{array}$ & $\begin{array}{l}\text { To some extent - goals not clear but } \\
\text { directives given and resourcing for } \\
\text { integrated studies } \\
\text { time allowance for learning groups. } \\
\text { Participants unsure of leadership } \\
\text { understanding }\end{array}$ & $\begin{array}{l}\text { Common goals not clear. } \\
\text { Support for ongoing PD and time } \\
\text { provided for learning groups }\end{array}$ \\
\hline $\begin{array}{l}\text { PD that is ongoing and } \\
\text { collaborative }\end{array}$ & $\begin{array}{l}\text { Bishop, 2008; Robinson \& Lai, } \\
\text { 200;Timperley et al., } 2007 .\end{array}$ & Dependent on departments & In learning groups & In learning groups \\
\hline $\begin{array}{l}\text { Ongoing monitoring, } \\
\text { support and feedback. }\end{array}$ & $\begin{array}{l}\text { Brown \& Sprangler, 2006; } \\
\text { Timperley et al., 2007; M. } \\
\text { Richardson, 2007; Deemer, } 2004 .\end{array}$ & No & No & No \\
\hline $\begin{array}{l}\text { Opportunities for } \\
\text { knowledge creation }\end{array}$ & $\begin{array}{l}\text { Mezirow, 1981; Darling- } \\
\text { Hammond \& Sykes, 1999; } \\
\text { Webster-Wright, 2009; } \\
\text { Hargreaves, 1995; M. Richardson, } \\
2007 .\end{array}$ & $\begin{array}{l}\text { Dependent on the } \\
\text { departments }\end{array}$ & $\begin{array}{l}\text { Potentially possible in learning } \\
\text { groups }\end{array}$ & Potentially possible in learning groups \\
\hline $\begin{array}{l}\text { Personal and professional } \\
\text { interlinked }\end{array}$ & $\begin{array}{l}\text { Robertson \& Murrihy, 2005; Bell } \\
\text { \& Gilbert, } 1994\end{array}$ & No & No & No \\
\hline $\begin{array}{l}\text { Learners actively and } \\
\text { interactively engaged }\end{array}$ & $\begin{array}{l}\text { Mezirow, 1981; Darling- } \\
\text { Hammond \& Sykes, 1999; } \\
\text { Webster-Wright, 2009; } \\
\text { Hargreaves, 1995; M. Richardson, } \\
2007 .\end{array}$ & $\begin{array}{l}\text { Individually but not } \\
\text { necessarily interactively }\end{array}$ & Within learning groups & Within learning groups \\
\hline Extended time to learn & $\begin{array}{l}\text { Bishop, 2008; Coburn, 2003; } \\
\text { Fullan, 2007; Piggot-Irvine, 2006; } \\
\text { Timperley et al., 2007; Webster- } \\
\text { Wright, 2009; Fullan et al., } 2005 .\end{array}$ & No & 40 minutes per week & Sometimes \\
\hline External expertise & $\begin{array}{l}\text { Timperley et al., 2007; Fullan, } \\
2001 .\end{array}$ & No & No & On one occasion \\
\hline
\end{tabular}




\begin{tabular}{|c|c|c|c|c|}
\hline Practice & Citation & Totara College & Kauri High School & Kawakawa College \\
\hline $\begin{array}{l}\text { Prevailing discourses } \\
\text { challenged }\end{array}$ & $\begin{array}{l}\text { Bishop, 2008; Timperley et al., } \\
\text { 2007; Luttenberg et al., 2011; van } \\
\text { den Berg, } 2002\end{array}$ & No & No & No \\
\hline $\begin{array}{l}\text { Opportunities to practise in } \\
\text { a PLC }\end{array}$ & $\begin{array}{l}\text { Fullan et al., 2005; van Veen \& } \\
\text { Sleegers, 2005. }\end{array}$ & In departments & $\begin{array}{l}\text { In team for integrated work } \\
\text { In learning groups }\end{array}$ & $\begin{array}{l}\text { In departments } \\
\text { In learning groups }\end{array}$ \\
\hline Coherence & $\begin{array}{l}\text { Coburn, 2003; Fullan \& Quinn, } \\
\text { 2012; Drath et al., 2008; } \\
\text { Luttenberg et al., 2011; Spillane et } \\
\text { al., } 2002 .\end{array}$ & No & No & No \\
\hline
\end{tabular}


All of the teachers had taken part in the 2 or 3 teacher-only days focussed on the NZC after which professional learning took place in departments for four of the participants, six were in self selected learning groups, two in groups to develop integrated studies, and two in a team teaching group. There were, therefore, regular opportunities for staff to work actively and interactively, to collaborate, and for knowledge creation at their own pace. However, it was not possible to gauge the extent to which this had happened.

The concept of learning groups in two of the contexts provided the teachers with a menu of possible interests that they could pursue. Jill stated that they were "self-regulated" with no monitoring of the learning. In Kauri High School documentation teachers were asked to consider creating learning groups which focussed on an aspect of the school priorities. These were named as:

- Developing and growing key competencies

- Developing blended learning

- Using ICT to open up new and different ways of learning as well as supplementing traditional ways of teaching

- Raising Māori achievement.

A list of 30 learning groups from previous years was included to provide some suggestions. They included:

- Building learning power and the key competencies

- Student-centered curriculum integration

- Student engagement

- Māori engagement and achievement

- Differentiation

- Assessment to Learn

Looking at these choices it was possible for staff to make a choice that linked to their personal goals or interests but was not necessarily related to the effective pedagogy or key competencies of the NZC. This suggests that in this context the implications of the NZC were just another item on a large menu.

Each of these learning groups in Kauri High School and Kawakawa College could be considered a learning community that was designed to focus on continuous learning for staff (Fullan, 2000). However, as discussed in chapter 2, merely being 
exposed to new ideas and working in a collegial community is not enough to bring about change (Peterson et al., 1996). Being part of a learning group at a designated time could be classed as "compulsory collaboration" (Hargreaves, 1994, p. 186). While teachers could choose their groups, it was not possible to know if they complied or had a genuine commitment to the inquiry of the group. The effectiveness of the group would depend on the individual's attitude to change to the dynamics and skills of the group (Stoll et al., 2006). Jill alluded to some of the issues: "Learning groups need someone to progress the group. They need structures and need some expertise work. They need guidance and need someone to ask critical questions ... some pressure is needed. You need to grow the expert in each area." Two of the teachers in Kauri High School demonstrated deep understanding of aspects of the effective pedagogy in the observed lessons. However, they had not joined learning groups exploring those aspects in which they may have led other teachers' understanding. Instead they chose groups that enabled them to pursue personal interests.

In Kawakawa College two of the participants did not join learning groups using the time to plan for team teaching. This was an effective professional learning community which could have provided a model for other learning groups. In these meetings Science, Social Studies and English teachers worked together with learning support teachers to discuss strategies and to plan the units of work. Teaching together the staff were in a position to critique and support each other, to discuss the needs of their students and to plan accordingly. In addition, they could use the expertise of the learning support teachers. Each year there was a change of half the team teaching staff allowing more teachers to take part. Susan described this as "spreading the love."

\subsubsection{The integration of key competencies}

As discussed in the previous section, there was a lack of a clear goal for the effective pedagogy and the integration of key competencies.

There had been work on what the key competencies meant but there was no evidence of development on how to integrate them. In the context where departments were expected to continue the professional learning, while there were references to departments that were developing their skills in integrating the key competencies there was no ongoing monitoring of this, it being left to the discretion of individual heads of departments. The work that had taken place appeared to focus on what each key competency meant but not on the theory underpinning the integration of them into learning. This is reflected in Amy's comment in 2009 that key competencies had not 
been discussed in any detail as a whole school or in her department. In subsequent interviews in 2010 and 2011, key competencies had still not been explored. The explicit integration of key competencies was not observed in this context.

Four of the participants were in a context in which staff had worked together as a whole and later in learning groups to produce a booklet that provided an unpacking of the key competencies. There were posters on the staffroom wall with details of each key competency and Mary believed that progress had been made: "Key competencies are quite good. The whole staff has been discussing what they look like. We have made charts what key competencies look like in maths." These booklets reflected extensive work and listed the strategies teachers could include to encourage the development of key competencies. However, no mention was made of the conceptual understanding involved in the integration of key competencies and at the time of observations they were observed being integrated in only one lesson.

In the context of Kawakawa College, Edward, from his perspective as head of a department, believed key competencies needed deeper consideration. He wondered if teachers were incorporating them effectively or just in a token way to comply with directives from management. This suggests that he had not facilitated meaning making or knowledge building in his department and that it had not happened in the wider context of the school either. Integrated key competencies were not observed in any lessons in that context.

In addition, no mention was made of exploration of the effective pedagogy or a common understanding of what the effective pedagogy involved. In one context the staff had been directed by management to share learning intentions and success criteria with the students. However, as discussed later in the enacted beliefs section, there appeared to be limited understanding of how these were to be incorporated into the lessons suggesting that the theory underpinning these strategies was not understood.

A key element of effective PD to support change - "prevailing discourses are challenged" - was not evident in any context. Comments were made by seven of the participants about some of their colleagues who resisted or did not see the need for any change. This suggests a lack of a shared mindset (Fullan \& Quinn, 2012) in their context:

For an enormous number of teachers their focus still is on feeding in facts.

I fully believe in the key competencies but there are some people that have put, maybe, a wall up. 
Yeah, it sort of requires people to sit down and rethink what they are doing and sometimes it's just too busy.

What worries me about teaching is that there are still a lot of teachers that teach in isolation and their little room is their island.

Some people's reaction when they read the document was "oh good, I'm already doing that or we are on the right path, we'll just keep going.

We do have people who have not changed....

If leaders of the implementation had investigated, they would have found in each context participating teachers who had at some stage experienced what they had found to be effective professional learning relevant to their personal goals: Amy in the Japanese lesson study model within the numeracy project as described above, Jill in her action research supported by a mentor from the university, Susan in her team teaching and in the cooperative learning project, and Nina in the classroom management course. Several comments reveal an understanding of what is needed for transformational learning. Jill, for example, maintained that for change to happen in a meaningful way a teacher needed to feel some discomfort with present practice and to look for a way to make it better. Other comments included:

It's our lesson, a group plan - that makes it more powerful when I am going into classes with other teachers I certainly have to think about what I am doing. (Amy)

I think they need to believe in it first, maybe they need to see it work to start with and then I think it needs to be done in a practice sense. You can't just say this is what you can do, try it. You need someone there to follow up and say, well, you are trying it but maybe tweak it a little bit and now try it again because otherwise it's just another piece of paper with other six I have just got in a pigeonhole. (Nina)

Professional development without the opportunity for deep thinking doesn't make a difference to your teaching. They could do PD but they don't think there is something they are not doing ... they believe what they are doing is fine, they haven't understood the new document, the essence of it ... A teacher thinks why do I need to change or what really needs to change. I'm ok. (Jill)

Susan described cooperative professional learning: In this programme, the staff would have a strategy demonstrated, be asked to use it during the following week and in the next session report back. In addition, teachers would take turns to model what they had done in their classes. She believed that this model created an environment where everyone could see what others were doing and she felt well supported in her learning. 


\subsubsection{Competing initiatives}

Blase's (1991, p. 1) statement that "schools exist in a vortex of government mandates, social and economic pressures, conflicting ideologies" was exemplified in each context. Mary summed up the pressures of the number of initiatives in her school when she described several aspects she needed to pay attention to in her class: "I can't do that many things all the time every time."

In each context the participating teachers were involved in other initiatives in addition to the implementation of the NZC. In Jennifer's context, projects had been embarked upon after the school analysed the needs of the students and Jennifer was enthusiastic about them: "That's what I love to see-its meeting the needs of the students." She was now wondering how they would embed the learning from these projects and manage the imposed change from the NZC. Her message for the MOE was: "So keep on asking us, keep on pouring in change, but don't expect that the changes will be what you want, because you've got one pathway, but the teachers have got other things coming in."

Amy, as described in chapter 5, was the coordinator of the numeracy project in the same school. It has been an effective project for her. However, she did not feel confident that the learning from the project would be embedded by other teachers within her department. Nor was she confident that the momentum of the project would continue without her leadership of it because staff had other responsibilities and other demands on them: "it comes back to time and priorities and it comes back to people resourcing within our department."

In Susan's, Edward's, Christopher's and Ruth's contexts the school was planning a whole school focus on differentiation, on e-learning, on using data for assessing the literacy level of juniors, and on the NZC. The outcome stated in the strategic plan for NZC professional learning was not on the implications of the effective pedagogy or key competencies but "Increased use and awareness of elearning." In addition, as explained above, teachers would pursue their own area of interest in their professional learning groups and the team teaching group would work together. This was in addition to the plan to develop a common pedagogical language.

In Mary's, Nina's, Jill's and Joseph's contexts there were also other initiatives in place. The teachers had been directed by senior management to work on goal setting with their students. In addition, there was a requirement for teachers in the integrated studies teams (Jill and Mary) to teach essay writing skills. They had been provided with a three lesson structure to do this. Mary felt that teaching writing 
was outside her area of expertise and she was also concerned that three lessons on writing would take time away from her mathematics teaching. Nina believed that the range of initiatives can be overwhelming for a busy teacher:

I do think so because at the same time they're still trying to plan, they're still trying to mark, they're still trying to manage their classes and I think that if you are going to be an effective teacher you need to master one thing at a time, you can't try and do everything at once.

All these competing initiatives militate against a coherent focus in the implementation of the effective pedagogy and key competencies of the NZC. It is also difficult to understand how teachers could develop a conceptual understanding of any of the messages in these projects with the limited time allowed and with the busyness of their days.

In summary, as shown in Table 25, with the exception of Joseph, no teacher, in their appraisal of their context fully believed that it provided the environment to support the changes signalled in the NZC.

Table 24. The teachers' appraisal of their context's support for the changes.

Key: + indicates a belief that the context would support the implementation, - indicates a belief that the context would not support the implementation

\begin{tabular}{|c|c|}
\hline Teacher & Context beliefs \\
\hline Amy & $\begin{array}{l}\text { - No time provided. } \\
\text { - Lack of departmental goals. } \\
\text { - Little collegial and leadership support. }\end{array}$ \\
\hline Christopher & $\begin{array}{l}\text { - School and community pressure for NCEA results. } \\
\text { - Being judged by NCEA results. } \\
\text { - Lack of time. } \\
\text { - Number of assessments. }\end{array}$ \\
\hline Edward & $\begin{array}{l}\text { - The structure of timetable and class sizes makes it difficult. } \\
\text { - Student centred threatens coverage. } \\
\text { - The assessment culture prevents it. }\end{array}$ \\
\hline James & $\begin{array}{l}\text { - Pressure to teach to tests and NCEA assessments. } \\
\text { - A range of other responsibilities. } \\
\text { - No time provided. }\end{array}$ \\
\hline Jennifer & $\begin{array}{l}\text { - Pressure to increase roll. } \\
\text { - Inadequate resourcing provided. } \\
\text { - No time funded. } \\
\text { - Alignment to NCEA assessments will take the focus away from teaching and } \\
\text { learning. } \\
\text { - More assessment. } \\
\text { - } \text { Threat to sustainability of prior professional learning. }\end{array}$ \\
\hline Jill & $\begin{array}{l}\text { - Credibility of leadership. } \\
\text { - Lack of a common vision. } \\
\text { - Change process not understood. } \\
\text { - Coverage /NCEA pressure message in the school. } \\
\text { - Culture of individuality. } \\
\text { - No time allowance for teachers. }\end{array}$ \\
\hline
\end{tabular}




\begin{tabular}{ll}
\hline Teacher & Context beliefs \\
\hline Joseph & + Leadership will drive the changes. \\
\hline Mary & - Lack of common understanding. \\
& - Too much required. \\
& - Pressure of NCEA. \\
\hline Michael & - No one is an expert. \\
\hline Nina & - More PD needed. \\
& - Some resistance from staff. \\
& - Lack of ongoing support to embed changes in pedagogy. \\
& - No time allowance for teachers. \\
\hline Ruth & - Timetable, class sizes make it difficult. \\
& - No time allowance for teachers. \\
\hline Susan & + Collaboration with colleagues. \\
& - Some colleagues lack of collaboration. \\
& - School culture focus on external results. \\
& - Being judged by NCEA results. \\
\hline
\end{tabular}

The components addressed in this chapter are summarised below and will be discussed in more detail in the following chapters. 


\section{Table 25. Teachers' appraisal of the signalled changes}

Key: -indicates a negative appraisal, + indicates a positive appraisal

\begin{tabular}{|c|c|c|c|}
\hline Teacher & Relevance to personal goals & Emotional response & Context beliefs \\
\hline Amy & $\begin{array}{l}+ \text { There is a link between the } \\
\text { numeracy project and the NZC } \\
\text { effective pedagogy. } \\
\text { - Detracts from focus on subject and } \\
\text { other initiatives. }\end{array}$ & $\begin{array}{l}\text { + Pleased it fits with the numeracy principles. } \\
\text { - Frustration with leadership. } \\
\text { - Frustration with other staff. }\end{array}$ & $\begin{array}{l}\text { - No time provided. } \\
\text { - Lack of coherent vision. } \\
\text { - Little collegial and leadership support. }\end{array}$ \\
\hline Christopher & $\begin{array}{l}+ \text { Fits with espoused personal beliefs } \\
\text { with Juniors. }\end{array}$ & $\begin{array}{l}\text { + Happy with the freedom it represents with junior } \\
\text { students. } \\
\text { - Anxious about appraisal and succeeding in NCEA. } \\
\text { - Torn between personal satisfaction and pressure for } \\
\text { results. }\end{array}$ & $\begin{array}{l}\text { - A culture in which NCEA results are measure of } \\
\text { effectiveness. } \\
\text { - Lack of time. } \\
\text { - Appraisal and succeeding in NCEA. }\end{array}$ \\
\hline Edward & + Fits with espoused personal beliefs. & $\begin{array}{l}\text { + Pragmatic. } \\
\text { - Not realistic in the assessment environment. }\end{array}$ & $\begin{array}{l}\text { - The structure of timetable and class sizes makes it } \\
\text { difficult. } \\
\text { - Student centred threatens coverage. }\end{array}$ \\
\hline James & + Fits with espoused personal beliefs. & $\begin{array}{l}\text { + Supports the concepts. } \\
\text { - Frustration at other responsibilities. } \\
\text { - Concerned about lack of time. }\end{array}$ & $\begin{array}{l}\text { - Pressure for coverage - common testing for juniors, } \\
\text { NCEA for seniors. } \\
\text { - A range of other responsibilities. } \\
\text { - No time provided. }\end{array}$ \\
\hline Jennifer & $\begin{array}{l}\text { - Detracts from embedding other } \\
\text { initiatives. } \\
+ \text { Focus on teaching and learning. }\end{array}$ & $\begin{array}{l}\text { + Supportive of the emphasis on teaching. } \\
\text { - Anger at lack of acknowledgement of teachers' work. } \\
\text { - Frustration at increased workload. } \\
\text { - Anger at more change. } \\
\text { - Frustration that it would distract from local efforts. } \\
\text { - Suspicious of external assessment of key competencies. }\end{array}$ & $\begin{array}{l}\text { - In a Market model pressure to increase roll. } \\
\text { - Inadequate resourcing provided. } \\
\text { - No time funded. } \\
\text { - Alignment to NCEA will take the focus away from } \\
\text { teaching and learning. } \\
\text { - More assessment. }\end{array}$ \\
\hline Jill & + Fits with espoused personal beliefs. & $\begin{array}{l}\text { + Practice affirmed by philosophy of NZC. } \\
\text { - Concerned that workload and time allowance will } \\
\text { impact negatively on other teachers' understanding. }\end{array}$ & $\begin{array}{l}\text { - Credibility of leadership. } \\
\text { - Lack of a common vision. } \\
\text { - Change process not understood. } \\
\text { - Coverage /NCEA pressure. } \\
\text { - Culture of individuality }\end{array}$ \\
\hline
\end{tabular}




\begin{tabular}{|c|c|c|c|}
\hline Teacher & Relevance to personal goals & Emotional response & Context beliefs \\
\hline Joseph & $\begin{array}{l}\text { Elements fit with espoused personal } \\
\text { beliefs. }\end{array}$ & + Will follow orders. & + Leadership will drive the changes \\
\hline Mary & + Fits with espoused personal beliefs. & $\begin{array}{l}\text { - Self-esteem battered by pressure of initiative. } \\
\text { - Stressed finding balance. } \\
\text { + Excited by philosophy of NZC. }\end{array}$ & $\begin{array}{l}\text { - Other teachers not as confident. } \\
\text { - Too much required. } \\
\text { - Pressure for coverage. } \\
\text { - NCEA for seniors. }\end{array}$ \\
\hline Michael & + Fits with espoused personal beliefs. & $\begin{array}{l}\text { - Resentment of more change. } \\
\text { - Concerned for teachers vulnerability. }\end{array}$ & - Challenge leading differentiated PD. \\
\hline Nina & + Fits with espoused personal beliefs. & $\begin{array}{l}\text { +Excited by philosophy of NZC. } \\
\text { - Concerned other teachers have not engaged. }\end{array}$ & $\begin{array}{l}\text { - More PD needed. } \\
\text { - Some resistance from staff. } \\
\text { - Lack of ongoing support to embed changes in } \\
\text { pedagogy. }\end{array}$ \\
\hline Ruth & + Fits with espoused personal beliefs. & $\begin{array}{l}\text { + Excited by philosophy of NZC. } \\
\text { - Not realistic with current structure, class sizes, time } \\
\text { allowance. }\end{array}$ & - Timetable, class sizes make it difficult. \\
\hline Susan & + Fits with espoused personal beliefs. & $\begin{array}{l}\text { - NCEA pressure precludes use with seniors. } \\
+ \text { A fit with her developing practice. } \\
\text { - Torn by division of junior and senior. } \\
\text { - Wishes for more collaboration with other colleagues. }\end{array}$ & $\begin{array}{l}+ \text { Collaboration with team teaching colleagues. } \\
\text { - A culture in which NCEA results are measure of } \\
\text { effectiveness. }\end{array}$ \\
\hline
\end{tabular}




\subsection{Chapter summary}

In this chapter I have interpreted the way in which the teachers further constructed their professional identities when they encountered a critical incident which created a sense of dissonance and motivated them to seek a way to resolve it. This provides some insight into how teachers seek sources of learning to develop their practice. What was shown in these examples, contrary to what is sometimes suggested, teachers do embrace change if it is significant to their goals for their practice.

However, the teachers' perception of the signalled changes in the NZC was a different story. The key feeling of dissonance that could be resolved by the proposed changes was not apparent in the study. While teachers wished to continue to develop their practice, none of the teachers felt dissatisfied enough with their practice to consider a different conceptual approach. Nine of the teachers believed that their approach was appropriate in the assessment environment and were unsure that a constructivist approach would prove to be so. They therefore did not perceive the change would be of benefit for them. This is reflected in Table 18 linking responses to the NZC with their personal goals. Despite some teachers - Susan, Christopher and James - feeling drawn to constructivism, they still did not believe it would be appropriate for senior students. There were ambiguous goals in their contexts. While there was work associated with the $\mathrm{NZC}$, it was success in NCEA assessments that was perceived to be the key goal in their context. It may have not been explicitly articulated but that was the implicit message and one that the teachers subscribed to. They subsequently internalised this school goal into a personal one. Thoonen et al. (2011) and Ford (1992) maintain that individuals will adopt goals shared by many of the others in their context and will commit themselves to goals assigned by a legitimate authority. This appeared to be the case with most of the participants in the study. Their perception was their success as a teacher and their school effectiveness was measured by their students' success in the external assessment system. As Christopher expressed it, "Assessment acts as a carrot and stick - its bad pedagogy and we are being appraised on it".

Without a feeling of dissonance the teachers were not initially motivated to consider significant change. Interpreting the context beliefs, it appears that the chances of the participating teachers being motivated to instigate the changes were slim! However, this was their reality which should be seriously considered when change is being mooted. 


\section{The Teachers in Action}

Educational change depends on what teachers do and think. (Fullan, 2007, p.129)

\subsection{Chapter overview}

This chapter includes both description and interpretation of the participating teachers' practice. As Eisner (1998, p. 90) points out, "in writing education criticism a writer always tells an incomplete story. One does not - nor cannot - tell all.” My hope is that, in what I have selected to tell, there is sufficient description to allow a reader to "see' the class and to either support my interpretation or to develop their own. There are four sections: in the first section, Teaching Approaches, I have explained the categories I used to interpret what I observed. This is followed in the second section by a description of some of the lessons I observed. The aim of this study was not to simply label the teachers' practice but to ascertain the significance of the signalled changes of the NZC to the teachers' beliefs and practice. Therefore, an overview of the extent to which the observed practice linked to NZC effective pedagogy is interpreted in the next section. As an indication of the curriculum focus, this is followed by an interpretation of the relevance the teachers attached to the learning in the classes. Finally, to establish if the pedagogy of the NZC and the integration of key competencies were relevant to the teachers' manifested beliefs, I have attempted to identify the beliefs that underpinned the observed lessons. Data that support this section are from classroom observations, the template (see appendices), and the post-observation interview.

This chapter addresses the following questions:

- What is the significance of the NZC to their beliefs and practices?

- What is the significance of the NZC to their personal agency?

- How do elements of the current context interact with and shape their beliefs and practice?

\subsection{Interpretation through the lens of an educational connoisseur}

The teachers' observed practice did not neatly fit within either a) a transmission theory of teaching and learning (Brooks \& Brooks, 1993, p. 17) and an objectivist epistemological belief or b) elements of the effective pedagogy described in the revised curriculum (MOE, 2007b, p. 34) based on constructivist epistemological beliefs. As discussed in chapter 2, a person may hold a set of 
personal epistemological beliefs that are part of a wider epistemological world view (Hofer, 2004). Bereiter and Scardamalia (1996) refer to this style of teaching as “dualism', describing it as:

One moment the teacher wears the hat of a biologist or space scientist, and knowledge is treated as something brought before the class to be discussed and understood. The next moment the teacher puts on a pedagogical hat and asks questions to probe knowledge, now regarded as stuff hidden away in the minds of individual students. (p. 410)

This was evident in the lessons observed with elements of both objectivist and constructivist epistemological beliefs appearing to be demonstrated in many of them. Schraw and Olafson (2008) maintain that attempts to label teachers' beliefs ignore the variables of the context and the reasons sitting behind the teachers' choices and actions. Therefore, in the following discussion of the lessons observed I have included discussions of what I perceived to be the situational aspects that could have impacted on teachers' approaches.

\subsection{Teaching approaches}

I have attempted to capture the complexity of the range of observed teaching approaches by adapting Boulton-Lewis, Smith, McCrindle, Burnett, and Campbell's (2001) categories for describing my interpretation of the participants' approaches to teaching and learning. From their interviews with 16 secondary school teachers in two Australian schools, Boulton-Lewis et al. identified four categories: 1) A conception of teaching as a transmission of content and skills and a conception of learning as an acquisition of content. 2) A conception of teaching as a development of skills and of learning as a development and application of skills. 3) A conception of teaching as a facilitation of understanding and learning as a development of understanding. 4) A conception of teaching as transformation and of learning as students grow and change.

Adapting their approach, the observed lessons are described as being on a continuum from what I have called "monitored development of understanding" through "facilitated development of understanding" to "facilitated knowledge building" (see figure 8). Each of these categories is further explained in the following sections followed by a description and interpretation of some of the observed lessons.

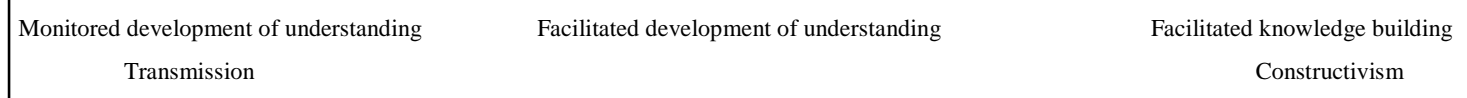

Figure 7. Range of teaching approaches used 


\section{Monitored development of skills}

I have used the word "monitored" because in these observed classes the teacher appeared to be carefully checking that the students absorbed the required knowledge with the focus on their achieving a "correct" understanding through selected activities. Teachers presented the information and used strategies to motivate the students, used materials and asked them to do practical activities. As the students worked, the teachers monitored their progress towards reaching the level of skill and understanding required to meet an assessment. Efforts were made to increase engagement though activities to "stimulate the curiosity of students" but not to "use or apply what they learned in new contexts" (MOE, 2007b, p. 34). While in these classes students did "work in groups and have conversations with other people," they did not have "ownership of the learning" (MOE, 2007b, p. 34). Instead, the activities were designed to shape the learning to fit the imminent assessment. Therefore the goals for the learning and the process for achieving the goals were decided by the teacher. The atmosphere in these classes was one of compliance, with little evidence of active learning. Students did what was asked of them but exhibited little interest in the learning. This was not obviously the transmission model described by Brooks and Brooks (1993, p. 17): “Teachers generally behave in a didactic manner, disseminating information to student." Nevertheless, this category suggests a view of teaching as "filling the mind as a container" (Bereiter \& Scardamalia, 1996; Berliner, 2002; Schommer 1998). This approach did not seek to encourage knowledge construction or critical reflection. Instead, it focused on ensuring an understanding of the prescribed content (Magrini, 2010).

\section{Facilitated development of understanding}

In the facilitated development of understanding category the teacher facilitated the students' learning by supporting them towards an understanding by working with them, asking probing questions and providing activities that required deeper thinking, but again it did not work towards knowledge construction or critical reflection. As in monitored development of content, in these classes the learning outcomes were nonnegotiable limiting the possibility of student's pursuing goals for learning other than those determined by the teacher. However, the students were actively involved in deepening their understanding often through group work. This approach to teaching met to some extent: "Effective teachers look for opportunities to involve students directly in decisions relating to their own learning" and to the following criteria of the effective pedagogy of the NZC: "Students learn as they engage in shared activities and 
conversations with other people. Challenge, support and feedback are always available" (MOE, 2007b, p. 34).

\section{Facilitated knowledge building}

In the facilitated knowledge building category teachers provided stimulus to develop their students' conceptual understanding and their world view through a range of strategies (Boulton-Lewis et al., 2001; Trigwell, Prosser, \& Taylor, 1994). In this category of teaching the students were "knowledge building" (Bereiter, 2002, p. 68). Scardamalia and Bereiter (2007, p. 15) use the term knowledge to refer to "the production of knowledge." It involves inquiry into a topic which, through activities which may include collective questioning and discussion, modelling or lecturing, results in a gradual development of ideas (Scardamalia, 2002). The process of knowledge building advances the understanding not only of the individuals within a group but also that of the other students in the class.

This approach meets the criteria for the effective pedagogy of the NZC:

Curricular activities rely heavily on primary sources of data and manipulative materials. Students are viewed as thinkers with emerging theories about the world. They critically review the material they encounter and consider other ways of thinking. Teachers generally behave in an interactive manner, mediating the environment for students. Students primarily work in groups. Teachers seek students' point of view in order to understand students' present conceptions for use in subsequent lessons. Assessment of student learning is interwoven with teaching and occurs in a variety of ways. (MOE, 2007b, p. 34)

\subsubsection{Examples of observed practice}

In the following sections a selection of the lessons I observed are described and interpreted using the categories described above.

\section{Monitored development of content and skills}

Christopher dominated the observed Year 12 Biology lesson, showed and told the students what to do, and monitored their progress guiding them to the "correct' answers in an approach that I believed was a monitored development of skills. A poster on the wall with the heading "three basic rules" suggested a class where the teacher is very much “in charge': 1) Follow the teacher's instructions; 2) Stay seated unless the teacher gives permission; 3) Complete assigned work.

The students wandered into the sunny laboratory and, as they were seated, were told by Christopher that the purpose of the lesson was to prepare for the assessment which it appeared they would do by learning from their notes and graphs. In this class Christopher was focussed on ensuring that the students developed their 
skills and knowledge to achieve the level required for the imminent assessment, telling them: "This week we are going to learn about the theory. It will be intense for the next few weeks so you will have to be on your game." His anxiety that sufficient work would be covered appeared to underpin the lesson. For example, the students were asked to consider three questions as they graphed their data from their experiment in an earlier lesson. However, when none of them volunteered an answer Christopher supplied it for them. While not actually lecturing, this nevertheless did seem to be a transmission of content and skills.

The same material was presented to all the students who displayed very little engagement, and copied notes from the board while chatting to each other on a range of topics unrelated to the learning. Christopher asked them to graph their results from an earlier experiment explaining the method as he modelled it on the whiteboard. The students copied the work, again talking off task which suggested that they were not attempting to make sense of it. As the students worked, Christopher moved around the room commenting on the quality of the students' graphs, not on the learning. For the next section of the lesson Christopher showed a diagram of osmosis on an overhead projector and explained it to the students. During the explanation he asked the students questions without looking at them often while still facing the overhead screen and when, after waiting for a very short time, there was no response from them, he answered the questions himself. Young (1991) classifies these types of questions as the ones in which the questioner knows the answer and the answerer is being tested. In Christopher's case it appeared that he was answering the questions to ensure that the students copied down the correct answers.

Halfway through the observed lesson Christopher related the learning to a real life situation. There was immediately a noticeable change of energy in the room and the students were keen to ask questions. However, Christopher did not explore the topic in any depth, expressed concern about the limited time available before the assessment, and moved quickly back to focus on the content of the lesson. In his interview after the observation Christopher stated that he looked for opportunities to encourage the students to think critically on real life dilemmas: "I like to squeeze it in. If something is important screw the assessment." In the observed lesson, with his worry about coverage, the relevant example was indeed squeezed in. Finally, Christopher gave each student a diagram saying: "Ok is everyone happy with that? We don't have time to discuss it. Before you go, read the question - you will be engrossed in preparing for an internal so you can do this by next Monday." 
This lesson was obviously a follow-up to a practical experiment leading to an assessment. In his post-observation interview Christopher described himself as anxious about meeting deadlines. This perhaps explained his obvious concern throughout the observed lesson that the necessary work would be covered in time for the assessment. Watching him teach seniors raised the question of how Christopher would teach without the worry of an assessment (and the implications for his perceived competence) hanging over him. Did he hold objectivist epistemological beliefs or was an objectivist approach the only way he believed was possible given the number of assessments his students faced? He had described how he enjoyed working in a more constructivist model with a junior class. However, his belief that he could not work this way with the seniors suggested that constructivism did not fit with his epistemological beliefs. Or, perhaps, it suggests that, in striving to comply with the requirements of an assessment regime, Christopher was compromising his true self (Neyland, 2010; Nias, 1997).

Jennifer. I also perceived Jennifer's teaching of a senior class as one in which a monitored development of skills occurred. It was a brief observation and this snapshot is included here because it suggests that a teacher's default approach may be a teacher-centred one and that a student-centred pedagogy may not reflect her genuine beliefs about teaching and learning. It is also an example of the complexity of a teacher's working day and Jennifer's reality in which she was required to switch to different modes of operating and to a different focus within a short space of time.

It was a challenging scenario. The students had experienced an abrupt shift from a high energy extended session in the gym to sitting passively in a classroom. I had observed Jennifer in the gym leading the preparation for a sports day. It was an impressive, high energy and demanding undertaking during which she organised the huge area filled with possibly 200 excited students and their teachers. When it finished, Jennifer rushed to her classroom trailed by the students who, unlike their teacher, were moving at a desultory pace. There were approximately 30 minutes remaining until their morning break; many students were muttering that they were hungry and surreptitiously sneaking snacks from their pockets. They wandered into the class and eventually sat slumped at their desks.

Jennifer asked the students to get their novels and their log books out of their desks which they slowly did. She told the students: "we are getting through it" (the novel) giving an impression that reading this book was a chore for both her and the class. This was another example of the teacher "driving the learning." Jennifer strode the room and attempted to engage the reluctant students with her energy, reading the 
novel in a dramatic voice and asking low level questions: "Peter tell me what has happened? Who did that?" In this class the questions appeared designed to maintain control by encouraging the students to concentrate on the reading and to test that they were paying attention (Bishop \& Glynn, 1999). The students remained passive and reluctant to answer. They were next asked to take turns to read from the novel which did increase their attention and Jennifer continued to ask questions periodically. This pattern continued for the remainder of the short lesson. I sympathised with Jennifer having to so quickly move into a different role, to assemble her thoughts and to face students who obviously did not want to be there. While it seemed that Jennifer responded to the situational dilemma by applying a teacher-centred approach it may be that this was her only option when faced with hungry, restless students.

\section{Combined approaches}

Nina's Year 11 Health lesson took place in the library. This was a change for the students and I was aware that working in a different location can be a source of distraction. This was not the case with Nina's class. Throughout the lesson Nina circled the students who were working in groups around tables and with her energy and positive affirmations orchestrated an environment in which the students were highly engaged.

Her way of teaching was a fit with the image of herself as a teacher that she described in her interviews. She supported the students in their learning and praised any initiative they showed, praised all effort and asked students to write their names on the board to acknowledge how well they were working. Any students who believed they had worked well but had been overlooked were also invited to write their names on the board. I wrote in my field-notes: "I am impressed that Year 11 students who seem so proud of their “cool' appearance are obviously delighted to do this!" The lesson ended on a positive note: Well done Year 11 - awesome work."

Nina's lesson contained aspects of both facilitated development of understanding and monitored development of skills. In one aspect of the lesson, effectively integrating key competencies, she facilitated the development of understanding. During the lesson the students were asked to evaluate their selfmanagement strategies, reflect on their progress, and to make the changes they believed would develop their skills. Her rationale for this approach, explained in the interview after the observations, was not related to a life skill but to achieve success in NCEA assessments because having the ability to reflect she believed enabled them to develop the deeper understanding needed to achieve an excellence. Nevertheless, through a process of setting their goals, reflecting on their skills development, and 
making appropriate changes, the students were constructing their own understanding. The students undertook this exercise seriously and there was a perceptible increase in concentration for the remainder of the lesson.

However in the content part of the learning, Nina monitored the development of content and skills to meet prescribed criteria. The purpose was on the whiteboard: “Aim: To identify different types of contraception. This will help in your assessment." Students worked in groups to find the information from a variety of sources but they were not asked to critically evaluate the source of the information or the quality of it, simply to find different types of contraception. She reminded them to use the correct terms: "STIs, not STDs or it will be a not achieved in the assessment." As noted in the previous chapter, despite the fact that this topic would appear to be highly relevant for the students, there was no discussion of how they would be able to use the information beyond an assessment. As Nina explained:

I link it to NCEA ... you know ... why are we doing it, this will help you in your assessment, this is going to help you answer things properly so at least I don't get the oh why are we doing this, I explain why right at the start.

Joseph. My first impressions were that Joseph's teaching was a monitored development of skills and content approach. Watching Joseph teach in the classroom I could sympathise with his struggle to engage the students who sprawled passively at tables. He began his lesson by explaining to the students that the focus for the lesson was to begin a unit of study at the end of which they would have the opportunity to earn credits. On the whiteboard he had written: "Learning intention: Start to understand new unit of study: To set a short term goal.” The learning was based on a fixed curriculum; however, Joseph explained to the students that the skills of setting goals could be useful in their lives, giving them an example from his own experience. In doing this he was demonstrating the belief that "Students learn most effectively when they understand what they are learning, why they are learning it and how they will be able to use new learning" (MOE, 2007b, p. 34).

After a sluggish start, with little response from the students, Joseph abruptly asked them who had earned credits, presumably to trigger their interest in the topic. However, this did not increase their engagement, they slumped back and for the remainder of the lesson Joseph lectured on setting SMART goals from a PowerPoint presentation to indifferent students. Joseph and the students seemed unhappy.

In the next part of the lesson when the class moved outside I began to reconsider what I was observing. Before they left the room, Joseph told the students to 
think of short-term goals for their skateboarding and Frisbee skills. They moved eagerly and once outside, the atmosphere changed dramatically. This was a different class. The students were energised and eagerly began to work on their skateboarding and Frisbee skills. Joseph was also full of energy as he worked with individual students asking them probing questions: "What's your short term goal? Be specific ... what skills will you make your goal? How long will you give yourself to learn it?" The strength of Joseph's relationship with the students was evident; they were relaxed with him, openly discussed their ideas and appeared to feel safe to take risks in their attempts to learn. One of the students with significant learning difficulties was accompanied by a teacher's aide and James patiently scaffolded him towards the learning. The students experimented and discussed their progress with Joseph and with each other. During this section of the lesson they could identify what they needed to do to improve. At the end of the lesson, as they sat casually around Joseph on the court, they eagerly contributed to the discussion and were able to both describe SMART goals to Joseph and to evaluate each other's goals. They had achieved the intended learning for the lesson making me reconsider the effectiveness of the "lecture" in the classroom; despite appearing to be passive indoors they had evidently understood the basics of SMART goals and were able to build on their understanding with practical application outdoors.

Joseph had told the students that they would be doing this unit for two or three weeks and they would "see how they got on." His reflection time at the end of the lesson gave him an opportunity to assess their progress meeting a description of constructivist practice.

It was apparent that the outdoor lesson was where Joseph and the students felt most comfortable and that it could have been a more effective way to start the lesson. I wondered if that would have been his preferred way if he did not have someone coming to observe him. Another possible explanation for his formal monitoring of the development of knowledge approach in the classroom was because he was trying to implement a "directive from the top." He was referring to his adjustment to include learning intentions, success criteria, and explicit key competencies in his teaching which, while on the whiteboard, were not referred to in the inside lesson. Ironically, in the outside lesson Joseph was establishing effective learning intentions and success criteria. While he did not explicitly share the key competencies with the students, it was possible to see how this could have been done as they worked on their skills and checked each other's progress. Joseph's natural approach was to 
construct the learning with the students. With observation and feedback from a peer or a Head of Department I believe Joseph could have been supported to make small adjustments without compromising his personal style of teaching. Unfortunately, despite many efforts to do so, Joseph and I were unable to schedule a follow-up interview so I was unable to discuss these points with him.

\section{Facilitated development of skills}

Edward's teaching in his senior History class appeared to belong to facilitating the development of skills category. Edward warmly welcomed the students into the room and organised them in groups. He told them: "Today is kind of a consolidation spell." They were asked to revisit and collate their notes from previous lessons. To help them they were given worksheets which required them to decide on the differences and similarities between two historical campaigns. At first the students willingly set to work but when the work became more challenging many were off task and passively writing notes. At that stage, about two thirds through the lesson Edward told them "If we can be aware of the thinking behind these actions we can apply what we know in a new context." However, this concept was not explored. (In my field- notes during the observations I wrote "difficult to know from the students' body language if they understand this concept.") The students were told their priority was to get their own list of ideas by copying down the ideas from the group discussion.

As Edward explained in the interview after the observation, on reflection he realised the relevance of the learning should have been addressed at the beginning of the lesson. This had not happened in his haste "to get the ball rolling." This reflects a teacher's reality when wishing to get a large number of young people settled and busy at their work, especially when being observed. However, it may have also indicated that conceptual understanding was not the dominant focus for Edward. Working in groups I wondered if, through this activity, the students were developing their understanding or simply helping each other organise the material in order to gradually "achieve the level of skill and understanding of the teacher" (BoultonLewis et al., 2001, p. 41) and prepare to write paragraphs for the assessment.

Edward explained in the interview after the observation that he used this type of activity with other classes:

For year 13 History, they had to learn about the various industries of $19^{\text {th }}$ century. Rather than going through each one and spending a couple of spells on each one - I said right here's the week you learn, you're in groups and they summarise the notes, they write some activities for the rest of the class 
and they wrote a quiz so everyone had to learn a little bit about them, be an expert.

In each of these examples while the students were working together it did not appear that they were "building knowledge." Instead, through various strategies they were finding the material needed to pass the assessment and sharing it with each other. The activities were a fit with the effective pedagogy of the NZC. However, as Bereiter (2002) points out, while there is "nothing wrong with students helping each other learn, this is not the same as collaborative knowledge building" (p. 20). These activities stop short of meeting the description in the effective pedagogy of the NZC that "students are viewed as thinkers with emerging theories about the world" or that "Teachers encourage students to stand back from the information or ideas that they have engaged with and think about these objectively" (MOE, 2007b, p. 34).

A range of strategies was observed being employed by other teachers to engage the students in learning what would be required to pass assessments. These lessons could also fit the description of teaching being facilitated development of skills towards achieving the prescribed outcome.

James's teaching style in his junior Social Science class also appeared to be, in the main, one of a facilitated development of skills approach. The students were studying the topic "Me and the Law" which James later explained was a unit his department required to be taught under the concept of "Who is the boss?" The students could choose an aspect of law that interested them and decide on the layout of their booklet. This did provide an element of "looking for opportunities to involve students directly in decisions relating to their own learning and take ownership of their own learning" (MOE, 2007b, p. 34).

The lesson began in the classroom with James presenting a powerpoint which contained the instructions for the period. The students were to go to the Youth Law home page and choose an aspect of the law they were interested in investigating, read the relevant information and, in groups summarise it and create booklets. Although James had in his interview maintained that he had co-constructed the success criteria for the topic with the students in this particular lesson, the booklets they produced would be assessed using a version of an NCEA level 1 achievement standard. To gain an excellence, for example, they would need to show "Evidence of paraphrasing and organising content. Message is clearly and appropriately communicated. All work completed" (Student handouts). This criterion was not explored leaving it unclear to an observer exactly what was expected of the students. The first sentence, 
for example, appeared to be a publishing requirement to simply paraphrase what was read on the website and to organise it well in a booklet. In addition, there was no link made to the conceptual understanding of "who is the boss" in the lesson observed.

The students expressed pleasure at having the choice of layout for their booklet and hurried to the computer lab where they were soon busily engaged around computers. They appeared to enjoy working in their groups, linking to the NZC effective pedagogy descriptor: "Students learn as they engage in shared activities and conversations with other people" (MOE, 2007b, p. 34). While they were working together to compile information from the webpage there was no requirement for them to evaluate what they were reading or to draw their own conclusions as suggested in the effective pedagogy of the NZC: "critically evaluate the material they use and consider the purpose for which it was originally created" (MOE, 2007b, p. 34). Instead, they were identifying the key ideas and summarising them. This could be considered an information retrieval exercise which, while employing more modern methods such as the internet and publishing software, was in essence much like projects that were carried out in the past.

In his interviews James spoke of his preferred way of teaching. Ideally he would like fewer prescribed topics: "Then they (the students) would take responsibility for their own learning, what topic and then look at what they want to $d o . "$ He maintained he did attempt to work in that way with juniors while managing to comply with the college test regime. However, this approach was not evident in the junior lesson observed. Lack of time was often mentioned in James's interviews and it may have been that in this lesson he felt pressured to teach to the assessment schedule that had been prescribed by his department. As he explained in the interview after the observation, the activities had been developed by the staff in the department and outlined in the departmental scheme. However, believing the benefits of group work are underestimated and "group work makes learning happen," it had been his decision to put the students in groups of mixed ability and with a range of skills.

Ruth's class appeared to be another example of facilitating the development of skills. There were thirteen Year 11 high special needs students in the class, two of whom had teacher aides to support them. Ruth's demeanour created a warm, relaxed atmosphere. The students appeared very comfortable in the room and welcomed me in an open and friendly way. Ruth explained that the purpose of the lesson was to help the students to focus on understanding the criteria for the unit standard on 
metals and non-metals on which they would be assessed. She drew their attention to the list on the whiteboard of what they needed to do to meet the criteria. For the remainder of the lesson Ruth used a range of creative strategies to support the students in their learning by stimulating their interest with amusing and memorable stories and demonstrations. She asked them to stand around her: "come closer and have a look" as she showed them samples of metals and non-metals and spoke in a quiet calm voice, using stories such as linking mercury to the mad hatter and using colourful phrases such as "silicone, its semi and doesn't know which way it goes. A bit bisexual really." In another example, the students were obviously delighted by her descriptions of mercury being used as a switch for dynamite and telling them: "Hold it carefully!" The students were captivated by the stories and eagerly answered her questions.

She explained later: "You have got to grab them and draw them in, vary the pitch and use jokes to draw them." By these means she encouraged the students to construct their own understanding, supporting them to reach the correct answer that would enable them to pass the assessment. As I noted: "She had extended conversations with individual students and asked them about their work guiding them to discover the qualities of the substances for themselves" (field-notes). One student was wandering away from the group turning in circles, apparently in a world of his own. Ruth gently asked if he would like to join the group to which he replied: "No thank you." He was left alone. In the post-observation interview Ruth explained that this student was autistic and could only cope with short amounts of interaction. Another was profoundly deaf and needed to be reminded to "come out of your head and join the class."

While the students were encouraged to learn from discovering or doing they were ultimately steered to the correct answer. It was clear that Ruth held a constructivist belief of learning that all students can learn. She was obviously acutely aware of the learning needs for this challenging class and had carefully considered how to engage them. Her teaching linked to the effective pedagogy:

Students learn best when they are able to integrate new learning with what they already know. Effective teachers deliberately build on what their students already know and have experienced. Students learn as they engage in shared activities and conversations with other people. (MOE, 2007b, p. 34)

This was the only time I have been hugged by a student when I stood up to leave at the end of the lesson! 
Amy's approach also appeared to be that of facilitated skills development.

She was observed teaching two junior mathematics classes. While there was a departmental scheme of work with basic learning outcomes, Amy's belief that it was important to look at the class and check that they have the prior understanding needed to access the curriculum level required was evident in these classes. Unlike any other class observed, the students were in ability groups and the tasks for each group were chosen to support individuals to the next stage of learning. On a daily basis Amy spent a considerable amount of time analysing the students' work, using the data to plan her lesson and making changes to accommodate their learning. This approach met the criteria: "Students learn best when they are able to integrate new learning with what they already know and effective teachers deliberately build on what their students already know and have experienced" (MOE, 2007b, p. 34).

In her observed classes Amy used tactile manipulative materials for the students to explore numbers and to develop their own understanding in preference to simply learning formulas. This supported a constructivist belief that learning is acquired by discovering and doing (Schommer, 1998). The students worked in groups with the materials and were invited by Amy to share their way of working and their conclusions. They were encouraged to question their own and others' methods of working towards a solution for their answers. Her students appeared confident to publicly share their ideas without fear of giving a "wrong answer." Amy roamed the classes asking questions that encouraged the students to think about their reasoning: "What working are we showing? What is happening here? Can we draw a diagram showing that? What would you have picked? Why? What does that mean? Does that make sense? Not really? Sort of?" Their questions contributed to a sense of shared learning in which the questioner does not already know the answer and the answerer is developing an understanding (Young, 1991, p. 100). The students' engagement in their learning and their excitement at discovery was evident from their responses to each other, as noted in my field-notes: "K explained - students clapped ...gasps of ohhh!! from some students."

There was a buzz of learning in Amy's classes. While the students were aware of an imminent test, they were constructing their understanding. The lessons met the criteria of:

Teachers encourage students to stand back from the information or ideas that they have engaged with and think about these objectively; Over time students develop their creativity, their ability to think critically about information and 
ideas and their meta-cognitive ability; Challenge, support and feedback are always available. (MOE, 2007b, p. 34)

In these classes there was no learning intention or success criteria on the whiteboard but in one lesson students were told that they were preparing for the test. Nor was any mention made of the relevance of what the students were learning. Their engagement appeared to come from Amy's energy and enthusiasm and the range of interesting activities. She made the learning exciting seemingly for its own sake. In a later interview, as explained in chapter 5, Amy had changed her opinion about relevance after interviewing students for research. However, it was not a feature in the lessons observed.

\section{Facilitated knowledge building}

Jill's senior class and the class in which she team taught with Susan both appeared to be examples of facilitated knowledge building. In this section I have provided a snapshot of each.

Jill explained after I had observed her senior class that the student were preparing a submission they were going to send to a governmental select committee on sustainability:

We had our big concept, environmental and social responsibility, from that idea we setup our ideas and came up with our framework. They just write down the big idea and the smaller ones it gives you the breadth and the depth. What are the resources out there for future generations? That was the thinking and then they were putting together their submission. We did lots of work about how valuable things are - arguments for and against - huge amount.

On the whiteboard Jill had written:

1) What are the resources in the community?

2) What activities could threaten the resources?

3) What could a community do to keep resources for the future?

4) How could conservation help?

The students worked in groups evaluating the material they had been given, for example a photo of an open caste mine, and information brochures on resources. Jill wandered around asking questions and joining groups at times but there was no sense of overt control in the room. The students were intent on developing their ideas. They were engaged in discussing the merit of information brochures and the potential threat represented by the photos. Each group considered their own position on sustainability based on the materials they had been given and their critical evaluation of them. Jill next asked groups to share their two most important ideas 
with the rest of the class. All ideas were affirmed by Jill, written on the board, and the students invited to comment. I was impressed by their insights and wrote in my field-notes "a sophisticated range of answers."

They then moved on to write a letter to a select committee expressing their views. All the students appeared to be fully engaged in the purpose of their learning and had thought about it as evidenced by one student's comment: "I changed my mind over the weekend - I thought it over." Ultimately this topic would also have been assessed by an internal achievement standard; however, Jill had used a concept that would allow the students to demonstrate their skills but which did not narrow the context they could investigate. Jill explained that she planned to "look for evidence and the quality of their thinking and the ideas they express."

Susan's junior team taught class with Jill was another example of this category. This is a specially chosen class with six students who need support. Jill was the subject specialist and Susan was the learning support teacher.

The following was on the whiteboard:

\begin{tabular}{|l|l|}
\hline Trekking & Tourists \\
\hline Culture & People \\
\hline
\end{tabular}

\section{How do these concepts link together?}

Figure 8. Susan's whiteboard notes

The students were asked to quietly think about this question and to write down their ideas. Both teachers roamed around the classroom supporting them and asking them to explain their thinking. Susan told the class that she had noticed a lot of thoughtful responses and asked if anyone wanted to share what they had written. Several students volunteered. Their answers were affirmed and when one student stated that "it's like a circle," Jill explained how the concept circle provided a way to show links within a concept. Susan explained after the lesson that the concept circle was a way of capturing the learning from the previous day's lesson and to link to the "big idea" which the students had earlier recorded in their books:

With Social Studies new curriculum we tried to start from a more conceptual emphasis rather than the old way which was to begin with the content ... we are trying to make the concept be more up front so kids are seeing we are looking at the impact of tourism, we are looking at the environment, we are looking at social change for people and making that sort of language more explicit.

Over the remainder of the period the teachers used various strategies to support the students to "build their knowledge". They were first asked to read, in pairs, material on the impact of tourism in Nepal and to highlight the negative and 
positive aspects of tourism in that country in the light of what they had learned. The students focussed and I noted "busy buzz" in my field-notes. When Susan asked each pair to share their opinion there was no sense of a "correct" answer. Students were asked to support their opinions with examples from the text and all were acknowledged. Jill next asked the students, using their material, to rank the positive and negatives of tourism in Nepal from 3 to 1, 3 being "really bad or really good." After sharing their results as a class the students were asked to stand on a continuum to indicate their stance on the benefit of tourism to Nepal. This had obviously occurred in a previous lesson and students were asked to explain if they had changed their position. Jill: "Where are you going to go? Many of you have changed your positions. What made you change?" In many cases students replied that their opinion had changed after considering the material and listening to others. Their reasons were respected and affirmed by the teachers who reminded them that this could continue to happen as they learned more.

After observing a range of subjects being taught, it did appear that, as van Veen (2001) suggested, (see section 2.5, p.27) the Social Science curriculum provided more scope for conceptual thinking and constructivist practices than some other disciplines.

\subsection{Links to the effective pedagogy of the NZC}

Table 26 summarises my interpretation of the links between what was observed and either the effective pedagogy and key competencies of the NZC or to a more transmission approach. In it I have noted the extent to which the practice I observed fitted with the descriptions of the effective pedagogy in the NZC or if it was more allied to a transmission approach.

The dominance of the NCEA assessments was apparent in the last two chapters. It may therefore not be surprising to learn that in eleven of the fourteen lessons observed teachers worked from a fixed curriculum which in senior classes appeared to be the requirements of the NCEA achievement or unit standards. In junior classes the curriculum was outlined in departmental schemes which appeared to be designed to lay the basis for working towards, in Amy's class, a test and in two others towards success in NCEA in the senior school. In those two Year 10 (junior) classes the learning was based on meeting the requirements of a modified version of a level 1 achievement standard. In two classes, however, one junior and one senior, the learning was focussed on developing conceptual understanding. Table 27 
presents examples of the expressed learning intentions for the lesson, in some instances written on the whiteboard and in others told to the students. 
Table 26. Stated relevance for learning in observed classes

Key: FC: Strict adherence to the fixed curriculum is highly valued; NZC: As described in the effective pedagogy, students learn most when they understand what they are learning, why they are learning it and how they will be able to use the new learning; MDC: Monitored development of content and skills; FDU: Facilitated development of understanding; FKB: Facilitated knowledge building.

\begin{tabular}{|c|c|c|c|c|c|c|}
\hline \multirow[t]{2}{*}{ Teacher } & \multicolumn{2}{|c|}{ Observation 1} & \multicolumn{2}{|c|}{ Observation 2} & \multirow{2}{*}{$\begin{array}{l}\text { Link to FC } \\
\text { or to NZC }\end{array}$} & \multirow[t]{2}{*}{ Approach } \\
\hline & What you are learning & Why you are learning it & What you are learning & Why you are learning it & & \\
\hline Amy & $\begin{array}{l}\text { Junior class } \\
\text { No explanation. }\end{array}$ & Prepare for the test. & $\begin{array}{l}\text { Junior class. } \\
\text { Decimals and fractions. }\end{array}$ & To understand them. & $\mathrm{FC}$ & FDU \\
\hline Christopher & $\begin{array}{l}\text { Senior class. } \\
\text { Learn the theory. }\end{array}$ & $\begin{array}{l}\text { To be able to answer } \\
\text { NCEA type questions on } \\
\text { cell biology. }\end{array}$ & & & $\mathrm{FC}$ & MDC \\
\hline Edward & $\begin{array}{l}\text { Senior class. } \\
\text { Reviewing what has been } \\
\text { learned so far. Compare and } \\
\text { contrast two historical } \\
\text { events, similarities and } \\
\text { differences. }\end{array}$ & $\begin{array}{l}\text { "If we can be aware of the } \\
\text { thinking behind these } \\
\text { actions we can apply what } \\
\text { we know in a new } \\
\text { context." } \\
\text { To prepare for an } \\
\text { assessment. }\end{array}$ & & & $\mathrm{FC} / \mathrm{NZC}$ & FDU \\
\hline James & $\begin{array}{l}\text { Junior class. } \\
\text { About youth law. }\end{array}$ & $\begin{array}{l}\text { To prepare a booklet that } \\
\text { will be assessed by a Year } \\
10 \text { version of a NCEA } \\
\text { assessment. }\end{array}$ & & & $\mathrm{FC}$ & MDC \\
\hline Jennifer & $\begin{array}{l}\text { Junior class. } \\
\text { Prepare a powerpoint for } \\
\text { their speeches. }\end{array}$ & $\begin{array}{l}\text { To prepare to make a } \\
\text { speech. Year } 10 \text { version of } \\
\text { a NCEA assessment. }\end{array}$ & $\begin{array}{l}\text { Senior class. } \\
\text { We are getting through the } \\
\text { book. }\end{array}$ & NCEA assessment. & $\mathrm{FC}$ & $\begin{array}{l}\text { MDC } \\
\text { FDU }\end{array}$ \\
\hline Jill & $\begin{array}{l}\text { Environmental and social } \\
\text { responsibility. }\end{array}$ & $\begin{array}{l}\text { Explore the concept of } \\
\text { sustainability. } \\
\text { To prepare a submission to } \\
\text { a select committee. }\end{array}$ & $\begin{array}{l}\text { Junior class team taught with } \\
\text { Susan. } \\
\text { Evaluating the impact of } \\
\text { tourism on Nepal. }\end{array}$ & $\begin{array}{l}\text { Be able to be critically aware } \\
\text { of the impact of tourism on a } \\
\text { country. }\end{array}$ & $\mathrm{NZC}$ & FKB \\
\hline Joseph & $\begin{array}{l}\text { Senior class. } \\
\text { To understand a new unit of } \\
\text { work: Short-term plans. }\end{array}$ & $\begin{array}{l}\text { Useful in life. Short-term } \\
\text { goals help to reach long- } \\
\text { term goals. } \\
\text { For an assessment. }\end{array}$ & & & FC/NZC & FDU \\
\hline
\end{tabular}




\begin{tabular}{|c|c|c|c|c|c|c|}
\hline \multirow[t]{2}{*}{ Teacher } & \multicolumn{2}{|c|}{ Observation 1} & \multicolumn{2}{|c|}{ Observation 2} & \multirow{2}{*}{$\begin{array}{c}\text { Link to FC } \\
\text { or to NZC }\end{array}$} & \multirow[t]{2}{*}{ Approach } \\
\hline & What you are learning & Why you are learning it & What you are learning & Why you are learning it & & \\
\hline Mary & $\begin{array}{l}\text { Senior class. } \\
\text { Recap understanding. }\end{array}$ & Prepare for assessment. & & & $\mathrm{FC}$ & FDU \\
\hline Nina & $\begin{array}{l}\text { Senior class. } \\
\text { Different types of } \\
\text { contraception. } \\
\text { How to manage yourselves. }\end{array}$ & $\begin{array}{l}\text { Prepare for assessment. } \\
\text { Develop self-management } \\
\text { skills. }\end{array}$ & & & $\mathrm{FC} / \mathrm{NZC}$ & FDU/MDC \\
\hline Ruth & $\begin{array}{l}\text { Senior class. } \\
\text { Understanding metals and } \\
\text { non-metals. }\end{array}$ & Prepare for the assessment. & & & $\mathrm{FC}$ & FDU \\
\hline Susan & $\begin{array}{l}\text { Junior class. } \\
\text { Study a film. }\end{array}$ & $\begin{array}{l}\text { Learn how techniques used } \\
\text { in film create impressions } \\
\text { to an audience. }\end{array}$ & $\begin{array}{l}\text { Junior class team taught with } \\
\text { Jill. } \\
\text { Evaluating the impact of } \\
\text { tourism on Nepal. }\end{array}$ & $\begin{array}{l}\text { Be able to be critically aware } \\
\text { of the impact of tourism on a } \\
\text { country. }\end{array}$ & $\mathrm{NZC}$ & FKB \\
\hline
\end{tabular}




\subsection{Teachers' beliefs}

What is the significance of the NZC to their beliefs and practices?

In this section I have presented my interpretation of the enacted beliefs of the teachers in the study. In Table 28 I have compared them with the beliefs they espoused in their interviews. As can be seen, despite all teachers espousing support for the effective pedagogy and the key competencies of the NZC in eleven of the classes observed, the teaching was focussed on a summative assessment and integration of the key competencies was observed in only one class. Three classes could be described as student centred where the students were facilitated to build on their prior knowledge. In other classes strategies were generally used to engage the students and to lead them to the understanding needed to meet the test. These issues will be further discussed in the following chapter.

Table 27. Teacher beliefs

\begin{tabular}{|c|c|c|}
\hline Name & Espoused Personal beliefs & Enacted Beliefs \\
\hline Amy & $\begin{array}{l}\text { Saw it as "a global goal, teaching and } \\
\text { how we are going to teach, why we are } \\
\text { teaching it and then refining it to lesson } \\
\text { level." }\end{array}$ & $\begin{array}{l}\text { Teaching focussed on supporting students } \\
\text { to develop their understanding based on } \\
\text { diagnosis of their needs. } \\
\text { No purpose or relevance provided for the } \\
\text { students beyond preparing for the test. } \\
\text { Learning develops from students' prior } \\
\text { knowledge. } \\
\text { Students can construct their } \\
\text { understanding. }\end{array}$ \\
\hline Christopher & $\begin{array}{l}\text { Espoused beliefs about teaching and } \\
\text { learning fit well with the focus of } \\
\text { effective pedagogy in the NZC. }\end{array}$ & $\begin{array}{l}\text { There are defined content and skills to be } \\
\text { understood. } \\
\text { Worked to prescribed criteria. }\end{array}$ \\
\hline Edward & $\begin{array}{l}\text { Espoused beliefs about teaching and } \\
\text { learning fit well with the focus of } \\
\text { effective pedagogy in the NZC. }\end{array}$ & $\begin{array}{l}\text { Students learn in groups. } \\
\text { There are defined content and skills to be } \\
\text { understood. } \\
\text { Worked to prescribed criteria. }\end{array}$ \\
\hline James & $\begin{array}{l}\text { Espoused beliefs about teaching and } \\
\text { learning fit well with the focus of } \\
\text { effective pedagogy in the NZC. }\end{array}$ & $\begin{array}{l}\text { Students can choose within a topic. } \\
\text { Students learn in groups. } \\
\text { There is defined content to be understood. } \\
\text { Worked to prescribed criteria. }\end{array}$ \\
\hline Jennifer & $\begin{array}{l}\text { It's not foreign to me and given the } \\
\text { professional development in schools it's } \\
\text { not as foreign now to staff as it was } 20 \\
\text { years ago. }\end{array}$ & $\begin{array}{l}\text { In one class: Giving student choice } \\
\text { engages them. } \\
\text { Students learn in groups. } \\
\text { In other class: Work to prescribed criteria. }\end{array}$ \\
\hline Jill & $\begin{array}{l}\text { Espoused beliefs about teaching and } \\
\text { learning fit well with the focus of } \\
\text { effective pedagogy in the NZC. }\end{array}$ & $\begin{array}{l}\text { Teaching was a fit with the focus of the } \\
\text { effective pedagogy in the NZC. }\end{array}$ \\
\hline
\end{tabular}




\begin{tabular}{lll}
\hline Name & \multicolumn{1}{c}{ Espoused Personal beliefs } & \multicolumn{1}{c}{ Enacted Beliefs } \\
\hline Joseph & $\begin{array}{l}\text { Espoused beliefs: Supports the } \\
\text { management directive to have the learning } \\
\text { intentions of the lesson written up so that } \\
\text { the students are aware of it and to try to } \\
\text { co-construct the success criteria for the } \\
\text { learning with the students. } \\
\text { Relationship building most important. }\end{array}$ & $\begin{array}{l}\text { Students can develop their understanding } \\
\text { Relationship building is most important } \\
\text { directives. }\end{array}$ \\
\hline Mary & $\begin{array}{l}\text { Espoused beliefs about teaching and } \\
\text { learning fit well with the focus of } \\
\text { effective pedagogy in the NZC. }\end{array}$ & $\begin{array}{l}\text { Attempted to link to relevance. } \\
\text { Worked to prescribed criteria. }\end{array}$ \\
\hline Michael & $\begin{array}{l}\text { The descriptions of effective pedagogy } \\
\text { "sit well with me." }\end{array}$ & Not observed. \\
\hline Nina & $\begin{array}{l}\text { Espoused beliefs about teaching and } \\
\text { learning fit well with the focus of } \\
\text { effective pedagogy in the NZC. }\end{array}$ & $\begin{array}{l}\text { Worked to prescribed criteria. } \\
\text { Integrated key competencies effectively. }\end{array}$ \\
\hline Ruth & $\begin{array}{l}\text { Espoused beliefs about teaching and } \\
\text { learning fit well with the focus of } \\
\text { effective pedagogy in the NZC. }\end{array}$ & $\begin{array}{l}\text { Worked to prescribed criteria. } \\
\text { Students constructed their understanding. }\end{array}$ \\
\hline Susan & $\begin{array}{l}\text { Espoused beliefs about teaching and } \\
\text { learning fit well with the focus of } \\
\text { effective pedagogy in the NZC. }\end{array}$ & $\begin{array}{l}\text { Teaching was a fit with the focus of the } \\
\text { effective pedagogy in the NZC. }\end{array}$ \\
\hline
\end{tabular}

\subsection{Chapter summary}

This chapter provides a description and interpretation of the teachers' practice through the lens of an educational connoisseur. In seeking to ascertain the extent to which the signalled changes of the NZC were significant for the participating teachers, I have attempted to identify how the changes fit with their current practice and their enacted beliefs. While all the teachers, to varying degrees, included activities for the students to develop a greater understanding of the learning, with the exceptions of Jill and Susan, all worked towards a prescribed criteria. This acceptance by the teachers of defined knowledge limited the degree to which the students could be genuinely constructing their own knowledge and that they could "over time develop their creativity, their ability to think critically about information and ideas and their meta-cognitive ability (MOE, 2007b, p. 34). It was a privilege to be present in these classes and I acknowledge the commitment of the teachers. They were working for their students' success within the constraints of the current educational environment. The reasons for this situation are explored in the following chapter. 


\section{It's a good idea but...}

Running against the walls of our cage is perfectly absolutely hopeless.

(Wittgenstein, 1929)

\subsection{Chapter overview}

This chapter addresses the evaluative and thematic stages of educational criticism. In the role of an educational critic, I have explored the ways in which the participants in this study believed that elements of the New Zealand educational system affected their perception of the significance of the signalled changes to the NZC. Each participant in the study maintained that they supported the effective pedagogy and the key competencies as expressed in the NZC. However, while a positive attitude is important it is not, on its own, enough to motivate individuals to make changes (Kennedy \& Kennedy, 1996). In the study, the participants' espoused support for the signalled changes was not, in itself, sufficient to motivate them to engage fully with the implementation of the signalled changes. As indicated by the title of this chapter, each teacher had reservations about the implementation for a range of reasons. It is these reasons that I believed formed the walls of the cage referred to in the Wittgenstein quote and which limited the significance of the NZC changes for the participating teachers. In this chapter the "walls of the cage" are first indentified followed by a discussion of each.

\subsection{The walls of the cage}

From the findings in this study the following "walls" appeared to be barriers to the significance of the signalled changes in the NZC for the participating teachers:

- Misalignment of the school goals, norms and the appraisal system

- The NCEA assessment regime

- Lack of time

- Lack of leadership

- Lack of conceptual understanding

- Lack of professional learning to support transformative learning.

Each of these "walls" is discussed in the following sections. 


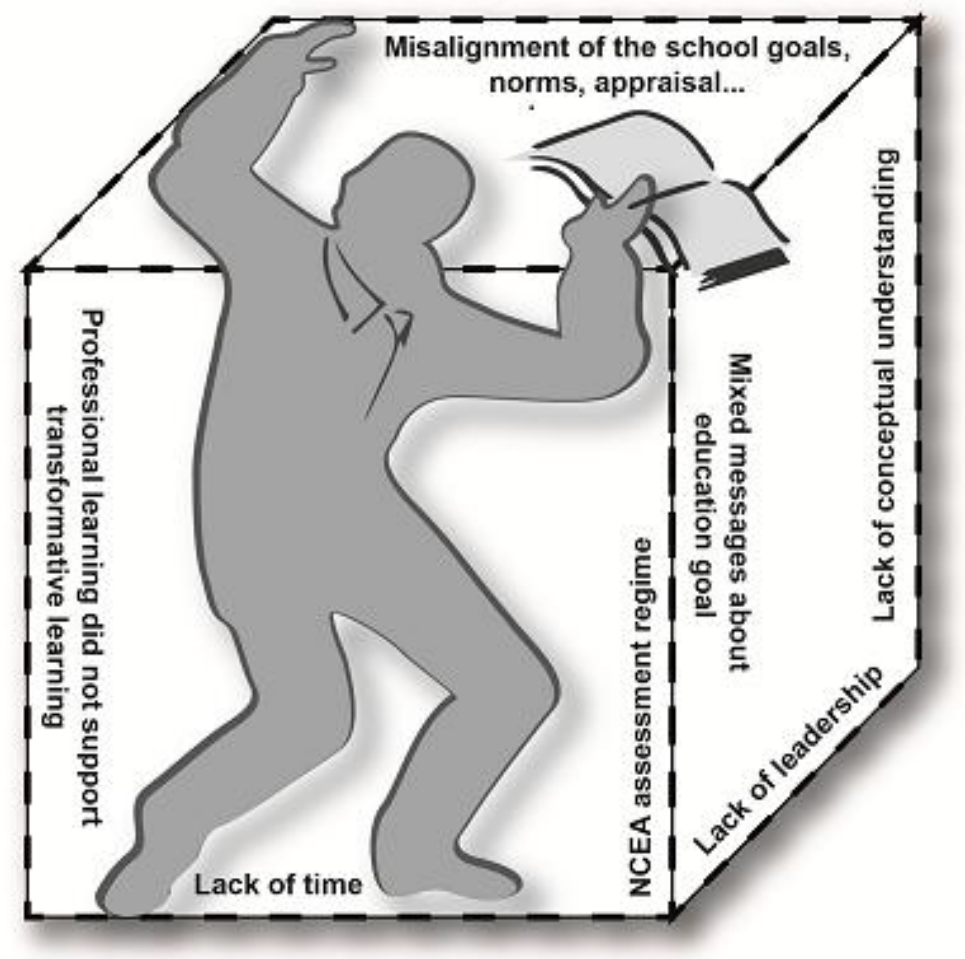

Figure 9. The "walls of the cage"

\subsubsection{Mixed messages}

As identified in chapter 6, the teachers appeared to be the recipients of mixed messages about the goals for education in the political environment and within their contexts. These messages created ambiguous and confusing dilemmas for teachers, potentially compromising any change to teaching practices (Deemer, 2004; Windschitl, 2002; Yates \& Holt, 2009). In particular, the tension between the aims of the NZC and the external pressure of accountability policies and standardised assessments created an environment in which achievement in NCEA assessment was perceived by the teachers in the study to be of greater significance than the vision of the NZC.

This situation is further explored in this section. First the goals of the education expressed in the political environment are discussed, followed by the goals within the participating teachers' context.

\subsubsection{Messages from the political environment}

The findings of this study suggest that eleven of the participating teachers felt that their performance and that of their schools would be judged by the academic success of their students in NCEA assessments. In this section the possible reasons for their perception are discussed.

The government's educational focus is "on building a world-leading education system that equips all New Zealanders with the knowledge, skills and 
values to be successful citizens in the 21 st century." (MOE, 2011a).The vision in the NZC document (MOE, 2007b) reflects this focus:

Our vision is for young people

who will be creative, energetic, and enterprising

who will seize the opportunities offered by new knowledge and technologies to secure a sustainable social, cultural, economic, and environmental future for our country

who will work to create an Aotearoa New Zealand in which Māori and Pākehā recognise each other as full Treaty partners, and in which all cultures are valued for the contributions they bring

who, in their school years, will continue to develop the values, knowledge, and competencies that will enable them to live full and satisfying lives

who will be confident, connected, actively involved, and lifelong learners. (2007b, p. 8)

However, this vision is undermined by media attention given to the call by the MOE for greater educational accountability which suggests that it will be not be the vision of the NZC but NCEA achievement which is used as a means to evaluate teachers. The ministry advisory paper (2011b) to the Minister of Education states:

It is also important that providers feel themselves accountable for continually improving learning and student achievement. Developments in both the schooling and tertiary sectors have been seeking to do this through making greater use of existing accountability requirements to assess performance, support improvement and address sustained non performance. (p. 13)

As Susan, James and Christopher indicated, teachers expressed concerned about how their performance would be measured, suspecting that NCEA achievement would play an important part. Subsequently, the pressure of NCEA assessments prevented a whole hearted engagement with the pedagogy of the NZC and the incorporation of key competencies. The findings in this study suggest that when teachers do feel this pressure, their default position is teacher-centred pedagogy and to have a lack of faith that student-centred teaching is effective for student learning. As James pondered: " $I$ think it's about how to marry the two, the use of this form of pedagogy with getting the results. I worry about that. Will the benefit equal the effort?"

The government has also signalled that in addition to senior students' NCEA results, in some way yet to be explained, the academic performance of junior secondary school students will also be made public (Hartfelt, 2011) which may raise fears that this information will also be used to judge teacher performance (Benade, 2009). This perhaps explains a trend in the schools in this study for junior assessments to be aligned to NCEA. The Minister of Education has announced that she is considering establishing a website to compare the performance of secondary 
schools stating that she wants to encourage professional competition in the context of collaboration (Hekia, cited in Hartfelt, 2012, emphasis added). Timperley et al. (1999) query how teachers can be expected to develop collaborative relationships with staff in other schools when "the cause of the competitive and in some cases destructive, interschool relationships was, in their view, the direct result of government policy on school choice?” (p. 3).

The Treasury Secretary Gabriel Makhlouf's comment contributed to this concern. He promoted greater accountability for teachers and suggested ways to assess teacher quality (Hartfelt, 2012). He justifies the Treasury's interest in this topic because it was important to the New Zealand economy stating that "high quality teachers produce better-performing students who go into the workforce and make a significant contribution to economic growth. Education is the third largest area of government expenditure, and we need to get the best results from this investment" (Makhlouf, 2012, p. 1). This view appeared to reduce education to a commodity with the narrow aim of preparing students for the job market (Codd, 2005) which Neyland (2010) describes as the scientific management of education in which the teacher is merely a technician. Benade (2011) refers to it as an example of Human Capital Theory, "the notion that capital investment in education leads to enhanced skills and knowledge for individuals, representing a return on investment for the state" (p. 8).

Makhlouf's (2012) suggested ways to assess teacher performance also appeared to link to those of a business model: a mix of class appraisal by peers and principals, feedback from the clients (students and parents), and data on student progress. There have been reports that the issue of performance pay for teachers raised by Makhlouf and by politicians has contributed to the concerns surrounding the measurement of teacher performance (Latham, 2012; Leckie, 2012). In a speech to the Secondary School Principals' Association the Minister of Education stated that the government was in the early stages of devising an evaluation system that would have "integrity and regard" and capture all the different dimensions of quality teaching. This, she maintained, would be a way to identify high performing teachers and those who were not effective. In less than flattering terms to teachers, she told the principals: "You are the ones who sort the wheat from the chaff ... I don't think there's much wheat and chaff sorting that goes on these days" (Parata, 2012).

The political environment also adds to the focus on NCEA as reported in the Prime Minister's speech in March, 2012: 
So I want to see an increase in the proportion of 18-year-olds with NCEA level 2 or an equivalent qualification. Good progress has been made in this area over the last few years, but I want to see even more. For example, the Minister of Education has told me that for result number five she has set a target of 85 per cent of 18-year-olds having NCEA level 2 or equivalent in five years. The current figure is around 68 per cent, so achieving the target will be very tough. (The Dominion Post, 15 March 2012)

In Wylie's (2013) survey of secondary schools only 39\% of principals expressed confidence that their school would meet that target. This leaves a large number of teachers who could feel they will be blamed if this challenging target is not met, ignoring any of the socio-economic issues that may have impacted on student achievement (Doeke, Locke, \& Petrosky, 2004; Thrupp, 1998, 2007).

These messages in the political environment, highlighted by media reports, contribute the sense of a low trust in teachers (Codd, 2005). It would therefore be understandable if proposals for increased accountability measures, performance pay and for more league tables cause teachers to feel the need to prove their worth. This would be difficult to measure against the vision of the NZC, but easier against what they perceive as a tangible proof of their effectiveness: positive NCEA results

\subsubsection{Messages from their context}

The teachers' personal goals and the relevance for the learning described in chapter 7 reinforce the impression that they perceive NCEA achievement is the important educational goal in their contexts. The implication that the teachers consider the achievement of NCEA results to be a significant pressure in their contexts suggests that they also receive mixed messages about the goals of teaching and learning in their school and from the community. This was evident in each context the participating teachers worked in. While the goals of the NZC and their schools' mission statements state the aim of teaching and learning is to prepare the students for their future lives in an holistic way, from the comments of the participating teachers, the clearly understood goal in their contexts was achievement in NCEA. Each school mission statement suggests a broad and holistic education:

Totara College: This College challenges students to achieve excellence, develop a sense of self worth, and become motivated and responsible citizens.

Kauri High School: $\quad$ To be the school of choice for families seeking a supportive and a co-educational environment which promotes individual achievement and mutual respect.

Kawakawa College: $\quad$ Our purpose is highest quality education in a safe and stimulating environment. (School prospectuses) 
However, as described in chapter 6, while the goals for professional learning in each schools strategic plan are vague, those for NCEA results state clear expectations with specific outcomes as can be seen from the excerpts from the strategic plans below:

Totara College: Increased numbers of students gaining Endorsed with Merit and Excellence in NCEA. The goal for each of the next three years is to improve each of the figures by 5 students per year.

Kauri High School: $\quad$ A 75\% Level 2 NCEA pass rate and a $60 \%$ level 3 NCEA pass rate has been achieved for 2012. Level 1 continues to improve by $5 \%$.

Kawakawa College: Maintaining an achievement profile at or above the level of other decile 10 co-ed schools. (School strategic plans)

These conflicting messages constitute what Tyack and Cuban (1995) refer to as the unexamined beliefs about what school is really about and which are exacerbated by the educational environment discussed in the following section. Holistic elements such as self-worth and respect are more difficult to objectively gauge and for a parent considering where to send their children to school, the NCEA results are the more accessible measures of achievement.

\subsubsection{Impact of the competitive environment}

Another wall of the cage or barrier to the implementation of the change is the competitive environment in which all secondary schools in New Zealand operate and for which NCEA results could be considered a "selling point." The Tomorrow's Schools reforms of 1989 and the reforms of the 1990s shifted the school system to one with elements of a quasi-market system, in which competition between schools became the key driver for educational quality, with parents and children as consumers (Court \& O’Neill, 2011).

A market model of education exists in New Zealand with schools competing for students within their geographical area (Codd, 2005). The rationale underpinning school competition is that parents will choose to send their children to those schools they believe achieve the best student outcomes and that the competition would incentivise teachers to work harder to ensure student success (Arsen \& Ni, 2008). This model had impacted on the participants in the study.

All of the teachers involved in this study worked in areas where parents had a range of schools to choose from. Two of the schools had enrolment schemes which are designed "to avoid overcrowding or the likelihood of overcrowding at the school" 
(MOE, 2012). The fact they had enrolment schemes suggested that those schools were oversubscribed and when I compared the preferred maximum number of students stated in the schemes with their current roll they had indeed exceeded their limit. It can therefore be assumed that those two schools did not have concerns about roll growth. This, however, did not appear to lessen the pressure for the teachers in my study to maintain or improve their NCEA results, presumably in order to maintain their competitive edge. For example, in Kawakawa College's strategic plan a goal was: "Maintaining an achievement profile at or above the level of other decile 10 co-ed schools" (strategic plan). Participants at each school stated they felt the pressure to ensure students achieved well in the NCEA assessments with Jill in Kauri High School maintaining that it was common practice in her context for all learning in each year group to be linked to NCEA, and Susan in Kawakawa College stating that she felt in her context NCEA results were important to the school leadership and to the community.

In Totara College, roll growth was a serious matter. In this school, in addition to competing with other schools, a change in the demographics of the district had meant there was a smaller pool of secondary school-aged students. As discussed in the interviews with Jennifer, the school had experienced a falling roll each year which had resulted in the loss of staff. This was naturally a cause for concern which was reflected in the school's allocation of funds for marketing the school and a focus in the strategic plan on growing the roll (strategic plan, 2010). Marketing the school involved extraordinary funding and diverted staffing resourcing from teaching and learning. Jennifer, who chaired a promotions committee, explained the effort the school made:

We promote ourselves within a very tight budget of next to nothing. It has its price because you do have to be constantly looking at what we have to offer. It becomes extremely difficult to cut costs which then don't have some impact on teaching and learning. We have a big drive to bring in international students; we have had to invest in that to keep those numbers coming in. The principal has just done a month overseas promoting the school. We have got our Head of International Students at Melbourne at an agent's conference where she works morning, noon and night.

Other New Zealand schools share this dilemma: in her survey of New Zealand secondary schools, Wylie (2012) found that "Competition between schools for students is more the norm than exception. To encourage enrolments, some schools are spending more on marketing and property than they would like" (p. 2).

With Totara College's level of investment, and with jobs at stake, it is understandable that the goal to increase the roll is an urgent one and that staff would 
not wish to jeopardise it by producing unimpressive NCEA results. Wylie (2012) found that other New Zealand schools experienced similar pressures. Approximately half of New Zealand schools thought that their school rolls were affected by the publication of NCEA league tables with high decile schools gaining at the expense of low decile schools. There is definitely a tendency in many parts of New Zealand for students to attend a higher decile school outside their home area (Thrupp, 2007). New Zealand is not alone in this: Plank and Sykes' (2003) analysis of the impact of school choice found that internationally, higher or upper income parents, having greater access to information about schools and able to afford transport, were more inclined to exercise choice in schooling. The parental decision often involved their children by-passing a local school in favour of one perceived to be more effective and or that had a "middle class' student body that they related to. Therefore Totara College, a decile 5 school competing for students with higher decile schools within their area, is in a vulnerable position.

When selecting a school for their children it is understandable that parents seek the highest quality educational environment and it appeared that the participants in this study believed that their school's NCEA achievement rates became the criterion by which the schools' and the teachers' effectiveness were judged. James, for example, believed the good work that teachers do is rarely acknowledged and that they can be judged as inadequate by the public when league tables (of NCEA results) are published. James's perception is described by Codd (2005) as a reflection of a culture of perfomativity in which "good practice is defined by a set of pre-defined skills or competencies, with little or no acknowledgement of the moral dimensions of teaching" (p. 201).

\subsection{But... NCEA}

The pressure teachers in the study felt to achieve positive NCEA results was a significant wall of the cage or barrier that prevented the changes being of significance to them. In this section the impact of NCEA on New Zealand secondary schools is discussed. (For an explanation of NCEA see appendices.)

The introduction of NCEA between 2002 and 2004 excited much debate. Doubts were expressed about the reliability, validity, and manageability (Hall, 2000; Locke \& Hall, 1999). While the move from norm-referenced to outcomes-based assessment involved significant change for teachers, over time, after modifications, there was either increased support for it (Hipkins, 2013) or a weary acceptance 
(Locke \& Goodwyn, 2004). However, it has come at significant cost which militates against the signalled changes. Each of the costs is discussed in the following sections.

\subsubsection{NCEA impact on curriculum}

In 2001, Locke used the example of achievement standards in English to argue that the achievement criteria matrix would become the "defacto" curriculum and therefore would have "a powerful influence in shaping the way English as a subject is constructed in classrooms" (p. 104). His fears have been realised across all subjects. In her reports from the NZCER National Survey of Secondary Schools, Hipkins (2013) stated that $48 \%$ of teachers and $47 \%$ of principals believed a major issue facing their school was the NCEA was now driving the curriculum even at junior year levels. This appeared to be occurring in this study where Year 10 students were being assessed against a version of level 1 achievement standards, there was anxiety that juniors were not receiving sufficient grounding in their subject for senior assessment, and the purpose for the learning in 11 out of 14 lessons was to pass the assessment. Broadfoot (2003) refers to the "stranglehold of assessment's pervasive influence" (p. 202) which results in schools, instead of offering rich content, narrowing a curriculum to one which is designed to meet the requirements of the assessment and in which students see learning simply as amassing credits (Broadfoot, 2003; Locke, 2008). This was borne out by Moeed's (2010) investigation into how New Zealand Year 11 Science students' learning was affected by NCEA assessments. She found that the assessment system "encouraged a surface approach to learning rather than deep learning for understanding. Students set performance goals and were motivated to achieve credits and grades in the assessment" (p. 2). In this study Christopher appeared to be wrestling with the stranglehold, torn between conforming to the expectation of his environment and his sense of what was important. His comment ("screw the assessment") suggested that he viewed his attempts to contextualise his teaching as deviating from what he should be teaching and almost as an act of defiance.

The NZC effective pedagogy section (MOE, 2007b, p. 34) states that "effective teachers stimulate the curiosity of their students and require them to use or apply what they discover in new concepts or in new ways." However, in this study students' activities in 12 of the 14 lessons observed reduced the learning to either one of task completion which Bereiter (2002) describes as "engaged in the learning activity at a 
behavioural level but are not cognitively engaged" (p. 257) or, if they were more purposefully engaged in the learning, their interest was not in applying it to new concepts but in passing the assessment or test. The teachers, aware that both their success and that of their students will be measured by NCEA results, appeared to be locked into a curriculum that Locke (2008) believes ignores the "huge store of expert content knowledge" (p. 297) leaving them instead to work to an externally prescribed agenda (van Veen et al., 2001). The narrow focus stifles the curiosity of students, limits teachers' and students' creativity, and devalues the professional judgment of teachers (Broadfoot, 2003; Locke, 2008; Madaus, 1998; van Veen et al., 2001). Susan explained the dilemma:

We are so time bound with particular assessments that we can't just sort of explore something that is interesting that will use some of the, sort of the vision stuff that you would get from the curriculum - yeah it's like covering the assessments rather than following a learning path with something. And Jill: Even Y9 getting ready for NCEA. It can be a pressure. It would be possible [NZC] but here is always that pressure for covering would have to come off and I don't think that teachers want to.

Michael related how the high rejection rate by moderators of teacherdesigned tasks in the first years, requiring them to submit many attempts, was bruising to the teachers. While he believed that their belief in their professional judgment had gradually been restored, there remained a sense of vulnerability. Subsequently, teachers wishing to reduce anxiety and workload, increasingly rely on nationally developed assessment tasks, exemplars of "good practice" and marking schedules accessible from a government funded website (Locke, 2008; Moeed \& Hall, 2011). As a result, the teaching is reduced to conforming to reach an established standard rather than exploring a topic creatively. A message from a head of department on the secondary English online community reveals the extent to which this has become accepted practice. She reminded other teachers:

There is absolutely no obligation to use the tasks provided by NZQA. They are simply a guide for teachers and, in fact, have been designed so that teachers are required to flesh out the task suited to their own students. The exciting aspect that has become more explicit with the curriculum alignment is that teachers have the freedom to create tasks. This has always been the case, but the old tasks for NCEA pre-alignment definitely became the de-facto ones everyone used. (secondaryenglish-request@lists.tki.org.nz).

It remains to be seen if other teachers share her excitement and if the situation changes as a result of the realignment of the achievement standards to NZC currently being undertaken. The new curriculum may encourage more creativity but the issues of workload and anxiety remain. 


\subsubsection{NCEA impact on feedback}

The effective pedagogy of the NZC suggests that challenge, support and feedback are always available (MOE, 2007b). Hattie and Timperley (2007, p. 86) consider that feedback is one of the most powerful influences on a student's learning if it focuses on three questions: Where am I going (the goals for the learning); how am I going? (what progress is being made towards the goal?); where to next? (what do I need to do to make progress?). This feedback is formative assessment which is used, by the teacher and students, to modify their work in order to make it more effective (Black, 1995). Locke (2001) was concerned that the "assessment culture" (p. 106) engendered by NCEA would affect the use of formative assessment. Instead of providing feedback and feed forward for teachers and students on learning, he anticipated that formative assessment would be narrowed to steer students towards the summative assessment of the achievement standard criteria. This latter type of feedback was observed as the teachers walked around the classes checking the students' work. Feedback that directed the students towards the summative assessment was the focus of monitored and facilitated learning approaches observed in this study. For example: "STIS, not STDs or it will be a not achieved in the assessment" (Nina); "When you get to assessment make sure you remember little things like the lip" (Mary); "These are the sort of questions you can expect in the assessment" (Christopher); "Look at the marking schedule because you could have got yourself excellence but you limited yourself in this area" (Edward).

\subsubsection{NCEA impact on workload}

Another concern at the introduction of NCEA was that it would significantly increase teachers' workload and this has proved to be the case, representing another wall of the cage preventing teachers from engaging in transformative learning. The change to outcome-based assessment required substantial professional learning for secondary school teachers. Stress and workload were also associated with more paperwork for record keeping, moderation, and creating new assessment practices. Teachers perceived these activities to be diverting them from their core business of teaching and learning (Kane \& Mellon, 2006). Jennifer alluded to this when expressing approval for the NZC focus on teaching and learning which she felt had been neglected with the pressure of the work involved in introducing and becoming familiar with the NCEA assessment system. Teachers were required to develop high quality assessments, mark them, moderate them, and then quality assure them 
(PPTA, 2010). The pressure of the increased workload was particularly felt by heads of departments who were responsible for the oversight of systems to meet the bureaucratic requirements in their subject area and monitor budgets and resources in addition to providing pedagogical leadership for their staff (Kane \& Mellon, 2006; Schagen \& Hipkins, 2008). The stress this had caused was borne out by Christopher's anxiety at managing the number of internal assessments (one every four weeks), and by the comments by Amy and Jill about their heads of departments' lack of pedagogical understanding. All teachers of senior students involved in NCEA assessment mark and then moderate internal assessments with their colleagues. Every year, randomly selected internal standards are externally moderated by NZQA to make sure the marking done internally matches their expected standard. As an indication of the work involved, in 2009, 5,000,000 pieces of work were marked of which just over 3,500,000 were internally marked and moderated by teachers (NZQA, 2011).

Time issues were mentioned in several interviews. The participating teachers perceived lack of time to be a barrier to implementing the effective teaching practices suggested in the NZC (Mary and James) or to the consideration of the signalled changes in the NZC (James, Ruth, Jill, Nina). The busyness of teachers' lives is well documented (Ingvarson et al., 2005; Kane \& Mallon, 2006; OECD, 2005; Schagen \& Hipkins, 2008). Studies on this topic found that New Zealand secondary school teachers attributed the increased workload and the resulting stress to the demands of NCEA (Wylie, 2013; Ingvarson et al., 2005; Kane \& Mallon, 2005). In Schagen and Hipkins' (2008) report $68 \%$ of teachers saw lack of time as a barrier to curriculum change. Kane and Mallon's (2006) “The Perceptions of Teachers and Teaching" research project surveyed 790 teachers and principals and carried out follow-up interviews with 48 teachers and 16 principals. They found that as a result of their increasing workload and the required changes to curriculum and assessment teachers perceived that they had been diverted from the core business of teaching and learning. Ingvarson et al.'s (2005) study of secondary school teacher workload involved a survey of 1150 teachers, 936 senior and middle managers, 235 school principals and six detailed case studies. Their findings revealed that the participants had similar perceptions of their work: $48 \%$ of teachers felt their workload was unmanageable; $71 \%$ felt their workload was affecting the quality of their teaching; $39 \%$ felt they had little time to get to know their students well; and $66 \%$ felt they had little time to provide professional support to colleagues. In her survey of secondary 
schools, Wylie (2013) found the NCEA workload was more of an issue than it had been in the previous survey three years earlier. When the demands of transformative learning are taken into consideration it would appear to be unrealistic that teachers could undertake it on top of the busy lives they already lead.

\subsubsection{NCEA impact on relevance}

The effective pedagogy section of NZC describes the relevance of new learning in the following way:

Enhancing the relevance of new learning. Students learn most effectively when they understand what they are learning, why they are learning it, and how they will be able to use their new learning. Effective teachers stimulate the curiosity of their students, require them to search for relevant information and ideas, and challenge them to use or apply what they discover in new contexts or in new ways. They look for opportunities to involve students directly in decisions relating to their own learning. This encourages them to see what they are doing as relevant and to take greater ownership of their own learning. (MOE, 2007b, p. 34, emphasis added)

As discussed in chapter 6, the relevance as described above was not observed in eleven of the fourteen classes. Instead, the students were told that the relevance of their learning was to prepare for NCEA or for a common assessment. Even when researching contraception, a highly relevant topic to their lives, the students were reminded how to use their information for the upcoming assessment. In another class the students had been encouraged to seek containers around their home to measure and were offered a further variety of everyday objects in the class to check their measuring ability. However, the relevance of this skill to their lives was not mentioned in the observed lesson. Instead the students were reminded of the accuracy needed for their imminent NCEA assessment. In both these examples it is possible the students could see the relevance of their learning to their lives but it was not explicitly stated by the teachers. I was aware that I was only observing a snapshot of the students learning and it was possible that the learning was made more contextual in earlier lessons. For example, Mary spoke in her interviews about the tension between her desire to teach holistically and the pressure in her context to ensure her students succeeded in their NCEA assessment. As a teacher at the beginning her teaching career, Mary appeared to be torn between what Neyland (2010) describes as a tension between conforming to the norms of the context and her personal beliefs of what was important in education. This confusion was evidenced in her comments after the observation. One example was when she did not ascribe the use of tools to the desire to relate to the students' lives but to "give them 
practical experience. Handling helps them to get it for assessment." Another was that while she maintained that she was beginning to reconcile depth with coverage, her rationale was to enable the students to get at least "achieved" in their assessment and "maybe those with more understanding will get merit or excellence." She explained in the post-observation interview that in earlier lessons she had emailed the students to remind them to measure objects in their home environment: "when you are having breakfast, look at the weetbix packet - how much does it weigh etc. I encouraged them to think how big is this/how far is that/estimate everything, to get the importance using appropriate units." However, during the lesson her reasons for doing this were not explained with the focus being on preparing for an assessment. It was not clear whether the work at home was a way to encourage students to link the learning to their lives or a strategy to increase their engagement. Mary's explanation suggested that the assessment was a higher priority. Relevance to the students' everyday life was not mentioned in the interviews with the other teachers. On the contrary, one made it clear that she made links to NCEA for the learning in all her classes, even with the juniors.

As described in chapter 7, Ruth included real life, often amusing or startling stories about metals and non-metal to make the learning memorable. She did not, however, invite the students to consider how they may use this learning in their lives. The purpose for the learning, she told them, was to prepare for the assessment. In Jennifer's junior class, while the students appeared to understand that being able to give a speech would be a useful skill in life, the focus of the learning was clearly to prepare for the assessment with the students being reminded by the teacher how many lessons they would have before being assessed.

A focus on NCEA also appeared to be implied in the goal setting with junior students that took place in Ruth's context. Examples she cited were from her year 10 class 'Some of them have in their goals 'I want to get excellences' and for some of them it's 'I want to pass a test'. These goals, being vague rather than explicit, may have limited motivational value (Bandura \& Schunk, 1981). In addition, they are examples of performance goals that focus on achieving standards which can lead to shallow learning. Mastery goals on the other hand, which focus on gaining competence or mastering a new set of skills, have been found to be more motivating and to develop greater self-efficacy than performance goals (Bandura \& Schunk, 1981; Locke \& Latham, 1990;

Vansteenkiste, Soenens, Verstuf, \& Lens, 2009). 


\subsection{But... not motivated to make the change}

This study has proceeded with the premise that what motivates an individual to make changes is a mixture is of both cognitive and affective: what they feel as well as what they think (Fridja, Manstead, \& Bem, 2000; Leithwood \& Beatty, 2008). As previously described, to understand if the teachers in this study considered the changes to be of significance and were therefore motivated to engage in them a formula for motivation was used to interpret their stories: Goals plus positive emotions plus positive personal agency beliefs equals motivation (Ford, 1992; Leithwood et al., 2000; Pintrich et al., 1993; Rafferty, Jimmieson, \& Armenakis, 2013). In this study each of the participants had a negative response to one or more components in the proposed formula for motivation. In addition, 11 of them did not feel that any gap between their current state, in particular with senior students and where they wished to be, would be resolved by engaging with the signalled changes in the NZC. This suggests that they had either an insufficient sense of dissonance to motivate them to make significant changes, or they did not perceive the changes were appropriate to bridge any gap.

\subsubsection{Motivational significance of the implementation of the NZC}

Their students' academic achievement was an important personal goal for all of the participating teachers. In Amy's case this meant developing the junior students' mathematical understanding to an appropriate curriculum level. For Jill it was developing conceptual understanding. Ultimately for all the participating teachers, it was working towards success in NCEA assessments. Their behavioural belief (Ajzen, 1991) was that taking action towards meeting this goal would have a positive outcome for them and for their schools. The behavioural belief was translated into what Ford (1992) refers to as an "intention, a current concern that has been prioritised by cognitive and emotional regulatory processing and infused with emotional energy" (p. 116). An element of the processing was evaluating significance to the individual, that is, assessing if it was relevant, important, and achievable and whether it would be personally rewarding (Ford, 1992). The goal of students succeeding in NCEA assessments was considered relevant because it was perceived to be the key goal in their context. It was important and potentially emotionally rewarding because they believed it was how their effectiveness as a teacher was judged by their school, by the community, and by their peers. It also aligned to another personal goal for their students to achieve academically. When this was accomplished by the achievement of 
NCEA credits, teachers would feel affirmed. These sources provided feedback that contributed to their self-esteem (Kelchtermans, 2009). Finally, their previous experience and that of their peers had demonstrated that they were capable of reaching this goal through their current teaching practices. The teachers were therefore motivated to use whatever means they believed were effective in order for their students to achieve success in their NCEA assessments. For the majority of the teachers this was through a monitored or facilitated development of skills and knowledge which, while including some elements reflecting the spirit of the NZC, was essentially teacher centred. Despite the pressure associated with preparing students for assessment, the teachers were not motivated to seriously consider an alternative approach. They wished to continue to develop their practice but a wholehearted consideration of the signalled changes of the NZC was not on their agenda because their energy was consumed by their current course of action which was supporting the meeting of their personal goals (Dzubay, 2001).

Once again, looking at Ford's (1992) formula for motivation in conjunction with the goal for students to succeed in NCEA assessments, it can be seen that it is addressed by each component:

Goals: Achievement in NCEA was relevant to their goal for their students to succeed and to their image of themselves as effective teachers.

Emotional response: Emotions commit an individual to a course of action (Oatley, 2000).The pressure of covering the curriculum, the many assessments and the pedagogical approach did cause some anxiety. However, this did not diminish the emotional commitment to the goal. Because it was important in their context, success in NCEA provided the emotional rewards of being seen as effective teachers and of feeling that they had met the needs of their students. Conversely, the concern that lack of success would result in a negative perception of their competence was motivation to commit to this goal and to invest energy in it.

Personal agency: The teachers believed they had the ability to achieve this goal by continuing their current practice. Even those teachers who experienced satisfaction working in a student-centred way with juniors did not have the confidence to employ it with their senior students. Context belief: This goal was supported by peers and the community. In addition, their belief that their current practice was shared by other teachers in the context made it more resistant to change (Feldman, 2000). 
To change, individuals must feel dissatisfied with the outcomes of their current practice and then see the change as a way to solve the problems and thus that will meet the goals. In other words, they will perceive the change as something that will benefit them (Feldman, 2000). If the participating teachers' readiness to incorporate the changes is appraised using Armenakis et al.'s (2007) precursors, the components are not all met.

Discrepancy: Teachers must believe that change is needed. There were indications from two teachers of the need for some change: Susan felt unhappy with her teaching approach with seniors. James wished to be free to work in a way that gave students more ownership.

\section{Appropriateness: Teachers believe that the implemented changes will} work towards eliminating the discrepancy. Teachers believed that the discrepancy would be addressed, not by the NZC but by structural changes, for example Susan (fewer assessments) and James (fewer responsibilities).

\section{Efficacy: Teachers believe they are capable of including the changes in} their classroom practice. While there were some elements of the effective pedagogy and espoused commitment to the key competencies, the nine of the 11 teachers observed demonstrated an objectivist epistemology in their lesson. The extent to which teachers incorporated the philosophy of the new curriculum into their practice was influenced by their beliefs about their capacity to do so but this appraisal went further than a consideration of their personal skills and understanding. They also considered if they could carry out the changes given the norms, values and expectations of their school and community.

\section{Principal support: Teachers are confident that the change is supported} by key personnel in the school. There was little evidence that key personnel in each context "walked the talk.'

Valence: Teachers believe that they will personally feel the benefits of the change. In their current environment nine of the 12 teachers did not perceive the signalled changes would support their goal of achievement in NCEA. This was reflected in the teachers' emotional response to the changes. In considering the valence of any change teachers considered "what is at stake for me?" While Armenakis et al.'s (2007) model does not include an emotional dimension, readiness was not simply a cognitive function. There was also an affective dimension: as identified in chapter 6 , the implementation aroused a range of emotional responses, both positive and negative. 
On the face of it, a goal of success in NCEA assessment could be classed as an extrinsic motivation described as doing something as a means to an end because it leads to a reward compared to intrinsic motivation in which a person does not look for any external benefit (Pintrich \& Schunk, 2002; Ryan \& Deci, 2000). However, in the case of the teachers in the study this core goal was aligned with other personally important goals. It appeared that extrinsic and intrinsic motivation were both evident in these teachers' classrooms. While working towards the goal of success in NCEA assessment, teachers were also, for example, able to incorporate another personal goal of developing positive relationships with students. In some cases (Nina, Mary and Amy) this was an intrinsic goal (Ryan \& Deci, 2000), a personal driver, something that was personally satisfying to them. In others (Edward, Christopher and Joseph) building a positive relationship was an extrinsic goal, a means to an end; if the students related to the teacher they would work to please them and work harder to succeed in NCEA assessments.

However, rather than focussing on extrinsic or intrinsic goals, Dzubay (2001) believes it is more useful to consider how intentional a person feels about what he or she is doing and to ask whether they are they self-motivated, "pursuing this course of action with a sense of purpose or just being swept along?” (p. 6). The interviews with the teachers indicated an acceptance that the assessment culture was a reality of the arena in which they worked. They were able, with a sense of purpose, to use strategies to encourage student engagement but the learning was scaffolded towards the assessment. The exception was Jill who was committed to a student-centred approach and supported her students to explore concepts that were relevant to their lives. She was able to fit the assessment to the learning as opposed to narrowing the learning to fit the assessment.

\subsection{But...Time}

Even without the assessments, secondary school teachers' days are very busy. They may have five or six classes a day each with up to 30 students. Each participant stated that developing positive relationships with students was very important to them, a challenging task when they have contact with up to 150 students. The effective pedagogy section of the NZC suggests that teachers link the learning to the students' prior knowledge, cater to the range of different learning needs, and encourage metacognitive reflection, critical analysis, and relevant contextual learning incorporating key competencies. All this requires careful consideration and planning. Each 
participant considered that lack of time was a barrier to the implementation of effective pedagogy for a range of reasons: 1) time to cover the curriculum; 2) time to focus on teaching learning and planning; and 3) time allocated for professional learning.

\subsubsection{Time to cover the curriculum}

As already discussed, those concerned about the coverage of the curriculum for NCEA assessments considered lack of time to be an issue. This impacted on their pedagogy. Edward, for example, spoke of the difficulty of meeting the individual needs of students. Pressured to ensure all the content for NCEA assessments was covered in their classes meant that the teachers could resort to teacher-centred methods. This was particularly evident in the observation of Christopher's class which took the form of a lecture with minimal student input. It also appeared to be the case in Jennifer's class where she was in the role of "sage on the stage", trying with her enthusiasm to motivate the students to engage with a novel. Four of the participants believed that the pressure to cover the curriculum to prepare for NCEA assessments prevented them from teaching all their students in a student-centred way. While they employed aspects of the effective pedagogy described in the NZC in their junior classes, they felt this was not possible for their senior classes because of the pressure to prepare their senior students for NCEA assessments. They were therefore anxious that their students did succeed and found that they chose a teachercentred pedagogy to achieve good results. This stance presents a contradiction in the teachers' beliefs about the learning process and a lack of belief that student-centred teaching and learning is effective or acknowledged.

As described in previous chapters, Christopher, Susan and James all expressed frustration at their perception of effective pedagogy on the one hand and the pressure to cover the curriculum on the other. However, all three felt they were unable to teach seniors in this way, as Susan explained: "I see a real distinction between the junior school and the senior school in the way that I teach."

Edward expressed concern that the pressure of coverage for NCEA assessment would negatively impact on the implementation of the effective pedagogy of the NZC. Coverage was also worrying Mary. When discussing the integrated project she was working on with a group of teachers, she stated that she believed it was appropriate for some subjects but that she was concerned that the focus on a common concept across subjects would mean her junior students were not adequately prepared for NCEA when they were in the senior classes. 


\subsubsection{Time to focus on teaching and learning}

The busyness of their teaching lives was a frustration for several of the participants. Ruth, when describing teaching as becoming busier and busier, likened it to "uber-parenting" maintaining that she simply did not have the time to attend to the individual needs of her students. Mary had similar time issues compounded by class sizes: "My big thing is that I am unable to provide feedback and to check their understanding because of the number of students."

James had time-consuming dean responsibilities and described his concern that this prevented him from having enough time to concentrate on his teaching. His busyness impacted on his choice of pedagogy. For example, when asked about students working in groups as suggested in the effective pedagogy of the NZC, James stated he would like to work this way more often but did not have the time with his other responsibilities as a dean and as head of his department. Amy also believed that the busyness of teachers prevented them from using more group work. She used the example of a colleague who had five classes and was a dean. Being this busy, she maintained, meant he did not have sufficient time to prepare for and to organise group work for his students. In her case she had experimented with working with a part-time workload and a full-time one and had now decided she could not work full time and teach properly, echoing James's comment: "I don't want to be this busy. I want to be able to teach."

\subsubsection{Time allocated for professional learning}

A three-year implementation programme was designed to support schools in understanding the curriculum intent and enacting it in a way that best suits the diverse learning needs of their students and the expectations of their communities. In 2007 all schools were allocated a teacher-only day to explore the intent of the NZC; in 2008 two additional teacher- only days were allocated to secondary schools for this purpose. Resources (online and paper-based) were made available. Subsequently the time for PD was left to the discretion of the schools. This required schools to incorporate an implementation process within their existing timetables.

Jennifer believed that schools would struggle to find the time to effectively implement the NZC: "In an ideal world you require more funding and time to plan, problem solve." In her position as a senior leader, Jennifer expressed concern that the need to align the new NCEA assessments to the NZC would add to heads of departments' responsibilities and prevent them from leading teachers in their 
departments in developing their skills in teaching and learning and engaging with the effective pedagogy of the NZC. In all the schools in the study, curriculum development, student assessment, and NCEA implementation were subject department responsibilities overseen by the head of the department. This was particularly pertinent in Totara College, where subject departments appeared to be the main source of PD for teachers. Jennifer described the head of department roles as "absolutely crucial, they carry a significant role probably the most important role now with the new curriculum they have to unpack it with their department, realign it and have everyone on board with the direction it may or may not be taking." Her concerns that the heads of departments would struggle to carry out their pivotal roles appear to be justified. In their study of secondary teachers' workload, Ingvarson et al. (2005) found that $57 \%$ of heads of departments thought their workload was unmanageable; $77 \%$ felt their workload was affecting the quality of their teaching; $71 \%$ felt they could not do what they needed to do in a reasonable time; and, most worryingly during an implementation process, $70 \%$ felt they had no time to provide professional support to colleagues. It is therefore difficult to comprehend how heads of departments could possibly develop their own understanding of the signalled changes plus lead the learning with their staff.

Edward alluded to this when he spoke of the teacher understanding of key competencies. As head of department he could check that key competencies were included in the teachers' work plans but he needed time to provide professional support by observing if they were actually in the teachers' practice and if not, helping teachers to understand them. Other participants maintained that lack of time for professional learning would impact on the implementation of the NZC. The allocation of considerable time had been a feature of the learning of those teachers who had developed conceptual understanding. Jill and Nina, for example, believed that their personal practice was aligned to the spirit of the NZC because their previous experiences and the time they had invested in exploring the document had prepared them for it. They were, however, concerned that lack of time would mean that other teachers would not be able to implement the pedagogy of the NZC. Their own experiences had highlighted for them the importance of time to understand and to reflect on any changes in practice.

Jill had spent considerable personal time exploring the NZC and linking it to what she had learned in the initiatives she had previously been involved in. She had also had the time during her study leave to reflect on her learning. She believed it was 
unrealistic to expect that many teachers would be willing (or expected to) sacrifice their personal time given the time-consuming nature of their jobs. Nina had been involved for several years in her curriculum changes which had incorporated key competencies. This, she believed, had prepared her well for the NZC pedagogy and the inclusion of key competencies. Both she and Jill acknowledged the challenge it represented for teachers who had not been exposed to these concepts before and who were coping with a demanding profession. Ruth had also found having the time through her lessened workload to reflect had been essential for her own development and that this was difficult for teachers with a full-time workload.

Amy had found the professional learning in the numeracy project to be highly effective. This model provided time for the teachers to collaborate, observe each other, reflect and provide feedback. These elements had been key to changing her beliefs and practices, and she realised that without the time to explore the NZC in this way it was unlikely to be successful.

Collaboration with other teachers had provided the professional learning to develop Susan's practice. As a result, she was enthusiastic about collaborative practice, with teachers planning together and sharing their experiences. However, attempts to organise this form of professional learning with teachers outside the team teaching group had been thwarted by lack of time.

In each of these examples the teachers were able to identify what made their learning effective: extended time to learn, external expertise, having prevailing discourses challenged, and opportunities to practise and receive feedback in a challenging professional community of practice. However, they believed that in their current context the professional learning available did not provide these elements and therefore it was doubtful that it would provide the support teachers needed to implement the NZC. It seemed a shame to me that these teachers' experiences were not shared and the ingredients of their successful professional learning employed by the leaders of the NZC implementation in their contexts.

As identified in chapter 6, there was designated professional learning time for an hour each week in two schools. Sometimes this involved whole school discussions but more often the teachers worked in groups of shared interest. Teachers appreciated the opportunity to work together, but their learning depended on the expertise within the group. Jill believed these groups led to changes only if the teachers were ready to consider them. Referring to the learning groups, which took place at the start of the school day once a week, she maintained: 
Teachers at the start of the day, students are not the thing at the top of their heads. They are thinking about emails, planning, management of their classes etc. Learning groups need someone to progress the group.

At different times during the school year the groups reported their findings to the whole staff but it was not possible to know if the learning was transferred to the teachers' practice in the classroom.

Apart from teacher-only days there was no whole school discussion in Totara College, and only on occasions in the other contexts. This contributed to the lack of a common understanding of the goals of implementation. Boyd et al. (2005) found that whole staff learning provides opportunities that could have addressed many of the issues identified in the interpretation of the professional learning in each context. They include:

- develop a shared understanding of the school's vision and values

- identify and critique links between curriculum practice in classrooms and wider aspects of school life that signal the "hidden curriculum'

- develop a shared language for planned pedagogical innovations

- avoid mixed messages about expectations

- identify opportunities for creating a more coherent curriculum by exploring potential links and overlaps between courses and learning areas.

These discussions could subsequently be further explored in a departmental meeting. While teachers in Kauri High School and Kawakawa College could have elected to pursue aspects of the NZC in their weekly learning groups, this in itself did not lead to common understandings and depended on the expertise and level of challenge within the group.

\subsection{But...how do you do it?}

For the effective pedagogy and the key competencies to have sufficient significance for the teachers to encourage them to make changes would require an understanding of the philosophical and epistemological views underpinning it. It appeared that in this study ten of the 12 teachers either did not have a conceptual understanding of the signalled changes and/or did not believe in it.

While each participant maintained that they supported the effective pedagogy of the NZC and the integration of key competencies, under the pressure of coverage and time and the senior curriculum, they elected to teach in a more familiar teachercentred way (Windschitl, 2002; Yates \& Holt, 2009). This seems to indicate a lack of 
confidence that a student-centred approach would achieve their goals. This challenge was referred to in Meyer et al's (2010) evaluations of the Te Kotahitanga project. The evaluation did find evidence of pedagogical change but the focus on junior classes led the researchers to question whether the student centred approach had been transferred to senior teaching and learning.

In this study it was possible that a lack of understanding and or acceptance of the theory underpinning the effective pedagogy and the key competencies were the reasons for the reluctance to fully trust it as a teaching approach. The following comment from Edward, for example, suggests some uncertainty about the nature of student-centred teaching:

I think to make it completely student centred where they could look at any topic whatever, I don't necessarily ... I think you would lose cohesion and possibly the motivation and stuff that if I still think there is something that I have to teach you.

There were other suggestions of epistemological beliefs that differed from those underpinning the effective pedagogy of the NZC. For example, three teachers stated that they and other teachers did not use cooperative learning as much as they would like because of lack of time which suggests they may not believe that cooperative learning, while desirable for different reasons, maximises learning. As discussed in previous chapters, student-centred or social constructivist thinking requires a different epistemological orientation (Windschitl, 2002) or mindset (Hattie, cited in Boyd, 2009) from a transmission model of teaching. It seems unlikely that a teacher who genuinely held a social constructivist epistemological worldview would believe that reverting to an objectivist approach would be advantageous for students' learning.

Other opinions reinforced the suggestion that some teachers lacked a conceptual understanding. Three teachers - James, Christopher and Susan - did not consider a student-centred approach appropriate for senior classes where there was high stakes assessment; Edward considered that sometimes a transmission approach was more efficient. These points of view raise questions about their conceptual understanding: 1) Do the teachers have an understanding of the philosophical and epistemological theory underpinning the effective pedagogy of the NZC? and 2) Do these theories represent their personal beliefs? Jennifer maintained that "Nothing here that is radically different. You look at it and say, yes we are on that path." Looking for the familiar in a signalled change is a common response (DarlingHammond, 1990; Spillane et al., 2002). However, the signalled changes required not 
just applying recognisable aspects of the effective pedagogy but making sense of constructivism as a basis for all teaching (Windschitl, 2002). As noted in chapter 7, there were strategies in several classes that linked to the effective pedagogy of the NZC within the approach that was categorised as facilitated development of skills.

However, the use of these strategies was within a teacher-centred model suggesting an objectivist epistemological view of knowledge. This approach appeared to be a compromise reflecting their context; assimilating change strategies into their current repertoire but not accommodating the underpinning conceptual theory of the change (Luttenberg et al., 2011). For teachers to fully embrace the conceptual meaning of the effective pedagogy, to think as constructivists, this would need to be addressed and explored, a challenging prospect in cultures where the curriculum is firmly fixed by the assessment regime.

In contrast in Jill's class, the team taught class of Jill and Susan, and Susan's junior classes a constructivist view of knowledge was evident. Jill, who had moved from Kauri High School to Kawakawa College and was a leader in the team teaching progamme appeared to have influenced Susan's approach. It was significant that Jill's constructive world view had evolved through extensive study, support and challenge from a mentor and the time to develop deep conceptual understanding. Other teachers had not had this opportunity or any external expertise to facilitate their learning. Jill's approach provided a way for Susan to observe constructivist teaching in action, something other teachers had not experienced.

To explore the teachers' possible epistemological beliefs, in the following table I have linked the teaching approaches used in chapter 7 to elements of the effective pedagogy of the NZC and to Schommer's (1998) description of epistemological beliefs. If these links are a fair indication of the teachers' epistemological beliefs they suggest that, with the exception of Jill, they did not have an understanding of the epistemology underpinning the signalled changes. Susan appeared to be experiencing confusion. While she could see a more constructivist approach was effective with her junior classes she felt unable with the assessment regime to transfer it to her senior classes. With support she could possibly make a greater commitment to constructivist practices in all her classes. However, for other teachers who have not had her experience, the changes represent considerable transformative learning if the spirit of the effective pedagogy is to be implemented. 
Table 28. Links between approaches, NZC and epistemological beliefs

\begin{tabular}{|c|c|c|c|}
\hline Approach & Observed & Links to NZC & Epistemological beliefs \\
\hline $\begin{array}{l}\text { Monitored development of } \\
\text { skills. }\end{array}$ & $\begin{array}{l}\text { Christopher } \\
\text { Jennifer } \\
\text { Nina } \\
\text { James }\end{array}$ & $\begin{array}{l}\text { Students learn as they engage in shared activities and conversations with } \\
\text { other people. }\end{array}$ & $\begin{array}{l}\text { Knowledge: Teachers define concepts. } \\
\text { Certainty: Students learn as presented. } \\
\text { Teachers seek the correct answer to validate } \\
\text { student learning. } \\
\text { Source of knowledge: Teacher answers all } \\
\text { Speed: students learn from well designed } \\
\text { curricular materials and presentations. }\end{array}$ \\
\hline $\begin{array}{l}\text { Facilitated development of } \\
\text { skills. }\end{array}$ & $\begin{array}{l}\text { Edward } \\
\text { Ruth } \\
\text { Amy } \\
\text { Mary } \\
\text { Jennifer } \\
\text { Joseph }\end{array}$ & $\begin{array}{l}\text { Students learn as they engage in shared activities and conversations with } \\
\text { other people. } \\
\text { Effective teachers look for opportunities to involve students directly in } \\
\text { decisions relating to their own learning. } \\
\text { Students learn best when they are able to integrate new learning with what } \\
\text { they already know. Effective teachers deliberately build on what their } \\
\text { students already know and have experienced. } \\
\text { Challenge, support and feedback are always available. }\end{array}$ & $\begin{array}{l}\text { Knowledge: Teachers define concepts. } \\
\text { Certainty: Teachers seek the correct answer } \\
\text { to validate student learning. } \\
\text { Source of knowledge: the source, the } \\
\text { teacher or otherwise accepted uncritically. } \\
\text { Speed: Gradual - students learn from } \\
\text { discovering or doing. }\end{array}$ \\
\hline Facilitated knowledge building. & $\begin{array}{l}\text { Jill } \\
\text { Susan }\end{array}$ & $\begin{array}{l}\text { Students learn as they engage in shared activities and conversations with } \\
\text { other people. } \\
\text { Students learn most effectively when they understand what they are learning, } \\
\text { why they are learning it and how they will be able to use new learning. } \\
\text { Students learn best when they are able to integrate new learning with what } \\
\text { they already know. Effective teachers deliberately build on what their } \\
\text { students already know and have experienced. } \\
\text { Effective teachers look for opportunities to involve students directly in } \\
\text { decisions relating to their own learning and take ownership of their own } \\
\text { learning. } \\
\text { Over time students develop their creativity, their ability to think critically } \\
\text { about information and ideas and their meta-cognitive ability. Teachers } \\
\text { encourage such thinking when they require students to critically evaluate the } \\
\text { material they use and consider the purpose for which it was originally created. } \\
\text { Challenge, support and feedback are always available. }\end{array}$ & $\begin{array}{l}\text { Knowledge: Students examine complex } \\
\text { knowledge and draw their own conclusion. } \\
\text { Students allowed to develop alternative } \\
\text { conceptions. } \\
\text { Certainty: Students apply a critical eye to } \\
\text { what they hear and ask questions of each } \\
\text { other. } \\
\text { Ability: Students can learn to learn. } \\
\text { Learning is process orientated. } \\
\text { Speed: Gradual - students learn from } \\
\text { discovering or doing. }\end{array}$ \\
\hline
\end{tabular}




\subsubsection{Key competency understanding}

Lack of conceptual understanding of the key competencies was also apparent. The integration of key competencies was effectively demonstrated in Nina's class reflecting the development of this skill in her subject area. Nina related the relevance of the key competencies to NCEA assessments, not to a transferable life skill. Nevertheless, the students did construct their own understanding and monitor their own learning of self-management. She was deliberately developing integration of key competencies into her teaching: "So now my whole new thing is, instead of just the lesson, I will think about my aim, I connect the focus which is the key competencies."

Other teachers did not appear to have a conceptual understanding of key competencies, seeming to view them as an "add-on', something they felt compelled to do by their head of departments or senior management or, in Jennifer's case, a compliance issue that may be checked by an external authority such as ERO. The following are examples of the perception of key competencies by the participating teachers.

Ruth did not explicitly integrate key competencies into her teaching but believed that they encouraged her to look at the whole child and were particularly useful when writing reports for parents: "I find the key competencies incredibly useful for juniors in terms of the overall view for report, comments and progress."

Jennifer's description of key competencies appeared to be a common approach:

They are like an underpinning thing in a lot of classrooms I don't think we necessarily talk about, you know. They are skills that we encourage with the kids through a range of means but I'm not sure that we, like we tick the box on our unit planning thing and say oh yep, but do we make them explicit to the kids? and we probably should be making them more explicit, the kids should know... I'm not seeing that happening around me.

When speaking of her own classes, she said:

Are they aware of key competencies? No but they have to evaluate how I managed it, listened to other opinions at the end of the topic. These are key things I have always worked with. That's nothing new. But it's in here as an important thing.

While there had been some professional learning on "unpacking" the key competencies as evidenced by posters on classroom walls, apart from Nina's lesson they were not observed being woven through the learning. To successfully implement the effective pedagogy and the integration of key competencies may 
require an epistemological change, something which Nespor (1987) likens to a conversion. However, it was not obvious that, with the exception of Jill and a developing awareness on the part of Susan, the teachers in the study had an understanding of the concepts involved in the changes. This signals that this understanding and the theory underpinning their current practice were areas that would need to be explored before any attempt at "conversion" took place. An explanation represents considerable learning and reflection that would be difficult to schedule given all the time issues already discussed. It would also require what Ruth described as "head space" which is a challenging prospect in the busy and mentally demanding nature of a teacher's day-to-day work.

\subsection{But... where is the leadership?}

What appeared to be missing in any context was a clear message from the leadership promoting a shared understanding of what the change involved and what it would look like in practice. There also did not appear to be anyone in a leadership position who could lead the staff towards a conceptual understanding of the changes. Each of these elements could be expected to be facilitated and supported by leadership at all levels of the school (Fullan, 2008) which, in a secondary school, would be the senior management and the heads of departments or faculties. The deputy principal with responsibility for professional learning in Kawakawa College explained that in her school, "we don't have the vocabulary." This appeared to be the case in each context. Leaders of the implementation senior management and heads of departments could be considered "piggies in the middle" (Wallace, 2003, p. 22) required by a government mandate to introduce change they had not chosen, to which they had an uncertain commitment, and did not necessarily understand. The remark by John, the deputy principal with responsibility for professional learning, "No one is an expert - where do you find the expert?" was echoed by other participants. It indicated that within each context there were few, if any, who had a sufficiently deep understanding of the signalled changes to facilitate learning for the rest of the staff. In this study it appeared that the leaders were learning with the teachers. This lack of understanding made it difficult for them to monitor and support the teachers' implementation of the changes.

Jill's perception was that the leader in her school did not have a deep understanding of the conceptual framework of the effective pedagogy. Her head of department was also learning to understand the implications of the NZC for his 
department and did not yet feel equipped to lead his staff. She could understand how this happens: "Heads of departments can be behind (in their understanding). They are busy with administration and are aware that people are feeling the pressure of coverage."

In one context the lack of leadership left a participant feeling isolated and angry. She looked for overarching goals for her department and for meetings where the focus on learning could be shared. Her head of department was busy with administration and other responsibilities and she felt embarrassed that her enthusiasm for teaching and learning was not shared. In another context one teacher believed that the culture of acknowledging the importance of individuality meant that teachers were left to their own interpretation: "this is not a place where you can tell people what to do." There was an assumption that key competencies would be incorporated into lessons but support and or mentoring was not provided.

Fullan (2007) maintains that quality leadership is required to develop the skills and knowledge teachers need to make changes and to subsequently positively affect students' learning. Robinson et al.'s (2009) meta-analysis of 27 studies on the various practices of leadership that influence student outcomes and that would therefore meet the description of quality leadership makes a positive connection between pedagogical or instructional leadership and student learning. This style of leadership which involves "establishing an academic mission, monitoring and providing feedback on teaching and learning, and promoting professional development" (Robinson et al., 2009, p. 88) is supported by other research (Bryk \& Schneider, 2003; Dinham, 2007; Murphy, Elliot, Goldring, \& Porter, 2007).

However, instructional leadership is a challenge for many school leaders. Southworth (2004) actually wonders if, given the constraints on educational leaders, instructional leadership may be an impossible dream. This may be true of New Zealand secondary school principals who find that much of their time is dominated by administrative or managerial tasks (Schagen \& Wylie, 2008). As previously discussed, New Zealand has one of the most decentralised schooling systems in the OECD. Since the introduction of "Tomorrows Schools" in 1989 (Openshaw, 2008), most decisions relating to budgeting, resources, personnel, buildings, and planning have been made at school level. In this system the principal's role requires wideranging skills: human resource manager, building and infrastructure overseer, executive officer, instructional leader, community leader, major negotiator with all stakeholders, and as apparent in Totara College, in a competitive educational 
environment, marketing skills. Jennifer had experience of this: "what I found in my time as acting principal was that little part of my job was really to do with teaching and learning so much as to do with the politics.” The New Zealand MOE's (2008) document Kiwi Leadership for Principals, designed to present a model of leadership for leaders of New Zealand schools, states that as well as being instructional leaders, principals are responsible for the "day to day management of everything that happens in their schools" (p. 7). It is therefore not surprising that in a survey of secondary school principals, only $17 \%$ thought they had enough time for instructional leadership (Schagen \& Wylie, 2008).The time issues for heads of departments discussed earlier suggests that they, principals and other leaders did not have the opportunity to develop their own conceptual understanding of the NZC changes.

Instead, the styles of leadership that appeared to be occurring in this study were as described by Sergiovanni (1998): bureaucratic leadership that mandated for certain things to be done for specific outcomes to be achieved. This was carried out in Kauri High School and Kawakawa College by appraisals, requirements to implement specific strategies (Joseph "I will follow orders"), and expectations that targets for NCEA were met, or, as in Totara College, entrepreneurial leadership that applied market principles to the school. This leadership acknowledged the need to succeed in the competitive environment with the incentive of roll growth for achieving positive NCEA results and the concern of staff losses if targets were not met.

Importantly, there did not appear to be evidence that leaders understood the change process within teachers required for an implementation of change. Evidence of an understanding of change would mean establishing a compelling reason for the change, providing an opportunity for teachers to explore their current beliefs and exploring those of the change. This would be followed by opportunities for teachers to experiment with the changes with support and feedback. These elements were not in evidence in any of the contexts.

\subsection{But...there is so much else going on}

As described in chapter 7, the implementation of the NZC was not the only initiative in each context. The impact on Mary was eloquently expressed: "so the matrix is definitely not two dimensional. It's more like six dimensional." Neyland (2010) could have had Mary in mind when describing the tension caused by the number of initiatives teachers face: "a teacher can become overwhelmed by 
externally generated requirements which stretch her in many directions - no longer the improviser, but the juggler rooted to the spot dealing with an overabundance of flying objects" (p. 35).

The following initiatives were in place in the schools in the study:

Totara College: $\quad$ Meeting the needs of Māori, numeracy project, restorative justice.

Kauri High School: Literacy, differentiation, writing, integrated subjects, blended learning, and interests of the learning groups

Kawakawa College: ICT, differentiation, using data to inform practice.

There was anxiety expressed: Edward did not have enough time to do differentiation; Christopher worried about the literacy needs of his students; Joseph attempted to co-construct success criteria with his students; Mary was overwhelmed by multiple expectations; James had many responsibilities. There was also excitement: Jennifer for Bill Rogers and restorative justice; Nina over key competencies; and Amy over the numeracy project.

It is difficult to imagine how it is possible to develop anything other than a superficial understanding of so many initiatives or to deeply engage with the signalled changes of the NZC and the key competencies. Abrahamson (2004) maintains that every time an initiative is added, others slow down or (as I have earlier described observing in schools) they even disappear. Jennifer was aware of this: "the more you ask people to change things will happen. But what is the quality of the change and what is the cost?"

Darling-Hammond (1990) maintains that "A massive geological dig would be needed to unearth the tangled influences of the many policy layers that exist in schools" (p. 343). However, if such an exploration of the range of initiatives was undertaken there would be common key messages identified that could provide a coherent approach. For example, the projects for Māori students, restorative practice, differentiation, the effective pedagogy of the NZC, key competencies, are all underpinned by a constructivist epistemology. In their present form in the schools they are being treated as separate entities causing the juggling effect referred to by Neyland (2010). This would require schools to feel they had the ability to build a coherent picture of what they wanted to implement in their schools and to work towards a shared understanding of the theory. Doing this could also work toward preventing what Abrahamson $(2004$, p. 94) refers to as "repetitive change syndrome: initiative overload, change-related chaos, employee cynicism and burnout." 


\subsection{Chapter summary}

In this chapter I have described what I consider to be the issues preventing all the teachers in this study from engaging with the changes of the NZC. I believe these issues form the walls of a cage that the participating teachers and their leaders run against on a daily basis. These teachers were extremely hardworking dedicated individuals who were motivated to do their best for their students. However, the messages in their context and in the wider educational environment indicated that the success of their students, their competences as teachers, and the effectiveness of their schools would be decided on the basis of the understanding of predetermined knowledge or their NCEA results. In this environment, with the exception of Jill, the teachers did not perceive the signalled changes to be of significance to them. 


\section{Conclusion}

It's not what you look at that matters, it's what you see. (Henry David Thoreau)

\subsection{Chapter overview}

This concluding chapter provides an overview of the study and research findings. It begins by summarising the aims of the study and the findings that addressed the research questions. This is followed by a discussion of the possible implications for policy makers, secondary school leaders, and teachers arising from the themes identified in this study. Next the limitations of the study are explored, followed by suggestions for future research.

\subsection{Aims of the study}

The purpose of this study was to investigate the significance of the signalled changes in the effective pedagogy and the key competency sections of the NZC for New Zealand secondary school teachers. The literature review in chapter 2 revealed that while there is extensive research on educational change, studies generally overlook issues of teacher motivation to make the changes based on their perception of its significance for their personal goals, their existing beliefs and practice, their personal agency and their appraisal of the support within their context. Importantly, their emotional response is not acknowledged. I noted that it was ironical that a change underpinned by a constructivist approach should ignore the reality of the teacher as a learner. In particular, I wanted to ensure that the participating teachers' subjective perception of the signalled changes could be understood. The method of educational criticism was therefore used to seek to provide a nuanced view of the teachers' reality. The following section reviews how the study addressed the research questions.

\section{Key question:}

What is the personal significance of the changes signalled in a mandated curriculum to New Zealand secondary school teachers?

The findings from this study suggest that for eleven of the teachers in this study the signalled changes were not of sufficient significance for them to be motivated to fully engage with them. A reader may have begun, in chapter 5, to gain an understanding of each teacher and a sense of what did motivate them to make changes. My interpretation of their stories (which hopefully complemented that of a 
reader) is provided in chapter 6 . The sub-questions that supported the overarching key questions addressed in chapters 5 and 6 were:

- What are the crucial life episodes of the teachers' past personal and professional life that have impacted on their knowledge?

- How do elements of the current context interact with and shape their knowledge and practice?

- What is the significance of the NZC to their context?

- How does the implementation of the NZC impact on them emotionally?

- What is the significance of the NZC to their personal goals?

Chapter 7 describes and interprets the teachers' practice and their enacted beliefs. Through chapters 5, 6 and 7 a picture of the teachers' reality and their perceptions of the significance of the changes emerges. In chapter 8 , I suggest that the teachers" context creates "walls of a cage" which militate against the signalled changes being relevant to their situation. These walls are discussed in that chapter. The sub-questions addressed in chapters 7 and 8 are:

- How do elements of the current context interact with and shape their knowledge and practice?

- What is the significance of the NZC to their beliefs and practices?

The findings of the study suggest that the teacher as a learner has not been acknowledged in the implementation of the changes which were the focus of this study. To be motivated to change, the teachers needed to believe it would meet their personal goals, followed by ongoing expert support and, most importantly, time to reflect and develop conceptual understanding. Like all learners, teachers needed to be provided with an environment that facilitated knowledge building. The changes signalled in the NZC appeared to be mandated without consideration of the teachers' motivation, emotional reaction or of their needs.

\subsection{Implications for the implementation of change}

As has been established, unless teachers consider the changes to be of personal significance to them they will not be motivated to engage with them (van den Berg, 2002). In this study there were several barriers or walls that prevented most of the teachers from seeing that the changes signalled in the NZC were 
sufficiently significant in their contexts to motivate them to change. In the previous chapter I identified the walls as:

- Mixed messages about education goals

- Misalignment of the change to the school goals and norms

- The NCEA assessment regime

- Lack of time

- Lack of leadership

- Lack of conceptual understanding

- Professional learning did not support transformative learning

In the following sections, based on the findings in the study and the literature, I suggest how, in an ideal world, these barriers might be addressed.

\subsubsection{Aligned messages about education goals}

Regardless of the aims of the NZC, in the present educational climate, ten of the twelve teachers participating in this study perceived success in NCEA to be the significant educational goal. While this view exists, it is not realistic to expect teachers to change their approach to teaching from one that they consider will achieve the goal. This suggests that school leaders and staff, in partnership with their community, should clarify their goals for teaching and learning. Fullan (2004) refers to this as establishing a moral purpose; what the staff really believes is the goal of education and examining the extent to which their current practice works toward accomplishing it. To do this school leaders and staff, in partnership with their community, should clarify their goals for teaching and learning. The discussion would include an exploration of the stated aims of the NZC and a close examination of the effective pedagogy and the key competencies. If such a discussion takes place, there would need to be a safe space to investigate the questions: "If this is our goal what do we need to do to achieve it? How well are we doing now? What are the gaps between our current practice and what we are trying to achieve? What is currently preventing us? What are the implications of the effective pedagogy and the key competencies for our practice? What do we understand about them? How do we feel about them? Are we committed to them? Is there a fit with the school goals? Is there a fit with staffs' personal goals for teaching?" This would require explicitly - even ruthlessly - exploring the effects of the political environment, of NCEA, of time 
allowance, any leadership issues, of conceptual understanding of and commitment to the signalled changes and the need for professional learning. Each of these issues is complex and would require a significant investment of time and focus. Importantly, the discussions would need to take place in an environment that enabled everyone involved to trust that their fears, anxieties, and possible "unfashionable' point of view to be heard and respected. To do this would require some degree of courage from leaders and would be a test of their ability to establish and sustain relational trust.

To support teachers' intrinsic motivation, the process of unpicking the changes signalled in the NZC would additionally include opportunities for teachers to reflect on and possibly share their personal professional goals in a meeting with their heads of departments. It was ironical that in an implementation of learnercentred practices the teacher as a learner was overlooked. As well as providing a way for the teacher to construct their understanding, being offered choice and opportunities for self-direction promotes a feeling of autonomy which enhances intrinsic motivation (Ryan \& Deci, 2000). Individuals with intrinsic motivation are more likely to have high self-esteem, be enthusiastic about their work, and to be more creative than those who feel they are controlled by external pressures (Deci \& Ryan, 1991). In this study, those teachers who were pursuing their personal goals (Jill, Nina, Ruth, Amy) were demonstrably enthusiastic while those who felt constrained by the NCEA assessments or external innovations appeared to be dispirited and or, in James's, Michael's, Jennifer's, Christopher's and Mary's cases, overwhelmed. The goal-setting meeting would include work on development plans that enable teachers to work towards achieving what is important to them and establishing links with the overall educational goals of the context.

\subsubsection{Alignment of the school goals}

"Moral purpose relates to both ends and means. The means are also crucial" (Fullan, 2004, p. 23). The "means" to achieve the established goals depend on an aligned focus. Developing an aligned system would involve leaders examining each aspect of their school structure to ensure there is consistency throughout. This could be followed by identifying an aspect of the goal to initially focus on and relating that to the school structure. A systems approach could be used (see Table 30), and monitored to ensure practices and norms in the environment supported the focus. In this process schools would remain focussed on what they had identified as important to them and 
bring in expertise when needed to support their goals as opposed to external goals. As Jennifer acknowledged, schools have identified what their students need and in each context work had been undertaken. However, there was no evidence that this work had been sustained. Instead, staff energy had been expended on the next initiative. Schools would ignore other initiatives, remaining focussed on what they had identified as their core moral purpose in the earlier discussion described in 9.3.1.

Table 29. A systems approach to the alignment of focus.

(adapted from D. Kim , 2000)

\begin{tabular}{ll}
\hline Levels of Perspective & Desired future reality \\
\hline Vision & What is our vision of the future? \\
& $\begin{array}{l}\text { A specific, realistic vision. For example all students will be able to see the } \\
\text { relevance of their learning }\end{array}$ \\
\hline Mental models & What are the assumptions, beliefs and values needed to make our vision a \\
& reality? \\
& Clarify what they currently are - do they fit with the vision? For example \\
& do we genuinely believe that relevance is important? \\
\hline Systemic structures & What kinds of systemic structures (either existing or new or redesigned) \\
& are required to operationalise the new mental models and achieve the \\
& vision? \\
& If relevance will be an explicit part of every lesson do we understand how \\
& to do this? \\
\hline Patterns & What are the key indicators whose pattern of behaviour shows that the \\
& desired vision is a reality? \\
& For example: Students in all classes are able to explain the relevance of \\
& their learning \\
What are some specific events that illustrate how the vision is operating on \\
a day-to-day basis? \\
For example: Teachers in all classes are discussing relevance with their \\
students
\end{tabular}

\subsubsection{Conceptual understanding of professional learning to support transformative learning}

To address this perceived barrier to change the way professional learning is provided would need to be carefully considered. First, teachers would need to feel some discrepancy in their practice, a sense that there was an area that needed to change if they were to achieve the share goals. From this study it was evident that all teachers did have goals for their teaching but eleven of the twelve did not demonstrate that the signalled changes would support them. Therefore, for the implementation of the change of the NZC to occur, there would need to be an agreement that the effective pedagogy and the key competencies were a fit with their educational goals. This suggests the need for teachers to have positive experiences of constructivism in a supportive environment followed by the opportunity to discuss the conceptual understanding. An effective professional learning model could incorporate the findings of Bell and Gilbert's (1994) study. Their project addressed 
elements discussed in earlier sections of this thesis including: teachers were aware of a discrepancy; prior knowledge was affirmed; beliefs were surfaced; emotional responses were addressed; the learning was valued by the teachers; and an ongoing supportive context was provided.

Such a model would involve teachers forming small groups of eight or nine to focus on the aspects they wished to develop to meet their personal goals and those of their context. Leadership for the groups would ideally be sourced within the schools. In each of the contexts of this study there were teachers who had the expertise to lead a group. For example, Jill understood how to create an environment that encouraged knowledge building, Nina the integration of key competencies, Amy the use of data to differentiate her lessons. These teachers were precious resources and it is likely that such teachers exist in other contexts. However, they would need specific professional learning. If these teachers could be identified, they could work together with external support to further develop their understanding and to design the shape of the professional learning in the groups they would eventually lead. Importantly, they would need to understand how to provide non-confrontational challenge, understanding that a degree of conflict may be needed to ensure that change happens (Hopkins, 2005; Kreber, 2004; Senge, 2006). This suggests a high degree of responsibility for the teacher leaders which could be acknowledged by providing them with management units and a reasonable time allowance.

Group work could begin with an exploration of members' existing beliefs. The findings in this study suggest that, unless they had independently pursued the topic (Jill, Amy, Ruth, Nina), had an opportunity to observe and practise (Susan), or were struggling with conflicting ideas (James), teachers may not have had the opportunity since entering teaching to consider their educational beliefs. Their classroom lives are busy, giving them little time for reflection on their pedagogical theories or to understand the conceptual theory underpinning changes (Kagan, 1993). A way to support them to uncover their beliefs could be to provide an opportunity for teachers to explore the critical incidents that have impacted on their educational philosophy and their implications for their teaching. Establishing existing beliefs could provide a starting point from which to develop further professional learning. This approach is consistent with a constructivist model in which the learning is based on what the learner already knows or understands (Bell \& Gilbert, 1994; Mezirow, 1997; Timperley et al., 2007; Webster-Wright, 2009). Strategies and the theory underpinning the new learning could next be explored with teachers invited to choose an aspect they would like to try. 
Amy's Japanese lesson study model could be employed at this stage. In smaller breakaway groups of two or three, teachers could carry out cycles of planning together, trying new ideas, observing each other, collaboratively evaluating the learning and planning the next steps. Their findings and insights would then be reported back to the larger group. As in Bell and Gilbert's study (1994), within the larger group, the conceptual theory underpinning the strategies could be explored and teachers' emotional responses acknowledged and addressed. This cycle could then be repeated allowing the opportunity to practise and examine the new learning over an extended time. Figure 10 describes the suggested cycles of professional learning.

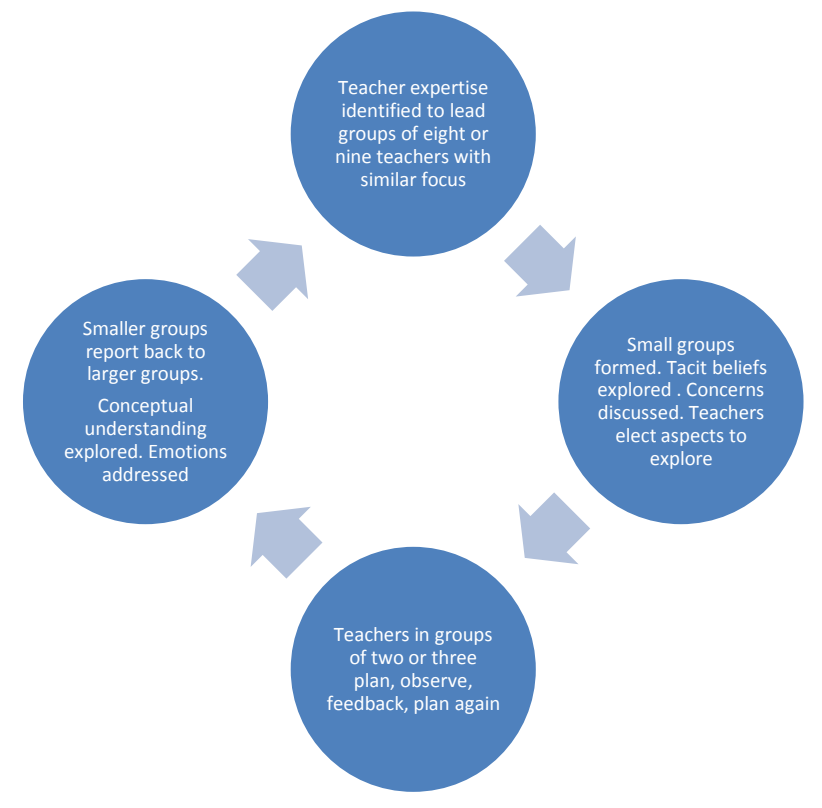

Figure 10. Cycles of professional learning

\subsubsection{Adequate time}

Given the busyness of teachers' lives and the degree of challenge involved for transformative learning to take place, it does not seem possible for change to happen without a serious consideration of time allowance. Lack of a time was a theme throughout this study and several studies described in chapter 8 have confirmed that teachers throughout the secondary sector in New Zealand have similar concerns. Time simply cannot be ignored if the implementation of the signalled changes is to succeed. In addition, for teachers to engage in a deep learning process, they will need what Ruth aptly referred to as "head space", that is, quality thinking time. It is questionable if the first period before school is the ideal time when, as Jill pointed out, teachers have other preoccupations. Nor is it realistic, in the New Zealand context, for teachers to attend special camps as in Howard et al.'s (2000) and Yager's (1999) examples described in chapter 2. Unfortunately, it is not 
reasonable, nor possible in many cases, for schools to fund extra time. The NZC is a mandated change and, as described in chapter 1, the Ministry of Education was clear in the aims of its implementation (MOE, 2007a):

- to create an environment that supports change at the school and system levels

- to support professional inquiry, exploration, and the development of professional practice.

The research clearly describes what is needed for transformative learning to take place but the challenge this represents appears to be underestimated by policy makers. I believe that the Ministry has a responsibility to provide the funding that would enable such an environment to be created. However, since there is no indication at this stage that this will happen, schools could work to manage the impositions on teachers' time by keeping their focus on the school's goals and, as described earlier, refraining from other initiatives. By identifying small but key changes for professional learning they could support teachers to actually embed them instead of trying, as Mary described, to work in a "multi-dimensional" way.

\subsubsection{Leadership}

A perception that leadership was either not committed to the changes or did not understand them well was also described by the participating teachers. The findings of this study suggest that leaders in general and middle managers in particular, have the responsibility for supporting their teachers' learning. To address this all leaders of the implementation could be provided with an opportunity for leadership development which includes an examination of their epistemological beliefs for teaching and learning, on their commitment to the changes, on change theory and on the components of effective professional learning including coaching and mentoring. They could also participate in the professional learning described above.

However, for this to happen there would need to be an examination of the workload of middle managers and consideration of what can be done to help them lead learning. For example, what administration tasks are duplicated, or could be done by support staff? It appeared in this study that administration dominated middle managers' time, leaving some reluctant or simply too busy to engage with the learning needed for change. Amy sadly described, her head of department's reaction when she requested a learning focus in her departmental meeting: "It's embarrassing... he rolls his eyes." 


\subsubsection{The assessment regime}

Locke (2004) maintains that the NCEA assessment system has introduced a surveillance culture into New Zealand secondary schools. Its effect pervaded this study and it is unrealistic to ignore the impact of NCEA on teachers and schools. Again, courage would be required of school leaders to inspire in their staff and their community that the changes will not only improve student achievement and personal development but also enable them to succeed in the NCEA assessment. Teachers like Jill who, through her independent study, had developed an understanding of social constructivism, could demonstrate how knowledge building can be broad and deep, relevant to the students' lives, based on conceptual understanding and collaborative problem-solving. She could also show how teachers have the ability to devise tasks that assess the learning, rather than planning learning to fit a standardised assessment task. Schools should identify and utilise such skills.

\subsection{Limitations of the study}

There are several limitations to this study: the potential for bias, the number and composition of participants and the number of observations and the views presented. Each of these is discussed in this section.

As explained in chapter 3, knowledge and experience is a pre-requisite of educational criticism. Rather than seeing subjectivity as a limitation, Eisner believes that a researcher's recognition that what they see is inevitably filtered through their unique personal lens is a strength which contributes to new knowledge (Eisner, 1998; Locke \& Riley, 2009). My own experience also meant that I respected the constraints that teachers encounter, and was therefore a driver to ensure that I presented their situation fairly. In addition, as the instrument for data collection and interpretation I had the advantage of being able to pick up on the body language of the participants, being able to consider the information immediately, pursue unusual responses and check that the impression is correct by asking clarifying questions (Merriam, 2009). On the other hand, the human researcher brings all the fragility and complexity that being human entails. It was therefore important to identify and monitor biases or subjective perceptions that may impact on the interpretation of the data (Merriam, 2009; Richards \& Morse, 2007). Patton (2002) recommends that qualitative researchers continually examine "what I know and how I know it" (p. 64). This involves being conscious not only of one's own subjectivity but also that of the participants and of the audience for the findings of the study. I have attempted to 
achieve a balance through my process of reflection and by addressing credibility issues as discussed in section 4.7. My prior knowledge and experience also had the potential to bias my selection of description, and my interpretation and evaluation. My hope is that there are sufficiently rich data for a reader to determine the credibility of my findings.

I also acknowledge my privileged position. Although I had years as a practitioner in a classroom, the last seven years have been in environments where I had the advantage of time and resources to read widely, learn from experts, and have support in my reflection. I am therefore aware that I could be seen in my roles as connoisseur and critic as judging the teachers' practice. I sought to address this through providing sufficient description of their environments to allow a reader to decide if my interpretation was fair.

There are also a limited number of participants. There is, however, a range of age, experience, teaching subject, seniority and different contexts. Amongst the teachers there were similar perceptions of the significance of the signalled changes. This does suggest that other New Zealand secondary teachers may have a similar response. In addition, the degree to which the teachers were open and willing to share with me compensated to some extent for the small numbers. The participants volunteered or were invited to do so by senior management because they were considered to be exemplary practitioners who were open to innovation. They were therefore proactive teachers interested in developing their practice. This does indicate a certain category of teacher in this study which may be a limitation. However, it also raises the question: If this is the perception of proactive teachers, what might be that of others who are less progressive? I can only surmise that less invested teachers would have stronger negative reactions.

Another potential limitation is the number of classroom observations. As discussed, I had originally planned to observe each several times over the period of an implementation process but as there was no planned professional learning designed to support change, there seemed little point to continue that plan. It was also possible that the lessons observed were not representative of the teachers' usual practice. However, the students in each class gave no indication that what I was observing differed from their usual experience to an extent that would suggest it was a "show lesson." In addition, there was often a contradiction between espoused and enacted beliefs, suggesting the teacher was not trying to produce a "politically 
correct" lesson. Once again, my hope is that there is sufficient description for a reader to make their own judgment.

Finally, while in this study the lens of educational criticism allowed a holistic description of the teachers' work and realities, it did not include the views of other stakeholders. Given that the purpose of education is to make a difference in the lives of students (Fullan, 2004) an exploration of the perception of the significance of the NZC for diverse groups of students and parents or caregivers would have contributed to the understanding of the complexity of schooling.

\subsection{Future research}

Undertaking this study I was impressed by the teachers' dedication. In hearing the stories of the self-directed study and experimentation teachers had undertaken I felt I was learning from valuable resources that were often overlooked in their contexts (and not acknowledged by the media!). These teachers had levels of expertise that were potentially invaluable to schools. I suggest that future studies could further explore the "hidden" funds of knowledge these teachers bring to their schools and work with them as suggested in section 9. 2. Researching this would also develop literature on teacher motivation that could inform the school change literature.

There is copious literature on constructivism suggesting reasons why teachers do not teach consistently with this theory of learning. As already discussed, the reasons identified often overlook the needs of the teacher as a learner. If the suggestions of the effective pedagogy were related to professional learning for teachers it is possible that transformational learning needed for teachers to accommodate new learning may take place. More research could develop a greater understanding of the teacher as a learner.

Finally, further research is needed to enable New Zealand teachers' voices to be heard and to be valued. The teachers participating in this study were not resistant to change. They were doing their best for their students in an environment that limited what they could do. Their stories need to be heard and acknowledged.

\subsection{Last words}

In this chapter I have provided an overview of the study, the aims of the study and how the questions were addressed. Implications for the educational sector are 
described. In addition, the limitations of the study and suggestions for future research were outlined.

It is hoped that by using the lens of an educational connoisseur and critic I have provided a reader with a rich picture of twelve New Zealand secondary school teachers' work and reality. It was a privilege to meet and learn with these dedicated professionals. They were committed to achieving success for their students and were rewarded by experiences such as described by Mary: "because at the end of the day when a light goes on or a kid walks out and says I really enjoyed that today or says I just feel like I've learned lots, there is a sense of that's what I am here for." 


\section{References}

Abbiss, J. (2011). Social sciences in the New Zealand curriculum: Mixed messages. Curriculum Matters, 7, 118-137.

Abrahamson, E. (2004). Avoiding repetitive change syndrome. MITSloan Management Review, 45(2), 92-95.

Abrami, P. C., Poulsen, C., \& Chambers, B. (2004). Teacher motivation to implement an educational innovation: Factors differentiating users and nonusers of cooperative learning. Educational Psychology: An International Journal of Experimental Educational Psychology, 24(2), 201-216.

Ajzen, I. (1991). The theory of planned behavior. Organizational Behavior and Human Decision Processes, 50, 179-211.

Albion, P. R., \& Ertmer, P. A. (2002). Beyond the foundations: The role of vision and belief in teachers' preparation for integration of technology. TechTrends, 46(5), 34-38.

Alesandrini, K., \& Larson, L. (2002). Teachers bridge to constructivism. The Clearing House, 75(3), 118-121.

Argyris, C., \& Schon, D. (1987). Organisational learning: A theory of school organisation. New York: Routledge.

Armenakis, A., Bernerth, J., Pitts, J., \& Walker, H. (2007). Organizational change recipients' beliefs scale: Development of an assessment instrument. The Journal of Applied Behavourial Science, 43(4), 481-505.

Arsen, D., \& Ni, Y. (2011). Shaking up public schools with competition: What does evidence say about the effects of charter schools on improving outcomes for non-choosers and their schools? School administrator, 68(7), 16-19.

Assaf, L. C. (2008). Professional identity of a reading teacher: Responding to high stakes testing. Teachers and Teaching: Theory and Practice, 14(3), 239-252.

Avenstrup, R. (2005). Tomorrow's curriculum today: Social transformation and curriculum. Curriculum reform and implementation in the 21st century: Policies, perspectives and implementation. Retrieved from http://tedp. meb. gov. tr/doc/Turkey 20 (2005).

Ballet, K., \& Kelchtermans, G. (2008). Workload and willingness to change: Disentangling the experience of intensification. Journal of Curriculum Studies, 40(1), 47-67.

Bandura, A. (1989). Human agency in social cognitive theory. American 
Psychologist, 44(9), 1175-1184.

Bandura, A., \& Schunk, D. (1981). Cultivating competence, self efficacy and intrinsic interest through proximal self motivation. Journal of Personality and Social Psychology, 41(3), 586-598.

Barone, T. E. (1987). On Equality, visibility, and the fine arts program in a black elementary school: An example of educational criticism. Curriculum Inquiry, 17(4), 421-446.

Barone, T., \& Eisner, E. (1997). Complementary methods for research: Washington, DC: American Educational Research Association.

Barrett, T. (1989). A consideration of criticism. Journal of Aesthetic Education, 23(4), 23-35.

Beals, F., Hipkins, R., Cameron, M., \& Watson, V. (2003). An evaluation of professional development. Report to the Ministry of Education. Retrieved from http://www.educationcounts.govt.nz/publications/curriculum/5755

Beck, J., Czerniak, C. M., \& Lumpe, A. T. (2000). An exploratory study of teachers' beliefs regarding the implementation of constructivism in their classrooms. Journal of Science Teacher Education, 11(4), 323-343.

Beer, M., \& Nohria, N. (2000). Cracking the code of change. Harvard Business Review, 78(3), 133.

Beijaard, D., \& De Vries, Y. (1997). Building expertise: A process perspective on the development or change of teachers' beliefs. European Journal of Teacher Education, 20(3), 243-255.

Bell, B. (2005). Pedagogies developed in the learning in science projects and related theses. International Journal of Science Education, 27(2), 159-182.

Bell, B., \& Gilbert, J. (1994). Teacher development as professional, personal and social development. Teaching and Teacher Education, 10(5), 483-497.

Benade, L. (2009).The New Zealand draft curriculum 2006: A policy case study with specific reference to its understanding of teaching as an ethical profession. Policy Futures in Education, 7(1). Retrieved from www.wwwords.co.uk/PFIE

Benade, L. (2011). From technicians to teachers: The New Zealand curriculum and the development of ethical teacher professionality (Unpublished $\mathrm{PhD}$ thesis). Auckland University, New Zealand.

Bereiter, C. (2002). Education and mind in the knowledge age. London: Lawrence Erlbaum.

Bereiter, C., \& Scardamalia, M. (1996). Rethinking learning. In D.R. Olson, \& N. 
Torrance (Eds.), The handbook of education and human development: New models of learning, teaching and schooling (pp 485-513). Cambridge, MA: Basil. Blackwell.

Berliner, D. C. (2004). Describing the behavior and documenting the accomplishments of expert teachers. Bulletin of Science Technology Society, 24(3), 200-212.

Bishop, R. (2008). GPILSEO: A Model for Sustainable Educational Reform. New Zealand Journal of Educational Studies, 43(2), 47-62.

Bishop, R., \& Glynn, T. (1999). Culture counts. Palmerston North: Dunmore Press. Bishop, R., Berryman, M., Tiakiwai, S., \& Richardson, C. (2003). Te Kōtahitanga: The experiences of year 9 and 10 Māori students in mainstream classrooms. Wellington: Ministry of Education.

Black, P. (1995). Assessment and feedback in science education. Studies in Educational Evaluation, 21(3), 257-279.

Blase, J. J. (Ed.). (1991). The politics of life in schools: Power, conflict, and cooperation. Newbury Park: Sage.

Bondy, A. (2007). The intended and interpreted technology curriculum in four New Zealand secondary schools. Does this all mean the same? (Unpublished doctoral thesis). Massey University, Palmerston North.

Borko, H., Davinroy, K. H., Bliem, C. L., \& Cumbo, K. B. (2000). Exploring and supporting teacher change: Two third-grade teachers' experiences in a mathematics and literacy staff development project. The Elementary School Journal, 100(4), 273-306.

Boulton-Lewis, G. M., Smith, D. J. H., McCrindle, A. R., Burnett, P. C., \& Campbell, K. J. (2001). Secondary teachers' conceptions of teaching and learning. Learning and Instruction, 11(1), 35-51.

Boyd, S. (2009). Spotlight on effective teaching. An interview with John Hattie. SET, $2,2-4$

Boyd, S., \& Watson, V. (2006). Shifting the frame: Exploring integration of the key competencies at six normal schools. Wellington: NZCER. Retrieved from http://nzcurriculum.tki.org.nz/Archives/Curriculum-project-archives/References\#b

Boyd, S., Bolstad, R., Cameron, M., Ferral, H., Hipkins, R., McDowall, S., \& Waiti, P. (2005). Planning and managing change: Messages from the Curriculum Innovation Projects (Final report to the Ministry of Education). Wellington: Ministry of Education. 
Bresler, L. (1994). Zooming in on the qualitative paradigm in art education:

Educational criticism, ethnography, and action research. Visual Arts Research, 20(39), 1-19.

Brewerton, M. (2004). Reframing the essential skills: Implications of the OECD Defining and Selecting Key Competencies Project - A background paper. (Paper prepared for the Ministry of Education's New Zealand Curriculum Marautanga Project). Retrieved from http://nzcurriculum.tki.org.nz/Archives/ Curriculum-project-archives/References\#b

Brickhouse, N. (1990). Teachers' beliefs about the nature of science and their relationship to classroom practice. Journal of Teacher Education, 41(3), 53-62.

Briscoe, C. (1991). The dynamic interactions among beliefs, role metaphors, and teaching practices: A case study of teacher change. Science Education, 75(2), 185-199.

Broadfoot, P. (2003). Assessment and intuition. In T. Atkinson \& G. Claxton (Eds.). The Intuitive Practitioner. Maidenhead: Open University Press.

Brodie, K., Lelliott, A., \& Davis, H. (2002). Forms and substance in learner-centred teaching: Teachers' take-up from an in-service programme in South Africa. Teaching and Teacher Education, 18(5), 541-559.

Brook, J., Catlin, S., DeLuca, C., Doe, C., Huntly, A., \& Searle, M. (2010). Conceptions of doctoral education: The $\mathrm{PhD}$ as pathmaking. Reflective Practice, 11(5), 657-668. doi:10.1080/14623943.2010.516981.

Brooks, J. G., \& Brooks, M. G. (1993). In search of understanding: The case for constructivist classrooms. Alexandria, VA: Association for Supervision and Curriculum Development.

Brown, C. R., \& Spangler, D. (2006). Creating sustainable reform. School Administrator, 63(8), 18-22

Bryk, A., \& Schneider, B. (2002). Trust in schools: A core resource for improvement. New York: Russell Sage Foundation.

Buchanan, M. T., \& Engebretson, K. (2009). The significance of theory in the implementation of curriculum change in religious education. British Journal of Religious Education, 31(2), 141.

Butt, R., Raymond, D., McCue, G., \& Yamagishi, L. (1992). In I. F. Goodson (Ed.), Studying teachers' lives. London: Routledge.

Capper, P., Fitzgerald, L. M., Welden, W., \& Wilson, K. (2000). “Technology’ and the coming transformation of schools, teachers and teacher education. In 
A. Scott \& J. Freeman-Moir (Eds.), Tomorrow's teachers: International and critical perspectives on teacher education. Christchurch: Canterbury University Press.

Carlisle, Y., \& Baden-Fuller, C. (2004). Re-applying beliefs: An analysis of change in the oil industry. Organisation Studies, 25(6), 987-1019.

Cho, J. (1998, April). Rethinking curriculum implementation: Paradigms, models, and teachers' work. Paper presented at the Annual meeting of the American Educational Research Association. San Diego, California.

Clarke, S., \& Wildy, H. (2010). Preparing for principalship from the crucible of experience: Reflecting on theory, practice and research. Journal of Educational Administration and History, 42(1), 1-16.

Coburn, C. E. (2003). Rethinking scale: Moving beyond numbers to deep and lasting change. Educational Researcher, 32(6), 3-12.

Codd, J. (2005). Teachers as "managed professionals' in the global education industry: the New Zealand experience. Educational Review, 57(2), 193-206.

Cohen, D. K., \& Ball, D. L. (1990). Policy and practice: An overview. Educational Evaluation and Policy Analysis, 12(3), 233-239.

Cohen, L., Manion, L., \& Morrison, K. (2000). Research methods on education ( $^{\text {th }}$ ed.). London: Routledge \& Falmer.

Colmar Brunton. (2006). The draft New Zealand curriculum: Penetration \& understanding. [PowerPoint presentation]. Wellington: Ministry of Education. Retrieved from http://nzcurriculum.tki.org.nz/references\#C.

Connell Wagner. (2001). Ministry of Education structural mitigation programme. Strengthening of Nelson blocks. Accessed http://www.minedu.govt.nz/ /media/ MinEdu/Files/EducationSectors/PrimarySecondary/PropertyToolbox/StateScho ols/Design/StructuralMitigation/StrengtheningNelsonBlocks1.pdf.

Court, M., \& O'Neill, J. (2011). “Tomorrow's schools' in New Zealand: From social democracy to market managerialism. Journal of Educational Administration and History. 43(2), 119-140.Retreived from http://www.tandfonline.com/doi/abs/10.1080/00220620.2011.560257

Craig, C. (2006). Why is dissemination so difficult? The nature of teacher knowledge and the spread of curriculum reform. American Educational Research Journal, 43(2), 257-293.

Creswell, J. W. (2007). Qualitative inquiry \& research design: Choosing among five approaches. London: Sage. 
Cronin-Jones, L. L. (1991). Science teacher beliefs and their influence on curriculum implementation: Two case studies. Journal of Research in Science Teaching, $28(3), 235-250$.

Cuban, L. (1990). Reforming again, again, and again. American Educational Research Association, 19(1), 3-13.

Cuban, L. (1993a). How teachers taught. Constancy and change in American classrooms 1880 - 1990. New York: Teachers College Press.

Cuban, L. (1993b). The lure of curricular reform and its pitiful history. Phi Delta Kappan, 75.

Cuban, L. (1995). The hidden variable: How organizations influence teacher responses to secondary science curriculum reform. Reforming Science Education, 34(1), 4-11.

Cuban, L. (1996). Myths about changing schools and the case of special education. Remedial \& Special_Education, 17(2), 75-83.

Czerniak, C., \& Lumpe, A. (1996). Relationship between teacher beliefs and science education reform. Journal of Science Teacher Education, 7(4), 247-266.

Darling-Hammond, L. (1990). Instructional policy into practice: The power of the bottom over the top. Educational Evaluation and Policy Analysis, 12(3), 339347.

Darling-Hammond, L., \& Sykes, G. (Eds.). (1999). Teaching as the learning profession: Handbook of policy and practice. San Francisco: Jossey-Bass.

Datnow, A. (2000). Power and politics in the adoption of school reform models. American Educational Research Association, 22(4), 357-374.

Datnow, A., \&. Castellano, M. (2000). Teachers' responses to success for all: How beliefs, experiences, and adaptations shape implementation. American Educational Research Association, 37(3), 775-799.

Day, C. (2002). School reform and transitions in teacher professionalism and identity. International Journal of Educational Research, 37(8), 677-692.

de Lima, J. (2001). Forgetting about friendship: Using Conflict in teacher communities as a catalyst for school change. Journal of Educational Change, 2(2), 97-122.

Debowski (2007, November). Achieving sustainable systemic change: an integrated model of educational transformation. Paper presented at Conference of the Australian Association for Research in Education, Melbourne, Australia. In AARE 2007 International education research conference: Fremantle: papers 
collection. Australia: Association for Research in Education.

Deci, E. L., Koestner, R., \& Ryan, R. M. (2001). Extrinsic rewards and intrinsic motivation in education: Reconsidered once again. Review of Educational Research, 71(1), 1-27.

Deemer, S. (2004). Classroom goal orientation in high school classrooms: Revealing links between beliefs \& classroom environments. Educational Research, 46(1), 73-90.

Denscombe, M. (1998). The good research guide for small scale research projects. Birmingham: Open University Press.

Deutschman, A. (2007). Change or die. Fast Company. Retrieved from http://www.fastcompany.com/magazine/94/open_change-or-die-html

DeWalt, K., \& DeWalt, B. (2002). Participant observation: A guide for fieldworkers. Walnut Creek, CA: AltaMira Press.

Dewey, J. (1929). The sources of a science of education. New York: MacMillan.

Dinham, S. (2007). How schools get moving and keep improving: Leadership for teaching and learning, student success and school renewal. Australian Journal of Education, 51(3), 263-275.

Dirkx, J. M. (2006). Engaging emotions in adult learning: A Jungian perspective on emotion and transformative learning. New Directions for Adult and Continuing Education, 109, 15-26. doi:10.1002/ace.204

Drath, W., McCauley, C., Palus, C., van Velsor, E., O'Connor, P., \& McGuire, J. (2008). Direction, alignment, commitment: Towards a more integrative ontology of leadership. The Leadership Quarterly, 19(6), 635-653.

Du Four, R. (2004). Leading edge: Culture shift doesn't occur overnight—or without conflict. JSD, 25(4), 63-64.

Duffee, L., \& Aikenhead, G. (1992). Curriculum change, student evaluation, and teacher practical knowledge. Science Teacher Education, 76(5), 493-506.

Duignan, P. (2009). Educative leaders building innovating deep-learning environments in schools. Accessed from: $\underline{w w w w . l e a d i n g t o i n s p i r e . c o m . a u}$

Dzubay, D. (2001). Understanding motivation and supporting teacher renewal. Northwest Regional Educational Laboratory. Retrieved from http://www.nwrel.org/qualityteaching/products/UnderstandingMotivation.pdf

Earl, L., \& Lee, L. (2000). Learning, for a change: School improvement as capacity building. Improving Schools, 3(1), 30-38.

Education Review Office. (2010). School reports. Accessed 


\section{http://www.ero.govt.nz/Early-Childhood-School-Reports/School-Reports}

Education Review Office. (2000). Evaluation of in-service teacher training.

Wellington, New Zealand.

Eisenhardt, K. (1989). Building theories from case study research. The Academy of Management Review, 14(4), 532-550.

Eisner, E. (1976). Educational connoisseurship and criticism. Their forms and functions in educational research. Journal of Aesthetic Education, 10(3/4), 135150.

Eisner, E. W. (1979). The use of qualitative forms of evaluation for improving educational practice. Educational Evaluation and Policy Analysis, 1(6), 11-19.

Eisner, E. (1985). The art of educational evaluation. A personal view. London: The Falmer Press.

Eisner, E. (1998). The enlightened eye: Qualitative inquiry and the enhancement of educational practice. Upper Saddle River, NJ: Prentice Hall.

Elkind, D. (2004). The problem with constructivism. The Educational Forum, 68(4), 306-312.

Elmore, R. F. (1995). Structural reform and educational practice. American Educational Research Association, 24(9), 23-26.

Elmore, R. F. (2000). Building a new structure for school leadership (pp. 1-46). Washington, DC: Albert Shanker Institute.

Ely, M., Anzul, M., Friedman, T., Garner, D., \& Steinmetz, A. (1991). Doing qualitative research; circles within circles. New York: Routledge \&Falmer.

Ertmer, P. (2005). Teacher pedagogical beliefs: The final frontier in our quest for technology integration? Educational Technology Research \& Development, 53(4), 25-39.

Evans, L. (2008). The effects of educational change on morale, job satisfaction and motivation. Journal of Educational Change, 1(2), 173-192.

Feldman, A. (2000). Decision making in the practical domain: A model of practical conceptual change. Science Education, 84(5), 606-623.

Fenstermacher, G. D. (1987). On understanding the connections between classroom research and teacher change. Theory into Practice, 26(1), 3-7.

Fernandez, T., Ritchie, G., \& Barker, M. (2008). A sociocultural analysis of mandated curriculum change: The implementation of a new senior physics curriculum in New Zealand schools. Journal of Curriculum Studies, 40(2), 187-213. 
Flinders, D. J. (1989). Educational practice can inform policy. United States of America: ERIC Clearinghouse on Educational Management, University of Oregon.

Flinders, D. J., \& Eisner, E. W. (1994). Educational criticism as a form of qualitative inquiry. Research in the Teaching of English, 28(4), 341-357.

Fogarty, R. \& Pete, B. (2007). From staffroom to classroom. Thousand Oaks, CA: Corwin.

Ford, D. H., \& Lerner, R.M. (1992). Developmental systems theory: An integrative approach. Newbury Park, CA: Sage.

Ford, M. (1992). Motivating humans: Goals, emotions and personal agency beliefs. London: Sage.

Forrest, L. M. (2008). The five-year change process at a secondary school (Unpublished Doctoral Diss.). University of Nevada, Las Vegas.

Fraser-Thomas, J. \& Beaudoin (2002). Implementing a physical education curriculum: Two teachers' experiences. Canadian Journal of Education / Revue canadienne de l'éducation, 27(2/3), 249-268.

Frijda, N., Manstead, A., \& Bem, S. (2000). Emotions and beliefs: How feelings influence thoughts. Paris: Cambridge University Press.

Fullan, M. (1994). Coordinating top-down \& bottom-up strategies for educational reform. DOI:http://www.ed.gov/pubs/EdReformStudies/SysReforms/fullan1.html

Fullan, M. (1996). Turning systemic thinking on its head. Phi Delta Kappan, 77(6), $420-423$.

Fullan, M. (2000). The return of large-scale reform. Journal of Educational Change, $1(1), 5-27$.

Fullan, M. (2007). The new meaning of educational change $\left(3^{\text {rd }}\right.$ ed). New York: Teachers College Press.

Fullan, M. (2008). School leadership's unfinished agenda. Education Week, 27(31), 36.

Fullan, M., Cuttress, C., \& Kilcher, A. (2005). Eight forces for leaders of change. $J S D, 26(4), 54-64$.

Fullan, M., \& Earl, L. (2002). Large scale reform. Journal of Educational Change, $3(1), 1-5$.

Fullan, M., \& Levin, B. (2009). The fundamentals of whole-system reform. A case study from Canada.

Fullan, M., \& Miles, M. (1992). Getting reform right: What works and what doesn't. 
Phi Delta Kappan, 73 (10), 745-752.

Fullan, M., \& Pomfret, A. (1977). Research on curriculum and instruction implementation. American Educational Research Association, 47(2), 335-397.

Fullan, M., \& Quinn, J. (2012, October). Leadership forum (closing session). Paper presented at the ISTE, Indianapolis, USA.

Geijsel, F., Sleegers, P., van den Berg, R., \& Kelchtermans, G. (2001). Conditions fostering the implementation of large-scale innovation programs in schools: Teachers' perspectives. Educational Administration Quarterly, 37(1), 130-166.

Gilbert, J. (2003). Catching the knowledge wave? The knowledge society and the future of public education in New Zealand. Wellington: NZCER Press.

Goodson, I. F. (1991). Sponsoring the teacher's voice: Teachers' lives and teacher. Cambridge Journal of Education, 21(1), 35.

Goodson, I. F. (Ed.). (1992). Studying teachers' lives. London: Routledge.

Gordon, J., \& Patterson, J. (2008). Its what we've always been doing: Exploring tensions between school culture and change. Journal of Educational Change, 9, 17-35.

Gregoire, M. (2003). Is it a challenge or a threat? A dual-process model of teachers' cognition and appraisal processes during conceptual change. Educational Psychology Review, 15(2), 147-179.

Grundy, S. (2002). Big change questions: Is large-scale educational reform possible? Journal of Educational Change, 3(1), 55-62.

Guba, E. G. (Ed.). (1990). The paradigm dialog. London: Sage.

Guerra, P. L., \& Nelson, S. W. (2009). Changing professional practice requires changing beliefs. The Phi Delta Kappan, 90(5), 354-359.

Guskey, T. R. (2002). Professional development and teacher change. Teachers and Teaching, 8(3), 381-391.

Hall, C. (2000). The national certificate of educational achievement: Issues of validity, reliability and manageability. New Zealand Annual Review of Education, 9, 173-196.

Hall, C., \& Irving, J. (2010). Understanding why radical policy reform takes time to embed: Illustrations from policy on assessment. In J. Kidman \& K. Stevens (Eds.), Looking back from the centre: A snapshot of contemporary New Zealand Education (pp. 103-118). Wellington: Victoria University Press.

Hall, C., \& Kidman, J. (2004). Teaching and learning: Mapping the contextual influences. International Education Journal, 5(3), 331-343 
Hannay, L. M., \& Ross, J. A. (1997). Initiating secondary school reform: The dynamic relationship between restructuring, reculturing, and retiming. Educational Administration Quarterly, 33, 576-603.

Hargreaves, A. (1994). Changing teachers, changing times: Teachers work and culture in the postmodern age. New York: Teachers College Press.

Hargreaves, A. (1997). Rethinking educational change: Going deeper and wider in the quest for success. Association of Supervision and Curriculum Development Yearbook. Alexandria, VA: ASCD.

Hargreaves, A. (2005). The emotions of teaching and educational change. In Hargreaves, A. (Ed.), Extending educational change. International handbook of educational change. SpringerLink (Online service).

http://download.springer.com.helicon.vuw.ac.nz/static/pdf/740/bok\%253A978$\underline{1-4020-}$ 4453.pdf?auth66=1380323659 28c7c934341284395a1aa5e5c1fd097d\&ext=.p $\underline{\mathrm{df}}$

Hargreaves, A., \& Goodson, I. (2006). Educational change over time? The sustainability and nonsustainability of three decades of secondary school change and continuity. Educational Administration Quarterly, 42(1), 3-41.

Hart, P., \& Hargreaves, A. (1998). Rethinking educational change with heart \& mind: 1997 ASCD Yearbook. Canadian Journal of Education, 23(2), 228.

Harris, A. (2000). What works in school improvement? Lessons from the field and future directions. Educational Research, 42(1), 1-11.

Hartevelt, J. (2011) Nats' education policy under attack. Retrieved http://www.stuff.co.nz/national/politics/policies/6008751/Nats-educationpolicy-under-attack

Hartevelt, J. (2012). Government eyes secondary school comparison site. Retrieved from http://www.stuff.co.nz/national/politics/6348290/Govt-eyes-secondaryschool-comparison-site

Hartevelt, J. (2012). Stick to knitting - teachers' union to Treasury. Retrieved http://www.stuff.co.nz/national/politics/6609098/Stick-to-knitting-teachersunion-to-Treasury

Hashweh, M. Z. (1996). Effects of science teachers' epistemological beliefs in teaching. Journal of Research in Science Teaching, 33(1), 47-63.

Hattie, J., \& Timperley, H. (2007). The power of feedback. Review of Educational Research, 77(1), 81-112. 
Herold, D. M., Fedor, D. B., \& Caldwell, S. D. (2007). Beyond change management: A multilevel investigation of contextual and personal influences on employees' commitment to change. Journal of Applied Psychology, 92(4), 942-951.

Hipkins, R. (2007). Engaging teachers in re-imaging curriculum. Curriculum Matters, 3,123-138.

Hipkins, R (2013). NCEA one decade on. Views and experiences from the 2012 NZCER National Survey of Secondary Schools. Wellington. New Zealand Council for Educational Research.

Hipkins, R., \& Boyd, S. (2011). The recursive elaboration of key competencies as agents of curriculum change. Curriculum Matters, 7. Retrieved from http://nzcurriculum.tki.org.nz/Archives/Implementation-project-overview/ Implementation-project-goals-and-objectives

Hipp, K., \& Huffman, J. (2010). Demystifying professional learning communities (pp. 11-21). Plymouth, UK: Rowman \& Littlefield Education.

Hoepfl, M. C. (1997). Choosing qualitative research: A primer for technology education researchers. Journal of Technology, 9(1).

Hofer, B. K. (2004). Introduction: Paradigmatic Approaches to Personal Epistemology. Educational Psychologist, 39(1), 1-3.

Hofer, B. K., \& Pintrich, P. R. (1997). The Development of Epistemological Theories: Beliefs about Knowledge and Knowing and Their Relation to Learning. Review of Educational Research, 67(1), 88-140.

Hopkins, D. (2001). School improvement for real. London: Routledge Falmer.

Hopkins, D. (Ed.). (2005). The practice and theory of school improvement. In A. Hargreaves (Ed.), Extending educational change: International handbook of educational change. Dordrecht: Springer.

Hopkins, D., \& Reynolds, D. (2001). The past, present and future of school improvement: Towards the third age. British Educational Research Journal, 27(4), 459-475.

Horn, P. (2000). Teacher talk: A post-formal inquiry into educational change. New York: Peter Lang.

Howard, B., McGee, S., Schwartz, N., \& Purcell, S. (2000). The experience of constructivism: transforming teacher epistemology. Journal of Research on Computing in Education, 32(4), 455.

Hoyle, E., \& Wallace, M. (2007). Educational reform: An ironic perspective. Educational Management Administration \& Leadership, 35(1), 9-25. 
Hynds, A. (2007). Navigating unchartered water: Teachers collaborating across difference (Unpublished doctoral thesis). Victoria University of Wellington, New Zealand.

Hynds, A. (2010). Unpacking resistance to change within school reform programmes with a social justice orientation. International Journal of Leadership in Education, 13(4), 337-392.

Hyslop-Margison, E., \& Strobel, J. (2008). Constructivism and education:

Misunderstandings and pedagogical implications. The Teacher Educator, 43(1), 72 .

Ingvarson, 1., Kleinhenz, E., Beavis, A., Barwick, H., Carthy, J., \& Wilkinson J. (2005). Secondary teacher workload study report. ACER. Retrieved from http://www.acer.edu.au/research

Jantsz, J., \& Timmers, M. (2002). Emotional dissonance: When the experience of an emotion jeopardizes an individual's identity. Theory Psychology, 12, 79-75. doi: $10.1177 / 0959354302121005$.

Jones, K., \& Sherman, A. (1980). Two approaches to evaluation. Educational Leadership, 37(7), 553-557.

Joyce, B., \& Showers, B. (2002). Student achievement through staff development. Designing training and peer coaching: Our needs for learning. VA, USA: ASCD.

Kagan, D. M. (1989). The heuristic value of regarding classroom instruction as an aesthetic medium. Educational Researcher, 18(6), 11-18.

Kagan, D. (1990). Ways of evaluating teacher cognition: inferences concerning the goldilocks principle. Review of Educational Research, 60, 419.

Kagan, D. (1993). Who should decide how teachers teach? Educational Leadership, $51(2), 78$.

Kane, R. G., \& Mallon, M. (2006). Perceptions of teachers and teaching. Wellington: NZTC \& Ministry of Education.

Kelchtermans, G. (2009). Who I am in how I teach is the message: selfunderstanding, vulnerability and reflection. Teachers and Teaching: Theory and Practice, 15(2), 257-272.

Keltner, D., \& Gross, J. J. (1999). Functional accounts of emotions. Cognition \& Emotion, 13(5), 467-480.

Kennedy, C., \& Kennedy, J. (1996). Teacher attitudes and change implementation. System, 24(3), 351-360. 
Keys, P. (2003). Primary and secondary teachers shaping of the science curriculum:

The influence of teacher knowledge (Unpublished doctoral thesis). Queensland University of Technology, Australia.

Keys, P. (2007). A knowledge filter model for observing and facilitating change in teachers' beliefs. Journal of Educational Change 8, 41-60.

Kim, B. (2001). Social constructivism. In M. Orey (Ed.), Emerging perspectives on learning, teaching, and technology. Retrieved November 13, 2008, from http://projects.coe.uga.edu/epltt/

Kim, D. (1999). Introduction to systems thinking. Waltham: Pegasus Communications.

Koetting, J. R. (1988). Educational connoisseurs and educational criticism: Pushing beyond information and effectiveness. Paper presented at the Annual Meeting of the Association of Educational Communications and Technology, New Orleans.

Kotter, J. (1990). A force for change: How leadership differs from management. New York: Free Press.

Kreber, C. (2004). An analysis of two models of reflection and their implications for educational development. International Journal for Academic Development, 9(1) 29-49. http://dx.doi.org/10.1080/1360144042000296044

Labianca, G., Gray, B., \& Brass, D. J. (2000). A grounded model of organizational schema change during empowerment. Organization Science, 11(2), 235-257.

Lai, K.-W., \& Pratt, K. (2008). Positive to a degree: The effects of ict use in New Zealand secondary schools. Computers in the Schools, 24(3-4), 95-109.

Lashway, L. (1996). The strategies of a leader. ERIC Identifier: ED406718

Lasky, S. (2005). A sociocultural approach to understanding teacher identity, agency and professional vulnerability in a context of secondary school reform. Teaching and Teacher Education, 21(8), 899-916.

Latham, D. (2012). Teachers in an uproar over performance pay. Retrieved from http://www.stuff.co.nz/the-press/opinion/perspective/7183310/Teachers-in-anuproar-over-performance-pay

Leckie, I. (2012). Performance pay talk for teachers is flawed. http://www.stuff.co.nz/dominion-post/comment/6711917/Performance-paytalk-for-teachers-is-flawedool

Leithwood, K., \& Beatty, B. (2008). Leading with teacher emotions in mind. London: Corwin Press.

Leithwood, K., Louis, K., Anderson, S., \& Walstrom, K. (2004). How leadership 
influences student learning: A review of research for the Learning from Leadership Project. New York: Wallace Foundation.

Leithwood, K., Steinbach, R., \& Jantzi, D. (2000). Identifying and explaining the consequences for schools of external accountability initiatives or what in the world did you think I was doing before you came along? Annual meeting of the American Educational Research Association, New Orleans.

Levin, B. (2000). Conceptualising the process of education reform from an international perspective. American Educational Research Association, New Orleans.

Lewig, K.A., \& Dollard, M.F. (2003). Emotional dissonance, emotional exhaustion and job satisfaction in call centre workers. European Journal of Work and Organizational Psychology, 12(4), 366-392. doi:10.1080/13594320344000200.

Lincoln, Y. S., \& Guba, E. G. (2000). Paradigmatic controversies, contradictions, and emerging confluences. In N. K. Denzin \& Y. S. Lincoln (Eds.), The handbook of qualitative research ( $2^{\text {nd }}$ ed., pp.163-188). London: Sage.

Locke, E., \& Latham, G. (1990). A theory of goal setting and task performance. Englewood Cliffs, NJ: Prentice Hall.

Locke, T. (2001). English and the NCEA: The impact of an assessment regime on curriculum and practice. Waikato Journal of Education, 7, 99.

Locke, T. (2008). English in a surveillance regime: Tightening the noose in New Zealand. Changing English, 15(3), 293.

Locke, T., \& Goodwyn, A. (2004). Editorial: Reclaiming the professional development agenda in an age of compliance. English Teaching: Practice and Critique, 2(2), 1-7.

Locke, T., \& Hall, C. (1999). The 1998 year 12 English study design trial: A standard based alternative to unit standards. The New Zealand Annual Review of Education, 8, 167-189.

Locke, T., \& Riley, D. (2009). What happened to educational criticism? Engaging with a paradigm for observation. Educational Action Research, 17(4), 489-504.

Lortie, D. C. (1975). Schoolteacher: A sociological study (pp. 1-54). Chicago: University of Chicago Press.

Luttenberg, J., Veen, K. V., \& Imants, J. (2011). Looking for cohesion: The role of search for meaning in the interaction between teacher and reform. Research Papers in Education, 28(3), 289-308. doi:10.1080/02671522.2011.630746 
Madaus, G. F. (1988). The distortion of teaching and testing: High-stakes testing and instruction. Peabody Journal of Education, 65(3), 29-46.

Magrini, J. (2010). How the conception of knowledge influences our educational practices: Toward a philosophical understanding of epistemology in education. Curriculum Matters, 6, 6-27

Maharey, S. (2007). $21^{\text {ST }}$ Century learning environments. [Speech]. New Zealand Government. http://www.scoop.co.nz/stories/PA0706/S00068.htm

Makhlouf, G. (2012, March 27). Article on education by Secretary to the Treasury. Dominion Post. Retrieved from http://www.treasury.govt.nz/publications/mediaspeeches/speeches/economicleadership/educ-art-27mar12.pdf

Maxwell, J.A. (2005). Qualitative research design: An interactive approach. London: Sage.

McCutcheon, G. (1981). On the interpretation of classroom observations. Educational Researcher, 10(5), 5-10.

McGee, C., Jones, A., Cowie, B., Hill, M., Miller, T., Harlow, A., \& Mackenzie, K. (2003). Curriculum stocktake: National School Sampling Study: Teachers' experiences in curriculum implementation: English, languages, science and social studies. Wellington: New Zealand Ministry of Education.

http://www.minedu.govt.nz/web/downloadable/d111438_v1/cs-nsss-round2.pdf

Merriam, S. B. (2009). Qualitative research: A guide to design and implementation. San Francisco: Jossey-Bass.

Meyer, L. H., Penetito, W., Hynds, A., Savage, C., Hindle, R., \& Sleeter, C. (2010). Evaluation of Te Kotahitanga: 2004-2008. Wellington: Ministry of Education.

Mezirow, J. (1981). A critical theory of adult learning and education. Adult Education Quarterly, 32(1) 3-24.

Mezirow, J. (1991). Transformative dimensions of adult learning. San Francisco: Jossey-Bass.

Mezirow, J. (1997). Transformative learning: Theory to practice. New Directions for Adult and Continuing Education, 74, 5-12.

Miles, M. B., \& Huberman, A. M. (1994). Qualitative data analysis: An expanded sourcebook. London: Sage.

Ministry of Education. (2007a). Implementation project goals and objectives. http://nzcurriculum.tki.org.nz/implementation_project_overview/implementati on_project_goals_and_objectives 
Ministry of Education. (2007b). The New Zealand curriculum. Wellington: Learning Media.

Ministry of Education. (2008). Kiwi Leadership for principals: Principals as educational leaders. Wellington: Ministry of Education.

Ministry of Education. (2011). Briefing to the incoming minister. Accessed http://www.minedu.govt.nz/theMinistry/PolicyAndStrategy/ /media/MinEdu/F iles/TheMinistry/PolicyAndStrategy/EducationBIM2011.pdf

Ministry of Education. (2011). Policy and Strategy. Retrieved from http://www.minedu.govt.nz/theministry/policyandstrategy.aspx

Ministry of Education. (2012). Enrolment schemes. Retrieved from http://www.minedu.govt.nz/NZEducation/EducationPolicies/Schools/SchoolO perations/PlanningAndReporting/EnrolmentSchemes.aspx

Mintrop, H. (1999). Changing core beliefs and practices through systemic reform: The case of Germany after the fall of socialism. Educational Evaluation and Policy Analysis, 21(3), 271-296.

Moeed, A. (2010). Science investigation in New Zealand secondary schools: Exploring the links between learning, motivation and internal assessment in year 11 (Unpublished doctoral thesis). Victoria University of Wellington, New Zealand.

Moeed, A., \& Hall, C. (2011). Teaching, learning and assessment of science investigation in year 11: Teachers' response to NCEA. New Zealand Science Review, 68(3), 95-102.

Moroye, C. M. (2005). Common ground: An ecological perspective on teaching and learning. Curriculum and Teaching Dialogue, 7(1/2) 123-137.

Muro, M. (2007). Responding to change: The role of teacher emotion in educational change (Unpublished doctoral diss.), Ashland University, Ohio.

Murphy, J., Elliott, S., Goldring, E., \& Porter, A. (2007). Leadership for learning: A research-based model and taxonomy of behaviours. School Leadership and \& Management, 27(2), 179-201.

Murrihy, L. R. (2009). Coaching and the growth of three New Zealand educators: A multi-dimensional journey (Unpublished doctoral thesis). Waikato University, Hamilton.

Nespor, J. (1987). The role of beliefs in the practice of teaching. Journal of Curriculum Studies, 19(4), 317-328.

New Zealand Qualifications Association. (2011). Annual report on NCEA \& New 
Zealand scholarship data \& statistics (2010). Accessed

www.nzqa.govt.nz/assets/About-us/Publications/stats-reports/ncea-

annualreport-2010.pdf - 84k - 2011-05-04

Neyland, J. (2010). Rediscovering the spirit of education after scientific management. Rotherdam: Sense.

Nias, J. (1997). Would schools improve if teachers cared less? Education 3-13, 25(3), 11-22.

Nisbett, R., \& Ross, L. (1980). Human inference: strategies and shortcomings of social judgment. New Jersey: Prentice-Hall.

Oatley, K. (2000). The sentiments and beliefs of distributed cognition.In N. Frijda, A. Manstead, \& S. Bem. (Eds.), Emotions and beliefs: How feelings influence thoughts. Paris: Cambridge University Press.

OECD. (2001). Knowledge and skills for life: First findings from the OECD programme for international assessment (PISA). Paris, France. Retrieved from http://www.oecd.org/edu/school/programmeforinternationalstudentassessmentp isa/33691620.pdf

OECD. (2005). The definition and selection of key competencies. Retrieved from http://www.oecd.org/pisa/35070367.pdf

Olsen, J. (2002). Systematic change/teacher tradition:legends of reform continue. JCS OpEd, 34, 129-137

Openshaw, R. (2011). A long way to go before we win the battle. History of Education Review, 40(1), 62-80.

Oreg, S. (2006). Personality, context, and resistance to organizational change. European Journal of Work and Organizational Psychology, 15(1), 73-101.

Pajares, M. F. (1992). Teachers' beliefs and educational research: Cleaning up a messy construct. Review of Educational Research, 62(3), 307-332.

Palombo-Weiss, R. (2000). Emotion and learning: Implications of new neurological research for training. Training and Development, November, 44-49.

Patterson, D., \& Rolheiser C. (2004). Creating a culture of change ten strategies for developing an ethic of teamwork. Journal of Staff Development, 25(2), 1-4.

Patton, M. (2002). Qualitative research \& evaluation models. London: Sage.

Peterson, P. L., McCarthey, S. J., \& Elmore, R. (1996). Learning from school restructuring. American Educational Research Journal, 33(1), 119-153.

Piaget, J. (1954). The construction of reality in the child. New York: Basic Books. 
Piderit, S. K. (2000). Rethinking resistance and recognizing ambivalence: A multidimensional view of attitudes toward an organizational change. The Academy of Management Review, 25(4), 783-794.

Piggot-Irvine, E. (2006). Establishing criteria for effective professional development and use in evaluating an action research based programme. Professional Development in Education, 32(4), 477-496.

Pintrich, P. R. (2003). A motivational science perspective on the role of student motivation in learning and teaching contexts. Journal of Educational Psychology, 95(4), 667-686.

Pintrich, P. R., Marx, R. W., \& Boyle, R. A. (1993). Beyond cold conceptual change: The role of motivational beliefs and classroom contextual factors in the process of conceptual change. Review of Educational Research, 63(2), 167-199.

Plank, D., \& Sykes, G. (Eds.). (2003). Choosing choice: School choice international perspective. New York: Teachers College Press.

Polyzoi, E., \& Černá, M. (2001). A dynamic model of forces affecting the implementation of educational change in the Czech Republic. Comparative Education Review, 45(1), 64.

Post Primary Teachers Association. (2009). CAPNA [Curriculum and Pastoral Needs Analysis]. Accessed http://ppta.org.nz/index.php/collectiveagreements/conditions-of-employment/688-ca-capna-sept09

PPTA. (2010). PPTA survey on NCEA Workload. Accessed http://ppta.org.nz /index.php/search/SURVEY\%2BOF\%2Bncea\%2Bworkload?ordering=newest $\&$ searchphrase $=$ all $\&$ limit $=20$

Prawat, R. (1992). Teachers' beliefs about teaching and learning: A constructivist perspective. American Journal of Education, 100(3), 354-395.

Rafferty, A. E., Jimmieson, N. L., \& Armenakis, A. A. (2013). Change readiness: A multilevel review. Journal of Management, 39(1), 110-135.

Reio, T. G. (2005). Emotions as a lens to explore teacher identity \& change: A commentary. Teaching \&_Teacher Education, 21(8), 985-993.

Rhodes, C. (1996). Researching organisational change and learning: a narrative approach. The Qualitative Report, 2(4). Retrieved from http://www.nova.edu/ssss/QR/QR2-4/rhodes.html

Richards, J., Gallo, P., \& Renandya, W. (2001). Exploring teachers' beliefs and the processes of change. PAC Journal, 1(1), 41-64.

Richards, L., \& Morse, J. M. (2005). Users guide to qualitative methods. London: 
Sage.

Richardson, M. (2007). Constructivism in education: An overview of contributions to the literature and to the jpacte annotated bibliography. Journal for the Practical Application of Constructivist Theory in Education, 2(1), 1-15. Retrieved from http://www.jpacte.org/vol-2-no-1-fall-2007.html

Richardson, V. (1990). Significant and worthwhile change in teaching practice. American Educational Research Association, 19(7), 10-18.

Richardson, V. (Ed.). (1997). Constructivist teacher education: Building a world of new understanding. London: Falmer Press.

Robertson, J., \& Murrihy, L. (2005). Building the capacity of teachers for improved student learning: The missing basket-personal learning. Full report.

Nottingham, UK: National College for School Leadership.

Robinson, V., Lloyd, C., \& Hohepa, M. (2009). School leadership and student outcomes: Identifying what works and why. Best Evidence Synthesis Iteration [BES]. Wellington: Ministry of Education.

Robinson, V.M.J., \& Lai, M.K. (2006). Practitioner research for educators: A guide to improving classrooms and schools. Thousand Oaks, CA: Corwin Press.

Roehrig, G. H., Kruse, R. A., \& Kern, A. (2007). Teacher and school characteristics and their influence on curriculum implementation. Journal of Research in Science Teaching, 44(7), 883-907.

Rokeach, M. (1972). Beliefs, attitudes and values: A theory of organization and change. London: Jossey.

Ross, J. A., \& Hannay, L. M. (2001). Internalizing change capacity in secondary schools through organizational change. Alberta Journal of Educational Research, 47(4), 325-340.

Rossman, G., \& Rallis, S. (2003). Learning in the field: An introduction to qualitative research. London: Sage.

Rutherford, J. (2005). Key competencies in the New Zealand curriculum: A snapshot of consultation. Curriculum Matters, 1, 210-227.

Ryan, M. (2006). Curriculum change. Access, 20(2), 15-19.

Ryan, R. M., \& Deci, E. L. (2000). Self-determination theory and the facilitation of intrinsic motivation, social development, and well-being. American Psychologist, 55(1), 68-78. DOI: 10.1037110003-066X.55.1.68

Sahlberg, P. (2004). Teaching and globalization. Managing Global Transitions 2(1), 65. 
Saldana, J. (2009). The coding manual for qualitative researchers. London: Sage.

Sarason, S. (1998). Some features of a flawed educational system. Daedalus, 127,112.

Savasci, F., \& Berlin, D. (2012). Science teacher beliefs and classroom practice related to constructivism in different school settings. Journal of Science Teacher Education, 23(1), 65-86.

Scardamalia, M. (2002). Collective cognitive responsibility for the advancement of knowledge. In B. Smith (Ed.), Liberal education in a knowledge society (pp. 76-98). Chicago: Open Court.

Scardamalia, M., \& Bereiter, C. (2007). Knowledge building. In J. W. Guthrie (Ed.), Encyclopaedia of education (Vol. 4, $2^{\text {nd }}$ ed.). New York: Macmillan Reference USA, 2002. 1370-1373. 8 vols. Gale Virtual Reference Library. Thomson Gale. University of California Santa Cruz.

Schagen, S., \& Hipkins, R. (2008). Curriculum changes, priorities, and issues. Findings from the NZCER secondary 2006 and primary 2007 national surveys. Wellington: NZCER.

Schagen, S \& Wylie, C. (2008).School resources, culture and connections: NZCER National Survey Thematic Report. Wellington: NZCER

Schein, E. H. (2002). Models and tools for stability and change in human systems. Reflections, 4(2), 34-46.

Schmidt, M., \& Datnow, A. (2005). Teachers' sense-making about comprehensive school reform: The influence of emotions. Teaching and Teacher Education, 21(8), 949-965.

Schommer, M. (Ed.). (1998). The role of adults' beliefs about knowledge in school, $g$ and work, and everyday life. In M.C. Smith \& T Pourchot (Eds). Adult learning and development. Perspectives form educational psychology. London: Lawrence Erlbaum Associates.

Schon, D.A. (1995). Knowing in action: The new scholarship requires a new epistemology. Change, November/December, 2734.

Schutz, P., \& Zembylas, M. (Eds.). (2009). Advances in teacher emotion research: The impact on teachers' lives. New York: Springer.

Selby, L., \& Probert, E. (2004). Generating change through professional development: A New Zealand story. International Association of School Librarianship. 247-253.

Senge, P. (2006). The fifth discipline: The art and practice of the learning 
organisation. USA: Doubleday.

Sergiovanni, T. J. (1998). Leadership as pedagogy, capital development and school effectiveness. International Journal of Leadership in Education, 1(1), 37-46.

Sikes, P., Measor, L., \& Woods, P. (1985). Teacher careers. Crises and continuities. London: Falmer Press.

Silins, H. C., Mulford, W. R., \& Zarins, S. (2002). Organizational learning and school change. Educational Administration Quarterly, 38(5), 613.

Sinnema, C. (2011). Monitoring and evaluating curriculum Implementation. Final evaluation report on the implementation of the New Zealand Curriculum 20082009. (Report to the Ministry of Education). Wellington: Ministry of Education. Retrieved from www.educationcounts.govt.nz/publications.

Southworth, G. (2004). Primary school leadership in context: Leading small, medium and large sized schools. London: Routledge Falmer.

Spillane, J. (2000). Source cognition and policy implementation: District policymakers and the reform of mathematics education. Cognition and Instruction, 18(2), 141-179.

Spillane, J., .Reiser, B., \& Reimer, T. (2002). Policy implementation and cognition: Reframing and refocusing implementation research. Review of Educational Research, 72(3), 387-431.

Stake, R. (1995). The art of case study research. California: Sage.

Statistics New Zealand (2006). Geographic areas. Accessed http://www.stats.govt.nz/

Stoll, L. (1999). Realising our potential: Understanding and developing capacity for lasting improvement. School Effectiveness and School Improvement, 10(1), 1-30.

Stoll, L. (2000). School culture. SET, 3, 9-14

Stoll, L., Bolam, R., McMahon, A., Wallace, M., \& Thomas, S. (2006). Professional learning communities: A review of the literature. Journal of Educational Change, 7(4), 221-258.

Strauss, A. (2008). Mirrors \& masks: The search for identity. New Jersey: Transaction.

Sugrue, C., \& Day, C. (2001). Developing teachers and teaching practice: International research perspectives. London: Routledge.

Sutton, R. E., \& Wheatley, K. F. (2003). Teachers' emotions and teaching: A review of the literature and directions for future research. Educational Psychology Review, 15(4), 327-332. 
Swann, J., \& Brown, S. (1997). The implementation of a national curriculum and teachers' classroom thinking. Research Papers in Education, 12(1), 91-114.

Taylor, E. (2007). An update of transformative learning theory: A critical review of the empirical research (1999-2005). International Journal of Lifelong Education, 26(2), 173-191.

Television New Zealand. (2012). One news: Govt to develop performance pay for teachers. Accessed http://tvnz.co.nz/news.

Tellis, W. (1997). Application of a case study methodology. The Qualitative Report. 3(3). Retrieved from http://www.nova.edu/ssss/QR/QR3-3/tellis2.html

Thoonen, E. E. J., Sleegers, P. J. C., Oort, F. J., Peetsma, T. T. D., \& Geijsel, F. P. (2011). How to improve teaching practices. Educational Administration Quarterly, 47(3), 496-536.

Thrupp, M. (1998). Exploring the politics of blame: School inspection and its contestation in New Zealand and England. Comparative Education, 34(2), 195210.

Thrupp, M. (2007). Education's “inconvenient truth”: Part one - persistent middle class advantage. New Zealand Journal of Teachers' Work, 4(2), 77-88.

Tillema, H., \& Orland-Barak, L. (2006). Constructing knowledge in professional conversations: The role of beliefs on knowledge and knowing. Learning and Instruction, 16, 592-608.

Timperley, H., \& Parr, J., M. (2005). theory competition and the process of change. Journal of Educational Change, 6(3), 227-251.

Timperley, H., \& Robinson, V. (2001). Achieving school improvement through challenging and changing teachers' schema. Journal of Educational Change, 2, 281-300.

Timperley, H., Wilson, A., Barrar, H., \& Fung, I. (2007). Professional learning and development: Best evidence synthesis iteration (BES). Auckland: Faculty of Education, Auckland University

Trigwell, K., Prosser, M., \& Taylor, P. (1994). Qualitative differences in approaches to teaching first year university science. Higher Education, 27(1), 75-84.

Tschannen-Moran, M., Hoy, A. W., \& Hoy, W. K. (1998). Teacher efficacy: Its meaning and measure. Review of Educational Research, 68(2), 202-248.

Tyack D., \& Cuban, L. (1995). Tinkering towards Utopia: A century of public school reform. London: Harvard University Press.

Uhrmacher, P. B., \& Bunn, K. (Eds). (2011). Beyond the one room school house. 
Rotterdam: Sense.

van den Berg, R. (2002). Teachers' meanings regarding educational practice. Review of Educational_Research, 72(4), 577-625.

van Driel, J., Bulte, A., \& Verloop, N. (2008). Using the curriculum emphasis concept to investigate teachers' curricular knowledge in the context of educational reform. Journal of Curriculum Studies, 40(1), 107-122.

van Veen, K., Sleegers, P., Bergen, T., \& Klaassen, T. (2001). Professional orientations of secondary school teachers towards their work. Teaching and Teacher Education, 17(2), 175-194.

van Woerkom, M. (2010). Critical reflection as a rationalistic ideal. Adult Education Quarterly, 60(4), 339-356.

Vansteenkiste, M., Soenens, B., Verstuf, J., \& Lens, W. (2009). "What is the usefulness of your schoolwork?' The differential effects of intrinsic and extrinsic goal framing on optimal learning. Theory and Research in Education. $7,155$.

Värlander, S. (2008). The role of students' emotions in formal feedback situations. Teaching in Higher Education, 13(2), 145-156. doi:10.1080/13562510801923195.

Vulliamy, G., E., Kimonen, E., Nevalainen, R., \& Webb, R. (1997). Teacher identity and curriculum change: A comparative case-study analysis of small schools in England and Finland. Comparative Education, 33(1), 97-115.

Walker, K. D. (2006). Fostering hope: A leader's first and last task. Journal of Educational Administration, 44(6), 540.

Wallace, M. (2003). Managing the unmanageable? Coping with complex educational change. Educational Management \& Administration, 31(1), 9-29.

Waugh, R. F., \& Punch, K. F. (1987). Teacher receptivity to system wide change in the implementation stage. Review of Educational Research, 57(3), 237-254.

Webster-Wright, A. (2009). Reframing professional development through understanding authentic professional learning. Review of Educational Research, 79(2), 702-739.

Weiner, B. (2000). Intrapersonal and interpersonal theories of motivation from an attributional perspective. Educational Psychology Review, 12(1), 1-14.

Weiner, B. (2009) A theory of organizational readiness for change. Implementation Science 2009, 4, 67. doi:10.1186/1748-5908-4-67 
Westrup, J., \& Jack, B. (1998). Straight from the students' mouth: Andragogy in theory and practice. Australian Journal of Adult and Community Education, 38(2), 163-170.

Wheatley, K. (2002). The potential benefits of teacher efficacy doubts for educational reform. Teaching and Teacher Education, 18(1), 5-22.

Windschitl, M. (2002). Framing constructivism in practice as the negotiation of dilemmas: An analysis of the conceptual, pedagogical, cultural, and political challenges facing teachers. Review of Educational Research, 7(2), 131-175.

Wirth, R. A. (2004). Lewin/Schein's change theory. Retrieved April 13, 2007, from http://www.entarga.com/orgchange/lewinschein.pdf.

Wittgenstein, L. (1929). Lecture on ethics. The Galilean Library. Accessed http://www.galilean-library.org/manuscript.php?postid=43866

Woods, P. (1994). Teachers under Siege: Resistance and Appropriation in English Primary Schools. Anthropology \& Education Quarterly, 25(3), 250-265.

Wylie, C. (2012). Vital connections. Why we need more than self managing schools. Wellington: NZCER Press.

Wylie, C. (2013). Secondary schools in 2012 Main findings from the NZCER national survey. Wellington: New Zealand Council for Educational Research.

Yager, R. E. (1999). Scope, sequence and coordination: The Iowa Project, a national reform effort in the USA. International Journal of Science Education, 21(2), 169-194. Retrieved from http://dx.doi.org/10.1080/095006999290778

Yates, L., \& Holt, B. (2009). "Under pressure I fall back to being a teacher..." Confronting contending desires for schooling and teaching in a middle school reform project. The Australian Educational Researcher, 36(1), 27-42.

Yin, R. K. (2009). Case study research. Design and methods. London: Sage.

Young, R. (1991). Critical theory and classroom talk. Clevedon: Multilingual. matters.

Youngs, H. (2008, December).The implementation of the revised New Zealand curriculum: Unpacking the complexities of sustainability, school climate and distributed forms of educational leadership. Paper presented at AARE Conference, Brisbane, Australia.

Zembylas, M., \& Barker, H. (2007). Teachers' spaces for coping with change in the context of a reform effort. Journal of Educational Change, 8, 235-256. 


\begin{tabular}{|ll|}
\hline & \multicolumn{1}{c|}{ Appendices } \\
Appendix A: & Explanation of NCEA \\
Appendix B: & Ethical approval \\
Appendix C: & Information sheet for principal \\
Appendix D: & Information sheet for teacher \\
Appendix E: & Teacher consent forms \\
Appendix F: & Observation template \\
Appendix G: & Jill key theme \\
\hline
\end{tabular}




\section{Appendix A: Explanation of NCEA}

The National Certificate of Educational Achievement (NCEA) was introduced as New Zealand's main secondary school qualifications between 2002 and 2004. Students are assessed against Achievement Standards (AS) which have a credit value. The AS have been developed at three levels which are generally but not necessarily offered in the following way: NCEA Level 1 to Year 11, NCEA Level 2 to Year 12 and NCEA Level 3 to Year 13. To pass NCEA at each level students need to accumulate 80 credits. There is a mix of internal and external assessment which varies across subjects and NCEA Levels depending on the courses the school offers and the subjects the student chooses to study.

Students assessed against achievement standards can gain credits at three levels, achieved, achieved with merit or achieved with excellence. Table 1 is an example of an achievement standard title and the achievement criteria.

\section{Table 1. An example of an achievement standard title and achievement criteria.}

Subject Reference

Title

Level 2

\section{English 2.3}

Analyse significant aspects of unfamiliar written text(s) through close reading, supported by evidence

Credits 4
Assessment
External

\section{Achievement Criteria}

\begin{tabular}{|l|l|l|}
\hline Achievement & Achievement with Merit & Achievement with Excellence \\
\hline Analyse significant aspects of & Analyse significant aspects of & Analyse significant aspects of \\
unfamiliar written text(s) & unfamiliar written text(s) & unfamiliar written text(s) \\
through close reading, & convincingly through close & perceptively through close \\
supported by evidence. & reading, supported by evidence. & reading, supported by evidence. \\
\hline
\end{tabular}




\section{Appendix B: Ethical approval}

5th March 2009

Brenda Service

School of Education Policy and Implementation

Faculty of Education

Dear Brenda

\section{RE: Ethics application SEPI/2009/04, RM 16328}

I am pleased to advise you that your ethics application 'An investigation into how the implementation process of a revised curriculum affects teachers' educational beliefs and classroom practice: a case study' with the requested amendments, has been approved by the Victoria University of Wellington College of Education Ethics Committee. Please note that the approval for your research to commence is from the date of this letter.

Good luck with your research.

Yours Sincerely

Dr Judith Loveridge

Co-Convener

Victoria University of Wellington College of Education Ethics Committee 
Appendix C: Information sheet for principal

TE WHARE WĀNANGA O TE ŪPOKO O TE IKA A MĀUI

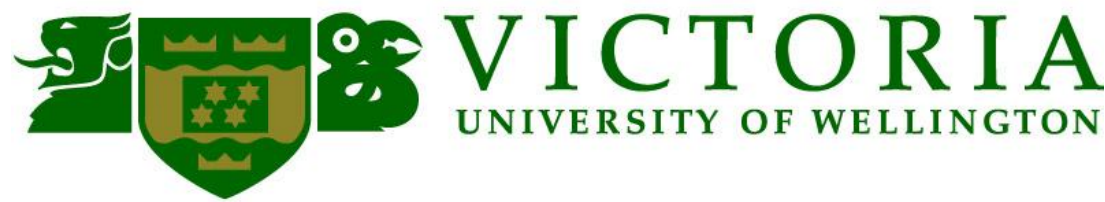

\section{Research project. Principal Information sheet.}

An investigation into how the implementation process of a revised curriculum affects teachers' educational beliefs and classroom practice.

\section{Researcher}

Brenda Service, School of Educational Policy and Implementation, Victoria University of Wellington.

This sheet gives you some information about this study. Please feel free to ask me any questions or for more information. I am undertaking this research for my PhD thesis. The research is being supervised by Dr Anne Hynds and Dr Liz Jones, School of Education, Victoria University of Wellington.

\section{The purpose of my PhD research.}

As you are aware all New Zealand schools are involved in the implementation of a revised New Zealand curriculum. My aim is to describe the process of the implementation through the eyes of secondary school teachers. An implementation project of this significance in New Zealand schools offers an opportunity to research what actually happens in secondary schools when teachers are required by government policy to reconsider their context, what they are teaching, and how they are teaching it. I would like, through this study and with your support, to be able to describe how it affects your staff and to identify support strategies or barriers for them as they work through an implementation process. This is not an evaluation of teachers in any way. Rather it is an opportunity to describe how the implementation process impacts on them and on their teaching practice.

\section{Research questions}


- What are teachers' existing beliefs about teaching and learning?

- What are their existing practices?

- What is the fit between the focus of the implementation and teacher beliefs and practice?

- What, if any, are the changes in teacher beliefs?

- What, if any, are the changes in teacher practices?

- What factors influence changes in teacher beliefs and practices?

- What factors support change?

- What are the barriers to change?

\section{Research process.}

I aim to develop an understanding of the implementation process from the perspective of the teachers over the next two years. To achieve this I plan to observe any professional learning that is part of the implementation. I would be taking note of the focus and the strategies used in the professional learning. I would not be naming or evaluating the participation of any of the staff. These observations would enable me to discuss the professional learning focus in subsequent interviews. I would also like to gather data from observations, interviews and videoing of teaching practice. The observations and video would be solely for the purpose of providing a way of discussing the educational beliefs underpinning the classroom practice with teachers. By observing professional development sessions, observing and videoing lessons and interviewing teachers over the two year period I will be able to describe your staffs' journey through the implementation process and address the research questions.

\section{Interviews}

The first interviews will be to elicit response to the revised curriculum and in particular to the section on effective pedagogy and to the inclusion of key competencies in all teaching. I will be especially interested in how teachers perceive the proposed changes relate to existing educational beliefs and to existing classroom practice. Data generated from the professional 
development observations, from lesson observations and from the videos will form the basis of the discussions in the following interviews. In these interviews I will ask opinions about the professional learning, the extent to which it has (or has not) affected educational beliefs and classroom practice, using the observation data and video clips to stimulate recall of the lessons.

\section{Research participants.}

I am asking for teachers to volunteer to take part in this research. This is an opportunity to ensure teachers' experience of an implementation of a revised curriculum is taken into consideration by educational leaders planning the implementation of change in the future.

\section{Confidentiality and access to information}

The information provided is strictly confidential. Your school and the research participants will not be identified in any way. Information collected will be kept in a locked filing cabinet at the School of Education. During and at the completion of the interviews I will check with the teachers that I have recorded their comments accurately. If there is any uncertainty I will ask them to elaborate or further explain their comments. They will be given the opportunity to change or delete their comments if they wish.

\section{Participation}

Participation would involve:

\section{For all staff:}

- Agreeing that the researcher may observe professional learning sessions

\section{For staff who volunteer:}

- Taking part in four interviews over the two year period.

- Allowing lessons to be observed and videoed three times over the two year period.

- Talking about observed professional development sessions.

- Being available for further interviews or discussions should that be required.

- Agreeing that the information given can be used by the researcher, Brenda Service for this study. 
Participants may withdraw from the research project for any reason at any stage prior to the data analysis and any data provided would then be destroyed.

\section{Publication of results.}

The information gained in this research will be used for publication purposes including academic or professional journals, conference papers and appropriate articles and for the deposit of the thesis at the Victoria University of Wellington library.

If more information is required you may contact the researcher, Brenda Service at Victoria University ph: 04463 9790. My email address is brenda.service@vuw.ac.nz.

Dr Anne Hynds and Dr Liz Jones can both be contacted at Victoria University of Wellington 044639500.

Your consent for this study is highly valued.

Thank you

Brenda Service

Principal Request for Research Summary.

I wish to be given a summary of the research findings.

Yes

No 
Appendix D: Information sheet for teacher

TE WHARE WĀNANGA O TE ŪPOKO O TE IKA A MĀUI

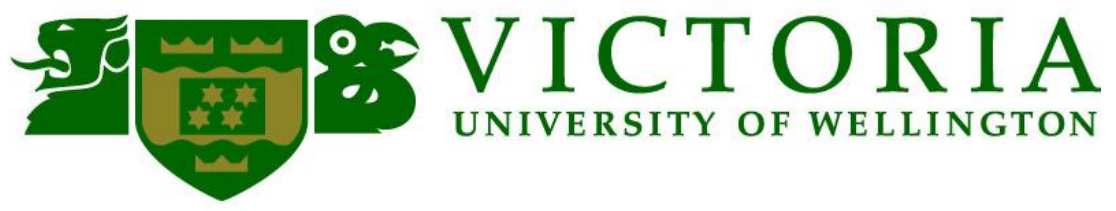

Research project. Teacher consent form.

An investigation into how the implementation process of a revised curriculum affects teachers' educational beliefs and classroom practice.

I agree to take part in the above research. I have had the project explained to me and I have had the chance to ask any questions.

Please read the following and place a tick in each box if you agree with it.

I agree that the researcher, Brenda Service can observe the professional learning sessions in which I participate.

$\square \quad$ I agree to take part in this research and to be interviewed by the researcher, Brenda Service.

$\square$ I am willing for the researcher to observe and video my classroom practice.

I understand that interviews will be recorded and transcribed.

I understand that the research is confidential.

I understand that the analysis and aggregation of the data obtained may be used for a thesis, for conference papers and/or publication.

$\square$ I understand that the data collected will only be used for the research project as described in the information sheet.

$\square \quad$ I understand that my participation is entirely voluntary.

I understand that I can withdraw from the research project for any reason at any stage prior to the data analysis and that any data provided would then be destroyed.

I understand that I will have a chance to comment on the research to check the accuracy of any interviews

$\square$ I understand that transcripts and tapes and raw data will be destroyed five years after the conclusion of the project.

Name

Signature

Date 
Appendix E: Teacher consent forms

TE WHARE WĀNANGA O TE ŪPOKO O TE IKA A MĀUI

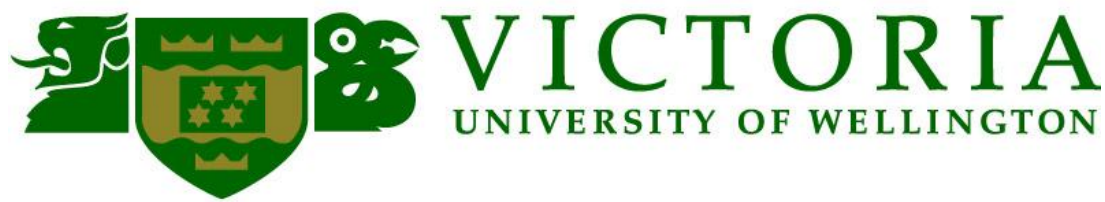

Research project. Teacher Information sheet.

An investigation into how the implementation process of a revised curriculum affects teachers' educational beliefs and classroom practice.

\section{Researcher}

Brenda Service, School of Educational Policy and Implementation, Victoria University of Wellington.

"This sheet gives you some information about this study. Please feel free to ask me any questions or for more information. I am undertaking this research for my PhD thesis. The research is being supervised by Dr Anne Hynds and Dr Liz Jones, School of Education, Victoria University of Wellington."

\section{The purpose of my PhD research.}

You will be aware that all New Zealand schools are involved in the implementation of a revised New Zealand curriculum. My aim is to describe the process of the implementation through the eyes of secondary school teachers. An implementation project of this significance in New Zealand schools offers an opportunity to research what actually happens in secondary schools when teachers are required by government policy to reconsider their context, what they are teaching, and how they are teaching it. I would like, through this study and with your support, to be able to describe how it affects you and to identify support strategies or barriers for you as you work through an implementation process. This is not an evaluation of teachers in any way. Rather it is an opportunity to describe how the implementation process impacts on you and on your teaching practice. 


\section{Research questions}

- What are teachers' existing beliefs about teaching and learning?

- What are their existing practices?

- What is the fit between the focus of the implementation and teacher beliefs and practice?

- What, if any, are the changes in teacher beliefs?

- What, if any, are the changes in teacher practices?

- What factors influence changes in teacher beliefs and practices?

- What factors support change?

- What are the barriers to change?

\section{Research process.}

I aim to develop an understanding of the implementation process from the perspective of the teachers over the next two years. To achieve this I plan to observe any professional learning that is part of the implementation. I would be taking note of the focus and the strategies used in the professional learning. I would not be naming or evaluating the participation of any of the staff. These observations would enable me to discuss the professional learning focus in subsequent interviews. I would also like to gather data from observations, interviews and videoing of teaching practice. The observations and video would be solely for the purpose of providing a way of discussing the educational beliefs underpinning the classroom practice with teachers. By observing professional development sessions, observing and videoing lessons and interviewing teachers over the two year period I will be able to describe your journey through the implementation process and address the research questions.

\section{Interviews}

The first interviews will be to elicit response to the revised curriculum and in particular to the section on effective pedagogy and to the inclusion of key competencies in all teaching. I will be especially interested in how teachers perceive the proposed changes relate to existing educational beliefs and to classroom practice. Data generated from the professional development 
observations, from lesson observations and from the videos will form the basis of the discussions in the following interviews. In these interviews I will ask opinions about the professional learning, the extent to which it has (or has not) affected educational beliefs and classroom practice, using the observation data and video clips to stimulate recall of the lessons.

\section{Research participants.}

I am asking for teachers to volunteer to take part in this research. This is an opportunity for you to ensure your experience of an implementation of a revised curriculum is taken into consideration by those planning the implementation of change in the future.

\section{Confidentiality and access to information}

The information provided is strictly confidential and participants will not be identified in any way. Information collected will be kept in a locked filing cabinet at the School of Education. During and at the completion of the interviews I will check with the teachers that I have recorded their comments accurately. If there is any uncertainty I will ask them to elaborate or further explain their comments. They will be given the opportunity to change or delete their comments if they wish.

\section{Participation}

Participation would involve:

For all staff:

- Agreeing that the researcher may observe professional learning sessions

For staff who volunteer:

- Taking part in four interviews over the two year period.

- Allowing lessons to be observed and videoed three times over the two year period.

- Talking about observed professional development sessions.

- Being available for further interviews or discussions should that be required.

- Agreeing that the information given can be used by the researcher, 
Brenda Service for this study.

Participants can withdraw from the research project for any reason at any stage prior to the data analysis and any data provided would then be destroyed.

\section{Publication of results.}

The information gained in this research will be used for publication purposes including academic or professional journals, conference papers and appropriate articles and for the deposit of the thesis at the Victoria University of Wellington library.

If more information is required you may contact the researcher, Brenda Service at Victoria University ph: 04463 9790. My email address is brenda.service@vuw.ac.nz.

Dr Anne Hynds and Dr Liz Jones can both be contacted at Victoria University of Wellington 044639500.

Your involvement in this study is highly valued.

Thank you

Brenda Service

Participant Request for Research Summary.

Name:

I wish to be given a summary of the research findings.

Yes

No 
Appendix F: Observation template

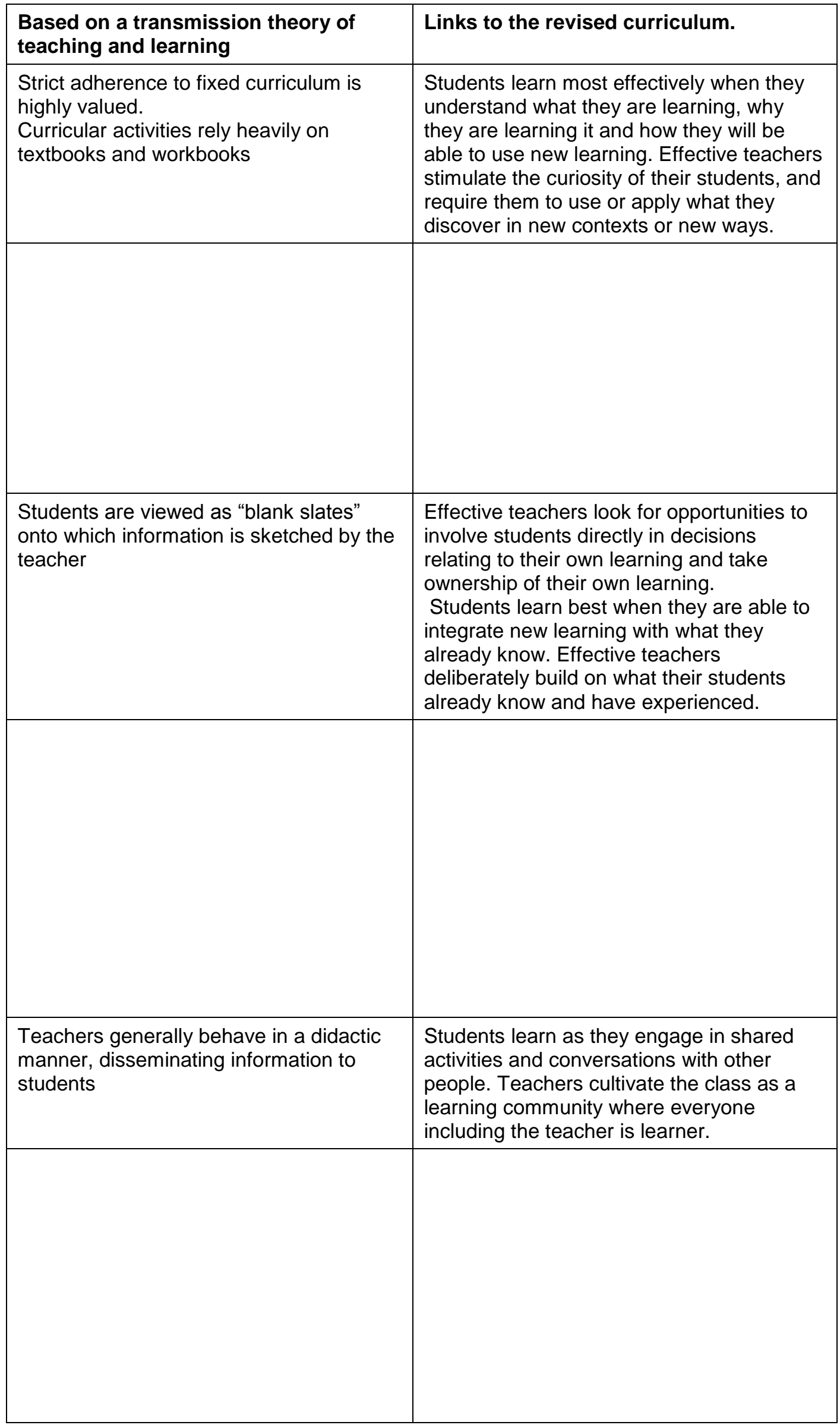




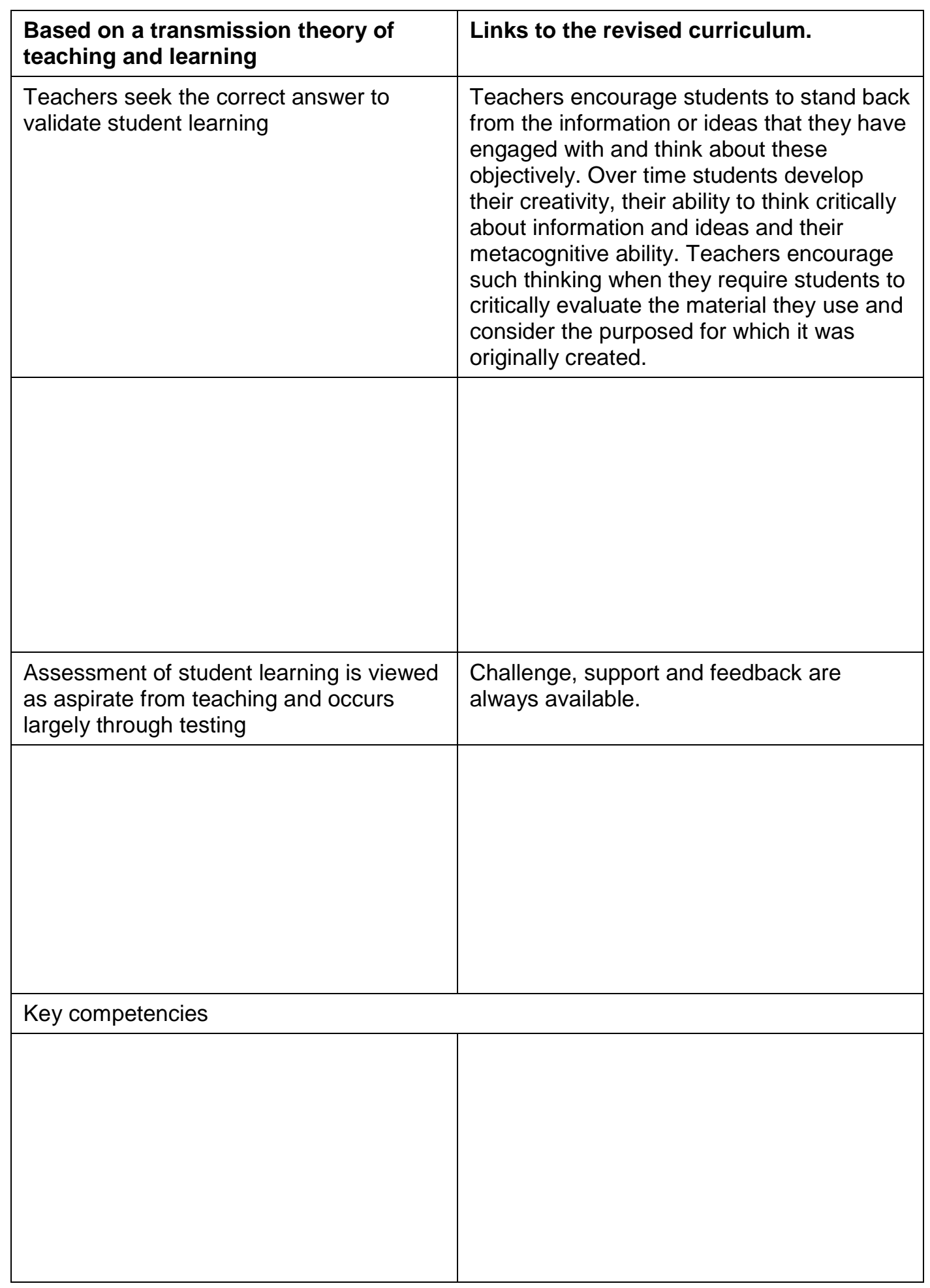


Appendix G: Jill key theme

Jill's key ideas

- In her own education felt some students were overlooked - wishes to give students voice

- Relevance for students very important

- Influenced by project that included student voice.

- Sought PD that would improve her vision of teaching.

- Has completed MEd and has had experience as a professional learning provider.

- Deep understanding of the pedagogy

- Believes leadership does not fully understand

- HOD does not understand - she supports him

- Connection exists with the pedagogy - it is a fit with the way she teaches and she will pursue the aspects that suit her style

- Sees herself as a facilitator 